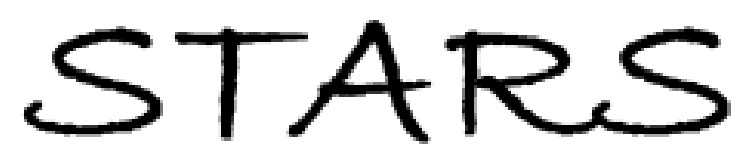

University of Central Florida

STARS

\title{
Experimental Study of Sinkhole Failure Related to Groundwater Level Drops
}

Mohamed Alrowaimi

University of Central Florida

\section{Part of the Civil Engineering Commons}

Find similar works at: https://stars.library.ucf.edu/etd

University of Central Florida Libraries http://library.ucf.edu

This Doctoral Dissertation (Open Access) is brought to you for free and open access by STARS. It has been accepted for inclusion in Electronic Theses and Dissertations, 2004-2019 by an authorized administrator of STARS. For more information, please contact STARS@ucf.edu.

\section{STARS Citation}

Alrowaimi, Mohamed, "Experimental Study of Sinkhole Failure Related to Groundwater Level Drops" (2016). Electronic Theses and Dissertations, 2004-2019. 5182.

https://stars.library.ucf.edu/etd/5182

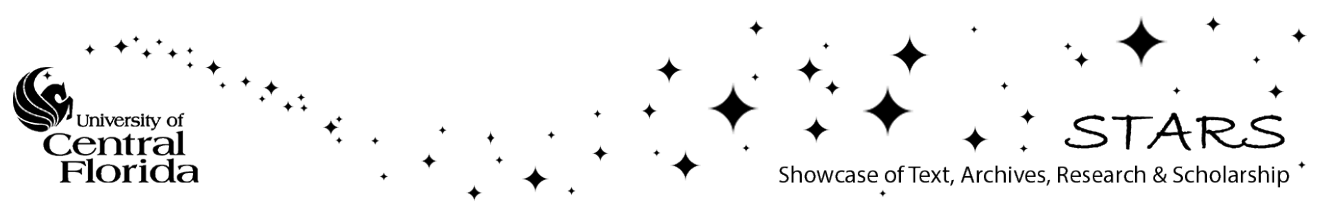




\title{
EXPERIMENTAL STUDY OF SINKHOLE FAILURE RELATED TO GROUNDWATER
} LEVEL DROPS

\section{by}

\section{MOHAMED ALROWAIMI}

B.S. University of Sirte, 2003

M.S. University Technology Malaysia, 2006

M.S. University of Central Florida, 2012

\author{
A dissertation submitted in partial fulfillment of the requirements \\ for the degree of Doctor of Philosophy \\ in the Department of Civil, Environmental and Construction Engineering \\ in the College of Engineering and Computer Science \\ at the University of Central Florida \\ Orlando, Florida
}

\section{Summer Term}

2016

Major Professor: Manoj Chopra 


\begin{abstract}
Sinkholes are natural geohazard phenomena that cause damage to property and may lead to loss of life. They can also cause added pollution to the aquifer by draining unfiltered water from streams, wetland, and lakes into the aquifer. Sinkholes occur in a very distinctive karst geology where carbonate, limestone, dolomite, or gypsum, are encountered as the bedrock that can naturally be dissolved by groundwater circulating through them. Sinkholes can occur gradually or suddenly with catastrophic impact depending on the geology and hydrology of the area. Predicting the formation and the collapse of a sinkhole based on the current ground investigation technologies is limited by the high levels of uncertainties in the soil properties and behavior. It is possible that progressing sinkholes can be missed by geotechnical site investigations especially during the development of a very wide area. In this study, a laboratoryscale sinkhole model was constructed to physically simulate the sinkhole phenomenon. The physical model was designed to monitor a network of groundwater table over time around a predetermined sinkhole location. This model was designed to establish a correlation between the groundwater table drops and the sinkhole development. The experimental small-scale model showed that there is a groundwater cone of depression that forms prior the surface collapse of the sinkhole. The cone of water depression can be used to identify the potential location of the sinkhole at early stage of the overburden underground cavities formation in a reverse manner. In addition, monitoring of single groundwater well showed that groundwater level signal has some sudden water drops (progressive drops) which occur at different times (time lags) during the sinkhole development. A time frequency analysis was also used in this study to detect the pattern of these progressive drops of the groundwater table readings. It is observed, based on the model,
\end{abstract}


that the development and growth of sinkhole can be correlated to progressive drops of the groundwater table since the drops start at the monitoring wells that are closer radially to the center of the sinkhole. Subsequently, with time, these drops get transferred to more distant monitoring wells. The time frequency analysis is used to decompose and detect the progressive drops by using a Pattern Detection Algorithm called Auto Modulating Detection Pattern Algorithm (AMD), which was developed by Yun (2013). The results of this analysis showed that the peaks of these progressive drops in the raw groundwater readings are a good indicator of the potential location of sinkholes at early stage when there are no any visible depression of the ground surface. Finally, the effect of several soil parameters on the cone of the water depression during the sinkhole formation is studied. The parametric study showed that both of overburden soil thickness and the initial (encountered) groundwater table level have a clear impact on the time of the sinkhole collapse.

While this model used a predetermined crack location to study the groundwater level response around it, the concept of groundwater drops as an indicator of sinkhole progression and collapse may be used to determine the ultimate location of the sinkhole. By monitoring the changes in natural groundwater levels in the field from either an existing network of groundwater monitoring wells or additional installation, the methodology discussed in this dissertation may be used for possible foreseeing of the surface collapse of sinkholes.

Keywords: sinkhole collapse investigation; small scale physical model; groundwater table drops; cone of water depression analysis; time frequency analysis 
To my beloved wife "Nadia", children "Issa and Lujane", mother "Kamila", father "Muftah", brothers, sisters and friends 


\section{ACKNOWLEDGMENTS}

Praise to God, the Most Gracious and Most Merciful, Who has created the mankind with knowledge, wisdom and power.

Special thanks go to Professor Dr. Manoj Chopra for giving this opportunity to work under his supervision and for sharing his great knowledge and experience with me.

I would like to convey my deepest gratitude to Assistant Professor Dr. Hae-Bum Yun who provided the assistance and shared his knowledge at various occasions. Appreciation is also extended to all people who gave the author heartfelt corporation and shared their knowledge and for giving some of their valuable time. Appreciation is also extended to all people who gave me heartfelt corporation and shared their knowledge and for giving some of their valuable time.

Finally, my biggest gratitude is to my beloved wife, Nadia, for her endless love, emotional support and belief in me. Thanks to my parents and friends, especially my friend Ahmad Mohamed, for their encouragement through my study period, without all of them I would never come up to this stage. 


\section{TABLE OF CONTENTS}

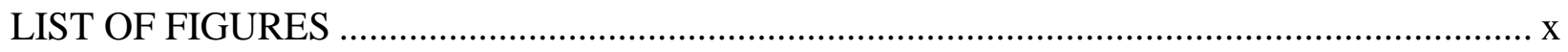

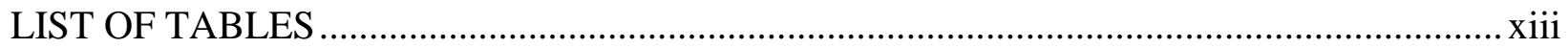

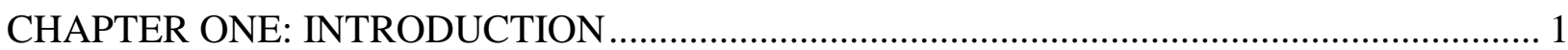

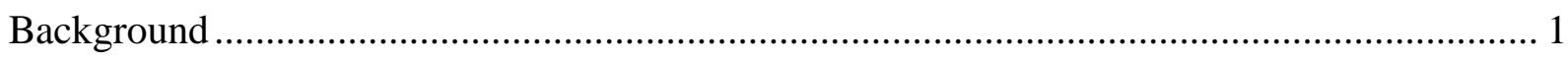

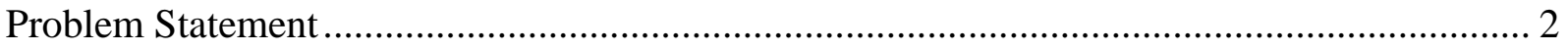

Research Scope and Objectives ........................................................................... 3

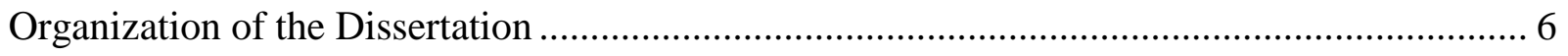

CHAPTER TWO: LITERATURE REVIEW .................................................................. 8

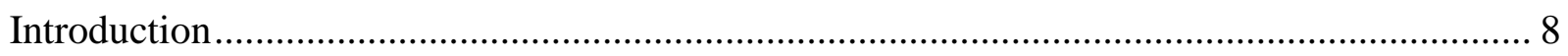

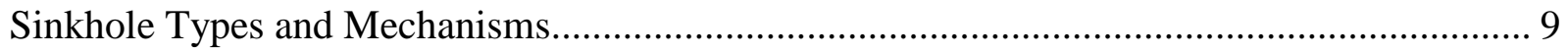

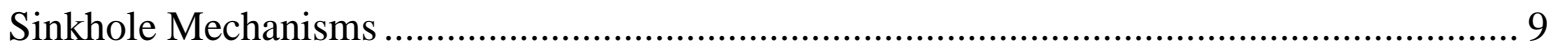

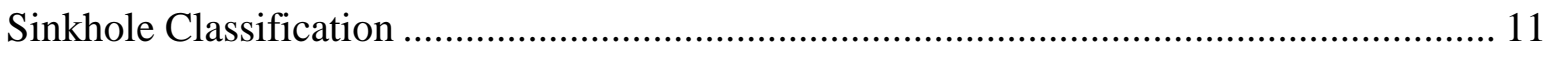

Sinkholes in Central Florida ............................................................................... 14

Hydrogeologic Factors Control Sinkhole Types in Central Florida ............................. 18

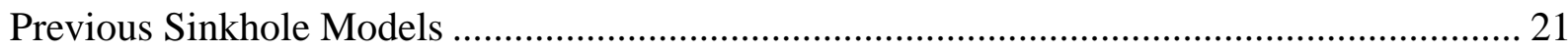

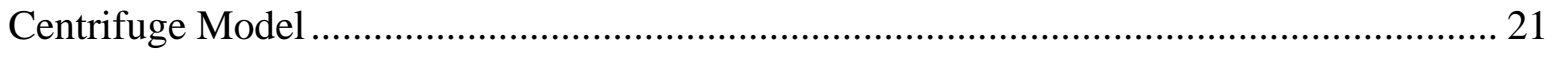

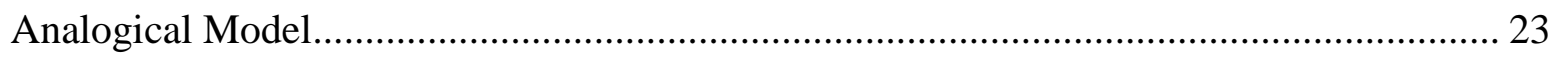

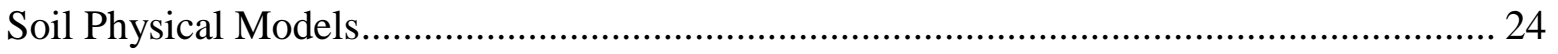


Initial Scaled Models

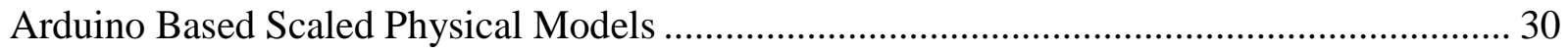

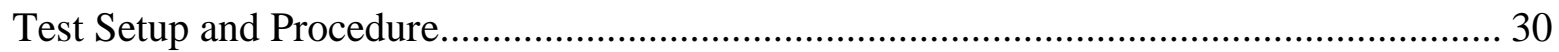

Experimental Results and Discussion ..................................................................... 32

Scaled Physical Models using NI 9234 Module .............................................................. 34

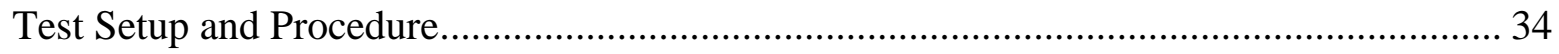

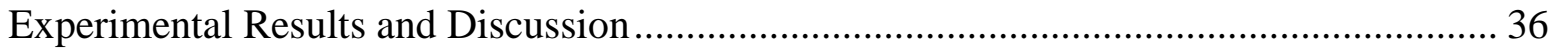

Final Test Setup: Scaled Physical Models using the NI PXIe-1062Q Module ...................... 37

CHAPTER FOUR: SINKHOLE PHYSICAL MODELS TO SIMULATE AND INVESTIGATE

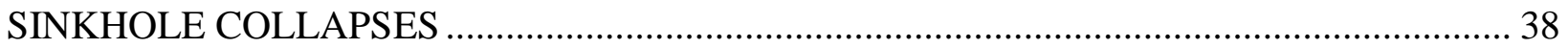

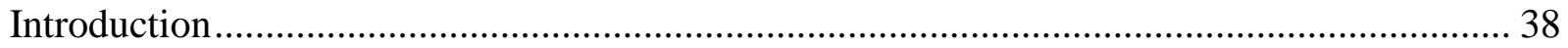

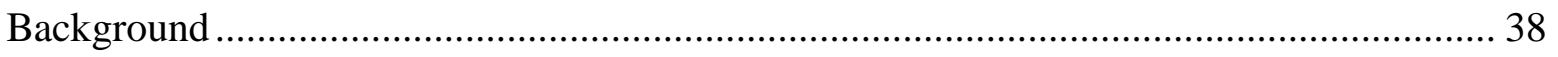

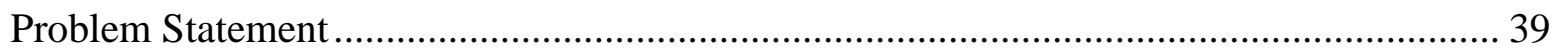

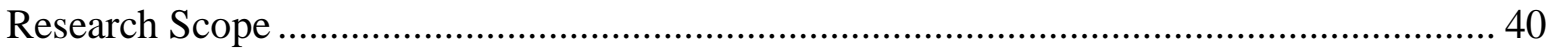

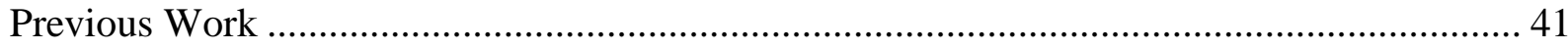

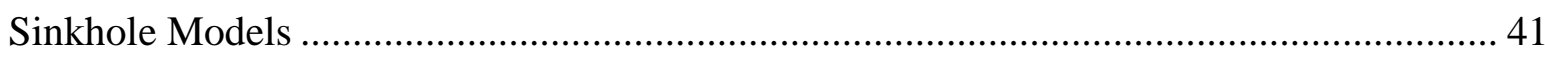

Sinkhole Evaluation Based on Groundwater Recharge ............................................ 43

Current Sinkhole Physical Model ................................................................................. 44 


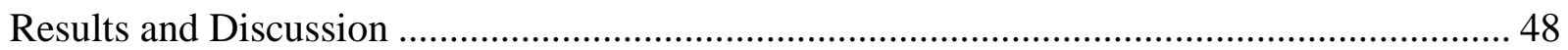

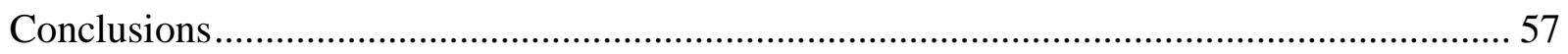

CHAPTER FIVE: EXPERIMENTAL STUDY OF SINKHOLE FAILURE RELATED TO

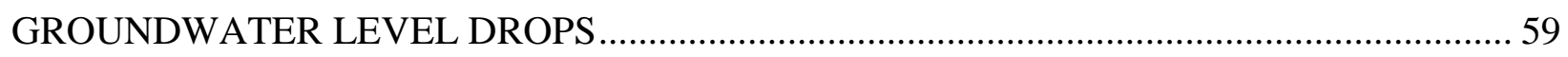

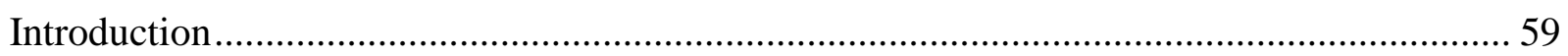

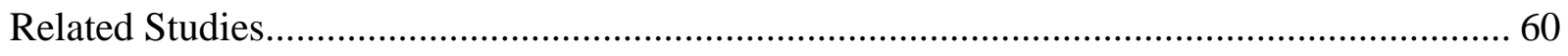

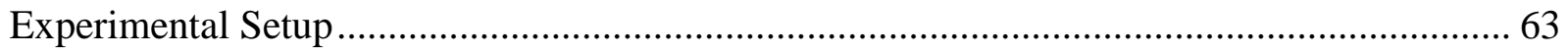

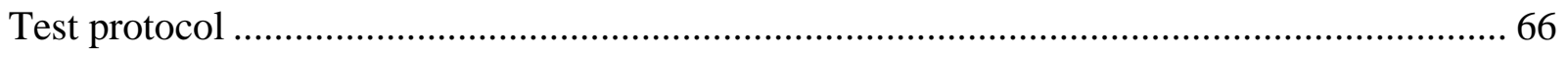

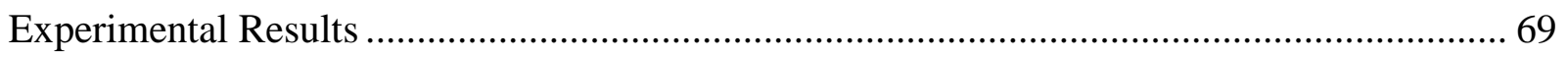

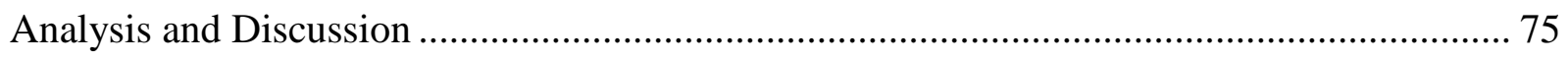

Cone of Depression Analysis ......................................................................................... 75

Time-Frequency Analysis (Peak Counts of the Progressive Drops) ................................... 79

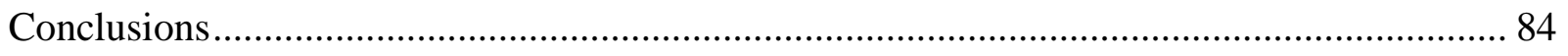

CHAPTER SIX: EFFECTS OF CONTROLLING PARAMETERS ON A PREDICTIVE

MODEL FOR SINKHOLES BASED ON GROUNDWATER DRAWDOWN ……….............. 86

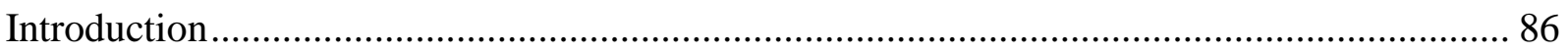

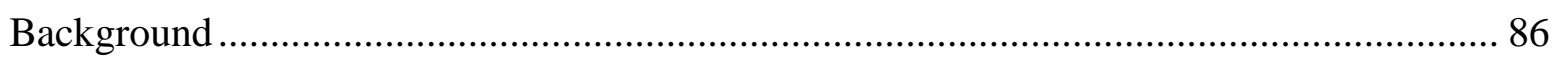

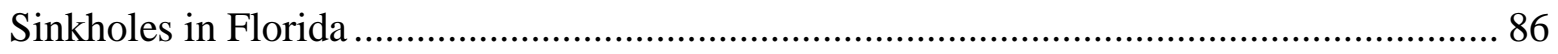

Research scope 
Summary of Testing Protocol and Parametric Study ..................................................... 88

Analysis and Discussion of the Experimental Results................................................ 92

Effect of Initial Groundwater Level ............................................................................. 98

Effect of Overburden Soil Thickness........................................................................... 102

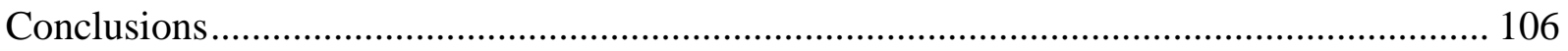

CHAPTER SEVEN: SUMMARY AND CONCLUSION ............................................... 109

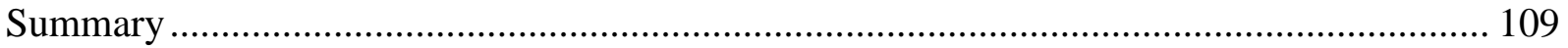

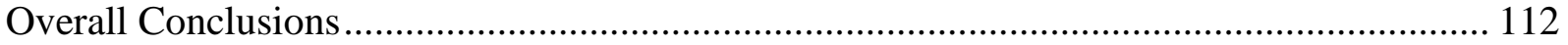

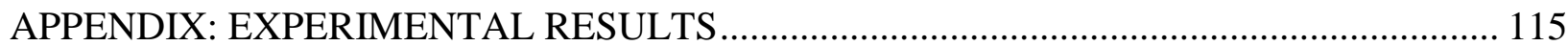

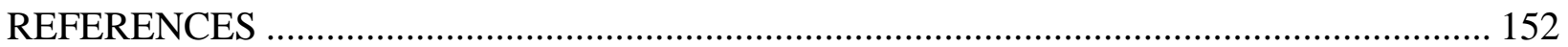




\section{LIST OF FIGURES}

Figure 1: Dissolution chemical processes (Tihansky, 1999) ...................................................... 10

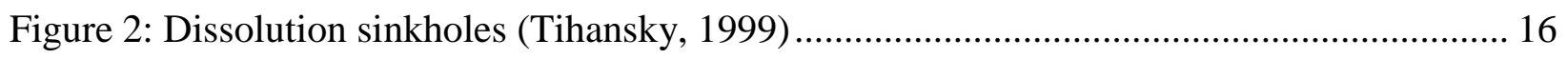

Figure 3: Cover-subsidence sinkholes formation (Tihansky, 1999) …………………................. 17

Figure 4: Cover-collapse sinkholes formation (Tihansky, 1999) …………................................ 18

Figure 5: Central Florida hydrogeological profile (Tihansky, 1999) ........................................... 19

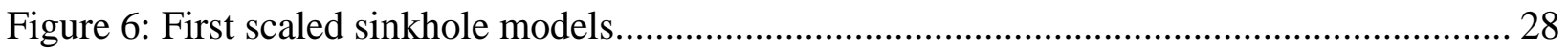

Figure 7: Second series of the initial tests and the Testwell water level meter ............................ 29

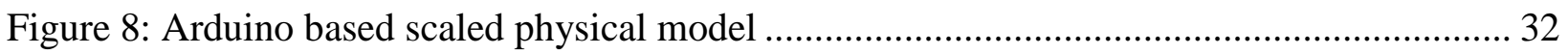

Figure 9: Groundwater level changes versus time plot in the scaled model using the Arduino

UNO

Figure 10: Groundwater level changes versus time plot for the sinkhole formation time period. 33

Figure 11: NI 9234 connected to four resistors in voltage divider circuits ................................. 35

Figure 12: Groundwater level changes versus time plot in the scaled model using the NI 9234

module

Figure 13: The Radial Location of the Eight Monitoring Wells and Physical Model Cross-

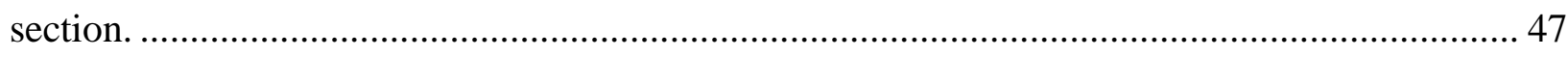

Figure 14: Sinkhole Physical Model Test Setup and sinkhole collapse. ....................................... 47

Figure 15: Sinkhole Experimental Model Setup Diagram....................................................... 49

Figure 16: Groundwater level drops with time in the sinkhole physical model test......................51

Figure 17: Groundwater selected readings in different times versus the wells radial locations ... 54

Figure 18: Groundwater table readings at three selected wells locations, TEST 1......................56 
Figure 19: Groundwater table readings at the nearest and furthest monitoring wells, TEST 1... 56 Figure 20: The Radial Location of the Eight Monitoring Wells and Physical Model Cross-section 64

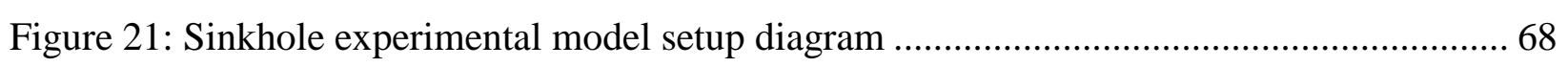

Figure 22 ( $\mathrm{a}$ and b): Sinkhole Physical Model Test Setup and sinkhole collapse ...................... 68

Figure 23 (a, b \&c): Groundwater level drops over time in the sinkhole physical model test ..... 71

Figure 24 ( $\mathrm{a} \& \mathrm{~b}$ ): Groundwater readings in different times versus the wells radial locations for

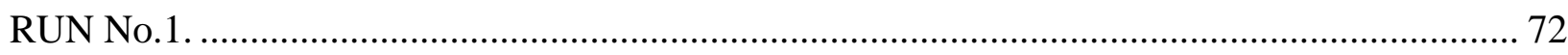

Figure 25: Groundwater table readings at three selected wells locations in RUN No.1: well Ch4 $4_{\mathrm{R}}$ well Ch6

Figure 26: Groundwater table readings at the nearest and furthest monitoring wells, RUN No.1:

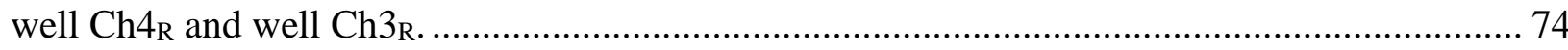

Figure 27 (a, b \& c): Groundwater level drops over the normalized time of sinkhole collapse ... 76

Figure 28: Groundwater trend line representation in RUN No.1 test..................................... 78

Figure 29: Raw data and processed data for peak-picking in two different monitoring wells ..... 80

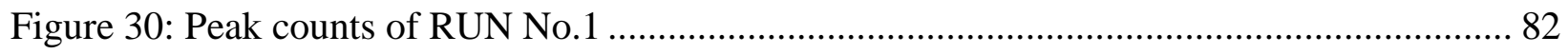

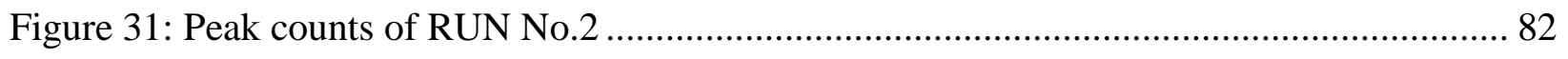

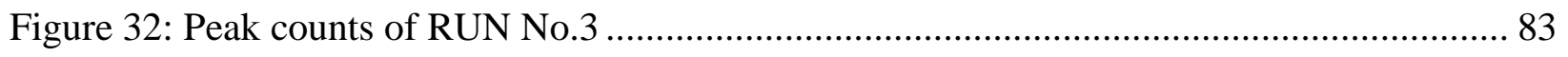

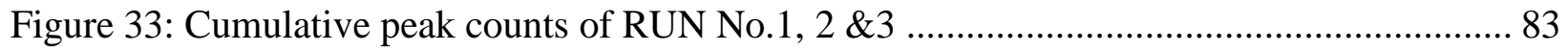

Figure 34: Cross-section of the Physical Model and the Radial Location of the Monitoring Wells

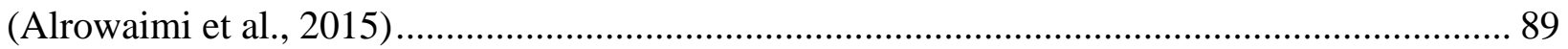

Figure 35: Normalized groundwater level drops over the normalized time of sinkhole collapse 93 
Figure 36: Groundwater trend line representation in RUN No.1 test. .................................. 94

Figure 37: $\alpha(\mathrm{t})$ constant over normalized time for three test runs ...................................... 95

Figure 38: The slope of the groundwater level data with its best fitting curve ....................... 97

Figure 39: Time constant changes with different initial groundwater levels for the $150 \mathrm{~mm}$

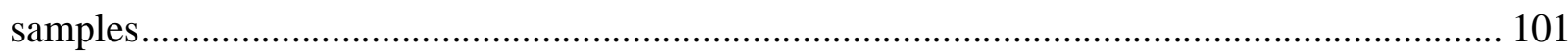

Figure 40: Time constant changes with different initial groundwater levels for the $200 \mathrm{~mm}$

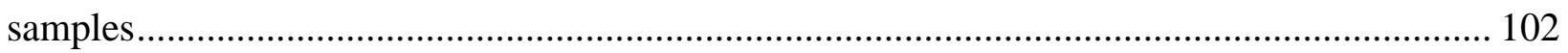

Figure 41: Time constant changes with different overburden soil thicknesses ...................... 104

Figure 42: Combined plot of time constant changes versus different overburden soil thicknesses

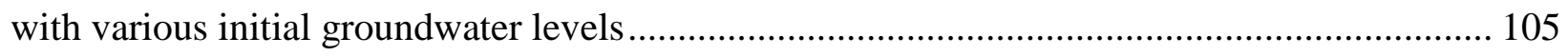

Figure 43: A flow chart of the total number of experiments \& their controlling parameters ..... 111 


\section{LIST OF TABLES}

Table 1: Test Protocol Summary of the Sinkhole Physical Model ........................................... 90

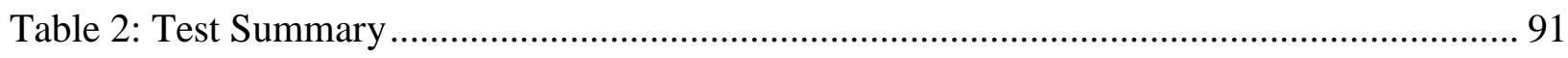

Table 3: Summary of the Slope Fitting Equation Variables for the $150 \mathrm{~mm}$ Soil..................... 98

Table 4: Summary of the Slope Fitting Equation Variables for the $200 \mathrm{~mm}$ Soil..................... 99 


\section{CHAPTER ONE: INTRODUCTION}

\section{$\underline{\text { Background }}$}

Sinkholes are common phenomena where carbonate, limestone, dolomite, or gypsum are encountered. Sinkholes can be defined as an area of the ground with a surface depression or a hole which may occur gradually or suddenly, depending on the geology and hydrology of the area. Most areas susceptible to sinkholes are located where the ground has no natural external surface drainage of the rainfall waters. Transport and erosion of the soils by water result in ground failure. Sinkholes can have a diameter ranging from 1 foot to hundreds of acres and a depth ranging from less than a feet to more than hundred feet. They also vary in shapes such as inverted cone, shallow bowl, or shaft shapes with vertical walls. Some sinkholes can hold water and result in wetlands and lakes (Tihansky, 1999) (Waltham et al., 2005).

Sinkhole formations occur in distinctive land terrains called karst terrain. These landforms have a bedrock that has experienced a dissolution caused by the groundwater. This dissolution process of the carbonate bedrock, limestone, dolomite, or gypsum may take tens of thousands of years to develop a significant cavity size to form a sinkhole. This karst terrain usually contains special features such as sinkholes, caves, valleys, and springs. All of these geological features are the products of the dissolution of the bedrock by the slightly acidic water and the carbon dioxide of the air and soil. This process creates conduits in the bedrock, which work as an underground drainage system that transports water from the surface of the bedrock to the underground cavities or springs. These underground conduits are subjected to the erosion caused by soil and water movements. The erosion helps in enlarging the size of conduits until they eventually form caves. When the bedrock cracks and conduits get large enough to start 
transporting the soil particles into the underlain caves in the bedrock (known as a suffosion process), a small gradual depression occurs at the ground surface and is called a coversubsidence sinkhole. This type of sinkhole occurs in areas in which sand is the dominant soil. In contrast, when the soil has a high amount of clay, the underground cavity may form a structural arch shape during its formation. Eventually, the soil arch collapses suddenly into the cavity and causes catastrophic failure which may lead to significant damage in the built environment. This type of sinkhole is called cover-collapse (Tihansky, 1999) (Waltham et al., 2005).

\section{$\underline{\text { Problem Statement }}$}

Sinkholes are very challenging events that can be caused by combination of hydrological and geological factors. Also, a sinkhole can be a combination of more than one type. Hence, the in-situ measurements of sinkhole collapse processes are difficult. It is difficult to predict and investigate the sinkhole triggering behavior prior to the surface collapse. Techniques for predicting a sinkhole based on the current ground investigation technologies are limited. Site investigation may not be very detailed for the whole area under study especially during the development of a very large area. Due to the inhomogeneity of the soils, it is possible that some vital information may be missed during site exploration studies in areas susceptible to sinkholes. This problem can be attributed to the high uncertainties in the subsoil condition and the limitation of some of the site exploration method, such as site borings which miss areas with progressing underground cavities.

Aerial and satellite remote sensing are used in the exploration of large areas. These techniques provide valuable information about surface depression. However, this surface 
depression, which is detected by both of aerial and satellite remote sensing, may or may not be an indication of a sinkhole as many surface depressions are ground settlements (Lei et al., 2005) (Waltham et al., 2005).

Given the above, there is a need for more investigation of potential locations of sinkhole collapses. It is observed that one of the main factors of causing and accelerating the collapse of a sinkhole is the increase of the groundwater levels due to rainfalls in the rainy season and decrease of the groundwater levels in the dry season. Taking into account the groundwater seasonal fluctuations, any significant drop from these natural levels can potentially indicate an anomaly which may be a sinkhole. There is a need to study the relationship between the sudden drop in the groundwater table level and the formation and progression of a underground cavity or sinkhole. An experimental study is undertaken here to address this topic.

\section{$\underline{\text { Research Scope and Objectives }}$}

In this research, scaled physical models are developed to simulate sinkhole development naturally. A monitoring system was designed to measure the groundwater changes over time, prior to and during sinkhole collapse. Sinkhole collapse is defined as the instance when it appears visually on the ground surface.

The physical model was designed to monitor the groundwater drops around a predetermined location. Eight monitoring wells were radially distributed around the central sinkhole location in the physical model. A typical profile of Florida's karst hydrology and geology was studied in the physical model. An important assumption in this test was that the dissolution process had taken place previously, which means that the limestone bedrock had 
already formed its conduits and cavities. In this model, the dissolution fracture is represented by a circular hole that transports a certain volume of soil through the limestone to an underground cavity. Moreover, this model was designed to simulate a period of time at the end of the dry season in Florida (May), where the groundwater drops to its lowest levels. The model is used to study the relationship between the groundwater drops and the formation, location, and time of development of the sinkhole.

A series of twenty-four test runs were conducted using the laboratory physical model. These test runs have been divided into two main groups based on the overburdened soil thickness in the model. Two different soil overburden thicknesses were used based on the size of the mold corresponding to the small scaled model (namely, 150 and $200 \mathrm{~mm}$ ). Each group is divided into four different soil samples in term of the initial levels of the groundwater table. The initial groundwater table was considered as a percentage of the whole soil thickness with the following values: $5 \%, 10 \%, 15 \%$, and 20\%. Overburden soil thicknesses and initial groundwater levels were the main controlling parameters in the study, while the bedrock crack opening, rainfall, and compaction level were kept constant in all test runs.

The objectives of this research are to correlate the groundwater level drops to the initial time and progression of the sinkhole formation in the model by analyzing a network of groundwater monitoring wells. The objectives can be summarized in the following points:

- To design and construct a scaled physical model that can simulate the natural sinkhole formation experimentally.

- To implement an accurate data acquisition system to receive a very high resolution data for subsequent analysis. 
- To study the groundwater table drops over time in different locations around a predetermined sinkhole location.

- To correlate the groundwater drops over time to the potential location of the sinkhole collapse in a reverse manner to formulate a possible predictive methodology.

- To study the groundwater readings in every single monitoring well and establish a relationship between the drops of the groundwater drops in the single wells over time with the potential location of sinkhole formation. This was achieved by using a time frequency analysis to detect the pattern of the drops of groundwater table readings. The time frequency analysis was used to decompose and detect the progressive drops by using a Pattern Detection Algorithm (AMD), which was developed by Yun (2013).

- To find a general trend and pattern of groundwater cone of depression.

- To study the effect of the thickness of the overburden soils (controlling parameter) on the time to sinkhole development.

- To study the effect of the initial groundwater levels (controlling parameter).

While this model used a predetermined crack location to study the groundwater level response around it, the concept of groundwater drops as an indicator of sinkhole progression and collapse may be used as an indicator to determine the ultimate location of a growing underground cavity that may become a sinkhole. By monitoring the changes in natural groundwater levels in the field from either an existing network of groundwater monitoring wells or additional installations, the methodology discussed in this dissertation may be used for possible foreseeing of the surface collapse of sinkholes. 


\section{Organization of the Dissertation}

This dissertation is divided into seven chapters. The first chapter is the introduction and includes the background, problem statement, research scope and objectives, and organization of the dissertation. In this chapter, a brief introduction about the sinkhole formation and mechanism is presented. The significance of modeling the sinkhole formation in order to investigate more this natural phenomenon is presented is also presented in Chapter one.

The second chapter is an extensive review of the relevant literature on sinkholes. It includes a discussion of the sinkhole mechanism, classification, and processes. The sinkholes in central Florida, in terms of their types, geology, and hydrology, are also discussed in this chapter too. Also, the previous physical models that simulate sinkholes are presented and explained.

The third chapter summarizes the preliminary scaled physical models which were conducted during in the initial phase of this research. It includes the initial scale model, the Arduino-based small scale model, physical models using NI 9234 module, and the final test setup.

A detailed explanation of the sinkhole physical model is provided in chapter four. It also includes the test setup, design, and procedure. The hypothesis of the cone of depression in the natural groundwater level and its relationship to the sinkhole formation location and time is explained in detail in this Chapter. The results from the network of ground monitoring wells along with the single well (sensors) and the related analysis of results are presented in this chapter.

The fifth chapter includes a journal paper about the experimental study of sinkhole failure related to groundwater level drops. The paper presents an extension of the study of the 
groundwater level drops and its correlation to the potential location of sinkholes. The response from a single well is studied in depth using three tests at that location. A time frequency analysis is presented in this study which is used to decompose and detect the progressive drops by using a Pattern Detection Algorithm named Auto Modulating Detection Pattern Algorithm (AMD), (Yun, 2013).

The sixth chapter provides an extensive parametric study of the effects of the soil controlling parameters, such as overburden soil thickness and initial groundwater table levels, on the formation of the cone of groundwater depression during the sinkhole formation.

The three previous chapters are synthesized from publications. Finally, the seventh chapter presents the general conclusions. It includes a summary for the entire research and the conclusions drawn from the findings in the dissertation. An appendix is then presented which contain the data for the soil classification results, the raw data from the experiments, and some analysis data. The references are provided at the end of the dissertation. 


\title{
CHAPTER TWO: LITERATURE REVIEW
}

\author{
$\underline{\text { Introduction }}$
}

Sinkholes are common phenomena where carbonate, limestone, dolomite, or gypsum are encountered. Sinkholes can be defined as an area of the ground with a surface depression or a hole which may occur gradually or suddenly based on the geology and hydrology of that specific area. Most areas susceptible to sinkholes are generally located where the ground has no natural external surface drainage of the rainfall waters. Transport and erosion of the soils by water, overlying the carbonate bedrock, results in ground failure. Sinkholes can have a diameter ranging from 1 foot to hundreds of acres and a depth ranging from less than a feet to more than hundred feet. They also vary in shapes such as inverted cone, shallow bowl, or shaft shapes with vertical walls. Some sinkholes can hold water and results in wetlands and lakes (Tihansky, 1999) (Waltham et al., 2005).

Sinkholes are very challenging events that can be caused by combination of hydrological and geological factors. Also, a sinkhole can be a combination of more than one type. Hence, the in-situ measurements of sinkhole collapse processes are difficult. It is difficult to predict and investigate the sinkhole triggering behavior prior to the surface collapse. Techniques for predicting a sinkhole based on the current ground investigation technologies are limited. Site investigation may not be very detailed for the whole area under study especially during the development of a very large area. Due to the inhomogeneity of the soils, it is possible that some vital information may be missed during site exploration studies in areas susceptible to sinkholes. This problem can be attributed to the high uncertainties in the subsoil condition and the 
limitation of some of the site exploration method, such as site borings which miss areas with progressing underground cavities.

Aerial and satellite remote sensing are used in the exploration of large areas. These techniques provide valuable information about surface depression. However, this surface depression, which is detected by both of aerial and satellite remote sensing, may or may not be an indication of a sinkhole as many surface depressions are ground settlements (Lei et al., 2005) (Waltham et al., 2005).

\section{$\underline{\text { Sinkhole Types and Mechanisms }}$}

Karst can be defined as distinctive terrain with its underground drainage, which develops as a result of rainfall and the infiltration of surface water into the ground. This landform always exists at areas that has either limestone rocks or other carbonate and soluble rocks. This karst areas contain sinkholes, caves, valleys, and springs. Also, the karst terrain has distinct hydrological conditions besides its unique geological features. When collapses of rocks or lands into the underground cavities (created by dissolution) occur, sinkholes begin to develop (Waltham et al., 2005).

\section{Sinkhole Mechanisms}

The two processes that create sinkholes with different types are dissolution and suffosion. The dissolution process is the main factor in creating all type of sinkhole as without it there would be no cracks or cavities in the limestone to allow the sediments to transmit to the underlain cavities. However, the sinkhole types are affected by the overburden soil thickness and 
type, and the local hydrological conditions. Dissolution process can be defined as the chemical reactions that occur to the soluble carbonate rock when it is exposed to weakly acidic water. The rainfall water, the air's carbon dioxide gas, and the soil reacts and results in carbonic acid. When this carbonic acid reaches to the carbonate bedrock, it reacts with both types of the carbonate rock, limestone or dolomite. As the dissolution of limestone or dolomite progresses, ions components of calcium, magnesium, and bicarbonate are formed. Eventually, ground cavities and voids develop in the bedrock. Figure 1 illustrates the dissolution process (Sinclair \& Stewart, 1985) (Tihansky, 1999).

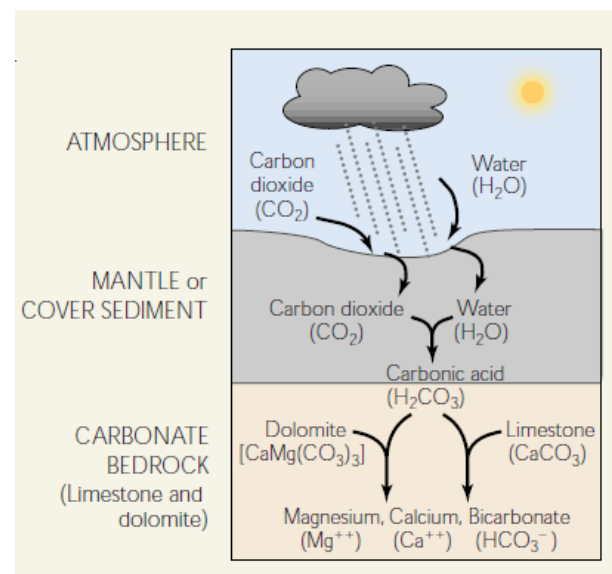

Figure 1: Dissolution chemical processes (Tihansky, 1999)

While suffosion is the physical process of sinkholes formation, it occurs right after the dissolution takes place. This results in underground cavities and voids in the bedrock. The suffosion takes place when the unconsolidated sediments start transmitting into the preexisting 
voids and cavities in the carbonate bedrock. This kind of sinking sediments' erosion is also called raveling, because it develops from the bottom to the top, from the bedrock surface and progresses upward to the ground surface (Tihansky, 1999).

\section{Sinkhole Classification}

Although sinkhole types vary based on the local geology, sinkholes can be also combinations of types of formation phases. Because sinkholes can occur due to these processes - bedrock dissolution, soil suffosion, rock collapse, and soil collapse -- sinkholes can be classified to six main types. These types are correlated to their development processes, which can be one or more of the above mentioned processes. These types are (1) Solution Sinkhole, (2) Collapse Sinkhole, (3) Caprock Sinkhole, (4) Dropout Sinkhole, (5) Suffosion Sinkhole, and (6) Buried Sinkhole (Lowe \& Waltham, 2002) (Williams, 2004) (Waltham et al., 2005).

Solution sinkholes occur mainly by the dissolution process in locations with where very thin or no soil cover (exposed bedrock) on the soluble rocks. These hosting soluble rocks can be limestone, dolomite, gypsum, or salt rocks. In the solution sinkhole, the dissolution process may take more than 20,000 years creating stable landforms like those nearby mountains and valleys. The typical size of this sinkhole is $20 \mathrm{~m}$ to $200 \mathrm{~m}$ across, however it can reach up to a maximum size of $1000 \mathrm{~m}$ in some cases. Also, the depression depth of sinkholes ranges from $1 \mathrm{~m}$ to over $100 \mathrm{~m}$. Shapes can be anything between gentle bowls to steep cones. Compared to all other sinkhole types, the solution sinkholes are the least important to the engineers when geohazards are evaluated. However, it is important to know that solution sinkholes may introduce some geohazards to the engineering foundations. This geohazard is the presence and possible 
progression of fissures and cavities below the engineering foundations. This type of sinkhole is also called a dissolution sinkhole, a cockpit sinkhole, or a doline sinkhole (Lowe \& Waltham, 2002) (Williams, 2004) (Waltham et al., 2005).

The second type of sinkhole is the collapse sinkhole. These occur in limestone, dolomite, gypsum, and basalt rocks. Collapse sinkholes are extremely rare sinkholes with a rapid failure event. The formation of these sinkholes rely on the dissolution of the limestone cracks to form larger fissures. These fissures gets larger, forming shafts and potholes in underground rocks. The dissolution process eventually erodes the limestone into blocks until they break and fall into the cavities below. A ground depression of the collapse sinkhole appears on the surface. One can differentiate between collapse and solution sinkholes by the formation processes. The collapse sinkhole is mainly an extensive collapse while solution sinkhole is a completely dissolutional depression. The typical maximum size of a collapse sinkhole is up to $300 \mathrm{~m}$ across and $100 \mathrm{~m}$ deep. They usually have steep rock profiles. They also are named cave collapse sinkholes, cenote sinkholes or tumour sinkholes (Beck and Sinclair, 1986) (Ford \& Williams, 1989) (Waltham et al., 2005).

The third type, caprock sinkholes, are very similar to collapse sinkholes in formation process and size. However, caprock sinkholes present failures as columns of collapsed debris with or without modern surface expression. While collapse sinkholes form when massive rocks collapse into cave chambers, caprock sinkholes commonly occur in gypsum and salt rather than in limestone. The engineering hazard of both collapse and caprock sinkholes is mainly the roof collapse of the rock when an engineering foundation is imposed on them. The terms subjacent collapse, interstratal collapse, and breccia pipe are names used for caprock sinkholes in earlier 
classification (Jennings, 1985) (Beck and Sinclair, 1986) (Williams, 2004) (Waltham et al., 2005).

The most hazardous sinkholes are the dropout (cover-collapse or alluvial) and suffosion (cover-subsidence or alluvial) sinkholes. Both of these sinkholes form by wash out of the soil into the underlying cavities due to the changes in the hydrology of the groundwater. Dropout sinkholes occur in karst geology with cohesive soils overlying carbonate bedrocks, while suffosion sinkholes occur when the carbonate bedrocks are covered by cohesionless soils overlying bedrock. The failure can be a catastrophic ground collapse (in few minutes) or a gradual ground surface depression (over months or years) resulting, respectively, in dropout or suffosion sinkholes. These sinkholes range in size from $1 \mathrm{~m}$ to $100 \mathrm{~m}$ across and up to $10 \mathrm{~m}$ deep (Boogli, 1980) (Beck and Sinclair, 1986) (Culshaw \& Waltham, 1987) (Waltham et al., 2005). Dropout and suffosion sinkholes are discussed in detail in the next section (Sinkholes in Central Florida).

The sixth and final type of sinkholes is the buried sinkhole, which typically ranges in size from $1 \mathrm{~m}$ to $1000 \mathrm{~m}$ across. Buried sinkholes are very similar to collapse sinkholes in terms of the upwards development by roof failure when dissolution that takes place on the limestone. After the dissolution occur, an inverted cone shape (size and shape may vary) of karst depression results on the rock surface. This depression is completely or partially filled by soil sediments, as a result of environmental changes, to form the buried sinkholes. This type of sinkhole is causing problems to engineers because buried sinkholes have local subsidence of soft fill (unstable ground) surrounded by stable rock. They are also known as filled sinkholes, paleosinkhole, and 
compaction sinkholes (Culshaw \& Waltham, 1987) (Lowe \& Waltham, 2002) (Waltham et al., 2005).

\section{Sinkholes in Central Florida}

Sinkholes are common natural phenomena in Florida. Sinkholes, in central Florida and elsewhere, cause a lot of damage and problems to buildings, structures and roads. In addition, sinkholes can cause problems by endangering the underlying aquifer as they may become conduits to transmit surface water to the groundwater. (Atkinson, 1977) (Tihansky, 1999)

Florida is one of the most susceptible states to sinkholes in the nation. The main reason behind that is the geology of the soil profile in Florida, which is underlain by carbonate deposits or bedrock. This carbonate bedrock is subjected to a dissolution process caused by the groundwater circulation. Also, as the groundwater in the carbonate aquifer declines due to the usage in the municipal, agricultural, and industrial water supplies, sinkhole development may be triggered or accelerated (Atkinson, 1977) (Quinlan et al., 1993) (Tihansky, 1999).

Florida's land consists of an irregular carbonate layer that is covered with sand and clay sediments. These unconsolidated, relatively insoluble sediments have different thicknesses and compositions depending on its location in the state. Because the sinkhole formation depends on the dissolution of limestone, the movement of the water, and also some other environmental factors, the rate of dissolution plays an important role in sinkhole process. This rate gets its highest value in areas subjected to high rate of precipitation, which occurs in Florida's climate. This dissolution creates cavities in the limestone which are products of a series of chemical and mechanical erosion of material. (Bottrell et al., 1991). Most of the bedrock of central Florida is 
below the water table. This allows the groundwater to create more cavities as the dissolution process can occur continuously on the carbonate bedrock. It is important to know that the size, development, and orientation of these conduits and cavities depend on the cracks, faults, mineral composition, and planes of the carbonate bedrock (Lattman \& Parizek, 1964) (Littlefield, et al, 1984) (Tihansky, 1999).

In central Florida, the buried karst terrain is called mantled karst, which is a result of karst processes on the rocks that are overlain by the relatively isolable deposits. In Florida, the occurrence of sinkholes or the existence of some surface topography which follows the underlying depressions is an indication of carbonate units not exposed on the ground surface. One can notice that in Florida the presence of several lakes and some surface depressions are the results of subsiding the overburden soil into the mantled karst. However, the thickness of mantled karst can affect the reflected depression on the surface. In other words, the thicker the mantled karst, the less the depression may or may not be noticed at all (White, 1970) (Brooks, 1981).

In central Florida, three major factors control the type and the recurrence rate of sinkhole formation. These are the overburden materials compositions and thickness, the limestone bedrock dissolution rate, and the hydrology of the area. Florida's sinkholes are generally divided into three types based on their formation processes: dissolution sinkholes, cover-subsidence sinkholes, and cover-collapse sinkholes (Sinclair \& Stewart, 1985) (Tihansky, 1999).

Sinkholes in Florida, as in general, always are categorized in distinct types; however, sinkholes also can be a combination of types or formation phases. 
Dissolution sinkholes are mainly caused by chemical erosions to the carbonate, limestone or dolomite, surface. They occur where the limestone and dolomite bedrock is covered with thin mantle sediments or even when the bedrock is exposed to the surface. In the northern part of central Florida, the carbonate rock is overlain by a thin highly permeable mantle of sediments with thickness up to 30 feet (Culshaw \& Waltham, 1987). The process starts when the rainfall water rapidly percolates through the existing joints in the limestone. After the carbonate bedrock surface erodes, the dissolved material is carried away and finally the surface depression starts to develop gradually. The dissolution rate gets higher where the water runs through the preexisting joints, faults, cracks, and bedding planes. It is also noted that the process can be more aggressive when the limestone is exposed to the surface water. In this case, wetlands can be formed especially when some carried debris plug the sinkhole development. Solution (dissolution) sinkholes are a common phenomenon in most of the state of Florida; these can be indicated by shallow depressions of the ground surfaces. Figure 2 illustrates the dissolution sinkhole (Tihansky, 1999).
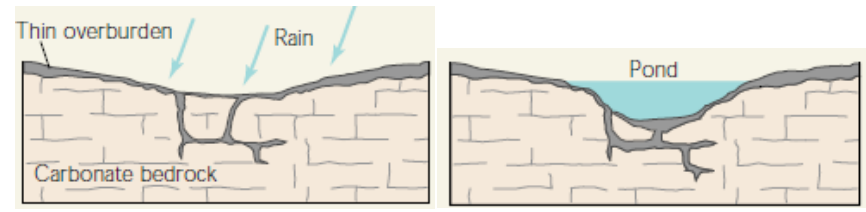

Figure 2: Dissolution sinkholes (Tihansky, 1999)

A cover-subsidence sinkhole is a gradual depression of the overburdened, mainly granular, materials due to movement into the underground voids and cavities in the bedrock. In the north part central Florida, the overburdened thickness can vary from 30 to 200 feet thick. In this overburdened geology, if the predominant soils are sands, a gradual sinkhole with inverted cone 
shape may formed (Sinclair \& Stewart, 1985). However, the same overburden thickness, predominantly of clay soil, may encounter a sudden collapse as a cover-collapse sinkhole. Cover-subsidence sinkholes are caused by suffosion with the presence of dissolution of the carbonate bedrock. Figure 3 shows the development stages of cover-subsidence sinkholes (Sinclair \& Stewart, 1985) (Tihansky, 1999).

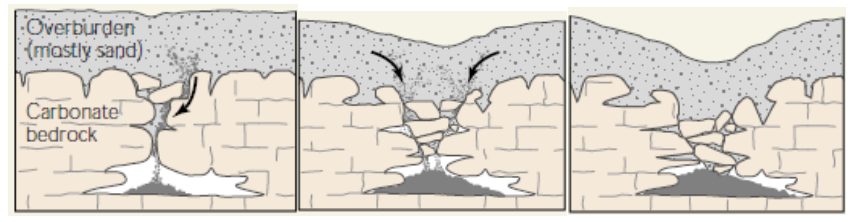

Figure 3: Cover-subsidence sinkholes formation (Tihansky, 1999)

Cover-collapse sinkholes occur suddenly and result in disastrous damages. They take place in the areas with thick overburden sediments and contain a large percentage of clay soils. Most of the southern part of central Florida are susceptible to cover collapse sinkholes due to the geology of the thick cohesive overburden sediments, generally greater than 200 feet, interlayered with the carbonate bedrock. As in the cover-subsidence sinkholes, the cover- collapse sinkholes are caused by continuous suffosion and dissolution. Generally, when the sediments infilling into the cavities in carbonate rocks, the clay soils form a small cavity which results in a structural arch. This cavity will progress as long as suffosion and dissolution occur. Finally, the structural arch falls down suddenly into the cavity and causes a cover-collapse sinkhole. Demonstration of 
the development of cover-collapse sinkholes is shown in Figure 4 (Sinclair \& Stewart, 1985) (Tihansky, 1999).
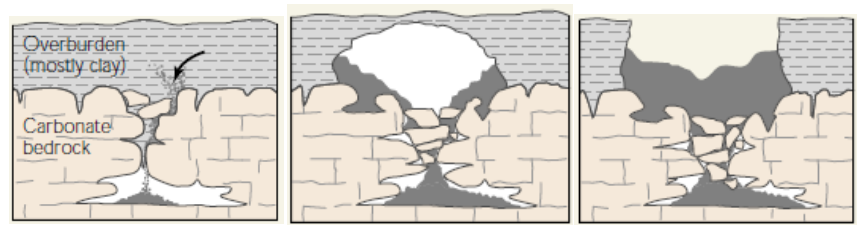

Figure 4: Cover-collapse sinkholes formation (Tihansky, 1999)

\section{$\underline{\text { Hydrogeologic Factors Control Sinkhole Types in Central Florida }}$}

In Central Florida, the type and frequency of sinkhole development are controlled by some hydrogeologic factors. Generally, sinkhole formation is easily affected by changes in the hydraulic and the natural or man-made mechanical stresses. These stresses are simply represented by the changes of the groundwater levels and the groundwater gradients. The stresses are caused either naturally due to sea level changes or manmade, by the development of groundwater resources. The size, thickness, and composition of overburden materials and the hydrology of the aquifer control the way the stresses are transferredwhile the groundwater chemistry determines the location of dissolution process of karst. Hence, it is important to study the hydrogeologic framework of Florida as it is related to the sinkhole formation (Ryder, 1985) (Tihansky, 1999).

In central Florida, the hydrogeologic profile, framework, consists of three layers of aquifer systems. The first is called the surficial aquifer system. It exists in the unconsolidated sands, clay 
and shell soils. The thickness of this layer varies from a few feet to 100 feet or larger. Because the water table is close to the ground surface, the deposits of the surficial aquifer transmit into the underlying cavities during the sinkhole formation. Under the surficial aquifer, an intermediate aquifer system, or also called intermediate aquifer units, exists. Finally, the third layer of the hydrogeologic framework is called the upper Floridan aquifer system. The intermediate confining units are generally composed of heterogeneous siliciclastic (sand and clay) sediments which overlay the carbonate rock. The existence or nonexistence of this intermediate layer, plays a role in frequency and type of sinkhole formation in central Florida (Southeastern Geological Society, 1986) (Tihansky, 1999). The upper Floridan aquifer has thickness of 500 feet to 1800 feet. The aquifer is the main source of groundwater withdrawals and springs that flow in central Florida. Figure 5 shows central Florida hydrological profile (Ryder, 1985) (Southeastern Geological Society, 1986).

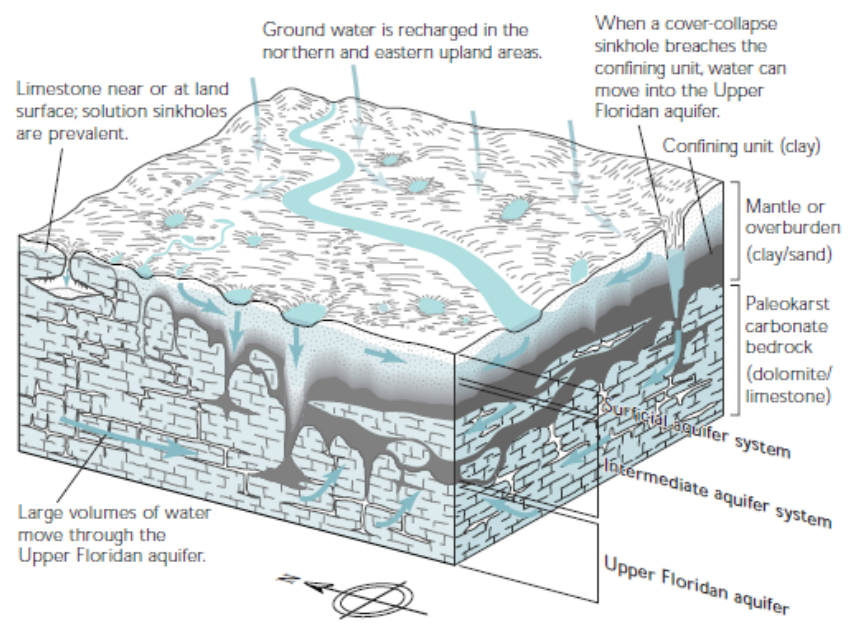

Figure 5: Central Florida hydrogeological profile (Tihansky, 1999) 
Generally the sinkhole formation can be enhanced in some of Florida's areas by the downward groundwater movements which wash away the unconsolidated sediments into the subterranean cavities. These downward movements of groundwater occur when the water level, hydraulic heads, in the Upper Floridan aquifer are lower than the levels in the surficial and intermediate aquifer. The ground water declines in the surficial aquifer to recharge the intermediate aquifer and the Upper Floridan aquifer (Brucker et al., 1972) (Stewart \& Parker, 1992) (Tihansky, 1999).

In central Florida, the end of dry season (May) has the lowest levels of the groundwater in the year while the groundwater levels gain their maximum high levels in the end of the rainy season (September). It is obvious that the seasonal weather variations significantly affect the groundwater levels' cyclical changes from minimum to maximum levels. It is also noted in Florida, that groundwater levels' seasonal fluctuations can cause temporary reversals in the direction of vertical flow. This condition occurs, either during the very long drought season or large rain events, and triggers more sinkhole to develop. In addition, long-term groundwater pumping, or sometimes extreme short-term pumping, can cause these reversals in groundwater flow directions. This decrease of groundwater levels and hydraulic gradient reversals may replace the existing springs to dry sinkholes (Lewelling et al., 1998) (Tihansky, 1999). 


\section{$\underline{\text { Previous Sinkhole Models }}$}

In this section, a discussion of previously published sinkhole physical models will be

presented. These models were implemented using either centrifuge models, analogical models, or actual physical models. In the centrifuge models, the sinkhole mechanisms in weekly cemented sand, either overlain by uncemented sand or not, was studied. The analogical model was conducted with material that was close in the behavior to represent the soil. Finally, an actual simulation for the same material at field has been studied using a large-scale experimental model. Each of these three models are discussed below.

\section{Centrifuge Model}

In 1996, Abdulla and Goodings studied sinkhole developments in soil profile with weakly cemented sand underlain by a layer of limestone. This weekly cemented sand is covered by uncemented sand. Fifty-one stress-correct centrifuge models were tested with and without uncemented sand cover. The interaction between some properties of the cemented sand, uncemented sand, and the underlying limestone bedrock formation was tested. These properties are the thickness, cohesive strength, and unit weight of the cemented sand; the thickness, and unit weight of the uncemented sand; and the diameter of the cavity in the limestone formation. The objective of this research was to understand the collapse mechanism in the weakly cemented sand that covers the cavity (Abdulla \& Goodings, 1996).

Their experimental program was designed to investigate the effects of a certain diameter of the cavity, which covered the cemented sand like a bridge, on sinkhole development. A strong aluminum boxed area of $387.5 \mathrm{~mm} \times 362 \mathrm{~mm}$ was used to construct the model inside it. A 
circular opening, ranging from $38.1 \mathrm{~mm}$ to $152.4 \mathrm{~mm}$, was made in the center at the top of the limestone bedrock. This opening was sealed by a plug and metal plate during the model preparation. During the centrifuge test, the opening will be unsealed to allow the soil to transport out of the box (Abdulla \& Goodings, 1996).

In 2002, Goodings and Abdulla tested forty-nine physical models using a centrifuge to simulate full scale sinkhole development in similar small scale models to the one described earlier in this section. The same soil profile was tested again. Twenty-seven models were tested with no uncemented sand cover layer in this case. The failure of these models was measured by the mass of soil falling into the cavity. This failure had different characteristics depending the cavity and the soil profile dimensions. The other twenty-two models were tested with uncemented sand overburden layer. These models were designed to simulate sinkhole collapses by increasing the centrifuge acceleration. All models were designed to reach to failure under their own self-weight due to increasing the stresses on the geotechnical centrifuge (Goodings \& Abdulla, 2002).

Finally, dimensionless design chart was developed for the soil profile without uncemented sand overburden based on the experimental results. Stability charts for predicting sinkholes were presented, but without the inclusion of any factor of safety. The authors also concluded that the nature of collapse of the sinkhole in their model was a function of the ratio of the cemented sand thickness to the cavity diameter (Abdulla \& Goodings, 1996) (Goodings \& Abdulla, 2002). 
Analogical Model

In 2006, Caudron designed a two-dimensional small scale physical model (soil and building) to study the soil-structure interaction during sinkhole development. The physical model was composed of a rigid, U-shaped steel frame which receives the soil mass. The soil particles represented by bi-dimensional Schneebeli metallic rods in small scale allowing fully controlled test condition (Schneebeli, 1956). These analogical soil materials are simply steel rods that allows only two-dimensional modeling. The results from this model were not quantitative but only qualitative since, according to the authors, some laws of similarities were not respected. The experimental model consists of the test bed and the analogical soil. The test bed has maximum dimensions of $750 \mathrm{~mm}$ width and $500 \mathrm{~mm}$ height above the cavity. The dimensions are representing $30 \mathrm{~m}$ and $20 \mathrm{~m}$ in the full scale respectively. Prior to the test, the cavity can be modeled in different widths (25 $\mathrm{mm}$ to $250 \mathrm{~mm}$ in maximum 10 steps). Also, the cavity's height can be simulated with dimension ranging from $25 \mathrm{~mm}$ to $100 \mathrm{~mm}$. As stated above, the analogical cohesionless soil consists of Schneebeli rods with three different diameters of 3, 4 and $5 \mathrm{~mm}$ and have length of $60 \mathrm{~mm}$. Cohesion soil was introduced in some desired places by soaking the metallic rods in aqueous solution of glue (Caudron et al., 2006) (Caudron et al., 2006).

Caudron conducted a series of tests to monitor the vertical and horizontal displacements of the metallic Schneebeli rods by using Digital Image Correlation technique at different stages of the underground cavity development. Initially, repeatability tests and a greenfield test were conducted. Finally, the test was performed with the same initial condition but with introducing a building model on the ground surface to study the soil-structure interactions. 
Following the previous study, Caudron conducted more studies using the same model with not only the physical modeling approach, but also a numerical modeling approach (Caudron et al., 2006). Lastly, the author used the physical model to study the influence of the position of a structure on the collapse of the underground cavity (Caudron et al., 2008). In general, it can be stated that Caudron's experimental model allowed him to study the soil-structure interaction with some limitations. However, this small scale model needed some improvements (Caudron et al., 2006) (Caudron et al., 2006).

\section{Soil Physical Models}

The institute of karst geology, CAGS, in Guilin, China, has been conducting a large-scale experimental study using sinkhole physical models. There have been six major sinkhole collapse events in Wuhan metropolitan area. The latest event modeled in this study occurred April $6^{\text {th }}$, 2000, in Hongshan district, China, and has formed more than 20 sinkholes that caused about 150 residential houses to be damaged. Starting in 1997, the Institute of Karst Geology based in China started a series of testing using a large-scale physical model for the field because they found that in China, there had been many theoretical and observational studies but were not systematic in studying the collapse mechanism. The main objective of their model has been to study the controlling factors of the sinkhole development and formation. Sinkholes in the Hongshan District were investigated using the large-scale physical models in order to review the collapsing processes in this district (Lei et al., 1994) (Lei et al., 2005).

The physical model was designed using three main components. These are a base unit, recharge-discharge system, and observational system. The base unit, also called the main model, 
is $3.0,2.0, \& 2.0$ meters in height, width, and depth respectively. The height is equally divided into two parts with $1.5 \mathrm{~m}$ each. The upper part is a soil box to simulate the natural overburden soils. Interconnected pipes are used in the lower part to represent the caves, conduits and openings in the limestone. Both the soil box and the pipes are connected by one or more opening to represent the cracks in limestone which will allow the sediments to transport through it (Lei et al., 1994) (Lei et al., 2005).

The recharge-discharge system (water supply and drainage) consists of two different systems for supplying and draining the water; one is for the soil box, and the other is for the pipes. The main function of those two systems is to change the hydrodynamic conditions of model in order to simulate different conditions soils and sediment structures. Water boxes are installed at both sides of the sediment box to maintain the water table level at a constant height in the soil. Also, some sprinklers are used to simulate the rainfall events, which are installed above the base unit. The water could be discharged through the soil box opening to the pipes system. A supply water box with height of 3.5 meters is used to recharge the karst cave system (pipes) with a certain water pressure. This hydrodynamic condition is created to model the confined karst water. A pumping well is used to simulate the discharge of the karst cave to decline the karst water level (Lei et al., 2005).

The observational (monitoring) system consists of monitoring karst water regime, monitoring pore water pressure regime, and measuring soil deformations. Water meters, pressure transducers, and piezometers are used to measure water level and pore water pressure. Soil deformation is measured by subsidence tube (soil transducers) which is connected to clock gauge and iron sheet. This iron sheet moves with any soil deformation. In this device, the vertical 
deformation is measured by the clock gauge's readings which reflected the iron sheet movement (Lei et al., 1994) (Lei et al., 2005).

In 2005, Lei and others tested two conceptual models for a certain sinkhole formation and geological condition with the same overburden properties, hydrodynamic condition and rainfall of the natural area of Hongshan District in China. The first conceptual model was designed to investigate the effects of the width of fractures and fissures in the limestone layer and the effects of pore water pumping on sinkhole formation. The second conceptual model was to investigate the effect of the thickness of mudstone, which overlays on the top of the limestone, on sinkhole formation (Lei et al., 2005).

Based on the experimental model, the authors concluded that pumping of pore water will trigger the sinkhole collapses. Also, the voids in the sediments get larger dimensions with the larger limestone cracks. The experimental model exhibited that one of the most important factors that causes high migration of soil sediments, which results in sinkhole collapse, is the rate of the water table drop. It is concluded too that sinkhole collapse might be predicted by monitoring carbonate aquifer's water table change and the drawdown rate in-situ (Lei et al., 2005). 


\title{
CHAPTER THREE: PRELIMINARY SCALED PHYSICAL MODELS
}

\author{
$\underline{\text { Initial Scaled Models }}$
}

In this chapter, a full history of the research designed models will be discussed. Several initial tests were conducted to prove that sinkhole collapses can be physically simulated in a small scale soil model. The challenges were not only to develop sinkholes in small soil molds but also to prevent the mold edges from controlling or contributing in the failure zone of the sinkholes. This involved choosing appropriate mold openings, soil thicknesses, and artificial rainfall intensities. The main objective of this first series of initial tests was to empirically come out with the right scale for the physical model size in terms of diameter, height, bottom opening, and soil thickness.

A Dark Brown Fine SAND (A-3) was used as the sinkhole physical model soils. This sandy soil has an optimum moisture content of $13 \%$, a maximum dry unit weight of $104 \mathrm{lb} / \mathrm{ft}^{3}$, and a specific gravity, $G_{s}=2.6$. This soil was collected from the east Orlando area, in the state of Florida, the United States. The soil was first air dried, cleaned from roots, gravels and stones, and big soil particles.

In the first series of initial tests, some plastic buckets were used as a soil mold. These buckets (five-gallon buckets) have internal diameters of $28.5 \mathrm{~cm}$ and heights of $36 \mathrm{~cm}$. Every bucket was modified to receive a vertical roller on the top of it. This vertical roller was used to measure the soil subsidence at different locations. Also, small openings of 5, 10, 15, 20, and 25 millimeters were drilled into the bottom of the plastic buckets to simulate different sizes of cracks in the limestone bedrock. In these initial tests, only soil surface subsidence was monitored 
at different location from the center of the soil mold to see if there was any indication of soil depression (inversed cone) at very early stage of sinkhole development. Figure 6 shows the initial runs of scaled sinkhole models.

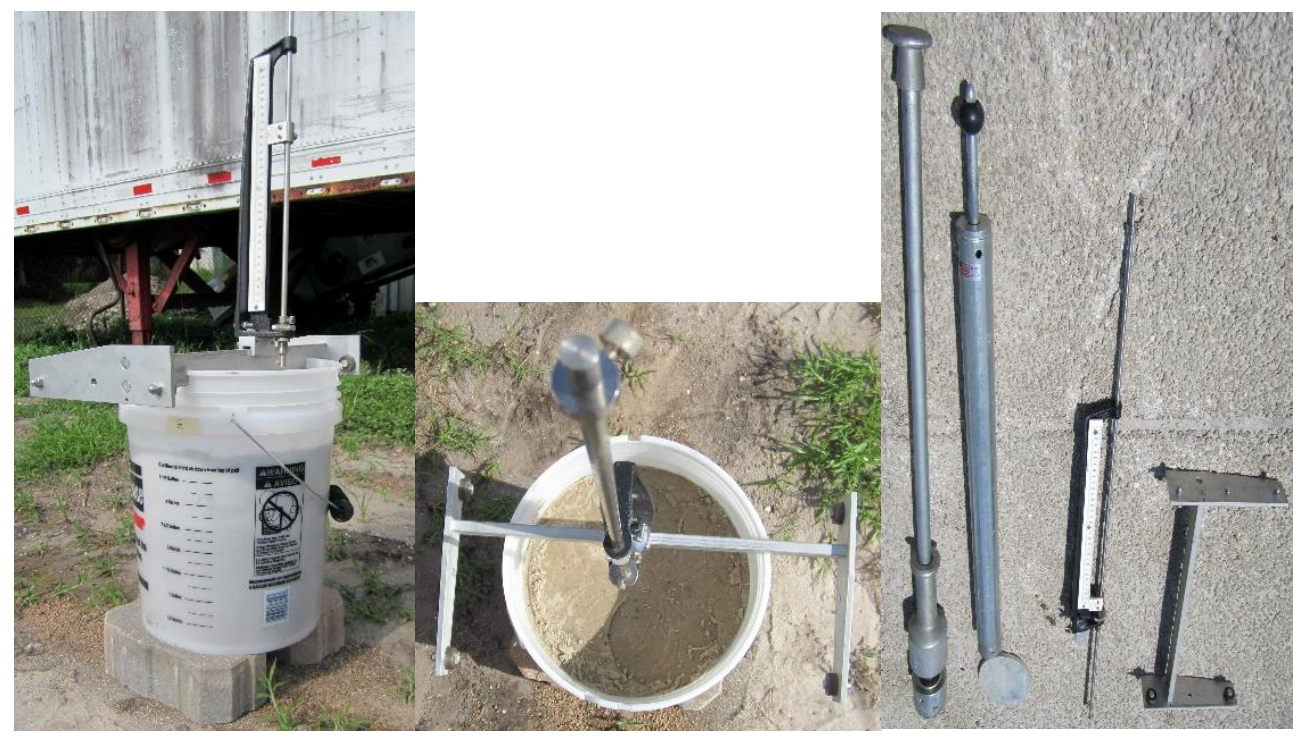

Figure 6: First scaled sinkhole models

Motivated by the main factor controlling the sinkhole collapse, groundwater fluctuations, the approach to this model was designed to monitor the groundwater table depression before and during the sinkhole collapses. In this series of tests, several mold sizes were used starting from the 5-gallon buckets to half of 55-gallon plastic drums, which have internal diameters of $56 \mathrm{~cm}$. Two monitoring wells were implemented in these tests. One well was located at $12 \mathrm{~cm}$, and the other one was at $20 \mathrm{~cm}$ from the center of the drum. PVC pipes were used for these monitoring 
wells. The PVC pipes were drilled to have holes on the pipes' entire outer circumference and were wrapped with geotextile fabrics. The geotextile fabrics were used to allow only water to get into the PVC pipes (monitoring well) and to prevent the soil particles from getting into the pipes. In other words, the fabric around the PVC pipe worked as a filtering system. A Testwell water level meter was used to measure the differences in water level of the two monitoring wells alternatively as shown in Figure 7. In these tests, samples were prepared following the given procedure in Chapter 4. The main purpose of these tests was to empirically prove if there was any groundwater level inclination toward the potential location of sinkhole formation prior to the surface collapse.

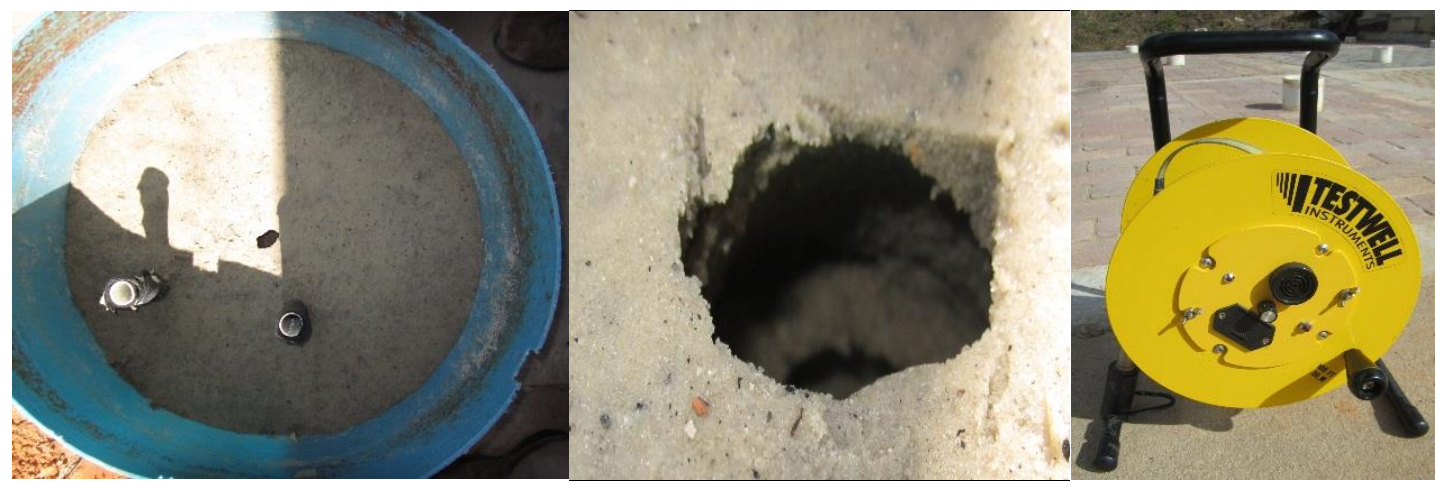

Figure 7: Second series of the initial tests and the Testwell water level meter 


\section{$\underline{\text { Arduino Based Scaled Physical Models }}$}

\section{Test Setup and Procedure}

In this test, a micro-controller, Arduino Uno, is used as a data acquisition system along with water level sensors, 12” eTape Liquid Level Sensors from MILONE technology.

The Arduino Uno is a microcontroller board based on the ATmega328. It has 14 digital input/output pins, 6 analog inputs, a $16 \mathrm{MHz}$ ceramic resonator, a USB connection, a power jack, an ICSP header, and a reset button. In this test, only the six analog inputs will be used for hooking up six eTape Sensors, in addition to the ground and five volts pins. Arduino Uno contains everything needed to support the microcontroller; it can be connected to a computer with a USB cable or powered by a AC-to-DC adapter or battery to get it started. It has an operating voltage of $5 \mathrm{~V}$ and voltage input limits range from 6 to $20 \mathrm{~V}$; however, it is recommended to use a range of 7 to $12 \mathrm{~V}$ (Arduino Datasheet).

The eTape Liquid Level Sensor is a solid-state sensor with a resistive output that varies with the level of the fluid. The eTape sensor's envelope is compressed by the hydrostatic pressure of the fluid in which it is immersed. This results in a change in resistance that corresponds to the distance from the top of the sensor to the surface of the fluid. The sensor's resistive output is inversely proportional to the height of the liquid: the lower the liquid level, the higher the output resistance, and vice versa (12" eTape Liquid Level Sensor Datasheet). The sensor has the following technical details:

- Sensor Length: 14.1" (358 mm), Width: 1.0" (25.4mm), \& Thickness: 0.015" (0.208 mm)

- Resistance Gradient: $150 \Omega$ / inch $(59 \Omega / \mathrm{cm}), \pm 10 \%$

- Active Sensor Length: 12.6" (320.7 mm) 
- Substrate: Polyethylene Terephthalate (PET)

- $\quad$ Sensor Output: $2250 \Omega$ empty, $400 \Omega$ full, $\pm 10 \%$

- Actuation Depth: Nominal 1 inch $(25.4 \mathrm{~mm})$

- Resolution: 0.01 inch $(0.25 \mathrm{~mm})$

- Temperature Range: $15^{\circ} \mathrm{F}-140^{\circ} \mathrm{F}\left(-9^{\circ} \mathrm{C}-60^{\circ} \mathrm{C}\right)\left(12^{\prime}\right.$ eTape Sensor Datasheet)

A circular metal mold with a diameter of $56 \mathrm{~cm}$ was used in this tests. This mold has a predetermined hole in its center of $5 \mathrm{~mm}$. This hole was designed to represent a crack or a few cracks in the limestone layer. As explained earlier, this hole was chosen after a series of experiments to have a scaled opening in the soil mold. This opening also was designed to allow the soil sediments to transport through it in an acceptable time rate, which is sufficient to monitor the sinkhole development during the experiment.

Six monitoring wells were implemented in the soil sample to monitor the groundwater drops in this series of tests. In each monitoring well, a 12" Liquid Level Sensor from MILONE Technology was introduced. These sensors were distributed in radial locations around the center of the soil sample. As described in the sensor calibrations, all of these liquid level sensors must always stay in a vertical orientation during the test to achieve the best results. Thus, one-inch PVC pipes were used as monitoring wells in the physical model. These PVC pipes were prepared the same way as explained in the previous initial tests. Figure 8 illustrates the Arduino physical model.

The six sensors were distributed in radial locations around the expected location of the sinkhole collapse. A series of tests were conducted to come out with a good plan to choose the wells' locations. Although this model has its drawbacks, its results were helpful in the process of 
upgrading the data acquisition system. The results of this model will be briefly discussed in the following section.

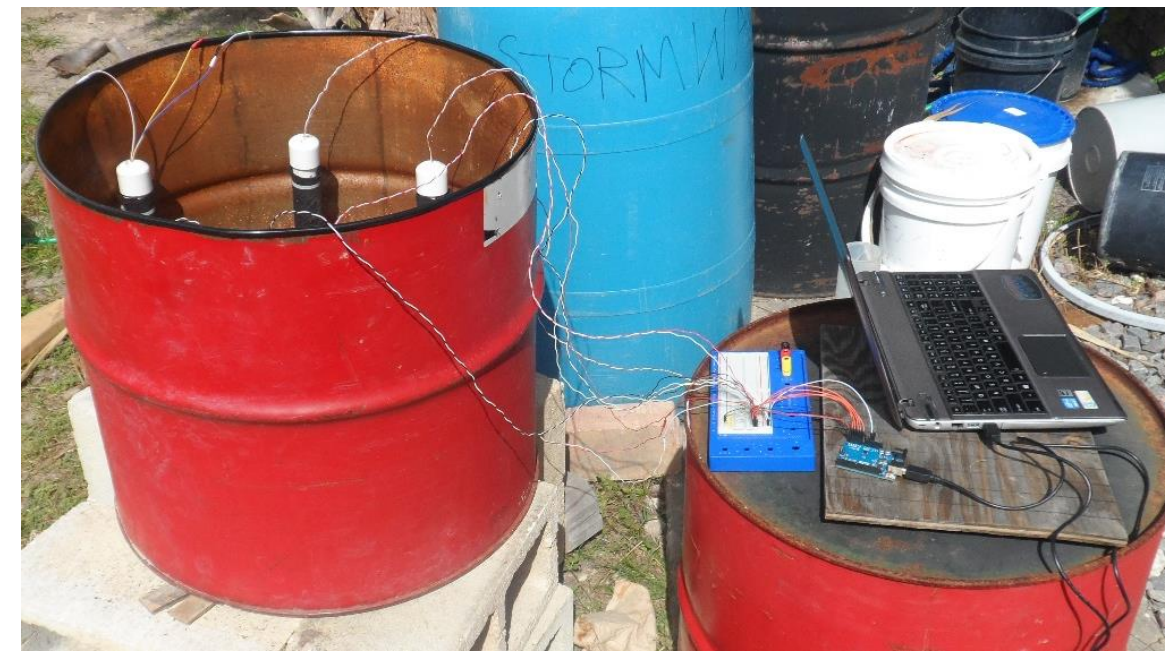

Figure 8: Arduino based scaled physical model

\section{Experimental Results and Discussion}

A few selected experimental results of the 6-channels Arduino based model will be presented and discussed in this section. Figure 9 and 10 show the elapsed time of the groundwater level drawdown in the Arduino based physical model. In this test run, a $150 \mathrm{~mm}$ soil depth sample was prepared with initial groundwater level of $20 \mathrm{~mm}$ from the soil surface. The bottom hole was opened at 6 minutes and 16 seconds from the test start time. A soil surface collapse was observed after 12 minutes. 


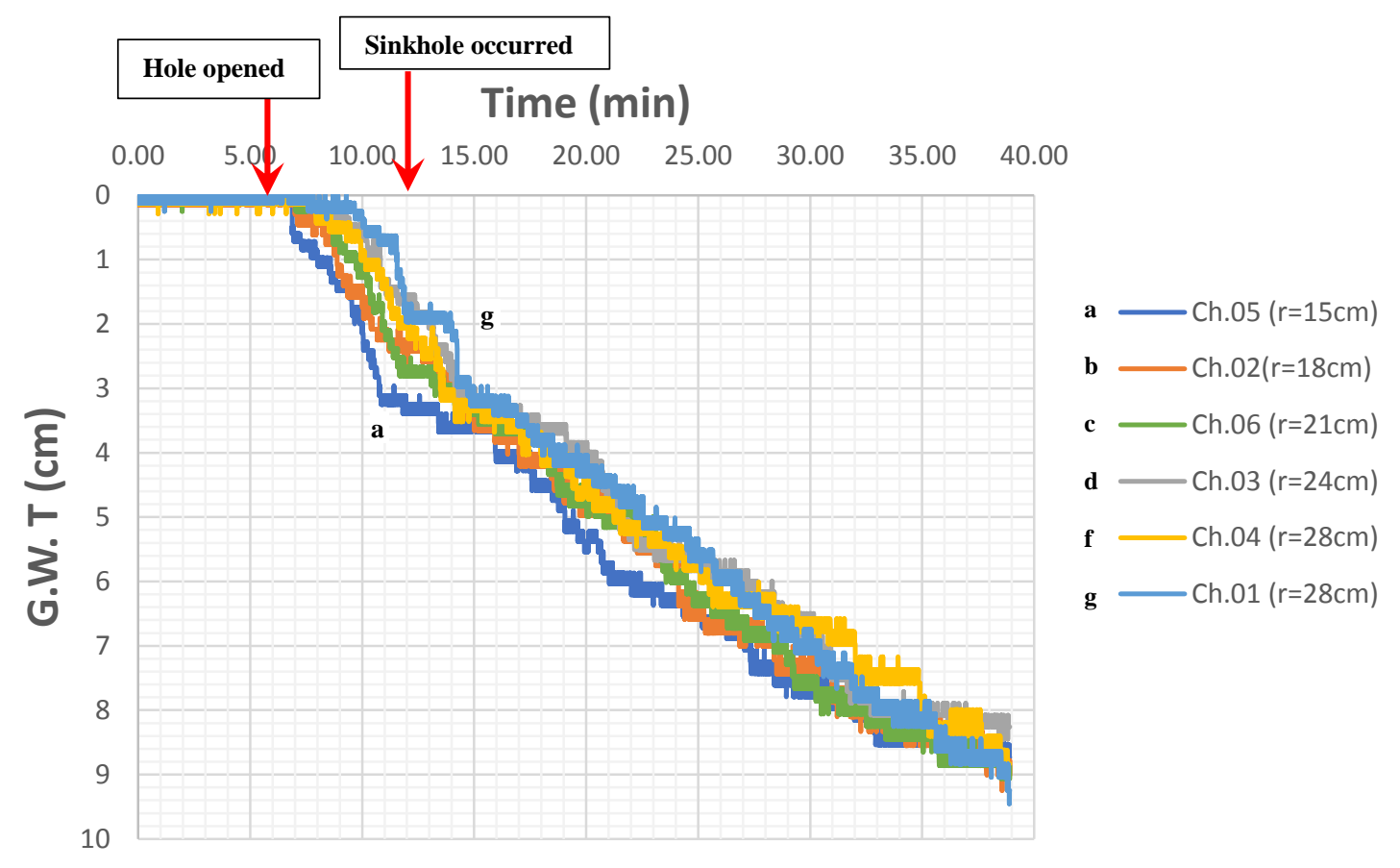

Figure 9: Groundwater level changes versus time plot in the scaled model using the Arduino UNO

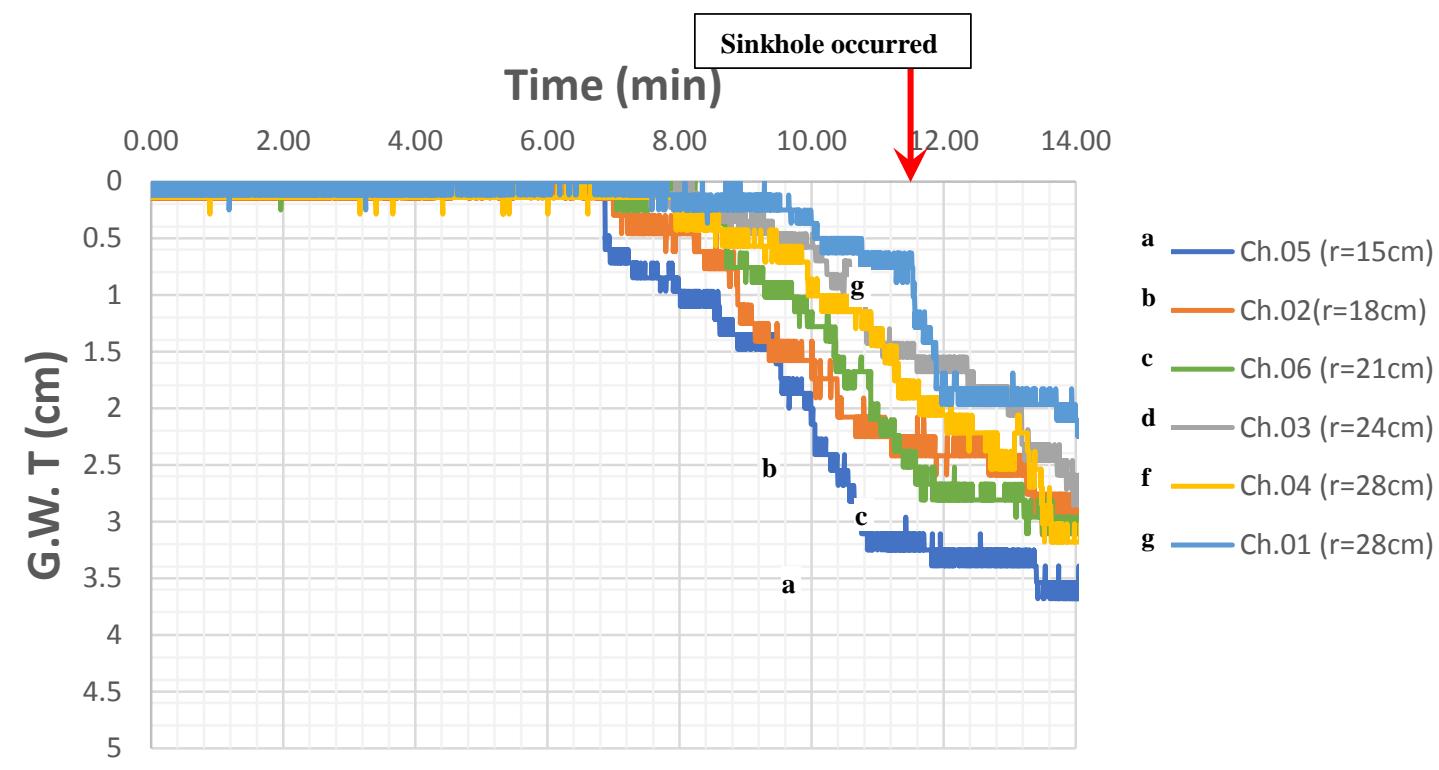

Figure 10: Groundwater level changes versus time plot for the sinkhole formation time period. 
From the previous figures, it can be noted that the groundwater levels in the monitoring wells are close to the sinkhole location, the center of the soil mold, and drop faster than the ones farther away. This trend indicates that there is an inclination in the groundwater surface toward the center prior to the sinkhole collapse. This water depression was developing with time from the horizontal groundwater level to a shape similar to a cone. For this reason, it is called a groundwater cone of depression, similar to the one that occurs during groundwater pumping.

However, in the Arduino based Model, the noise level of the data was large, about \pm 15 $\mathrm{mm}$ of the water level readings, which became an obstacle for any good analytical study. This margin of error of $\pm 15 \mathrm{~mm}$ can hide the early effects of the very small groundwater changes on the sinkhole development. In order to overcome the data noise problem and improve the accuracy, the NI 9234 module was used as the data acquisition system.

\section{Scaled Physical Models using NI 9234 Module}

Test Setup and Procedure

In this physical model, the NI 9234 module was used to acquire the data. A LabView code was also created to program the NI 9234 module to work with the eTape Liquid Level Sensors. The NI 9234 is a high-accuracy data acquisition (DAQ) module specifically designed for high-channel-count sound and vibration applications. The National Instruments 9234 are four-channel dynamic signal acquisition module for making high-accuracy measurements from IEPE sensors. The NI $9234 \mathrm{C}$ Series analog input modules deliver $102 \mathrm{~dB}$ of dynamic range and incorporate IEPE ( $2 \mathrm{~mA}$ constant current) signal conditioning for accelerometers and microphones. The four input channels simultaneously acquire at rates from 2 to $50 \mathrm{kHz}$ or, with 
the NI 9234, up to $51.2 \mathrm{kS} / \mathrm{s}$. In addition, the modules include built-in antialiasing filters that automatically adjust to your sampling rate. They are compatible with a single-module USB carrier and NI CompactDAQ and CompactRIO hardware. (NI 9234 Datasheet)

In this experiment, only 4 sensors were used to monitor the groundwater level drops with time. Preparations of sensors, soil, and sample are similar to the Arduino based Model except that the DAQ is been changed to the NI 9234 module coded with the LabView software. The NI 9234 and its connection is shown in Figure 11.

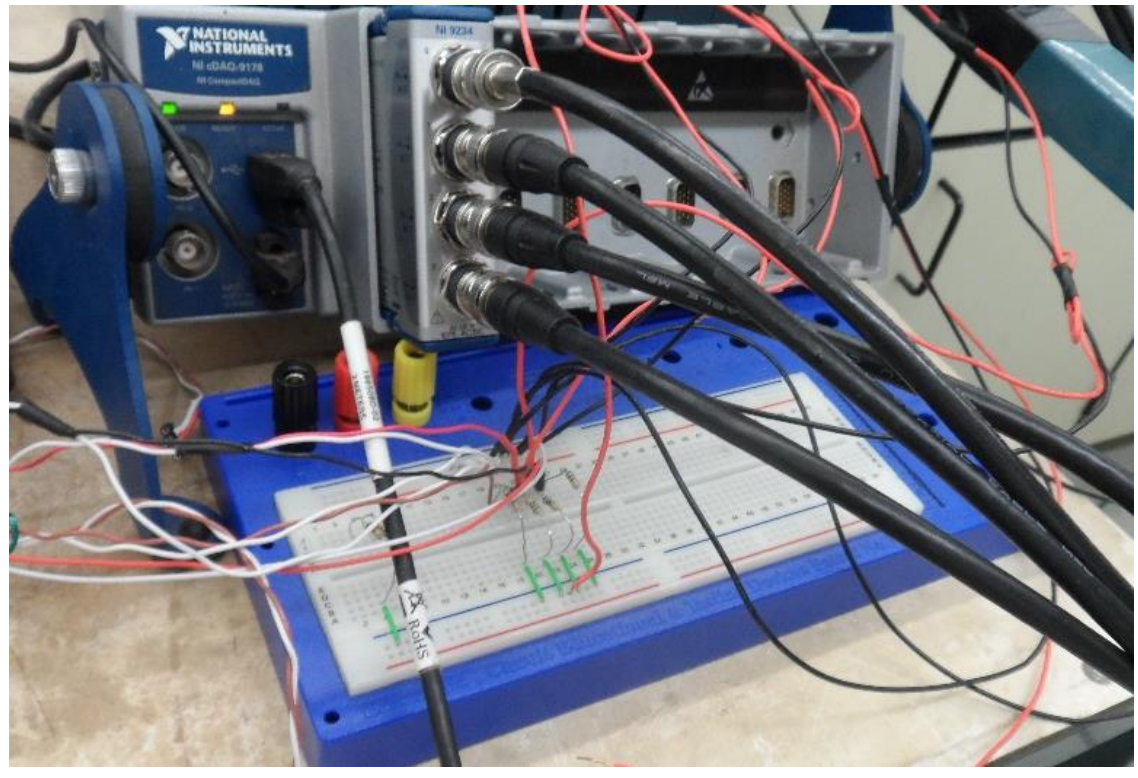

Figure 11: NI 9234 connected to four resistors in voltage divider circuits 


\section{Experimental Results and Discussion}

In order to overcome the data noise problem and improve the accuracy, the NI 9234 module was used as the data acquisition system. Figure 17 shows the results of a $180 \mathrm{~mm}$ thick soil test. The initial groundwater level was at $31 \mathrm{~mm}$ from the soil surface. The time of starting soil sediment transport, from opening the hole, was at $3 \mathrm{~min}$ and $30 \mathrm{sec}$. The sinkhole surface collapse was observed at $18 \mathrm{~min} \& 30 \mathrm{sec}$ from the test starting time $(\mathrm{t}=0)$. The results are shown in Figure 12.

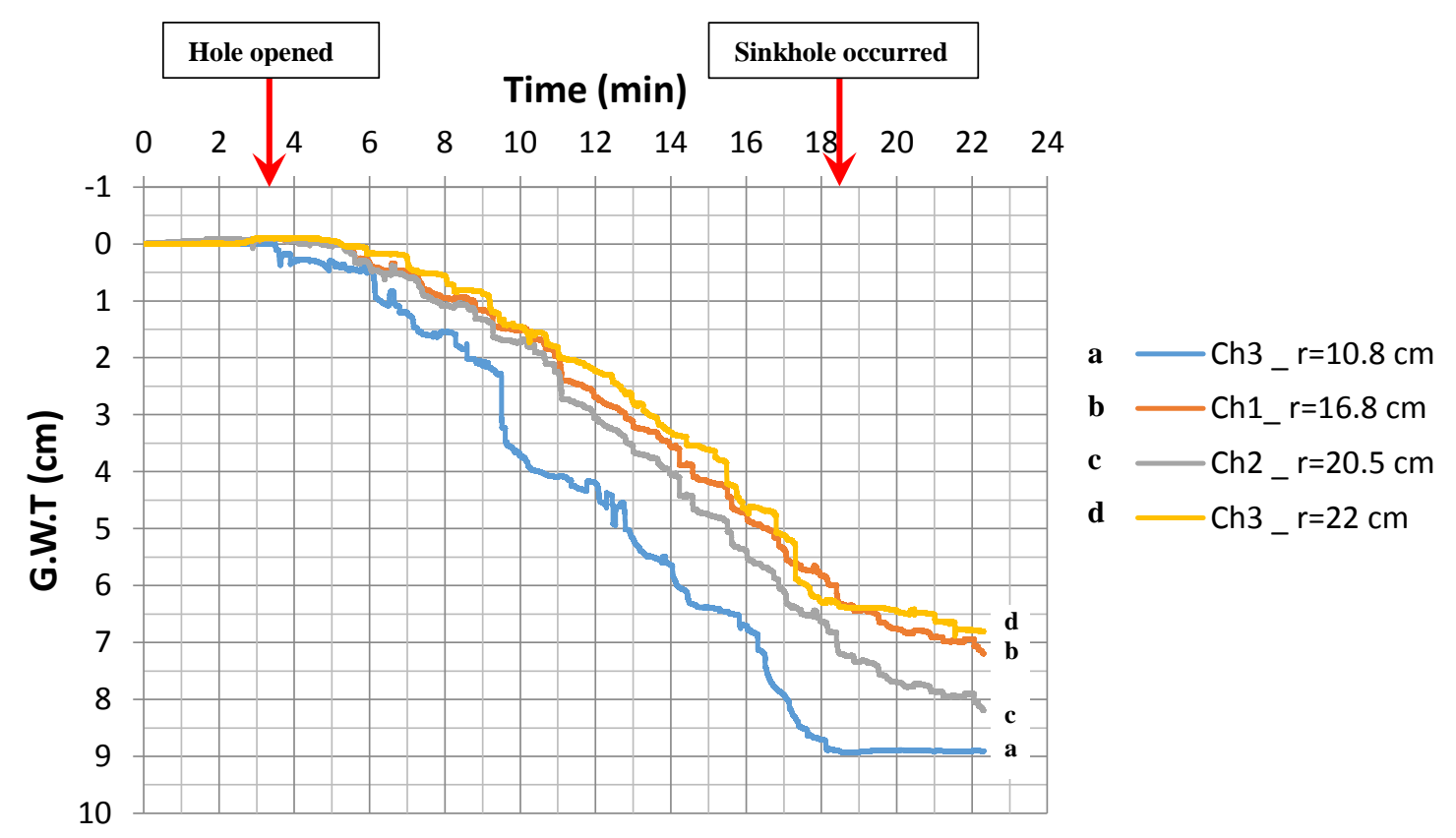

Figure 12: Groundwater level changes versus time plot in the scaled model using the NI 9234 module 
The theory of the groundwater cone of depression can be seen more clearly in this model because the data hasa lesser noise level than that of the Arduino Model. However, the drawback of this model was the limited number of channels ( 4 channels), which is the maximum number that can be hooked up to the NI 9234 module. The main issue was the problem in analyzing the water level and its slopes with only four data points. As only one NI 9234 module was available to perform this test, it was a necessity to reconsider changing or upgrading the data acquisition system to accommodate more channels. .

\section{Final Test Setup: Scaled Physical Models using the NI PXIe-1062Q Module}

In the final sinkhole physical model setup, eight monitoring wells were installed in the soil sample to monitor groundwater movements. The same previous metal mold, metal opening, and soil type were used also in this experiment. The NI PXIe-1062Q module was used in the physical model to acquire the data. A LabView code was also created to program the NI PXIe module with the eTape Liquid Level Sensors.

Detailed explanation of this test's equipment, preparations and procedures will be presented in Chapter Four and Five. 


\title{
CHAPTER FOUR: SINKHOLE PHYSICAL MODELS TO SIMULATE AND INVESTIGATE SINKHOLE COLLAPSES
}

\author{
Introduction \\ Sinkhole is a ground surface depression that occurs with or without any surface \\ indication. Sinkholes commonly occur in a very distinctive terrain called karst terrain. This \\ terrain mainly has a bedrock of a carbonate rocks such as limestone, dolomite, or gypsum. \\ Sinkholes develop when the carbonate bedrocks are subjected to dissolution with time to form \\ cracks, conduits, and cavities in the underground bedrock. These features allow the overburden \\ soils (on top of the carbonate bedrock) to transport through them to the underground cavities, \\ which results in surface collapse due to the upward progression of the soil cavity toward the \\ ground surface. Sinkholes vary in shapes and sizes. They have different shapes such as inverted \\ cone, shallow bowl, and shaft shapes. Also, they can range from less than a meter to hundreds of \\ acres and from $30 \mathrm{~cm}$ to 30 meters in depth (Waltham et al., 2005). \\ Sinkholes can be formed due to several processes such as bedrock dissolution, soil \\ suffosion, rock collapse, and soil collapse. Based on the formation processes, sinkhole generally \\ can be classified to six types: Solution (Dissolution) sinkholes, Collapse sinkholes, Caprock \\ sinkholes, Dropout (Cover-collapse) sinkholes, Suffosion (Cover-subsidence) sinkholes, and \\ Buried sinkholes (Lowe and Waltham, 2002) (Williams, 2004) (Waltham et al., 2005).
}

\section{Background}

The state of Florida is one of the most susceptible places to sinkholes in the United States due to its geology. Florida's karst geology is underlain by carbonate deposits, which is 
continuously subjected to a dissolution process due to the circulation of the groundwater (Atkinson, 1977) (Quinlan et al., 1993) (Tihansky, 1999). The dissoluble carbonate bedrock is overlain by several layers of sand and clay soils. These clay and sand sediments vary in thicknesses based on their location within Florida (Bottrell et al., 1991). Florida's sinkholes are mainly classified into three types: dissolution sinkholes, cover-subsidence sinkholes, and covercollapse sinkholes. All of these types are the results of one or both of the dissolution and suffosion processes. The dissolution process is the chemical process where the carbonate rock dissolves due to the exposure to acidic water forming cracks, fissures, conduits, and cavities in karst. While, suffosion is a physical process of transporting the unconsolidated soil sediments to the bedrock's underground cavities through the existing cracks and conduits (Sinclair and Stewart, 1985) (Tihansky, 1999).

Florida's climate has a very distinctive two seasons (dry and raining seasons). The groundwater reaches its highest level in the end of the raining season (September). However, this level decreases until it reaches its lowest level at the end of the dry season (May). This kind of groundwater seasonal variation is one of the most important factor that triggers sinkhole collapses in Florida (Lewelling et al., 1998) (Sinclair, 1986) (Tihansky, 1999).

\section{Problem Statement}

Sinkhole prediction is a complex task due to the combination of different factors (geological and hydrological factors) involve in forming sinkholes. There is a broad field of the ground investigation techniques that can be used to investigate possible sinkhole locations. These 
techniques can be direct investigation by using soil probing, poring, drilling and sampling, or indirect investigation by using either geophysical methods or aerial or satellite remote sensing. The problem with the direct methods is that the borehole can easily miss a progressing underground cavity. Besides that, sinkhole history maps, and aerial and satellite remote sensing are not providing assurance that all the surface depressions (subsidence) detected by these methods are actually sinkholes (Waltham et al., 2005). No single method works in all situations, and an integrated approach must be adopted. As a part of this integrated approach, we studied the relationship between groundwater levels and sinkhole collapse.

\section{Research Scope}

The motivation behind the present research was to find a 'sign' to guide the ground investigation team to the potential hazardous area of sinkholes based on existing information such as groundwater levels, Since groundwater change is one of the main driving forces to cause and accelerate sinkholes in Florida, it is anticipated that the indication of the sinkhole collapses may be noted in the groundwater behavior before the surface collapse occurs. Hence, a smallscale physical model was designed and built to naturally simulate sinkholes. This model is a spatial-temporal model type. It was mainly designed to monitor the groundwater drops around a predetermined sinkhole. The monitoring wells were radially distributed around the sinkhole in the physical model.

The model was initially designed based on a typical profile of Florida's karst hydrology and geology. An important assumption in this test was that the dissolution process has taken place 
previously. In this model, the dissolution fracture is represented by a circular hole that transports a certain volume of soil through the limestone to an underground cavity. Moreover, this spatialtemporal model was designed to simulate a period of time at the end of the dry season in Florida (May), where the groundwater drops to its lowest levels. In general, the model is used to study the relationship between the groundwater drops and sinkholes' formation, location, and time.

\section{Previous Work}

\section{Sinkhole Models}

A discussion on previous research on sinkhole soil models is presented in this section. In the past, some models were implemented using different approaches such as centrifuge models, analogical models, and actual soil physical models (Abdulla and Goodings, 1996) (Goodings and Abdulla, 2002) (Chen and Beck, 1989) (Caudron et al., 2006) (Caudron et al., 2008) (Lei et al., 1994) (Lei et al., 2005).

In 1989, Chen and Beck designed a two dimensional soil model to study the mechanisms of sinkholes. They used layers of natural sediments, which were tested in a parallel-plate type tank with a bottom opening. This tank has wooden bottom and Plexiglass sides. Chen and Beck (1989) simulated 23 different trials of homogeneous and stratified soils with initial conditions of dry, partially saturated, or saturated. This simple model was designed to simulate a covercollapse sinkhole. The objective of this study was to obtain some data about the sinkhole's mechanical processes which were not known at that time. In this model, the authors found that 
type of the sediments, namely sand or clay, controls the time of the collapse. Also, the initial conditions of the sediments, such as dry, saturated, or partially saturated varies the speed of the sinkhole development. The model also proved that in the stratified overburden, the collapse may stop when a cohesive stratum is encountered at the top of the opening. This will cease the internal erosion either permanently or temporarily. While this qualitative two-dimensional soil model is a very simple model, however it can provide some basis for more sophisticated quantitative physical models of sinkhole to be developed (Chen and Beck, 1989).

Finally, a large-scale experimental study of sinkhole physical models was conducted by the Institute of Karst Geology in China (CAGS) in 1997. The model was aimed at studying the factors that control the formation of a sinkhole (Lei et al., 1994) (Lei et al., 2002) (Lei et al., 2005). CAGS's physical model consists of three main components that are a base unit, rechargedischarge system, and observational system. It is a large-scale model with dimensions of $3 \mathrm{~m}$ in height, and $2 \mathrm{~m}$ in both depth and width (Lei et al., 1994) (Lei et al., 2005).

Next, Lei and others, in 2005, simulated certain sinkhole formations in Hongshan District by using two conceptual models. This study investigated the effects of the width of limestone cracks, rate of water pumping, and mudstone thickness (The mudstone layer is located on the top of the limestone). It was concluded that groundwater pumping triggers more sinkhole collapses. In addition, the cracks in the limestone have a direct relation to the voids in the soil sediments in terms of size. Finally, it was noticed that the rate of the declination of groundwater is an important factor in the sinkhole collapse (Lei et al., 2005). 


\section{Sinkhole Evaluation Based on Groundwater Recharge}

In 1994, Foshee and Bixler conducted a study of cover-subsidence sinkholes in Florida. The development of sinkholes around the state road 434 and Harbor Isle intersection in Seminole county, Florida, caused minor pavement settlement for that intersection. Since seven different sinkholes occurred north and south of State Road 434. These sinkholes also caused settlements to building, roads, and yards. Hence, the Florida Department of Transportation (FDOT) decided to monitor the pavement settlement for the State Road 434 to evaluate potential causes. A subsoil explorations program was conducted by using several cone penetrometer tests and the installation of permanent piezometers. The data evaluation of this study showed that there was a layer of very loose soils located at deeper ground strata. This loose soil was subjected to internal soil erosion (raveling). This raveling soil migrates slowly through limestone cracks to underground cavities and conduits in the carbonate bedrock. Eventually, this raveling process ends with a surface depression called cover-subsidence sinkhole. The main driving force of this raveling process is the downward groundwater movement, which is called recharge. This recharge occurs because of the difference in the shallow water table and the confining aquifer water level if recharge points exist which are the bedrock cracks. Recharge was observed in this site by studying the piezometer reading for almost two years. However, in this study, only piezometer readings at a specific time intervals were plotted as contour maps. The piezometer head contours showed a very clear depression indicating the settlement location. Foshee and Bixler (1994) stated that studying sinkholes by the pore-pressure-contouring technique should be further investigated to validate the reliability of this technique in different types of subsurface soil conditions. 


\section{Current Sinkhole Physical Model}

This current study's main objective is to conduct a spatial-temporal analysis for network of groundwater monitoring wells to try and predict the location of a sinkhole collapse. In reverse analysis, a network of wells were distributed in a radial distances around a predetermined sinkhole location. Sensor devices were chosen and programmed to detect the water level changes with a high degree of accuracy. The water level was monitored at $0.5 \mathrm{~mm}$ resolution. The data was also collected at a high sampling rate of $100 \mathrm{~Hz}$.

Due to the lack of initial research funds, a simple 55 -gallon metal drum to be used $(56 \mathrm{~cm}$ diameter) for testing. A $5 \mathrm{~mm}$ circular hole was drilled at center of the base of the drum. This hole represented a crack or a collection of close cracks in the limestone bedrock. The purpose of this circular hole was to transfer a certain volume of soil sediment out of the model to mimic the loss of soil through a limestone crack at a slow rate. Initially, the challenges encountered were related to the small-scale physical simulation of a sinkhole and the scaling of all the controlling parameters. These controlling parameters are the soil depth (overburden soil thickness on top of the limestone), location of the groundwater to cause sinkholes, artificial rainfall intensities, side (edge) effects on the development of the sinkhole, and the size of the base opening. The side

effect was one of the most important factors, since the sides should not control or interfere in the sinkhole formation and development zone. All these parameters were finally selected based on a series of initial tests. The results of these tests are not included in this paper, but were critical in finding the proper scale for the sinkhole simulator.

The sinkhole simulator included a network of eight groundwater monitoring wells. These monitoring wells were distributed in a radial manner around the center, which was the 
predetermined location of the eventual sinkhole. Figure 1 shows the radial distribution of the eight monitoring wells. Each monitoring well was made of a one-inch PVC pipe. These pipes were perforated all around to allow the water to enter. The pipes were then wrapped with a geotextile fabric to allow only the water to pass and filter the soil particles. Eventually, every PVC pipe (well) was equipped with a 12 Inch eTape Liquid Level Sensor (MILONE Technology). The PVC pipes were also used to maintain the sensors in vertical orientation during the test to achieve the highest accuracy of their results. The sensors were used to read the actual water levels at the eight monitoring wells. The locations of the monitoring wells were set to be at the following distances $(10 \mathrm{~cm}, 12 \mathrm{~cm}, 14 \mathrm{~cm}, 16 \mathrm{~cm}, 18 \mathrm{~cm}, 20 \mathrm{~cm}, 22 \mathrm{~cm}$, and $26 \mathrm{~cm}$ ) from the center of the test as shown in Figure 1. These locations were chosen based on a series of tests to make sure that they are far enough from the sinkhole failure zone. This assures that the closest pipes will not influence the formation, spread and collapse of the sinkhole cavity. A cross-section of the sinkhole simulator is also shown in Figure 13.

In this study, a sandy soil with $1 \%$ passing the 200 sieve from Orlando, Florida, was chosen for the physical model. This soil was classified as a dark brown fine sand (AASHTO type A-3). The soil had an optimum moisture content of $13 \%$, a maximum dry unit weight of 104 $\mathrm{lb} / \mathrm{ft}^{3}$, and a specific gravity of 2.6. The first step in the test was to seal the opening (limestone crack) using a rubber sheet in the bottom of the metal drum. Then, the pre-cleaned sandy soil with a moisture content $13 \%$ was well compacted in soil mold. Prior to adding the soil, the eight PVC pipes (monitoring wells) were installed at the radial locations shown in Figure 1. The thickness of the soil layer was varied between $150 \mathrm{~mm}$ and $200 \mathrm{~mm}$. The soil layer was fully 
saturated to a depth of $22.5 \mathrm{~mm}$ and $30 \mathrm{~mm}$ from the ground surface, respectively, for a period of 24 to 48 hours. These levels represent the shallow water table in the soil sample.

The data acquisition system used in this study consists of an NI PXIe-1062Q module from National Instruments, Labview software, and 12” eTape Liquid Level Sensors from MILONE Technology. The NI PXIe-1062Q module was hooked up to the eTape sensors with a voltage divider circuits. This DAQ system was coded using the Labview program to read a very sensitive water level changes of up to $0.5 \mathrm{~mm}$ with high sampling rate of 100 readings per second. Figure 2 and 3 show the sinkhole experimental model setup picture and diagram, respectively. After the full saturation stage to the desired groundwater level, the eTape sensors were dropped in the monitoring wells. The DAQ system then was turned on to start reading the water level drops. After approximately 3 to 8 minutes, the hole was opened. This represents the transport of the soil through the limestone crack/s to the underground limestone cavities. Finally, the soil was left to behave naturally due to the drops of the shallow groundwater until a collapse representing a sinkhole occurred on the ground surface as shown in Figure 12. 


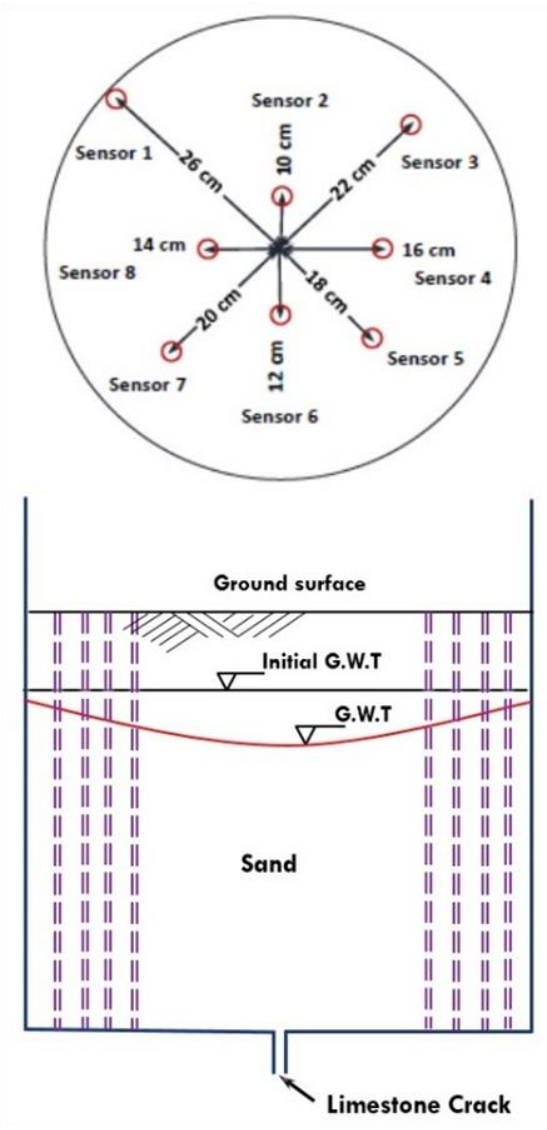

Figure 13: The Radial Location of the Eight Monitoring Wells and Physical Model Crosssection.

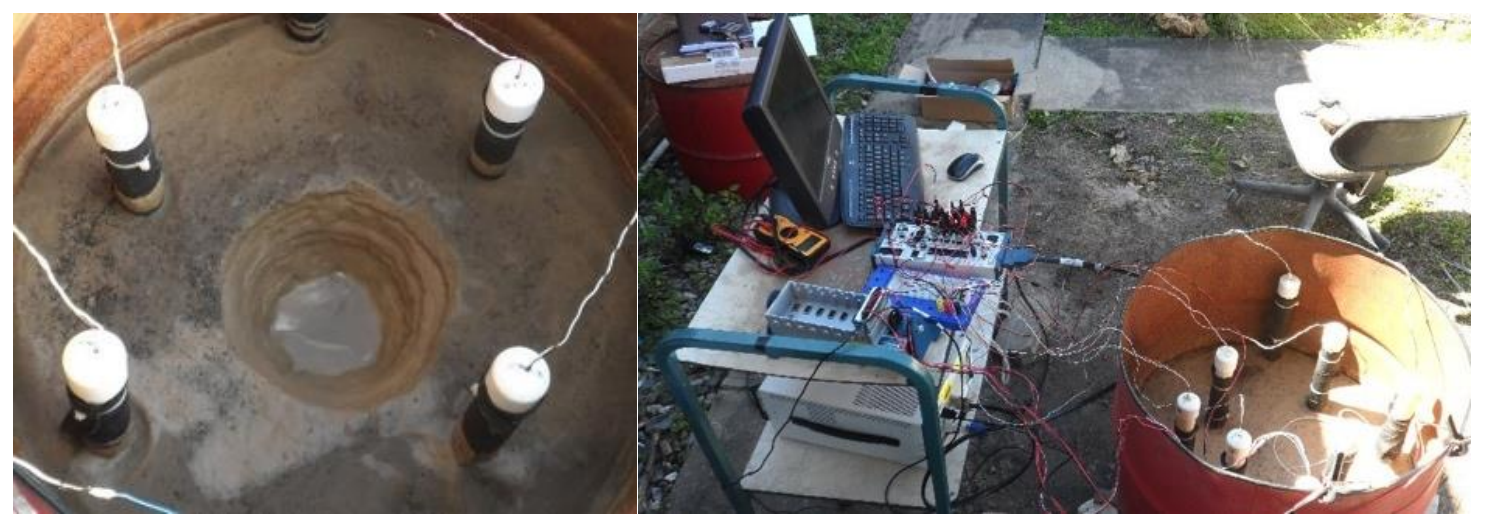

Figure 14: Sinkhole Physical Model Test Setup and sinkhole collapse. 


\section{$\underline{\text { Results and Discussion }}$}

In this study, more than 30 model configurations were tested. However, the results of only four different tests are presented in this paper. The first two tests were with soil thickness of $150 \mathrm{~mm}$ (representing the overburden soil above the limestone bedrock) and with initial groundwater level at $22.5 \mathrm{~mm}$ from the ground surface. While, the other two tests were with a $200 \mathrm{~mm}$ soil thickness and an initial groundwater level of $30 \mathrm{~mm}$ from the ground surface. This sinkhole physical model is designed to run a sensitive spatial-temporal analysis by using a dense network of water level sensors to read the groundwater changes with high resolution $(0.5 \mathrm{~mm})$ high sampling rate $(100 \mathrm{~Hz})$. The sinkhole occurred after 16.0, 19.7, 20.0, and 26.6 minutes in TEST 1, TEST 2, TEST 3, and TEST 4 respectively. 


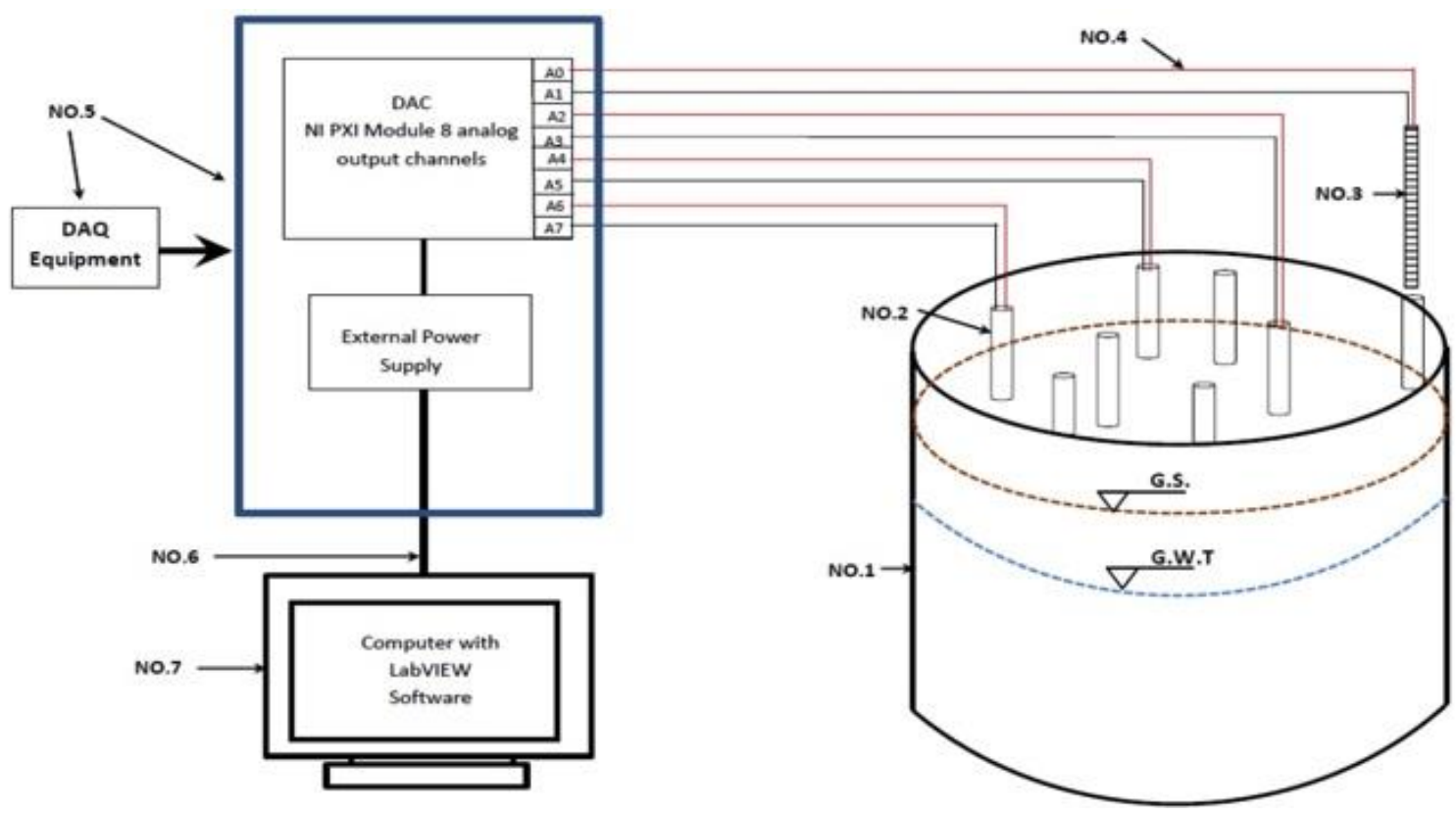

Figure 15: Sinkhole Experimental Model Setup Diagram.

The results of TEST 1, 2, 3, and 4 are plotted in Figure 16 to illustrate the groundwater drops with time. These figures also show the effect of the radial locations of the eight monitoring wells prior to the sinkhole collapse. It was observed in all tests that the groundwater drawdown was faster in the wells closer to the predetermined sinkhole location than the wells further away from the center. This natural phenomenon is called the cone of water depression. In all tests, the cone of depression developed well before surface collapse occurred. It is also observed that the cone of depression gets steeper with time as the underground cavity within the sediments gets bigger. 


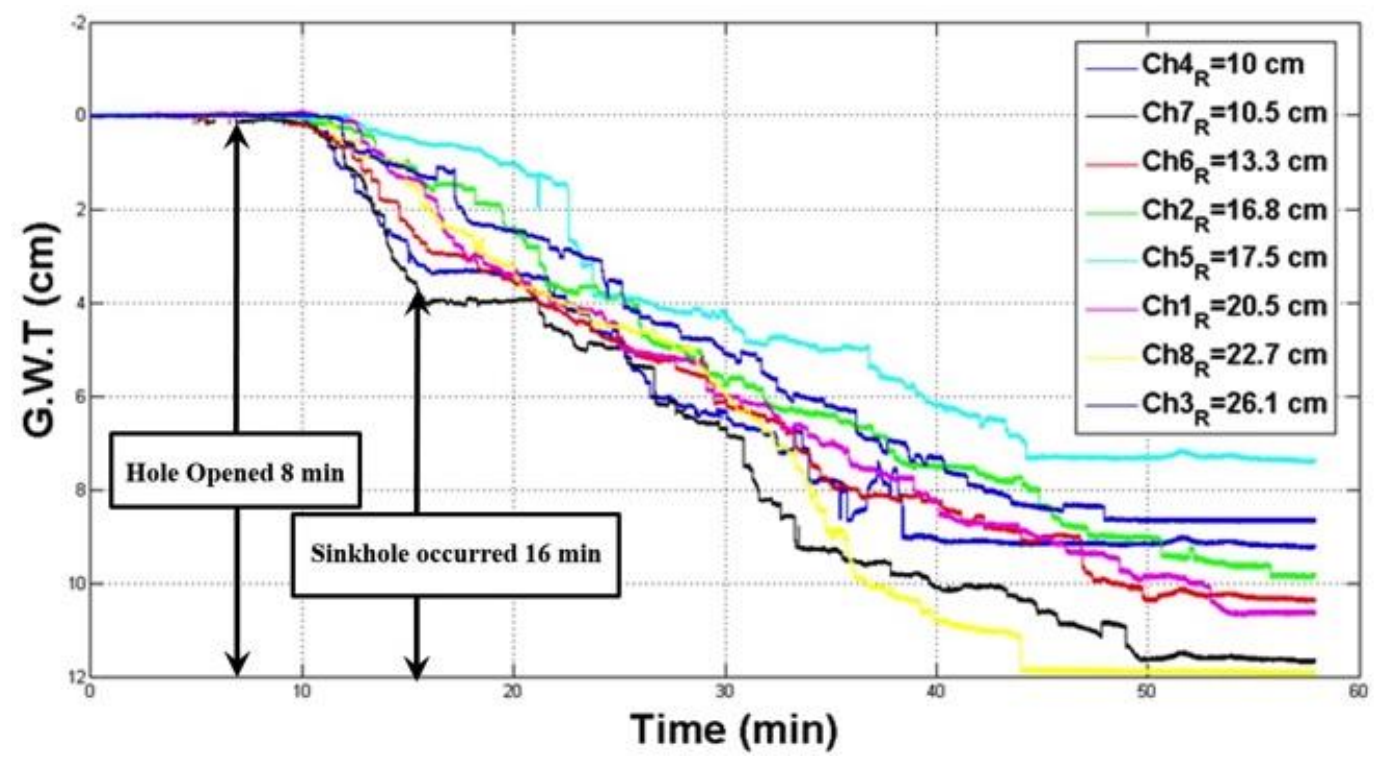

(a) TEST 1.

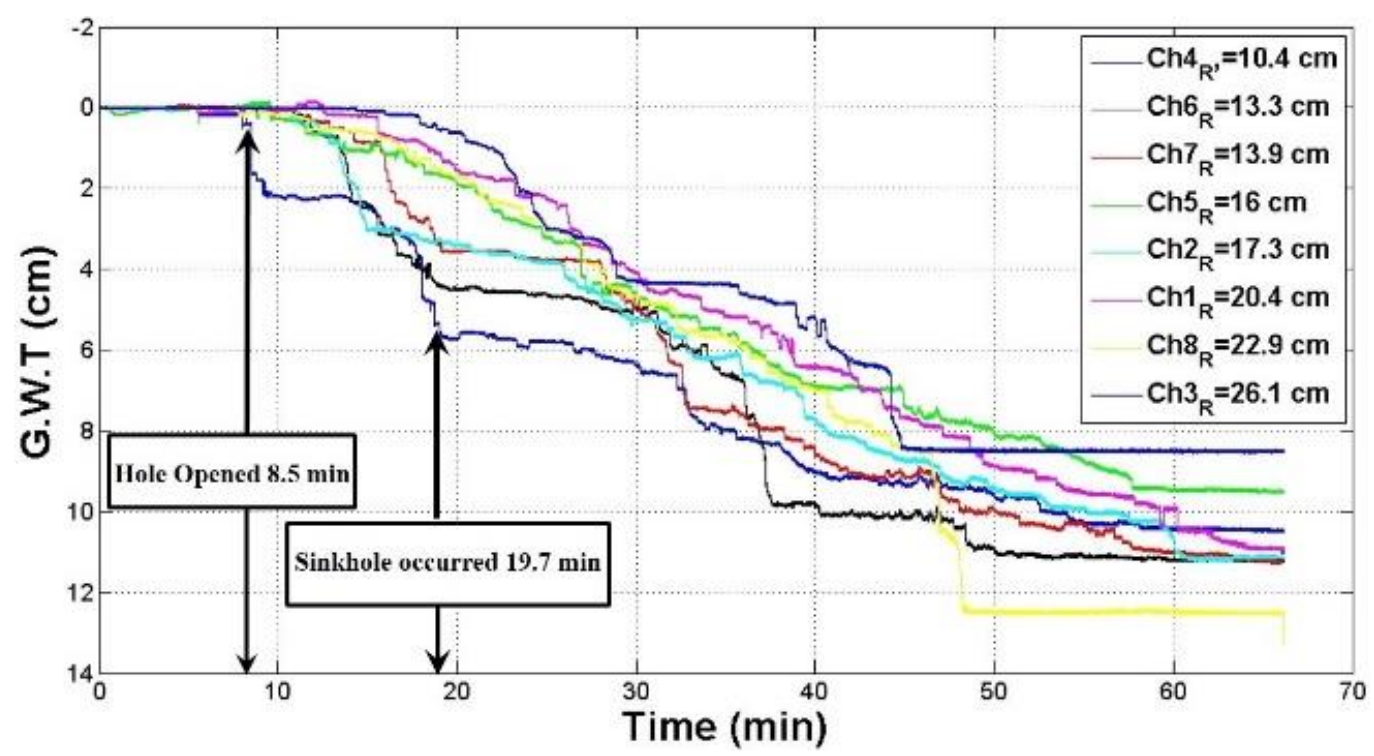

(b) TEST 2. 


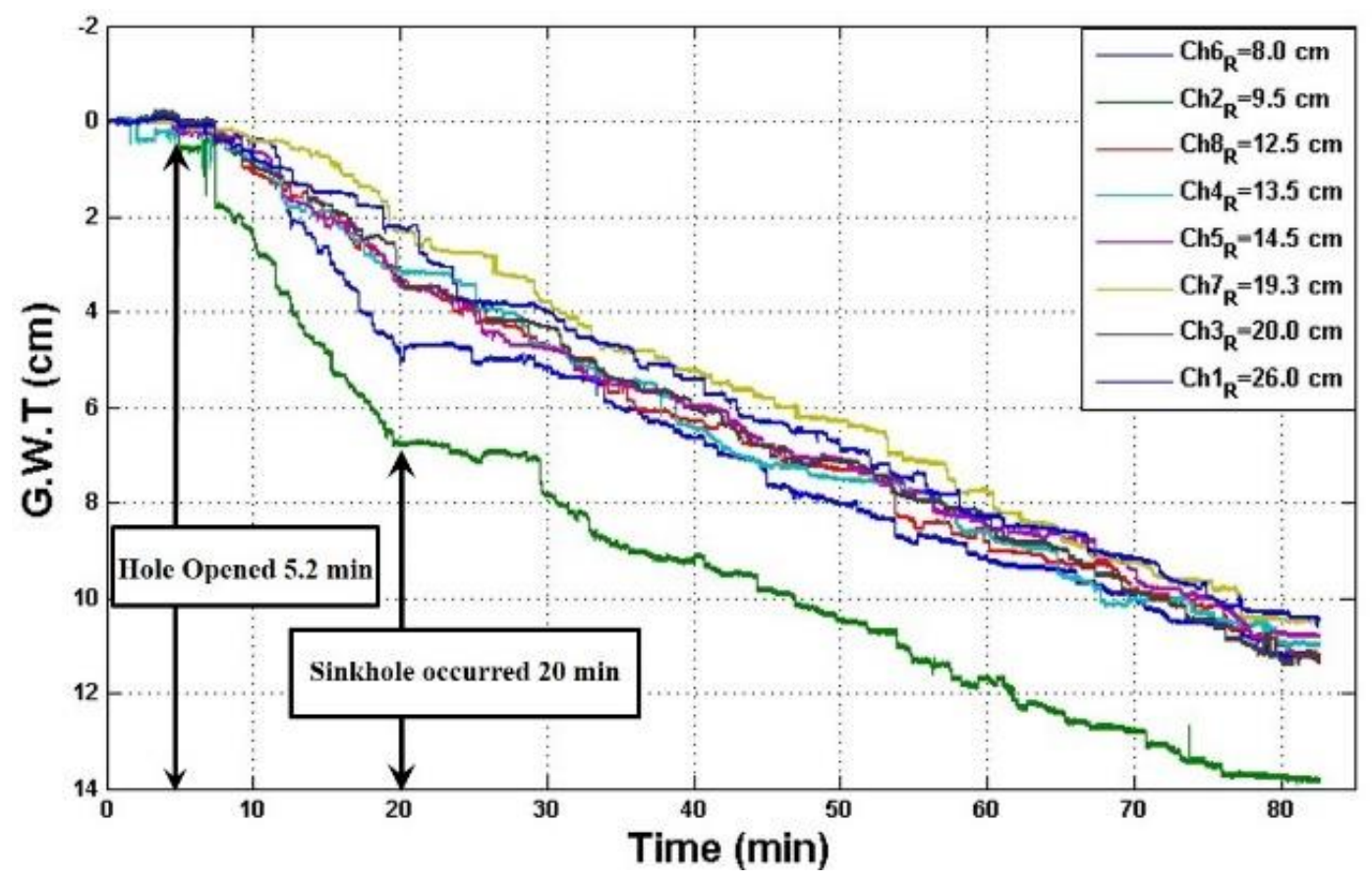

(c) TEST 3.

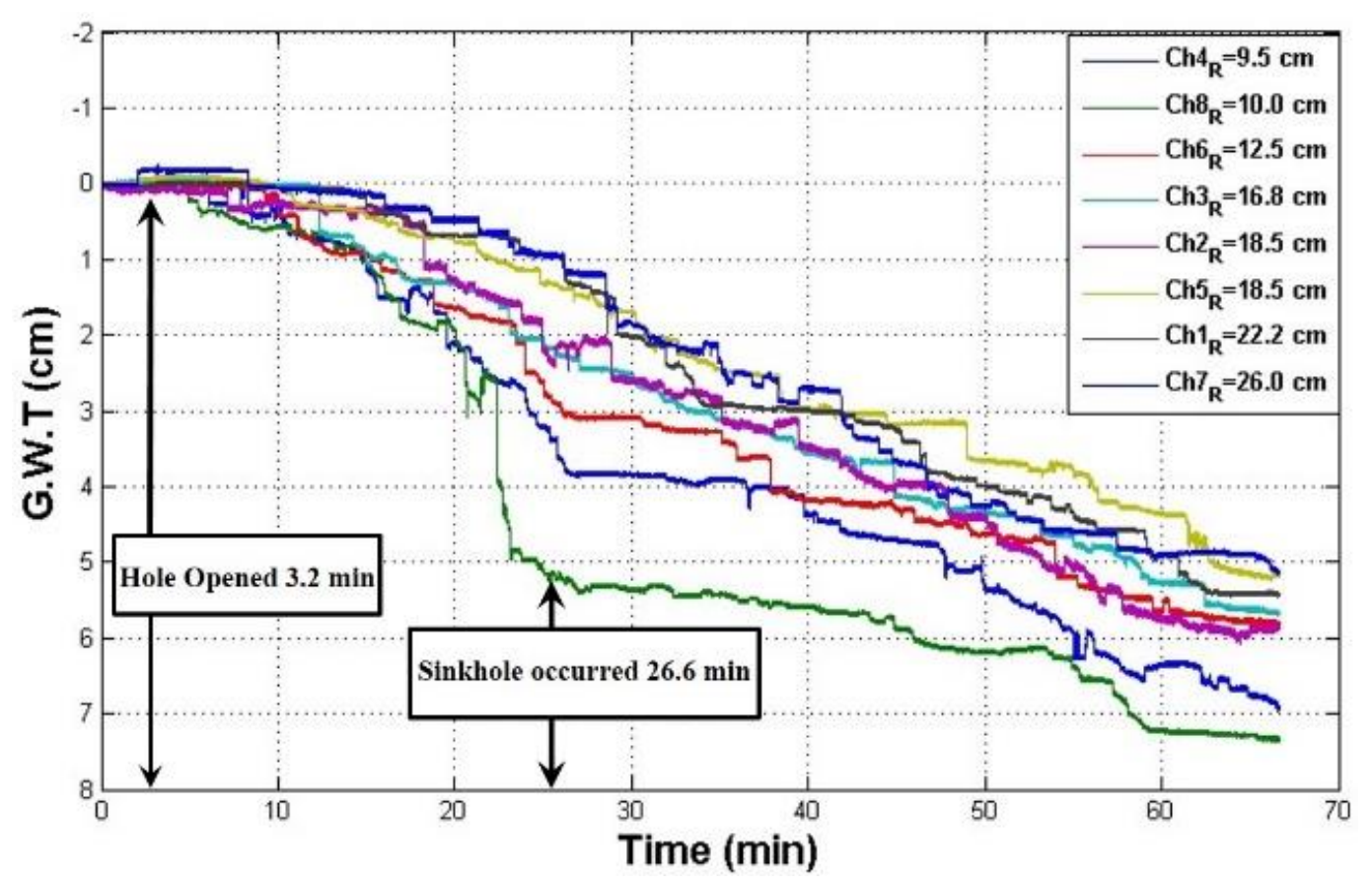

(d) TEST 4

Figure 16: Groundwater level drops with time in the sinkhole physical model test. 
In order to see the development of the groundwater cone of depression, the groundwater drawdown was plotted against the eight radial locations of the monitoring wells (i.e., $10 \mathrm{~cm}, 12$ $\mathrm{cm}, 14 \mathrm{~cm}, 16 \mathrm{~cm}, 18 \mathrm{~cm}, 20 \mathrm{~cm}, 22 \mathrm{~cm}$, and $26 \mathrm{~cm}$ distances from the sinkhole location). Figure 17 shows these plots for TEST 1 and TEST 2. It can be seen in Figure $17(\mathrm{a}, \mathrm{b}$, and $\mathrm{c})$ that there is a very distinctive water cone that starts right after the initiation of the sinkhole formation by opening the bottom hole. The top of this inverted cone is pointing toward the sinkhole location and also its slope gets steeper as time gets closer to the sinkhole collapse. It is also observed that some of the water level sensors might not follow the sequence of the drop in the water level, which implies that a closer sensor shows a higher water level than a more distant sensor. This kind of behavior is possibly due to the inability of having a very homogenous soil all around the sample, since compaction level may vary somewhat within the same soil. However, the general trend of the groundwater drawdown forms a very distinctive cone of depression, which can point to the potential location of a sinkhole that is developing underground. 


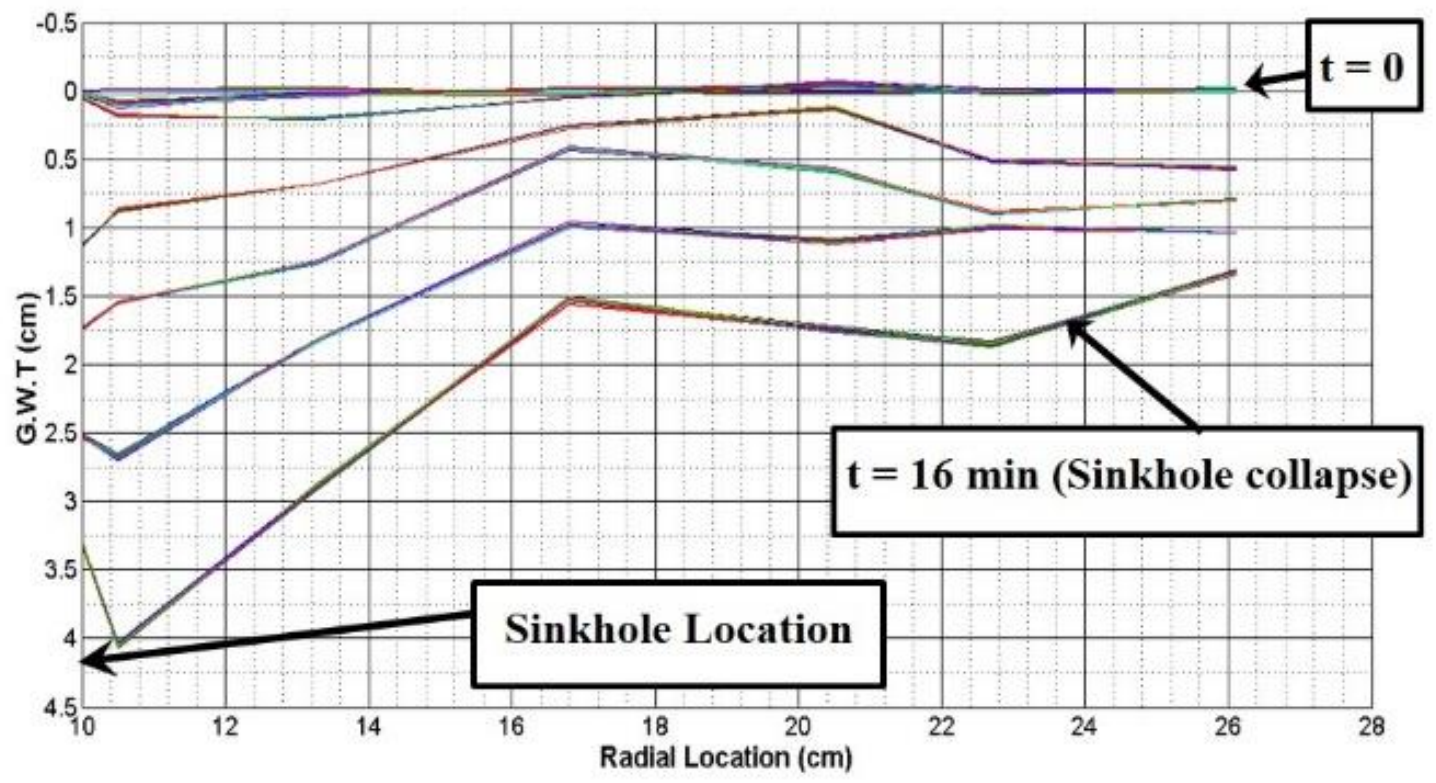

(a) TEST 1.

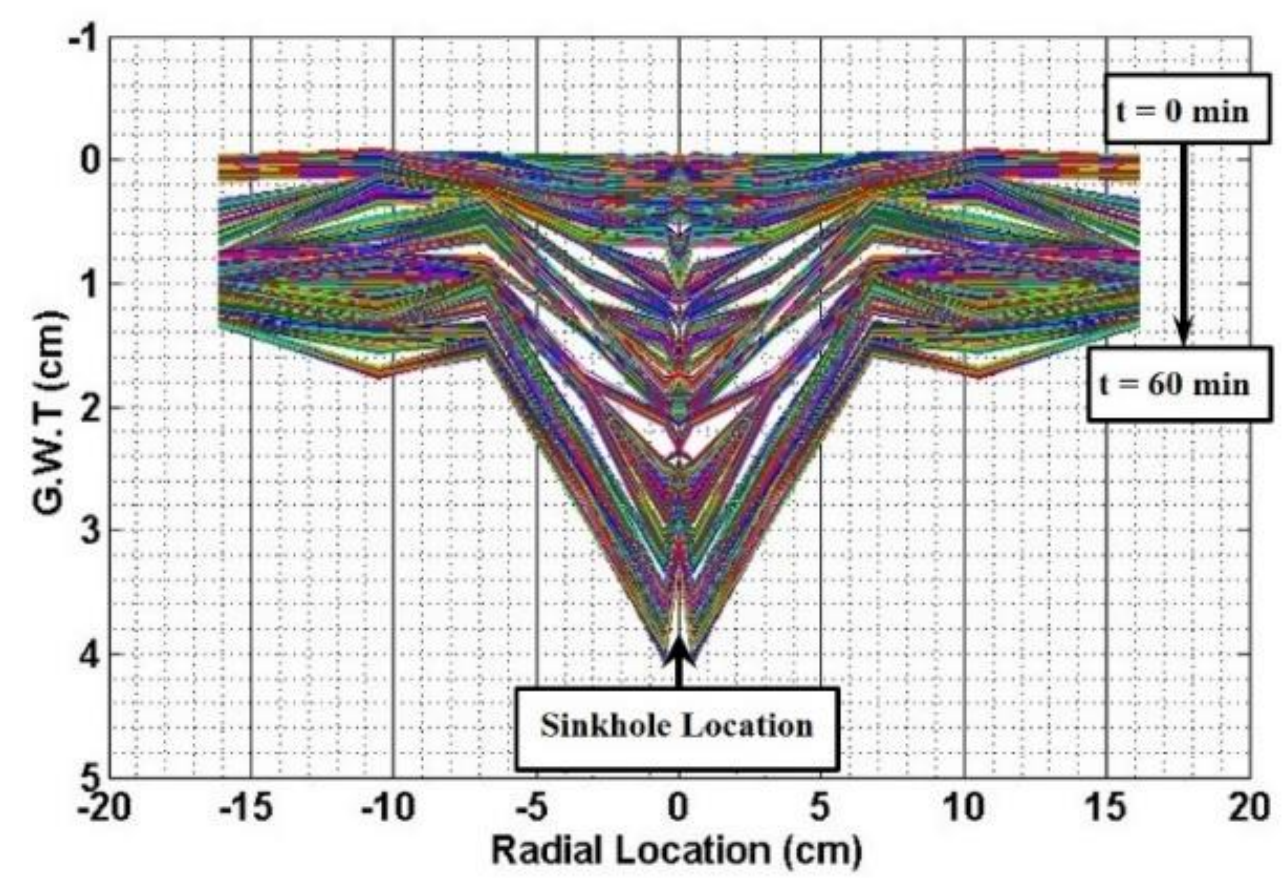

(b) TEST 1. 


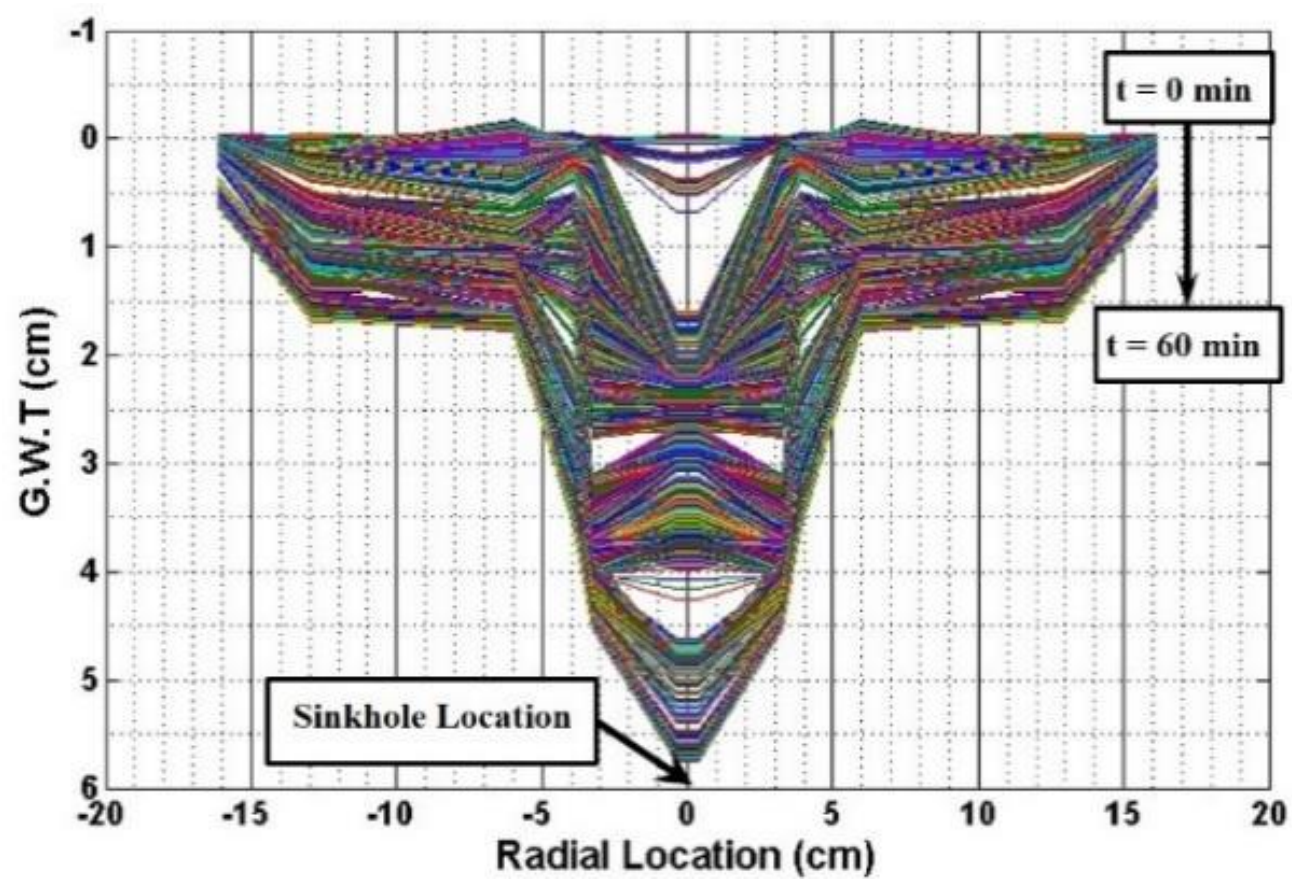

(c) TEST 2

Figure 17: Groundwater selected readings in different times versus the wells radial locations

During all tests, the sensor water readings showed distinctive progressive drops with time. The progressive drops were analyzed to investigate their relationship to the sinkhole collapse location and time. Only the results of TEST 1 were chosen to illustrate this behavior in this paper. As it is seen in Figures 18 and 19, there were progressive and sudden drops in the groundwater table. These drops start after initiating the sinkhole (by opening the hole) and then transferred from the nearest sensor to the sinkhole to the second nearest sensor with a time lag. These drops can be observed to move from the closer sensors to the further sensors with time. This behavior of the sudden drops of the groundwater level was also observed on the experiment display screen during the test, when the soil has a faster rate of sediment loss out of the bottom 
hole. This means that the progressive drops are representing a certain internal collapse of the cavity within the sediments. Also, the amplitude of the progressive drops is related to the rate of sinkhole formation. Thus, the progressive drops of the groundwater table can serve as an indicator for the potential location of sinkhole.

To avoid the overlap of the sensors data, only some selected sensors are studied in Figure 18 and 19. It can be seen clearly, that the progressive drops are repeatable behavior in different wells' readings. However, these drops were transferred with a time lag from the near sensor to the furthest sensor from the predetermined sinkhole location. The most likely explanation for this behavior is the internal collapse of the cavities within the sediments, since all other parameters and factors related to sinkhole formation were controlled. One can notice the effect of the sinkhole underground formation in early stage at a groundwater monitoring well located near a progressing sinkhole first. Then this behavior might be transferred to the next monitoring well over a certain time period (time lag). This time duration varies depending on the distance that well is from the progressing sinkhole location. In general, the time lags in the progressive drops could be used to measure the proximity of the sinkhole. This can be achieved in the future by correlating the expected sinkhole time to the progressive drops of the groundwater table. 


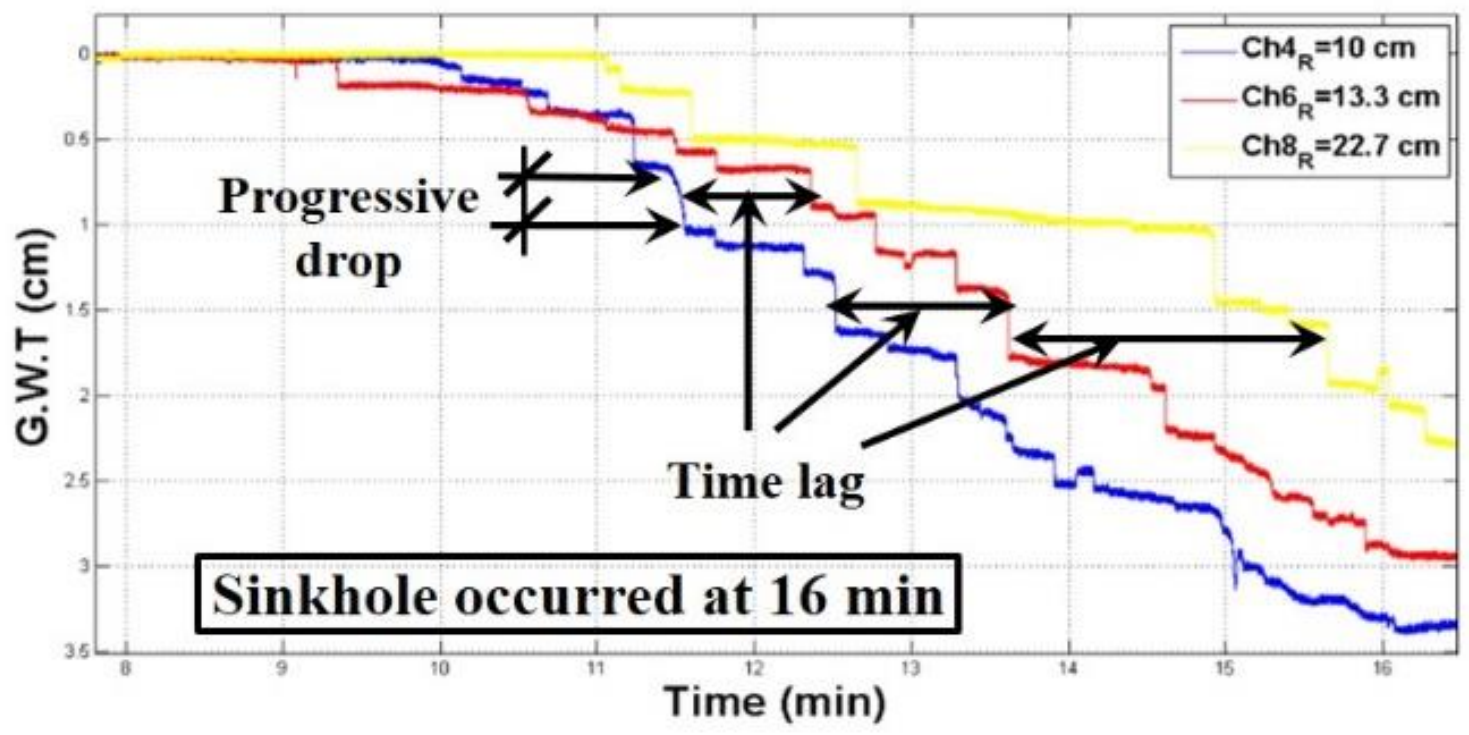

Figure 18: Groundwater table readings at three selected wells locations, TEST 1.

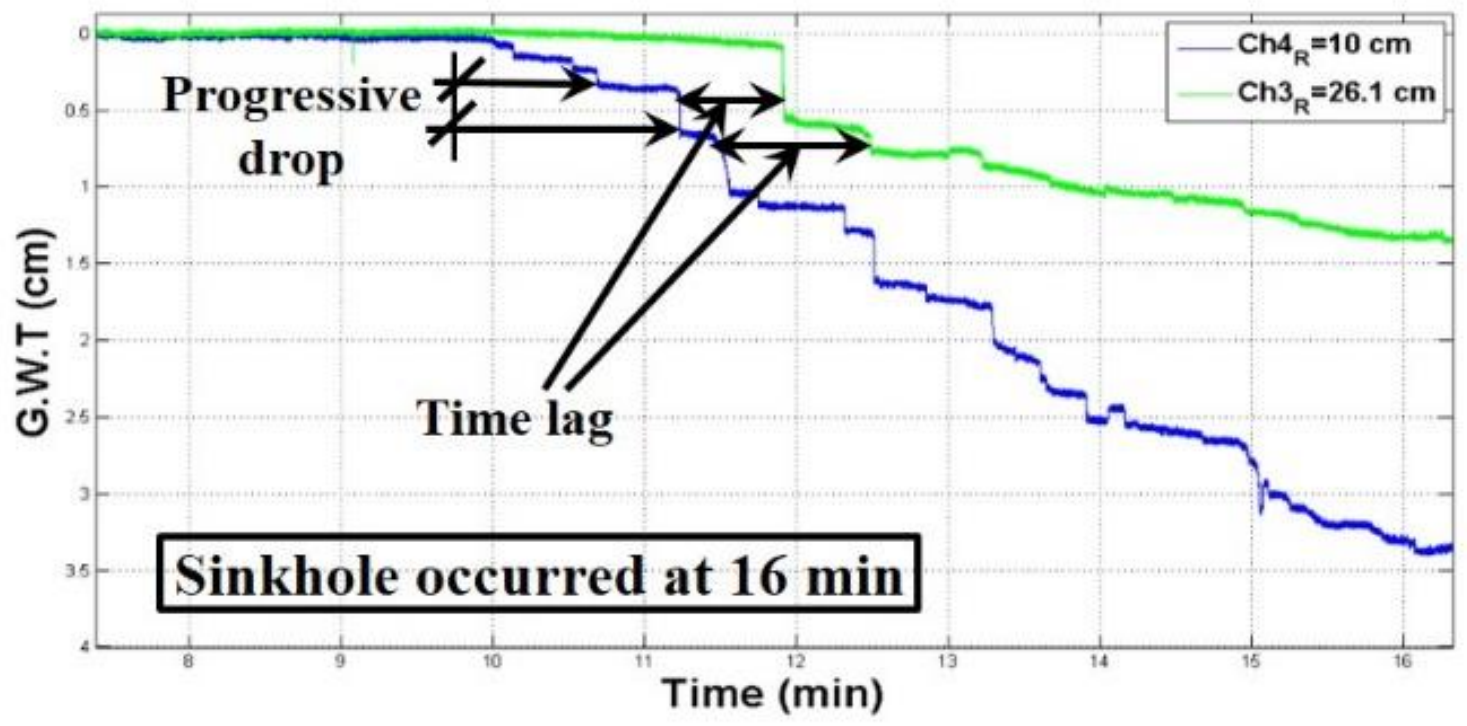

Figure 19: Groundwater table readings at the nearest and furthest monitoring wells, TEST 1. 
Finally, it can be noted that the trend of the variation of groundwater levels from all tests showed a good agreement in general. The spatial-temporal model proved that there is a groundwater cone of depression prior to the sinkhole surface collapse. This water cone indicates the future potential location of the sinkhole collapse. Also, repeatable groundwater progressive drops were observed in all models. These progressive drops were transferred from one well to another over a certain time period called time lag. Both the progressive drops and their time lags can provide information relevant to the sinkhole locations and their progression rates.

\section{$\underline{\text { Conclusions }}$}

In this paper, a small-scale sinkhole model used to physically simulate the natural sinkhole collapse and to provide a potential avenue to predict the location of a sinkhole. The sinkhole simulator consisted of two main components: The soil mold and the monitoring system. The monitoring system was used to conduct a spatial-temporal analysis of data collected from a network of groundwater monitoring wells (sensors). These wells were distributed in a radial pattern around a predetermined location of a sinkhole. A different soil levels (overburden soil) and initial groundwater levels were tested in this model. This model has a one circular opening to simulate a crack in the limestone that allows the transfer of a volume of soil through the dissolving bedrock layer. During all tests (more than 30 runs), the drops in the groundwater levels showed a very distinctive trend. The level in the wells nearer to the sinkhole always showed water levels lower than the distant wells. This naturally occurring behavior can be 
referred to as a cone of depression. It can be concluded, that the current physical model was successful in showing the formation of this groundwater cone of depression that occurs before there are any surface signs of sinkholes. This, in turn, in a reverse manner, can be used in predicting the potential location of sinkholes that are forming underground and show no surface indications.

By studying sensor data, some progressive drops were evident, which are consistently seen at the same location over multiple runs. Also, these progressive drops migrate in time from the closer sensor to the sinkhole to the further sensor. This time lag behavior and the corresponding progressive drops are indicators of the potential location of sinkholes. Thus, both the progressive drops and their time lags can help in investigating the sinkhole locations and the sinkhole progressing rate. This can be achieved by correlating an actual progressing sinkhole to the groundwater table drops and progressive drop measurements. This paper presented a simple physical model and more advanced testing is planned. 


\title{
CHAPTER FIVE: EXPERIMENTAL STUDY OF SINKHOLE FAILURE RELATED TO GROUNDWATER LEVEL DROPS
}

\author{
$\underline{\text { Introduction }}$
}

Sinkholes are common phenomena where carbonate, limestone, dolomite, or gypsum, encountered and subjected to dissolution. Sinkholes can be defined as an area of the ground with a surface depression or a hole which may occur gradually or suddenly based on the geology and hydrology of that area. Most areas that are susceptible to sinkholes are generally located where the ground has no natural external surface drainage of the rainfall. Surface failure occurs due to the transport and erosion of the soils, that overlie the carbonate bedrock due to interaction with water (Tihansky 1999; Waltham et al. 2005).

Sinkholes are very complex events that form generally by combination of hydrological and geological factors. In-situ measurements of sinkhole collapse processes are difficult. Therefore, it is difficult to predict the sinkhole triggering behavior before and during collapse. Prediction studies of the sinkhole location based on the current ground investigation techniques are limited. Wide areas are often studied with either aerial or satellite remote sensing which gives an indication of surface depression (subsidence). However, the surface depression that is detected by using such remote sensing techniques may or may not provide a true indication of sinkholes development as such subsidence may also be a result of soil settlement (Lei et al. 2005; Waltham et al. 2005).

In this research a small scale physical model is used to simulate sinkholes naturally. A monitoring system consisting of a network of water level sensors is designed to measure the groundwater changes with time before and during the sinkhole development. This model is both 
spatial and temporal in nature. The sinkhole collapse is assumed to occur when collapse is observed visually on the soil surface. In order to simplify this preliminary study, the sinkhole model is based on typical geological and hydrological properties representing areas in central Florida. In this model, it is assumed that there are existing cracks in the limestone bedrock due to dissolution over a long period of time. It is also assumed that the surficial groundwater level will drop all the way to the bedrock level and water migrates through this crack. This period of time represents the extreme drop of the groundwater table levels during the end of the dry season in Florida. A series of tests have been conducted with different overburden soil thicknesses, and different initial groundwater levels, but with the same soil type, bedrock crack opening, and soil compaction levels. Groundwater drops are monitored in the physical model before and during the formation of the sinkhole. The main objective of this study is to design a scaled physical model that can simulate the natural sinkhole formation, monitor the groundwater table drawdown with high accuracy, and establish a relationship between groundwater drops and sinkhole formations based on a spatial-temporal analysis and a time frequency analysis. While this model uses a predetermined crack location to study the groundwater level response, it may be used to determine the ultimate location of the sinkhole by monitoring the changes in natural groundwater levels in the field using the analysis method developed herein.

\section{$\underline{\text { Related Studies }}$}

Sinkholes cause damage to infrastructure if they form in the built environment and can also endanger the underlying aquifer since they may form conduits to transmit surface water to 
the groundwater (Atkinson 1977; Tihansky 1999). Florida is one of the most susceptible states to sinkholes in the nation due to its karst geology consisting of a carbonate bedrock. This carbonate bedrock is subjected to dissolution caused by the groundwater circulation. The dissolution may accelerate during times of excessive precipitation due to an increase head of water. Also, the groundwater levels may drop due to pumping for municipal, agricultural, and industrial water demand, which may trigger and accelerate the sinkhole development and collapse (Atkinson 1977; Quinlan et al. 1993; Tihansky 1999).

In central Florida, the buried karst terrain is called mantled karst, which is a result of karst processes on the rocks that overlain by relatively insoluble deposits. The thickness of mantled karst can affect the reflected depression on the surface. In other words, the thicker the mantled karst, the less noticeable the depression on ground surface (White 1970; Brooks, 1981).

Florida's sinkholes can be divided into three types based on their formation processes: dissolution sinkholes, cover-subsidence sinkholes, and cover-collapse sinkholes. Coversubsidence sinkholes is a gradual depression of the overburden granular materials. However, cover-collapse sinkholes occurs suddenly resulting in catastrophic failure (Sinclair and Stewart 1985; Tihansky 1999).

In central Florida, the type and frequency of sinkholes development are influenced by hydrogeological factors, such as changes in the hydraulic mechanical stresses due to natural or man-made reasons. These stress changes are reflected in the changes in the groundwater levels and the groundwater gradients. The size, thickness, and composition of overburden materials and the hydrology of the aquifer control the mechanism of transfer of these stresses (Ryder 1985; Tihansky 1999). The end of dry season (May) has the lowest levels of the groundwater in the 
year, while the groundwater levels gain their maximum high levels at the end of raining season (September). It is known that the seasonal weather variations significantly affect the cyclical changes from minimum to maximum levels of the groundwater. It is also noted that seasonal fluctuations can cause temporary reversals in the vertical flow direction. This condition occurs, either during the very long drought season or large rainfall events, and may trigger the formation of more sinkhole (Lewelling et al. 1998; Tihansky 1999).

Researchers have used physical model to simulate the behavior of sinkholes using different approaches, such as centrifuge models, analogical models, and soil-based physical models (Abdulla and Goodings 1996; Goodings and Abdulla, 2002; Chen and Beck 1989;

Caudron et al. 2006a 2006b; Caudron et al. 2008; Lei et al. 1994; Lei et al. 2005).

Chen and Beck (1989) designed a two dimensional soil model to study the mechanisms of sinkholes. They used a soil layer placed in a parallel-plate tank with a bottom opening. They simulated 23 different trials with initial conditions of dry, partially saturated, or saturated to simulate a cover-collapse sinkhole. The main objective of their study was to obtain data related to the mechanical processes of sinkholes. The authors have stated that the qualitative twodimensional soil model was a very simplistic model but can provide a basis for more sophisticated quantitative physical models of sinkhole (Chen and Beck 1989).

Lei et al. (1994) conducted an experimental study using a large-scale sinkhole physical model. The objective of this model is to study the controlling factors for the sinkhole formation and progression. Sinkholes and their collapse process in the Hongshan District in China, were investigated using this model in follow-up publications (Lei et al. 2002; Lei et al. 2005). 
The physical model of Lei et al. (2005) was designed using three main components. These are a base unit, recharge-discharge system, and observational system. The conceptual models were used to investigate the effects of the width of fractures and fissures in the limestone layer and the effects of pore water pumping on sinkhole formation and also to investigate the effect of the thickness of mudstone, which is overlaid on the top of the limestone, on sinkhole formation. The author observed that groundwater pumping triggers more sinkhole collapses. In addition, the voids in the sediments grow larger in dimension with larger limestone cracks.. Finally, they stated that the rate of the declination of groundwater is an important factor in the sinkhole collapse (Lei et al. 2005).

\section{Experimental Setup}

A circular metal mold with a diameter of $56 \mathrm{~cm}$ was used as a container to construct a scaled sinkhole model as illustrated in Figure 1. A $5 \mathrm{~mm}$ diameter opening was made at the center in the base of the mold. This hole was designed to simulate the cumulative effect of cracks in the limestone layer. This hole allows a certain volume of soil sediments to be transported through it in a time rate which simulates a certain volume of sediments that limestone cracks might transport in site (Alrowaimi et al., 2015).

A dark brown fine sand (AASHTO type A-3), from east Orlando in Florida, with 1\% passing the 200 sieve, was used as the soil in the sinkhole physical model. This sandy soil has an optimum moisture content of $13 \%$, a maximum dry unit weight of $16.3 \mathrm{kN} / \mathrm{m}^{3}$, and a specific gravity of 2.6. 
To measure the levels of the groundwater table over time, eight monitoring wells were placed in the soil sample. In each monitoring well, a 12-Inch eTape Liquid Level Sensor from MILONE Technology was introduced. These sensors were distributed at different radial locations around the center of the soil sample. One-inch diameter-PVC pipes were used as monitoring wells and the eTape sensors were lowered into the wells and secured to the well caps to hold them in place. These PVC pipes were perforated with holes extending over the entire pipes' outer circumference and wrapped with a geotextile fabric. The geotextile fabric was used as filter to only allow the water to get into the PVC pipes (monitoring wells) and to prevent the soil particles from entering the pipes (Figure 20).
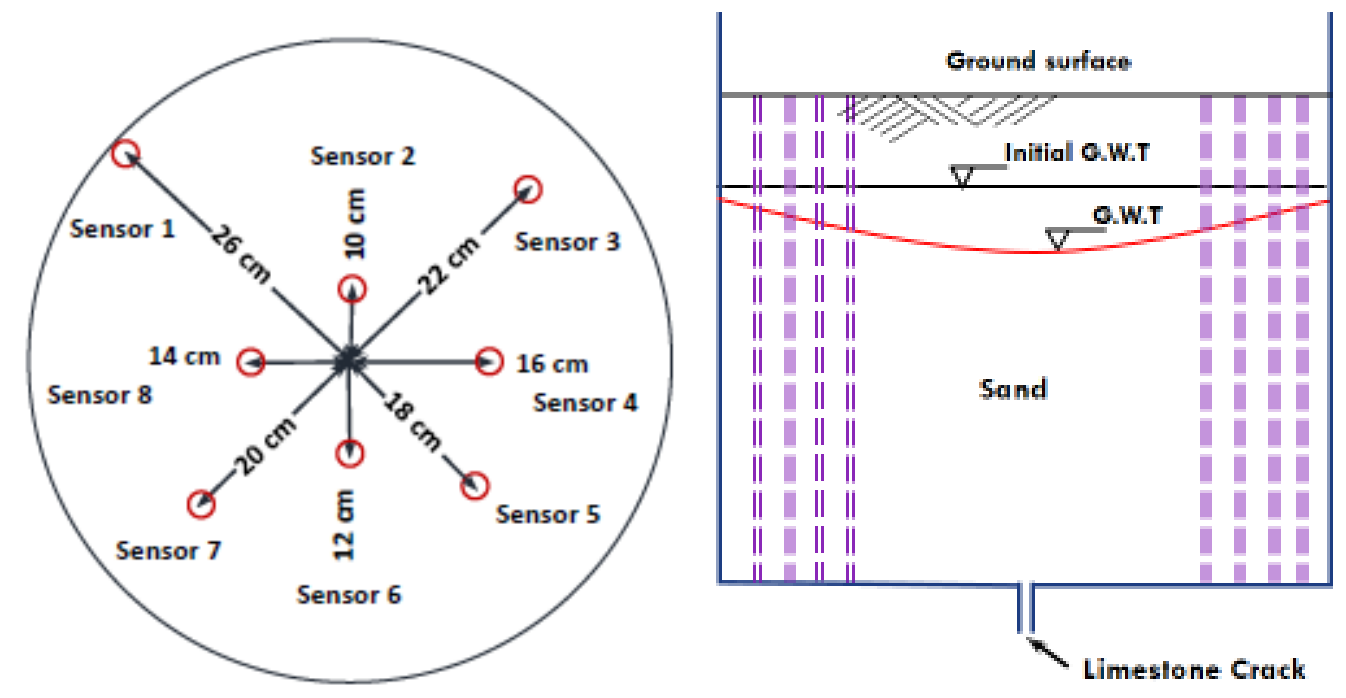

Figure 20: The Radial Location of the Eight Monitoring Wells and Physical Model Cross-section 
The wells locations were installed at the following distances from the center of the soil sample: $10 \mathrm{~cm}, 12 \mathrm{~cm}, 14 \mathrm{~cm}, 16 \mathrm{~cm}, 18 \mathrm{~cm}, 20 \mathrm{~cm}, 22 \mathrm{~cm}$, and $26 \mathrm{~cm}$. These wells were labeled as $\mathrm{CH} 1_{\mathrm{R}}, \mathrm{CH} 2_{\mathrm{R}}, \mathrm{CH} 3_{\mathrm{R}}, \mathrm{CH} 4_{\mathrm{R}}, \mathrm{CH} 5_{\mathrm{R}}, \mathrm{CH} 6_{\mathrm{R}}, \mathrm{CH} 7_{\mathrm{R}}$, and $\mathrm{CH} 8_{\mathrm{R}}$ for identification in the experimental data. Groundwater table levels were measured at the sampling rate of $100 \mathrm{~Hz}$ at each sensor.

At the start of each test, the hole at the base of the metal mold is closed and sealed by using rubber sheet on the outside surface of the mold. It is tested for any leakage of water. Next, the monitoring wells (PVC pipes) are installed and soil compaction is carried out in layers until the soil reaches its target maximum dry unit weight.

The compaction of the sample in the preparation procedure is controlled by the compaction energy imparted to each sample. Both the standard proctor hammer (weighs $2.5 \mathrm{~kg}$ and falls from 30 centimeters height) and modified proctor hammer (weighs $4.5 \mathrm{~kg}$ which falls from 45 centimeters height) were used in the sample preparation process. Additionally, a circular metal plate of $120 \mathrm{~mm}$ diameter and $7 \mathrm{~mm}$ thickness was used to distribute the falling hammer energy uniformly over the loose soil surface.

All soils were prepared with a moisture content equivalent to the optimum moisture content $(13 \pm 2 \%)$ to achieve the maximum dry unit weight of $16.3 \mathrm{kN} / \mathrm{m}^{3}$. The total height of the soil layer was kept at $150 \mathrm{~mm}$ in all cases as the overburden soil on the limestone layer. Each sample was compacted in three layers of soils. The first layer has an average thickness of about $80 \mathrm{~mm}$ of loose soil. This layer was compacted on two sub-stages: first, low energy compaction was carried out using Standard proctor hammer with an average of 80 blows, followed by higher energy compaction using the Modified proctor hammer with an average of 65 blows. Next, the 
second and the third layers (average thicknesses $50 \mathrm{~mm}$ ) were compacted in the same manner but with a less number of blows (65 blows using the Standard hammer and 50 blows using the Modified hammer). Both hammers were dropped on the above-mentioned metal plate during this specimen preparation procedure. The actual dry unit weight for this specimen was measured, with a target a value of $16.3 \pm 0.15 \mathrm{kN} / \mathrm{m}^{3}$. Finally, water is added to the soil sample to create a saturated layer upto the desired initial groundwater table level. This is left for a period of 24 to 48 hours to reach a constant level of full saturation.

A NI PXIe-1062Q module from National Instruments was used with this physical model to acquire the data. A LabView code was also created to program the NI PXIe module to work with the eTape Liquid Level sensors. This NI module is able accommodate up to 32 channels; but only 8 channels were used for the current study.

\section{$\underline{\text { Test protocol }}$}

A set of three test runs with the $150 \mathrm{~mm}$ overburden soil thickness and an initial groundwater table of $15 \%$ of the overburden soil thicknesses are presented in this paper. Soil type, rain fall intensity, bedrock crack (bottom opening of $5 \mathrm{~mm}$ ), and soil compaction were kept constant for all three runs. In order to validate the results of the trials, each test run was repeated at least three times with the same initial conditions and parameters.

Figure 21 shows the sinkhole experimental model setup diagram. After preparing the soil sample with the desired initial groundwater level, the eTape Liquid Level sensors were hooked up to the NI PXIe-1062Q module by using voltage divider circuits for each sensor. The sensors 
then were lowered in the PVC pipes and the pipes were covered with caps to make sure the sensors were protected and restrained from any vertical or bouncing movements as shown in Figure 22a. The sensors send information to the NI PXIe module, to provide direct measurements of the groundwater levels in the monitoring wells. The hole at the base of the mold was opened to allow the soil sediments to transport out of the model. The time when an external surface collapse is observed visually was recorded as the time of sinkhole collapse. Figure 22a and 22b show the sinkhole physical model test setup and an example of a typical surface sinkhole collapse. 


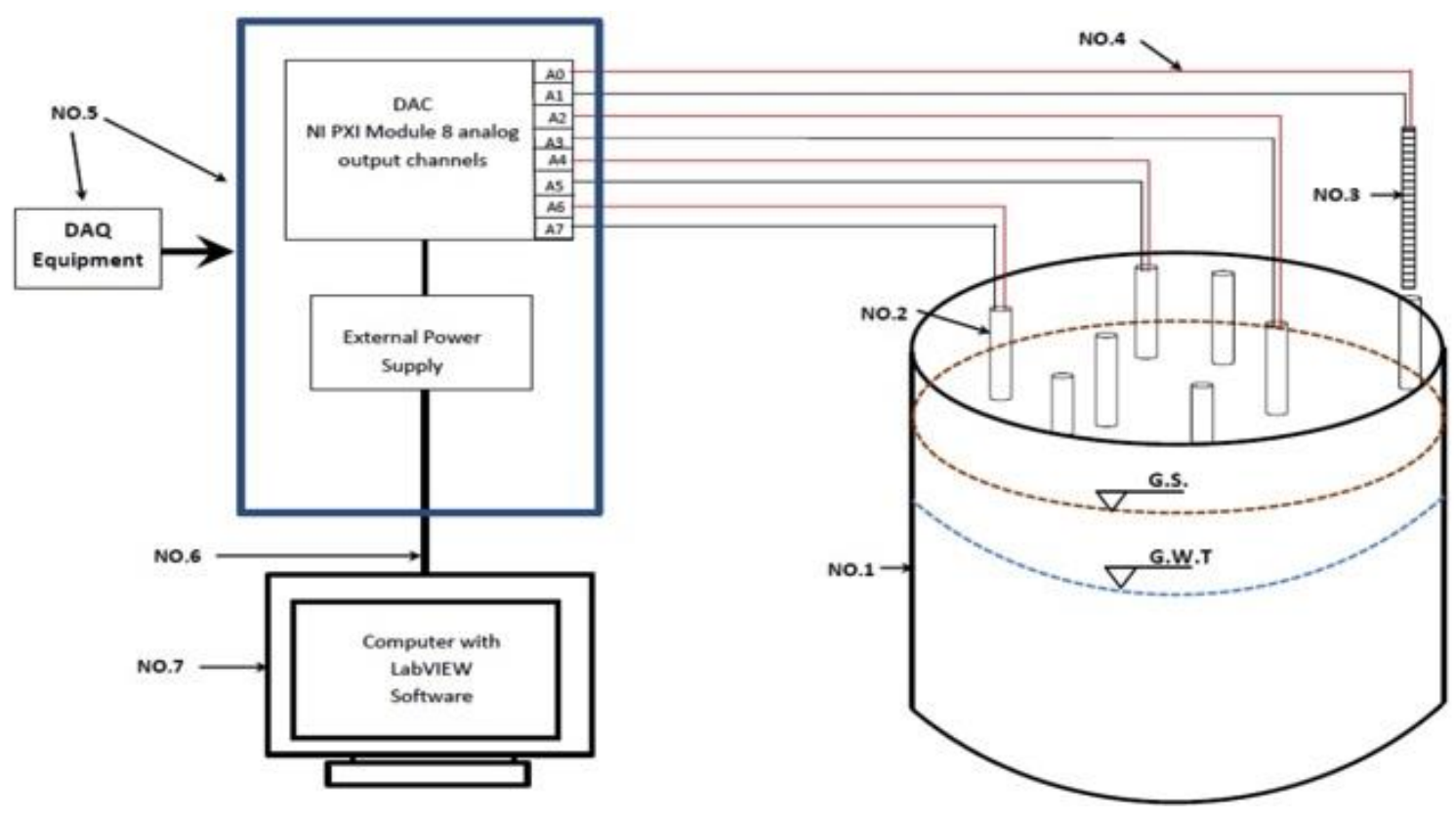

Figure 21: Sinkhole experimental model setup diagram

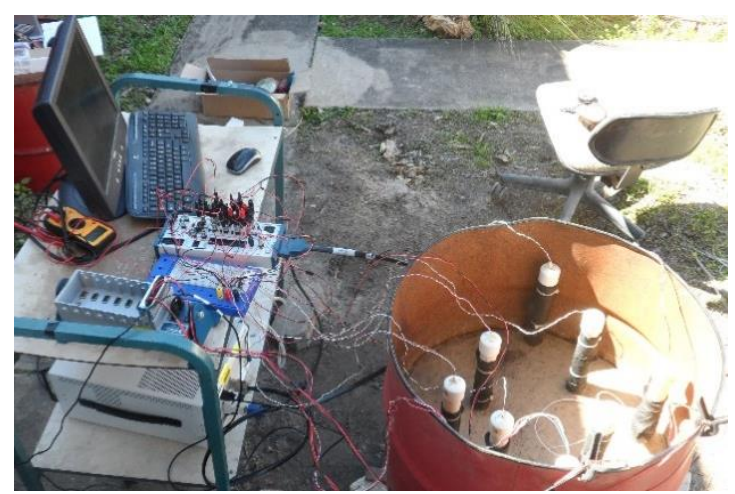

(a)

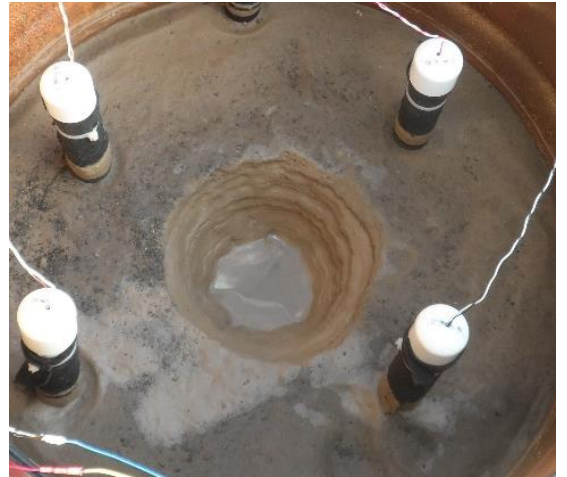

(b)

Figure 22 ( $\mathrm{a}$ and b): Sinkhole Physical Model Test Setup and sinkhole collapse 


\section{$\underline{\text { Experimental Results }}$}

The results related to $150 \mathrm{~mm}$ soil sample thickness are presented herein to describe the behavior of the sinkhole from its internal initiation to collapse. The initial groundwater level was maintained at $22.5 \mathrm{~mm}$ from the ground surface, which is $15 \%$ of the total overburden soil thickness. The observed time of surface collapse of the sinkhole were 16.0, 19.7, and 14.0 minutes for RUN 1, RUN 2, and RUN 3 respectively.

The effects of the radial distance of the eight monitoring wells on the groundwater drawdowns before and during the sinkhole formation is shown in Figure 23. It is always observed that the water levels are higher in the wells further from the sinkhole (located at the center of mold) compared to the levels in wells closer to the center. This tendency is an indicator of the water level inclination towards the center of the soil sample. This cone of depression of the water level starts as a horizontal surface and gets steeper with time until visible sinkhole collapse occurred. The plots in Figure 24, where the eight radial locations were plotted against the changes of the groundwater levels over time, further confirm the existence of the groundwater cone of depression prior to the sinkhole collapse. 


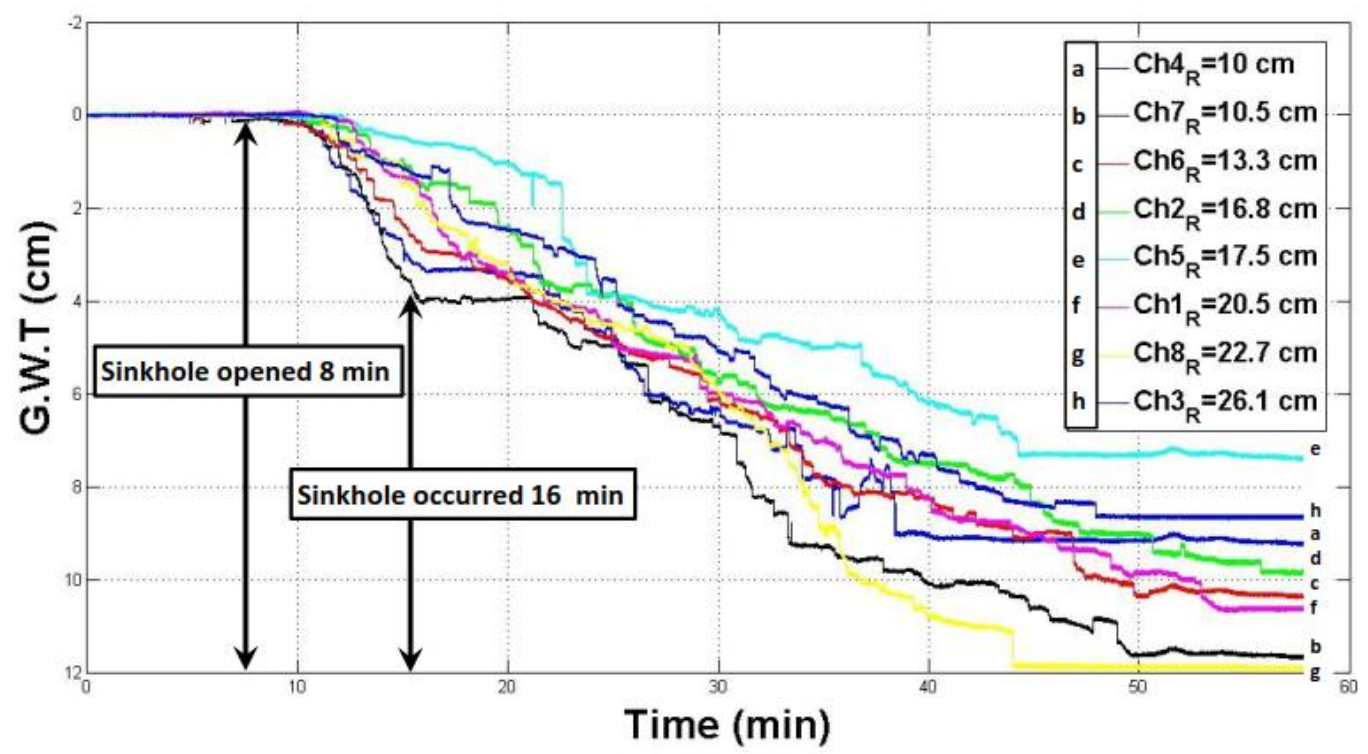

(a) RUN No.1

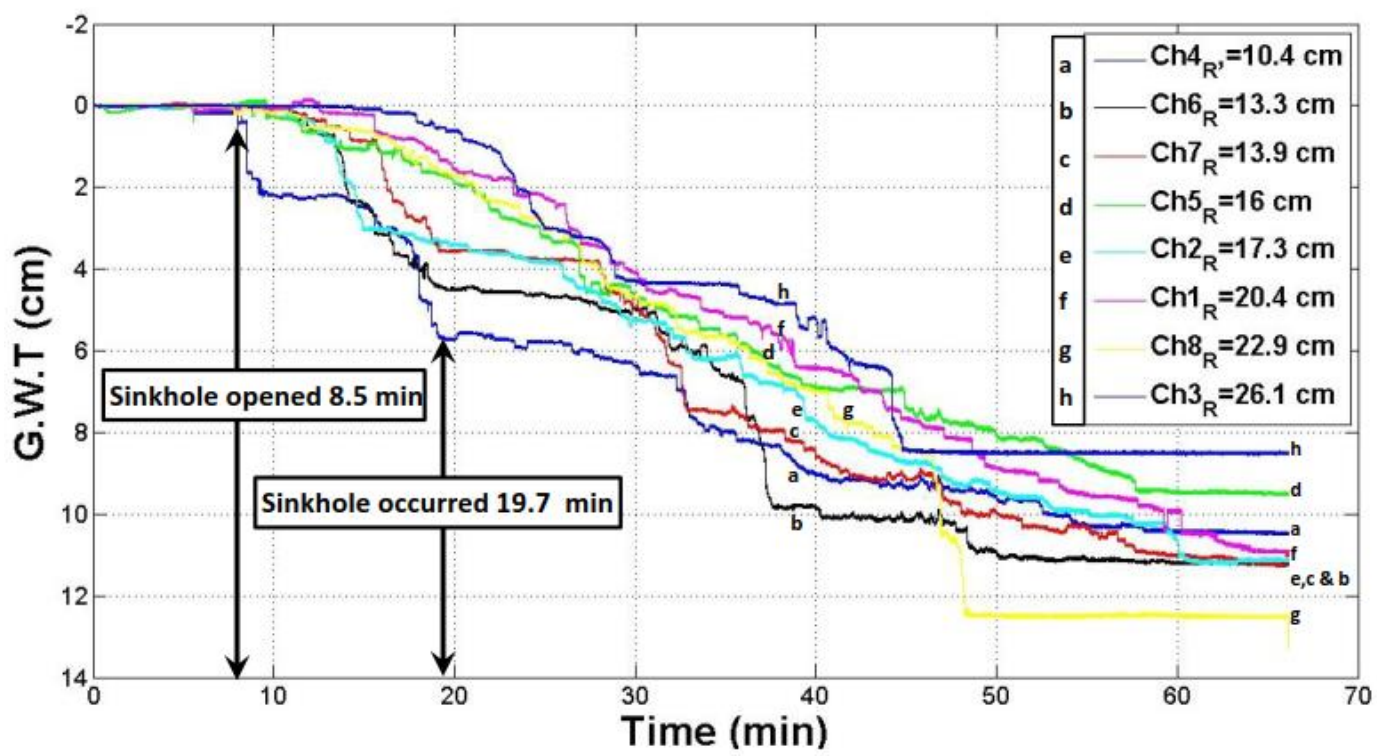

(b) RUN No. 2 


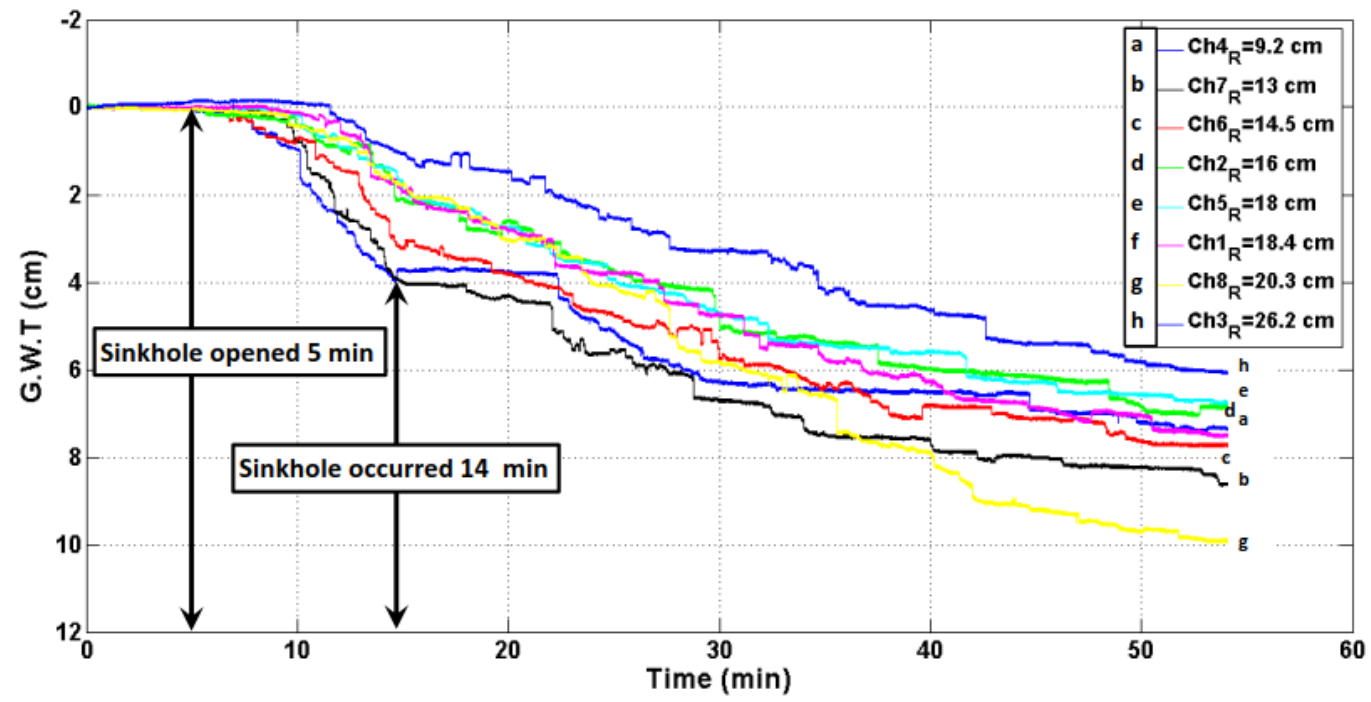

(c) RUN No.3

Figure 23 (a, b \&c): Groundwater level drops over time in the sinkhole physical model test 


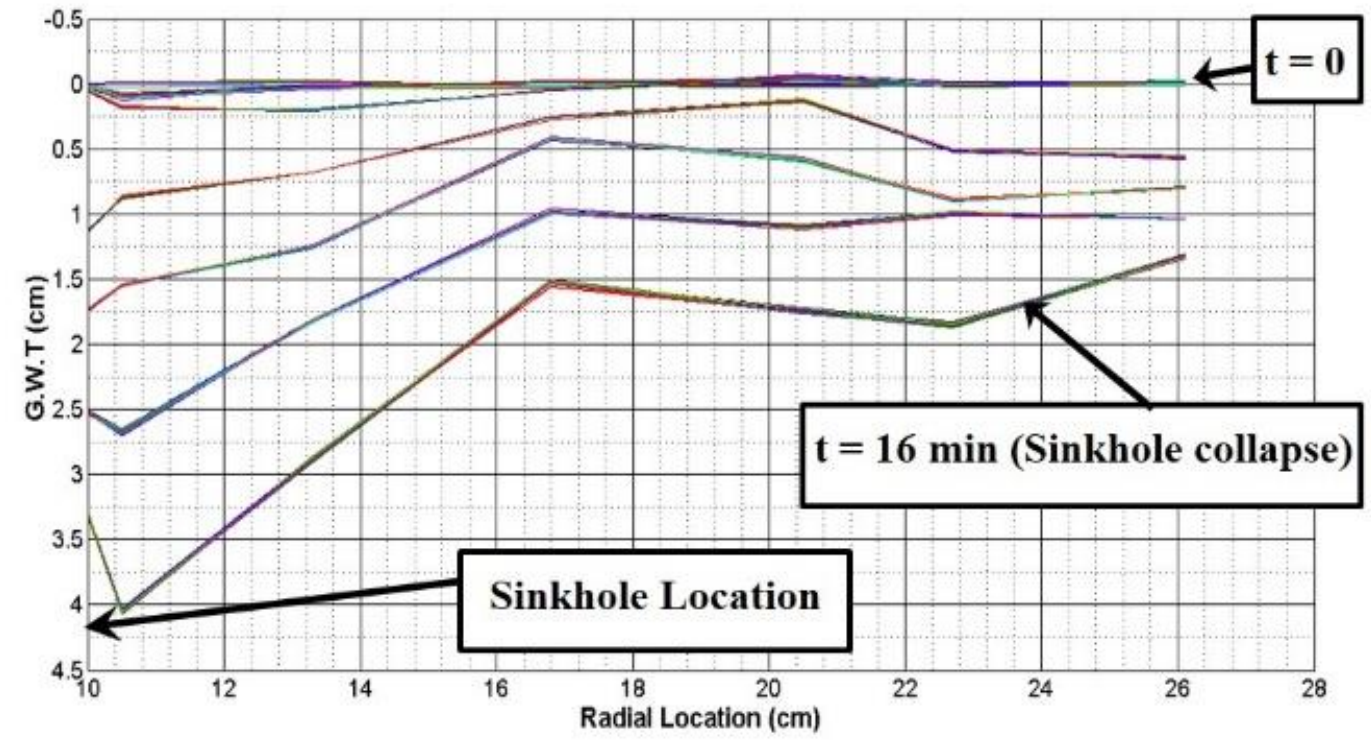

(a)

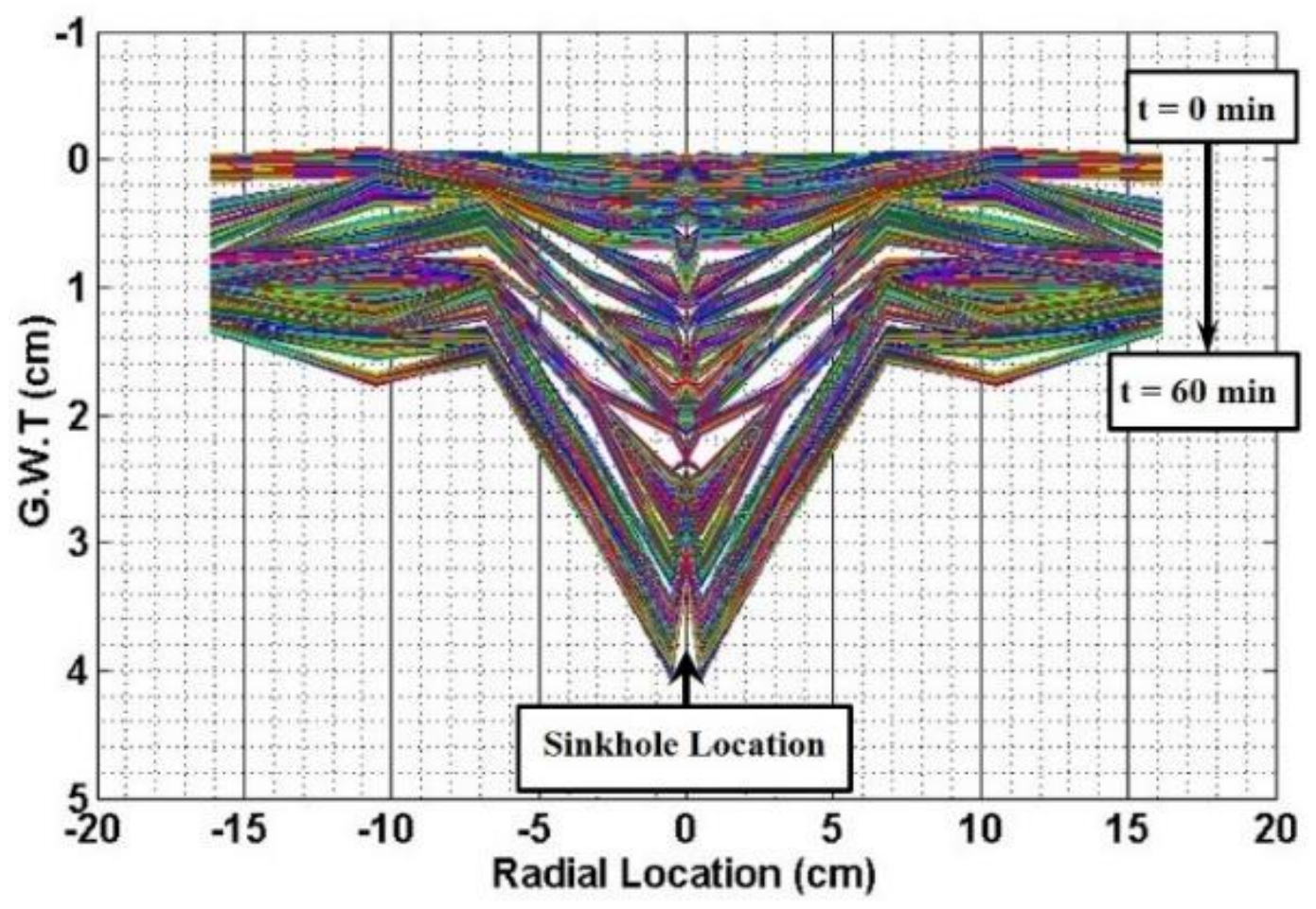

(b)

Figure 24 (a \& b): Groundwater readings in different times versus the wells radial locations for RUN No.1. 
Figure 25 illustrates the behavior of the groundwater level with time at three sensor locations with radial distances of $10 \mathrm{~cm}, 13.3 \mathrm{~cm}$ and $22.7 \mathrm{~cm}$. It is noted that the bottom hole was opened at 8 minutes from the start of the test, until the surface collapse of sinkhole was observed at the 16 minute mark. Next, Figure 26 illustrates the same behavior at the nearest and furthest locations from the center. During the test, it was observed that there are some progressive drops in the groundwater level readings. These drops start at the monitoring wells that are closer radially to the center of the sinkhole. Subsequently, with time, these drops get transferred to more distant monitoring wells. The drops were also observed in the experiment and corresponded with a faster rate of sediment loss from the bottom of the test mold. 


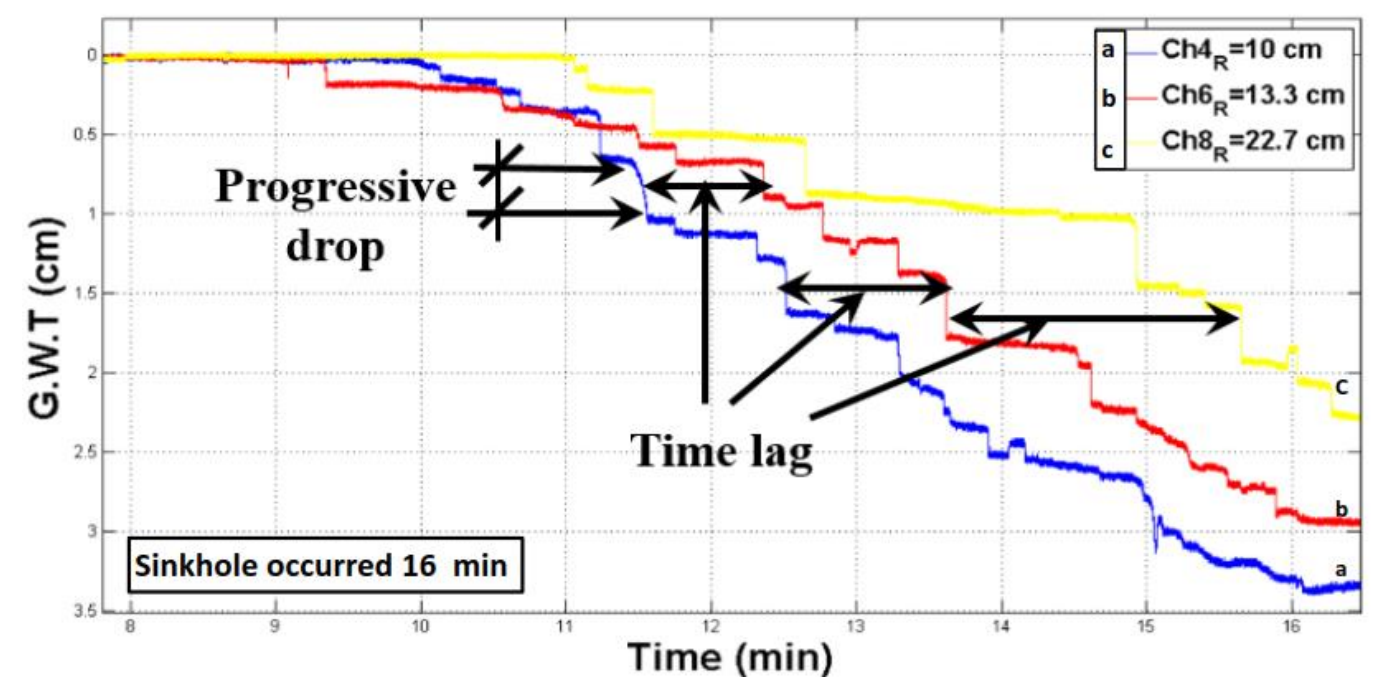

Figure 25: Groundwater table readings at three selected wells locations in RUN No.1: well Ch4 $4_{\mathrm{R}}$, well Ch6 $6_{R}$, and well Ch8 ${ }_{R}$.

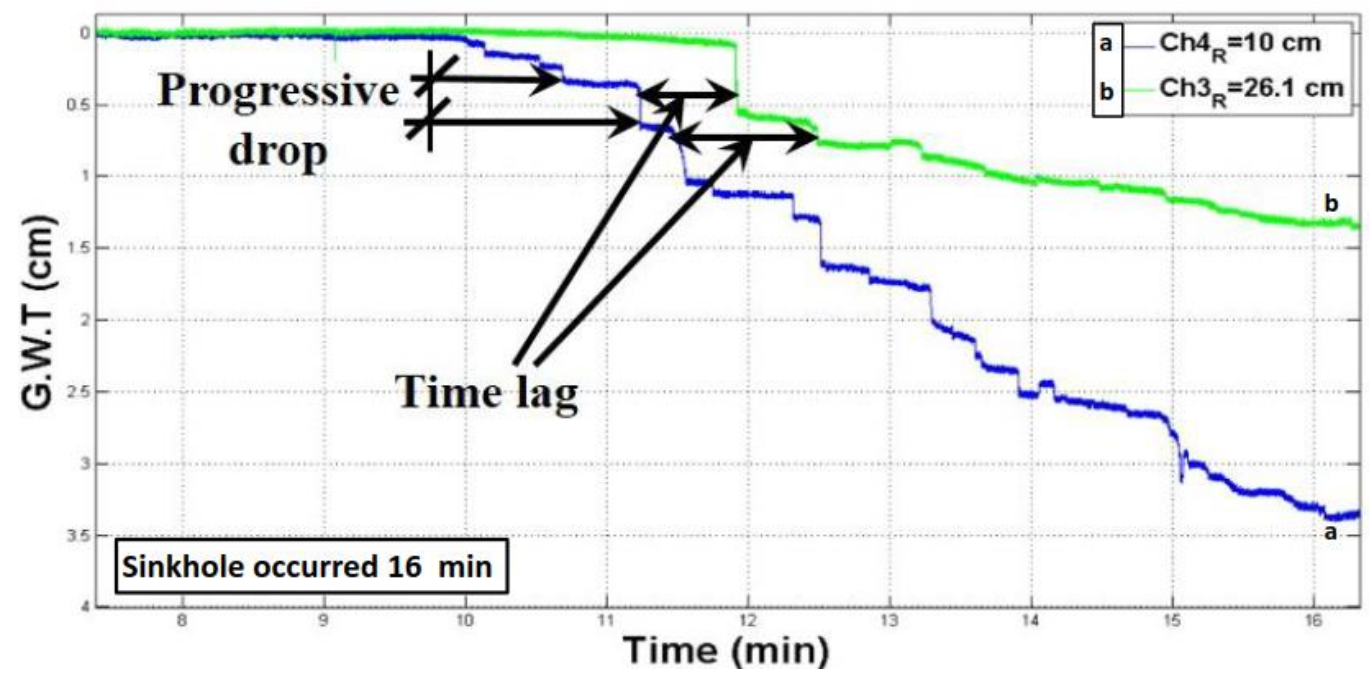

Figure 26: Groundwater table readings at the nearest and furthest monitoring wells, RUN No.1: well $\mathrm{Ch} 4_{\mathrm{R}}$ and well $\mathrm{Ch} 3_{\mathrm{R}}$. 


\section{$\underline{\text { Analysis and Discussion }}$}

\section{Cone of Depression Analysis}

The results of the monitoring of the drops of groundwater table using a network of sensors are discussed. The groundwater plots for all three runs in figure 23 (a-c) corresponded to experimental data and are replotted in figures 27 (a-c), but with time on the horizontal axis normalized by the sinkhole collapse time. Figure 8 reconfirms the cone of depression of the water level that starts as a horizontal surface and gets steeper over time until visible sinkhole collapse occurs.

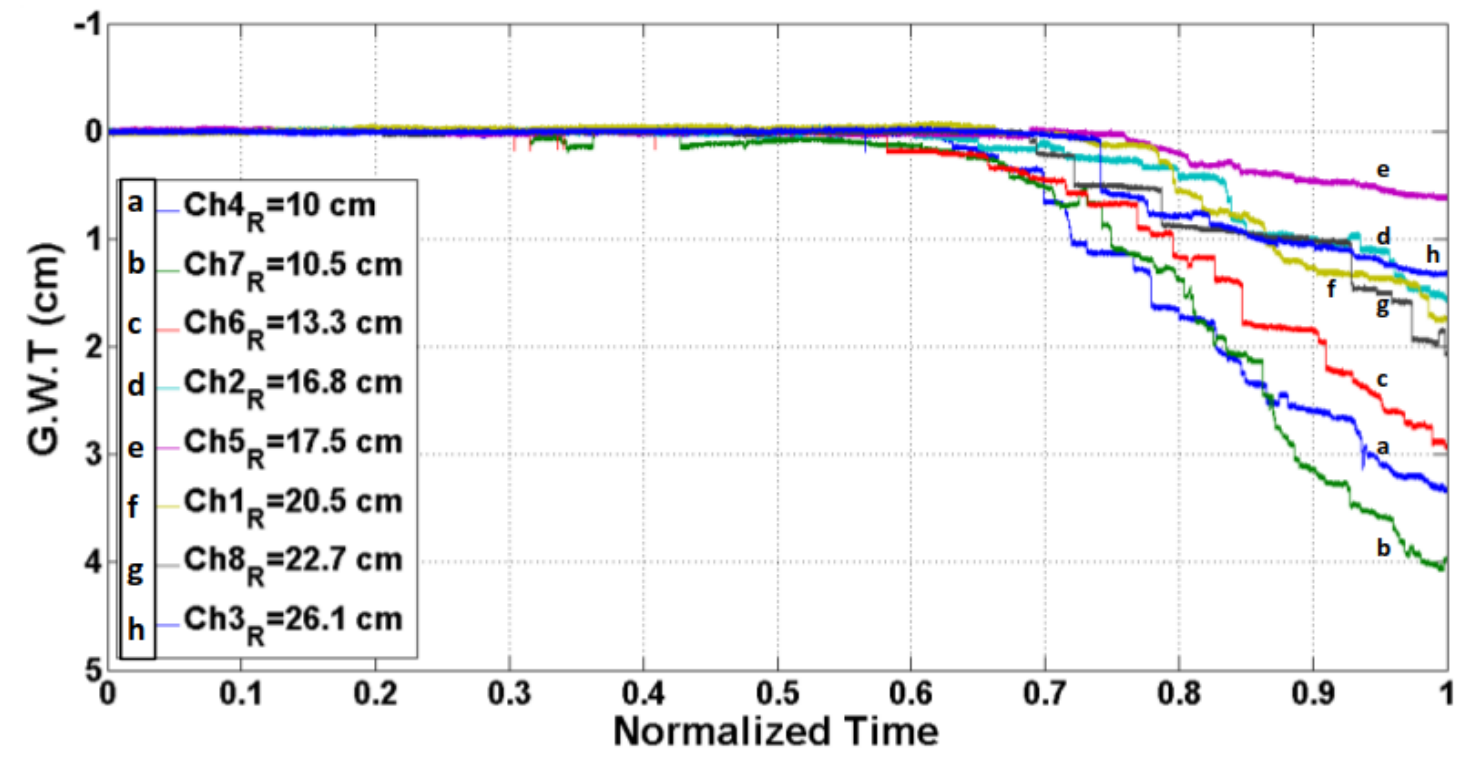

(a) RUN No.1 


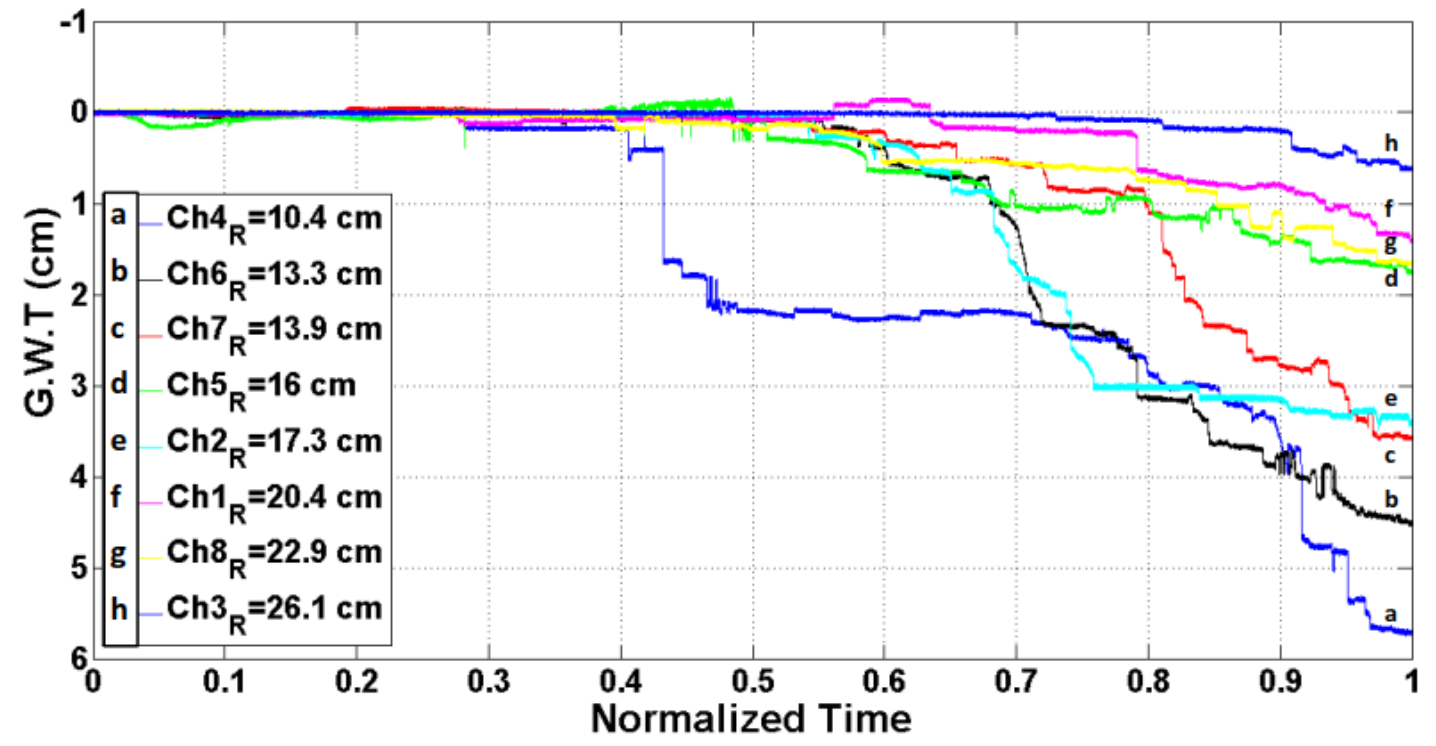

(b) RUN No.2

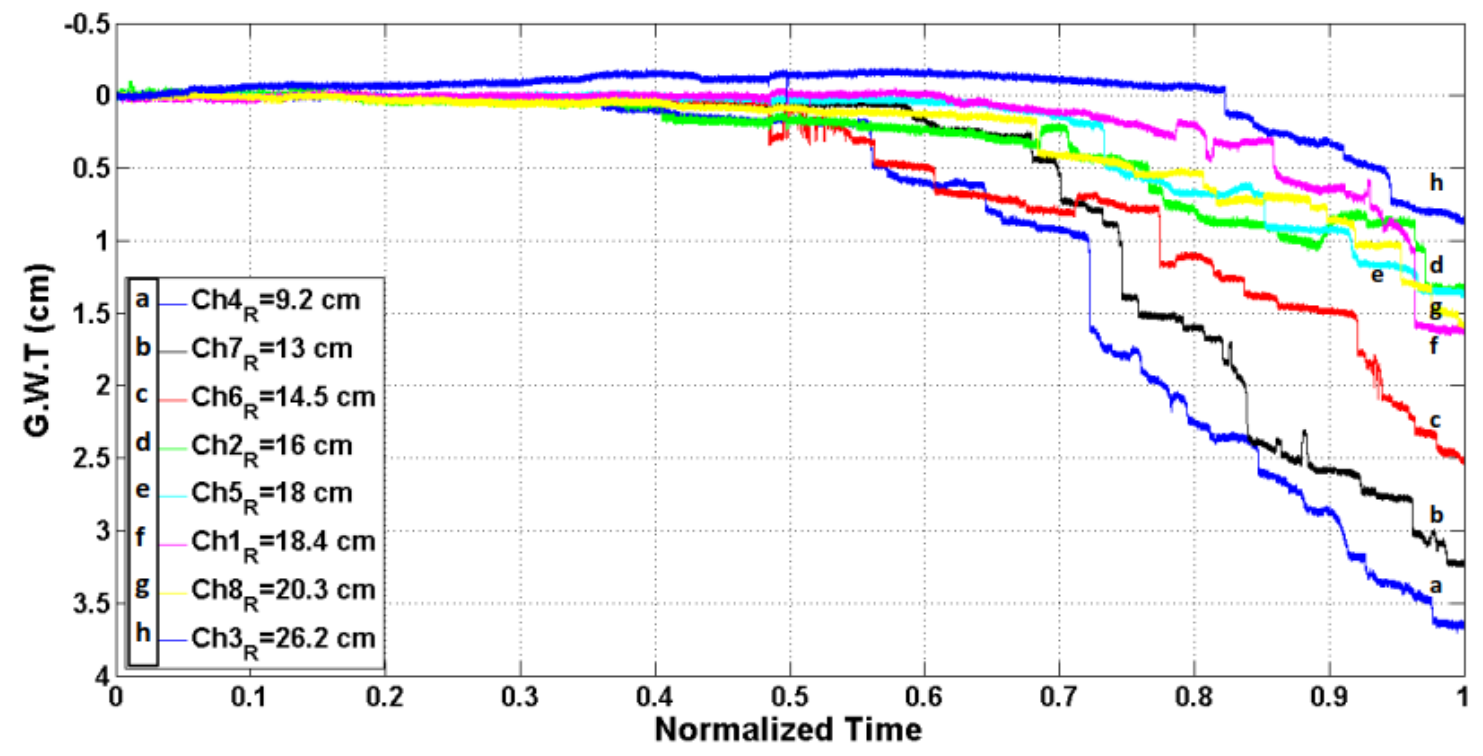

(c) RUN No.3

Figure 27 (a, b \& c): Groundwater level drops over the normalized time of sinkhole collapse 
In figure 28, only RUN No.1 test is used to illustrate the groundwater trend line representation. A logarithmic curve fitting is utilized to represent each changes of groundwater levels against the radial locations of the wells over time. The results of groundwater levels, wells' locations, and time were normalized to the overburden soil thickness, radius of test mold, and sinkhole occurrence time, respectively. This procedure was used to minimize the effects of the data outliers. This cone of depression of water levels could lead to determination of the potential location of a sinkhole and its eventual collapse when used in a reverse manner. The following equation is the groundwater cone of depression equation.

$$
y=\propto \ln (r)+b
$$

where, $y=$ the G.W.T level; $r=$ the radial locations of the monitoring wells; $\alpha=a$ value that controls the slope of the G.W.T curve; $b=$ a value that controls the intercept location.

A few water (sensors) readings do not show the slope in the water level to the same extent. This may be due to the inhomogeneity of the soil sample rising from differences in soil compaction over the whole area. However, the general trend of the groundwater cone of depression was very evident in figure 28 . 


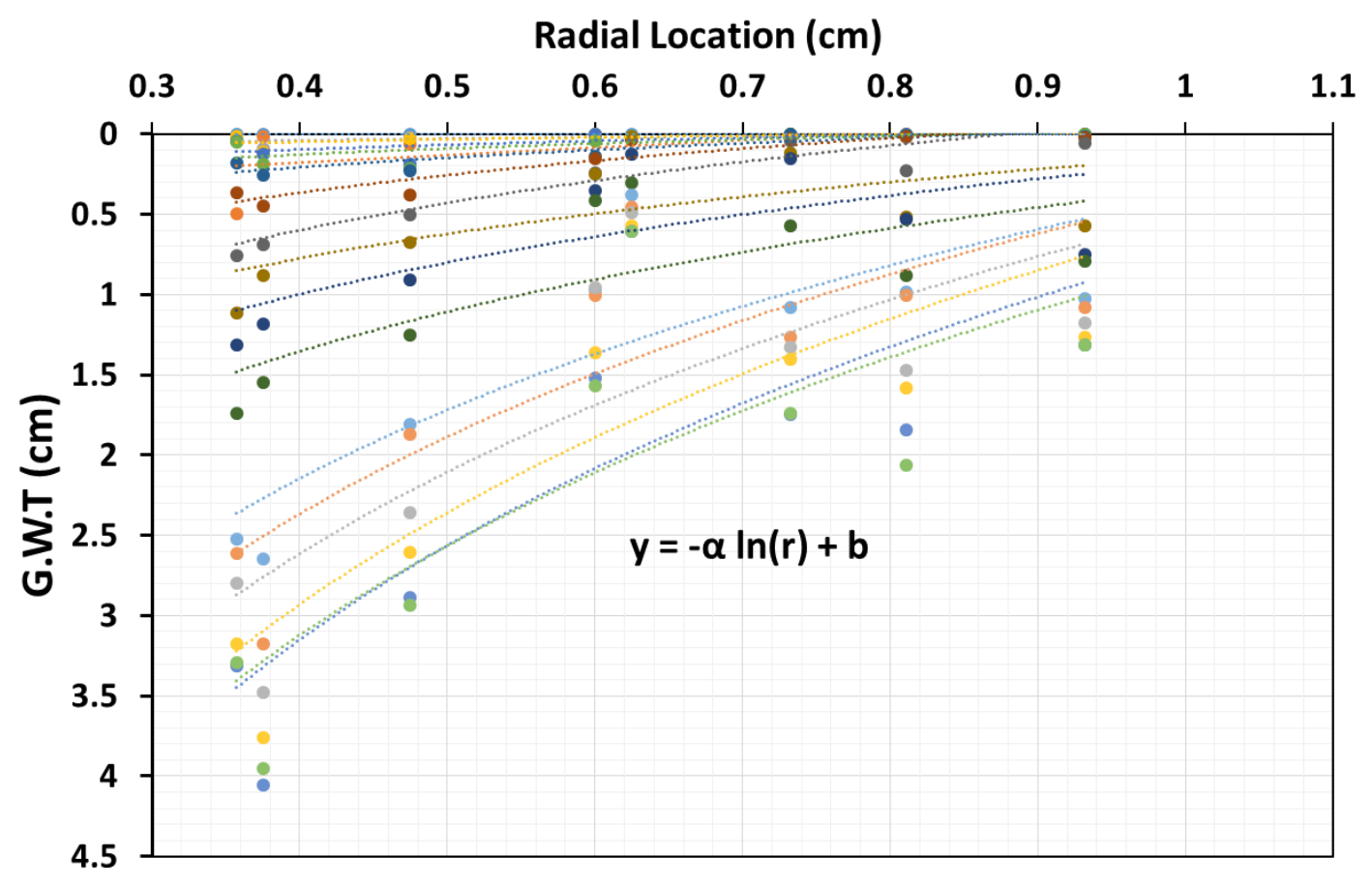

Figure 28: Groundwater trend line representation in RUN No.1 test.

In the following section, the study of single sensor data analysis and its relationship to the progression towards the sinkhole collapse will be discussed. As shown in figures 25 and 26, the progressive drops of the groundwater level are potentially related to the location of the sinkhole formation. In addition, the amplitude of these drops may be related to the rate of sinkhole formation. By comparing figures $25 \& 26$, it is evident that the progressive drops are a repeatable behavior in different groundwater sensor readings, but may have some difference in time lags from one sensor to another, which could be an indication of a hydrological behavior of the groundwater drawdown in the sinkhole physical model. Since all the other parameters and environmental factors are controlled in this model, it is anticipated that this hydrological 
behavior, namely water progressive drops and their time lags, is due to only the sinkhole internal formation, progression, and collapse. The nearest well is always affected by the internal cavity formation first, which indicates that the location of sinkhole is nearest to this sensor. These drops get transferred during the test from the nearest to furthest well with a time lag.

These time lags of the progressive drops can be further analyzed to measure the proximity of the sinkhole by finding the relationship between the sinkhole collapse time and the progressive drops of the groundwater table data.

All test results were found to follow a similar trend of groundwater drawdown, forming a cone of depression that progresses with time. Also, the tests have general agreement in term of the groundwater progressive drops and their time lags. These repeated progressive drops are readings from different wells along with their time lags will be studied in the next section, using a time-frequency analysis.

\section{Time-Frequency Analysis (Peak Counts of the Progressive Drops)}

It was observed in the previous analysis that there are some progressive drops in the groundwater reading data. It is our hypothesis that these drops can be related to the location and time of the surface sinkhole collapse. In this section, a time frequency analysis is used to decompose and detect the progressive drops. A Pattern Detection Algorithm called Auto Modulating Detection Pattern Algorithm (AMD), which was developed by Yun (2013), is used to analyze the groundwater data. This algorithm is an extension of the empirical mode decomposition (EMD) and Hilbert-Huang transform (HHT) techniques (Yun et al., 2013). Basically, the AMD is used to amplify the data and detect the progressive drops in the 
groundwater monitoring wells readings. These drops are presented as peaks in the processed data as shown in figure 29.
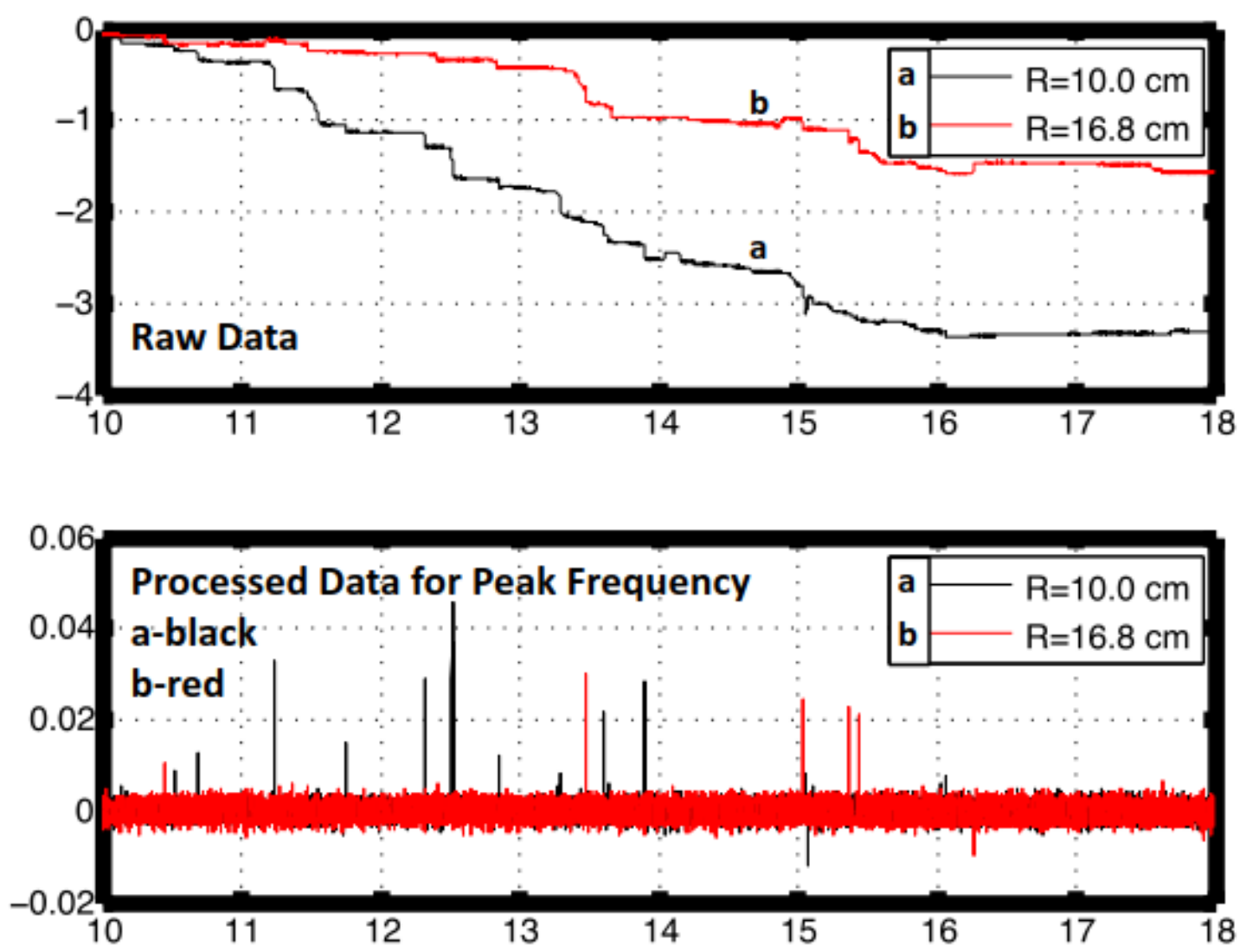

Figure 29: Raw data and processed data for peak-picking in two different monitoring wells 
Three (3) tests, with the same previous constant parameters (a $150 \mathrm{~mm}$ overburden soil thickness and $22.5 \mathrm{~mm}$ initial groundwater table from the ground surface), are studied in the peak detection analysis. The peaks frequency in the three tests are counted in every single groundwater sensor reading and plotted as 3D columns chart as shown in the figures 30,31 , and 32, respectively for each test. The overall time is divided into four quarters after establishing the sinkhole collapse time as the end time of the analysis. Figure 33 shows the cumulative number of the peak counts in the three sinkhole tests. 


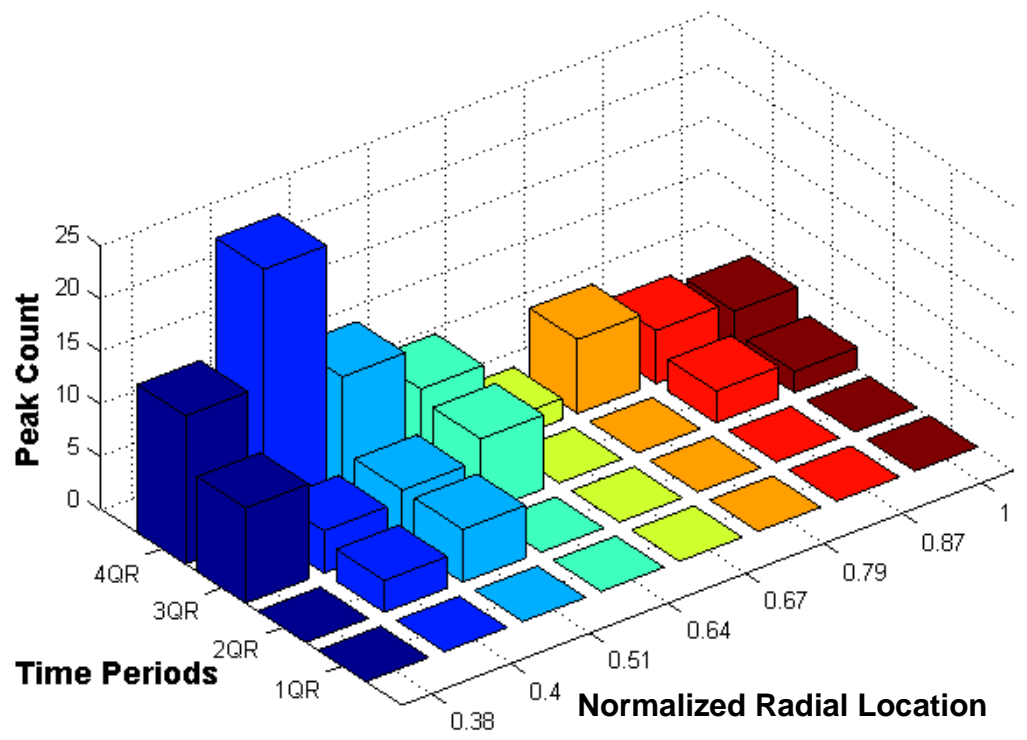

Figure 30: Peak counts of RUN No.1

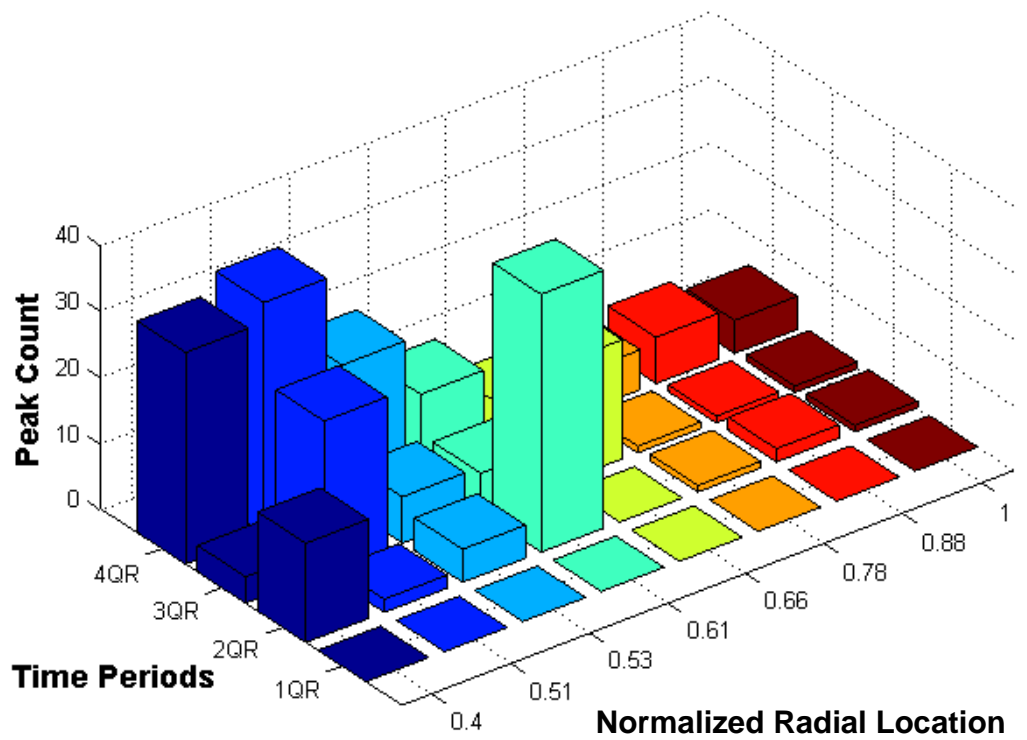

Figure 31: Peak counts of RUN No.2 


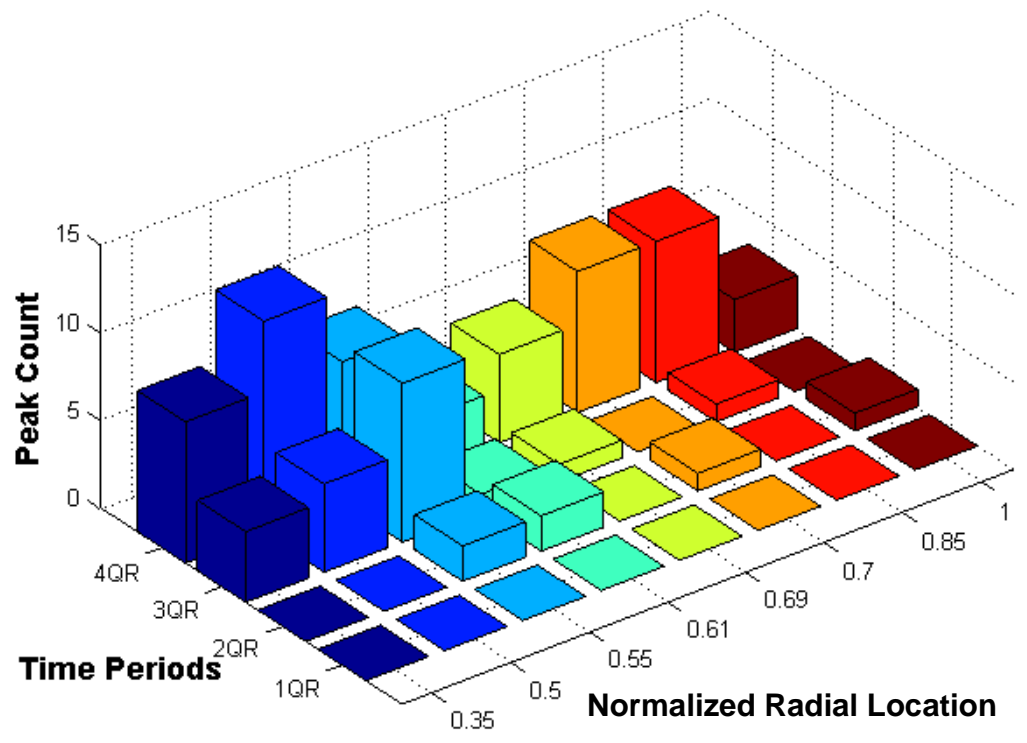

Figure 32: Peak counts of RUN No.3

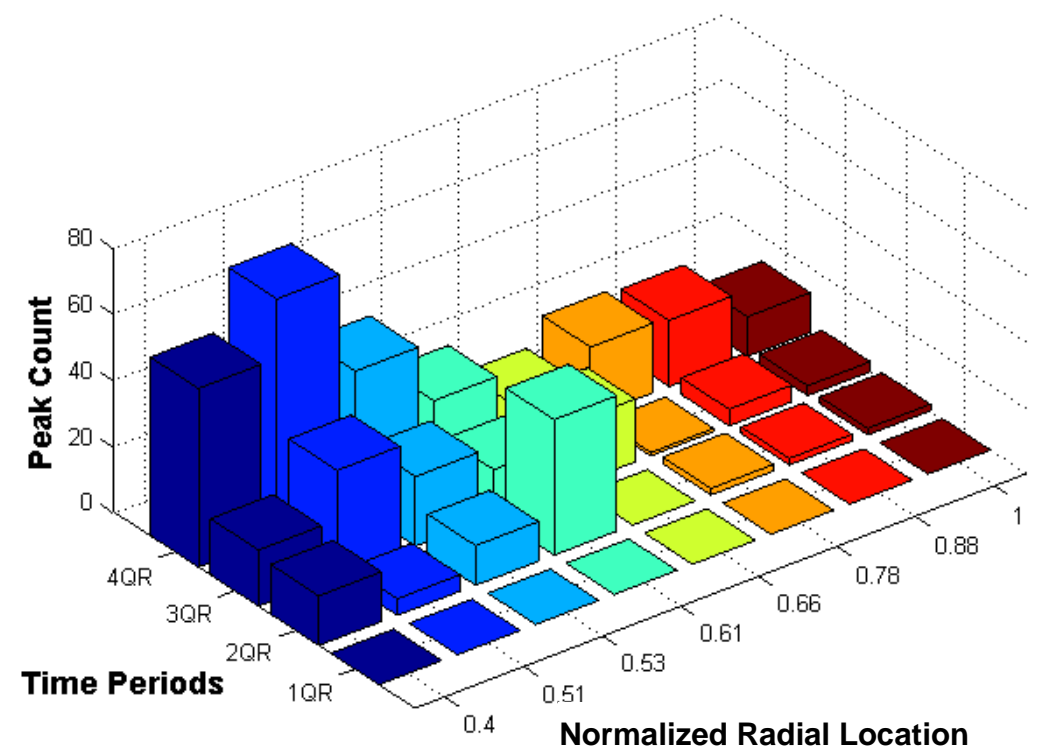

Figure 33: Cumulative peak counts of RUN No.1, $2 \& 3$ 
Figures 30, 31, 32and 33 demonstrate a very good correlation between the sinkhole collapse, which occurs at the end of the 4th quarter time period, and both peak counts and well locations. It can be observed that monitoring wells closer to the sinkhole location have more peaks than the one at the edge of the test specimen (distant wells). This behavior represented by height peak counts indicates that the effect of the sinkhole underground cavity on the groundwater reading is initially localized to an area which is closer to the failure zone. Subsequently, these peaks are transferred radially outwards with a time lag to the distant monitoring wells. In general, it can be said that the area with high peak counts may be an indicator of a potential hazardous area with a high likelihood of sinkhole related failure. Also, the incremental rate of the peak counts shift may be used as indicator of the time to collapse of the sinkhole.

\section{$\underline{\text { Conclusions }}$}

A sinkhole physical model is constructed to simulate and study a natural sinkhole collapse. This phenomenon was monitored in this study using a network of groundwater monitoring wells, which were distributed spatially in radial locations around a predetermined sinkhole location. A spatial-temporal approach with high resolution data was used to study the behavior of groundwater drawdown. This analysis showed a good relationship between the drops in the groundwater levels and the sinkhole collapse location. It is concluded, that prior to the eventual surface collapse of the sinkhole, even when there are no visible surface indications, a cone of the groundwater table depression develops due to recharge of the aquifer by migration of 
soil and water through the crack. This water cone may be used as a tool to predict the potential location of sinkholes if it can be measured in the field.

Sinkhole formation in the physical model was also accompanied by progressive drops in the groundwater levels. These drops are a result of actual material (soil sediment) loss rate in terms of the drop amplitude value. This can help in the determination of the potential location of sinkholes. In addition, the observed progressive drops are delayed by a certain time lags in the monitoring wells, which may be used to measure the time rate of the sinkhole development and the eventual time to failure. A time-frequency analysis of the progressive drops was also used in this study. It applies a pattern detection algorithm called Auto Modulating Detection Pattern Algorithm (AMD) on the raw groundwater table data to represent the progressive drops in terms of peaks. These peaks are then counted and plotted with distance and time. The results of the time-frequency analysis proved that progressive drops peaks of the groundwater are a good indicator of the potential location of the sinkhole formation prior to any visible signs on the ground surface of the collapse. Further studies on the effect of parameters and more elaborate time-frequency analyses are underway and will be presented in future publications. 


\title{
CHAPTER SIX: EFFECTS OF CONTROLLING PARAMETERS ON A PREDICTIVE MODEL FOR SINKHOLES BASED ON GROUNDWATER DRAWDOWN
}

\author{
$\underline{\text { Introduction }}$ \\ Background
}

Sinkholes are ground depressions which occur either gradually or suddenly with or without any visible signs on the ground surface. Sinkhole occurs in a very distinctive geology, called Karst terrain, where the carbonate, limestone, dolomite, or gypsum bedrock are encountered. These bedrocks experience progressive dissolution caused by interaction with the groundwater. This dissolution process may take tens of thousands of years to develop a significant underground cavity that can form a sinkhole. This karst terrain usually contains special features such as sinkholes, caves, valleys, and springs (Tihansky, 1999) (Waltham et al., 2005). While these underground cavities continue to grow, there may not be any visible indicator of the risk to the surface. A recent paper (Alrowaimi et al. 2016) described a laboratory physical model to study the relationship between the development a groundwater cone of depression to a potential location of a sinkhole. This groundwater drawdown may be used a possible sign of an anomaly that could lead to a surface collapse.

\section{Sinkholes in Florida}

Florida is one of the most susceptible states to sinkholes in the nation. The main reason for this vulnerability is the geology of the soil profile in Florida which is underlain by carbonate deposits or bedrock. This carbonate bedrock is subjected to a dissolution process caused by the 
groundwater migration. Also, as the groundwater in the carbonate aquifer may decline due to usage in the municipal, agricultural, and industrial water supplies, sinkhole development may be triggered or accelerated (Atkinson, 1977) (Quinlan et al., 1993) (Tihansky, 1999).

In central Florida, three major factors control the type and the recurrence rate of sinkhole formation. These are the overburden materials compositions and thickness, the limestone bedrock dissolution rate, and the hydrology of the area. Florida's sinkholes are generally divided into three types based on their formation processes: dissolution sinkholes, cover-subsidence sinkholes, and cover-collapse sinkholes (Sinclair \& Stewart, 1985) (Tihansky, 1999). Dissolution sinkholes are mainly caused by chemical erosions to the carbonate, limestone or dolomite, surface. They occur where the limestone and dolomite bedrock is covered with a thin mantle sediments or even in cases when the bedrock is exposed to the surface (Culshaw \& Waltham, 1987). A cover-subsidence sinkhole is a gradual depression of the overburden soils, mainly granular, due to its movement into the underground voids and cavities in the bedrock (Sinclair \& Stewart, 1985). Lastly, cover-collapse sinkholes occur suddenly and result in disastrous damages. They take place in the areas with thick overburden sediments that may contain a large percentage of clay soils (Sinclair \& Stewart, 1985) (Tihansky, 1999) (Waltham et al., 2005).

In central Florida, the end of dry season (May) has the lowest levels of the groundwater in the year while the groundwater levels gain their maximum high levels in the end of the rainy season (September). It is obvious that the seasonal weather variations significantly affect the groundwater levels' cyclical changes from minimum to maximum levels. This condition of the groundwater fluctuation during the very long drought season or large rain events may trigger the formation and collapse of sinkholes (Lewelling et al., 1998) (Tihansky, 1999). 
Research scope

Sinkholes are caused by a combination of hydrological and geological factors. Hence, the in-situ measurements of the processes and the triggering behavior prior to the sinkhole collapse are difficult. In related studies to this one, Alrowaimi et al. (2015) and Alrowaimi et al. (2016) presented the results of an investigation into the triggering behavior prior to the surface collapse with changes in the groundwater table. The experimental small-scale model showed that there is a clear groundwater cone of depression that forms prior to the surface collapse of the sinkhole. This cone of water depression can be used to identify the potential location of the sinkhole at an early stage of the overburden underground cavities formation (Alrowaimi et al., 2015) (Alrowaimi et al., 2016).

This research is an extension of the above referenced studies and presents the effects of controlling parameters on the behavior of the sinkhole. The impact of two parameters, namely overburden soil thickness and initial groundwater table levels, on the sinkhole progression and failure is studied.

\section{$\underline{\text { Summary of Testing Protocol and Parametric Study }}$}

A total of twenty-four (24) test runs were performed with overburden soil thickness (h) of $150 \mathrm{~mm}$ and $200 \mathrm{~mm}$. Each soil thickness was tested with four different initial groundwater tables which are $10 \%, 15 \%, 20 \%$, and $30 \%$ of the overburden soil thicknesses. In order to validate the results, each test run was repeated at least three times with the same initial conditions and parameters. Figure 34 shows a cross-section of the physical model and radial locations of the eight monitoring wells. The test protocol, in terms of constant and variable 
(controlling) parameters and their effects on the sinkhole formation can be summarized in table

1.
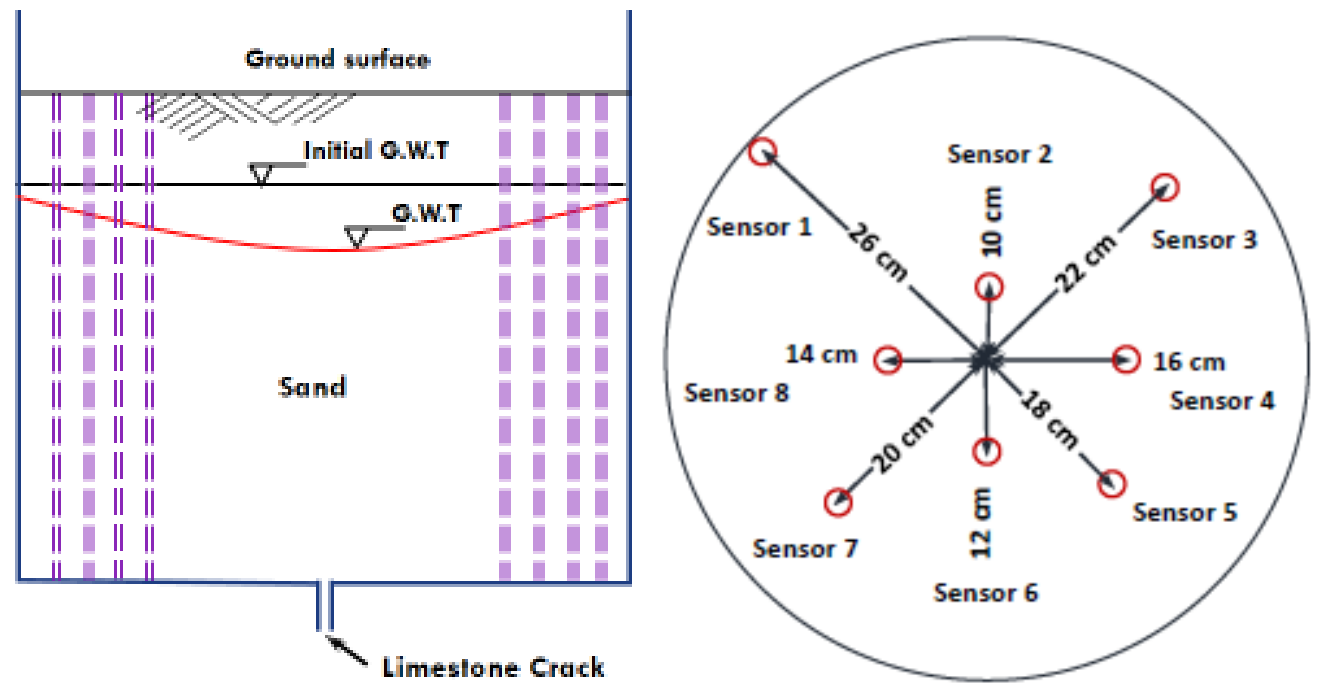

Figure 34: Cross-section of the Physical Model and the Radial Location of the Monitoring Wells (Alrowaimi et al., 2015) 
Table 1: Test Protocol Summary of the Sinkhole Physical Model

\begin{tabular}{|l|l|l|l|}
\hline $\begin{array}{l}\text { Constant } \\
\text { Parameters }\end{array}$ & $\begin{array}{l}\text { Effects on } \\
\text { Sinkhole }\end{array}$ & $\begin{array}{l}\text { Controlling } \\
\text { Parameters }\end{array}$ & $\begin{array}{l}\text { Effects on } \\
\text { Sinkhole }\end{array}$ \\
\cline { 1 - 2 } Soil type & $\begin{array}{l}\text { Controls the } \\
\text { sinkhole type }\end{array}$ & $\begin{array}{l}\text { Soil thickness } \\
\text { Rontrols the } \\
\text { underground } \\
\text { cavity } \\
\text { development in } \\
\text { terms of size and } \\
\text { rate and } \\
\text { hydrology / Add } \\
\text { pressure on top of } \\
\text { the surface } \\
\text { controls the } \\
\text { sinkhole. }\end{array}$ \\
\hline Compaction Level & $\begin{array}{l}\text { Loose soils easier } \\
\text { to get eroded and } \\
\text { eventually have } \\
\text { sinkhole. }\end{array}$ & $\begin{array}{l}\text { Initial groundwater } \\
\text { table level. }\end{array}$ & $\begin{array}{l}\text { Changing the } \\
\text { hydrostatic } \\
\text { pressure head } \\
\text { controls the } \\
\text { sinkhole collapse } \\
\text { rate and size. }\end{array}$ \\
\hline $\begin{array}{l}\text { Bottom opening } \\
\text { diameter (5 mm). }\end{array}$ & $\begin{array}{l}\text { Crack size controls } \\
\text { the underground } \\
\text { cavity formation } \\
\text { rate and size. }\end{array}$ & & \\
\hline
\end{tabular}

The sample preparation procedure is controlled in terms of compaction energy for all samples. Standard proctor hammer and modified proctor hammer were used in the sample preparation. Also, a circular metal plate with $120 \mathrm{~mm}$ diameter and $7 \mathrm{~mm}$ thick was used to uniformly distribute the falling hammer energy on the loose soil surface (Alrowaimi et al., 2015) (Alrowaimi et al., 2016). The sample preparation, the experiment setup, and the test procedure are similar to one developed by Alrowaimi et al. (2015) and Alrowaimi et al. (2016).

The test runs were divided into two groups. First group was conducted by using a soil thickness of $150 \mathrm{~mm}$. While, second group was conducted by using a soil thickens of $200 \mathrm{~mm}$. Twelve (12) samples were tested in each group. The $150 \mathrm{~mm}$ and $200 \mathrm{~mm}$ overburden soils were tested with different initial groundwater levels. The initial groundwater was taking as percentage 
of the overburden soil thicknesses: $10 \%, 15 \%, 20 \%$, and $30 \%$. The test summary is demonstrated in Table 2.

Table 2: Test Summary

\begin{tabular}{|c|c|c|c|c|c|}
\hline \multicolumn{3}{|c|}{ Overburden soil thickness, $h=150 \mathrm{~mm}$} & \multicolumn{3}{|c|}{ Overburden soil thickness, $h=200 \mathrm{~mm}$} \\
\hline Set \# & Run \# & Initial GWT & Set \# & Run \# & Initial GWT \\
\hline \multirow{3}{*}{ SET-1 } & RUN No.1 & \multirow{3}{*}{$10 \%$ of $h$} & \multirow{3}{*}{ SET-1 } & RUN No.1 & \multirow{3}{*}{$10 \%$ of $h$} \\
\hline & RUN No.2 & & & RUN No.2 & \\
\hline & RUN No.3 & & & RUN No.3 & \\
\hline \multirow{3}{*}{ SET-2 } & RUN No.1 & \multirow{3}{*}{$15 \%$ of $h$} & \multirow{3}{*}{ SET-2 } & RUN No.1 & \multirow{3}{*}{$15 \%$ of $h$} \\
\hline & RUN No.2 & & & RUN No.2 & \\
\hline & RUN No.3 & & & RUN No.3 & \\
\hline \multirow{3}{*}{ SET-3 } & RUN No.1 & \multirow{3}{*}{$20 \%$ of $h$} & \multirow{3}{*}{ SET-3 } & RUN No.1 & \multirow{3}{*}{$20 \%$ of $\mathrm{h}$} \\
\hline & RUN No.2 & & & RUN No.2 & \\
\hline & RUN No.3 & & & RUN No.3 & \\
\hline \multirow{3}{*}{ SET-4 } & RUN No.1 & \multirow{3}{*}{$30 \%$ of $h$} & \multirow{3}{*}{ SET-4 } & RUN No.1 & \multirow{3}{*}{$30 \%$ of $h$} \\
\hline & RUN No.2 & & & RUN No.2 & \\
\hline & RUN No.3 & & & RUN No.3 & \\
\hline
\end{tabular}

The detailed experimental results of test RUN No.1 of SET-1 are presented Alrowaimi et al. (2016). This run has an overburden soil thickness (h) of $150 \mathrm{~mm}$ and an initial groundwater table of $15 \%$ of the soil thickness. Detailed explanation of the behavior of the groundwater drawdown around a predetermined location of a sinkhole is presented in Alrowaimi et al. (2016) too. It was observed, in all test runs, that the groundwater drawdown was faster in the wells closer to the predetermined sinkhole location than the wells further away from the center. This 
cone of water depression developed well before surface collapse occurred. It is also observed that the cone of groundwater depression gets steeper over time as the underground cavity gets bigger (Alrowaimi et al., 2016).

\section{Analysis and Discussion of the Experimental Results}

In this section, a single test (RUN No.1) is selected to explain the steps of the analysis in detail. The results of the all test runs ( 24 runs) will be discussed in the next section. The groundwater raw data is normalized in the following manner. The time axis is normalized with the time to visible sinkhole collapse. The radial locations of the groundwater monitoring wells are normalized to the overall radius of the test mold. Finally, the raw groundwater level readings are normalized to the corresponding overburden soil thickness. Figure 35 presents the normalized groundwater level readings over the normalized time of sinkhole collapse. 


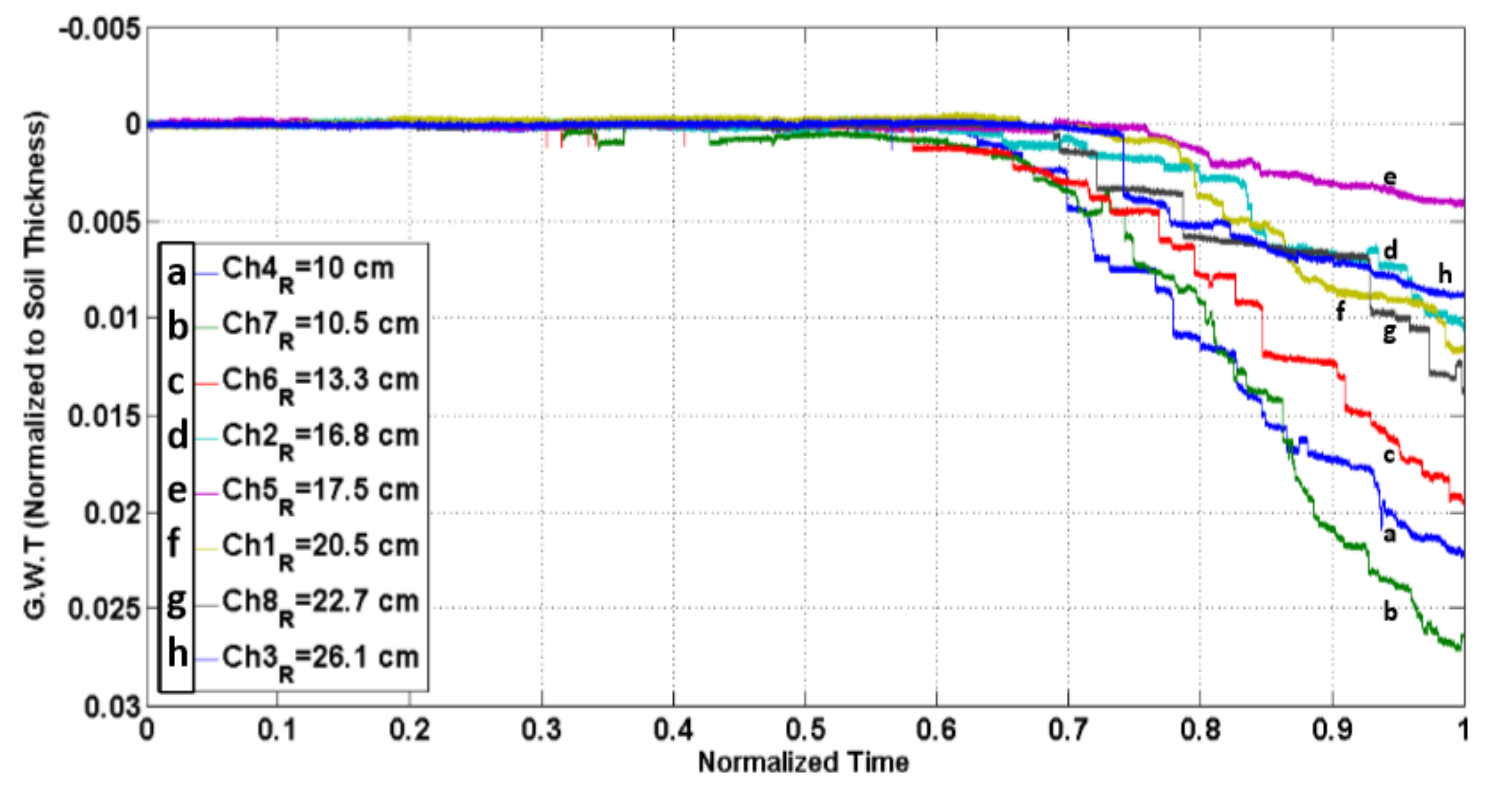

Figure 35: Normalized groundwater level drops over the normalized time of sinkhole collapse

In Figure 36, normalized groundwater data against the normalized monitoring wells location are plotted to study the cone of depression of the groundwater with respect to the sinkhole time and location. A logarithmic curve fitting method is utilized to represent each level of groundwater readings over the eight radial locations of the wells as shown in Figure 38. As explained in the previous study by Alrowaimi et al. (2015), the cone of depression of water levels may lead to determination of the potential location of a sinkhole and its eventual collapse when used in a reverse manner. The groundwater cone of depressions over time were represented using a logarithmic curve function as shown in equation 2. The GWT starts as horizontal (straight) line equation and develops to steeper curves over time until surface collapse occurs. 


$$
y(r, t)=-\propto(t)[\ln (r)]+b
$$

where, $y=$ the GWT level; $r=$ the radial locations of the monitoring wells; $\alpha=$ a constant that controls the steepness of the groundwater table cone of depression; $b=a$ constant that controls the intercept location.

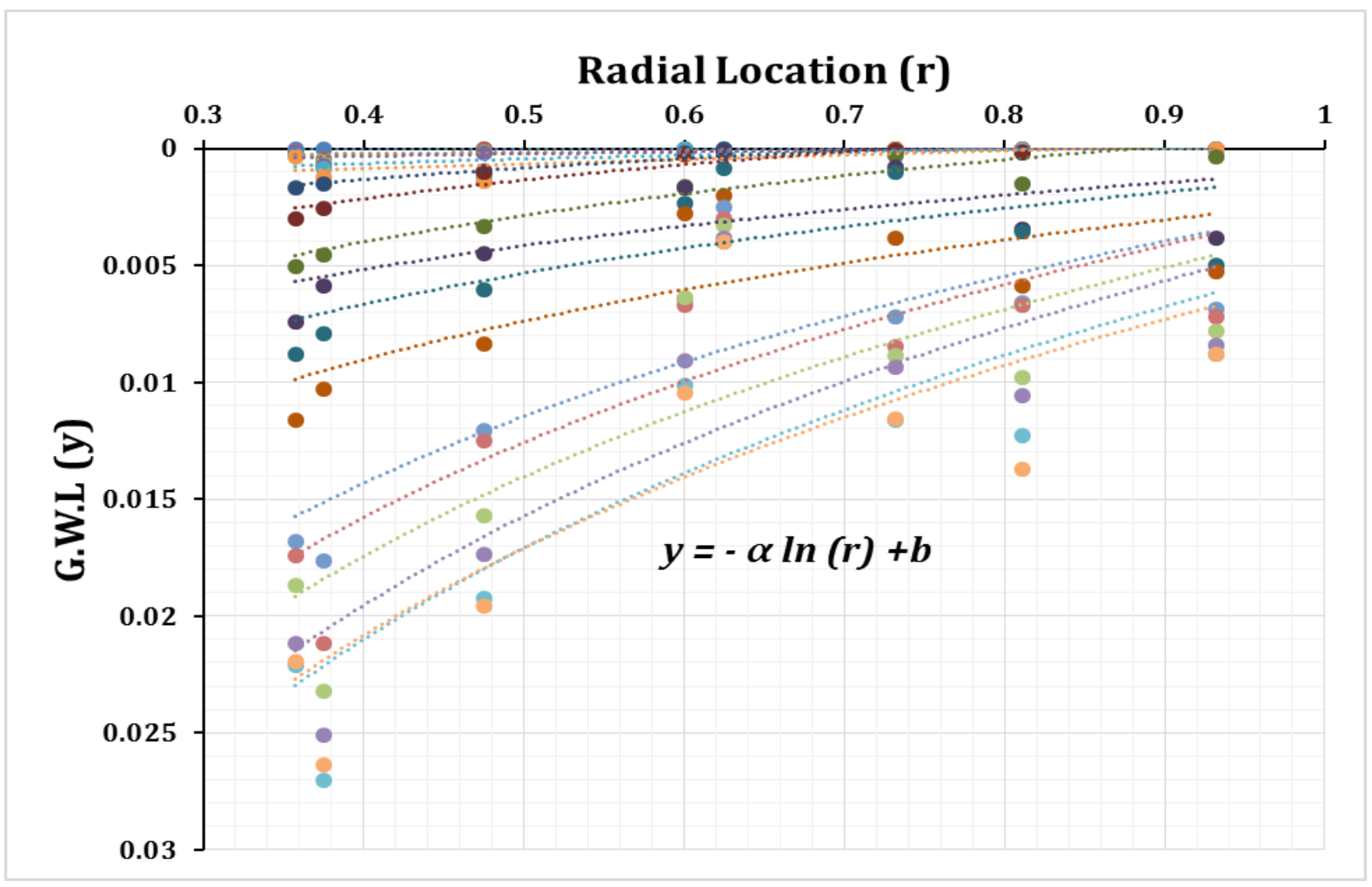

Figure 36: Groundwater trend line representation in RUN No.1 test. 
The value of " $\alpha$ "of each cone of groundwater drawdown over time is calculated. This $\alpha$ value defines the slope of the groundwater cone of depression. This slope is calculated for the entire data set of each test run from the beginning of the test to the time of surface collapse.

Figure 37 shows the changes of the slope of the water cone over time for the three test runs. It is observed from Figure 37 that the slope $(\alpha)$ of the groundwater starts with zero values up to the time of opening the bottom hole (triggering time). Subsequently, the values of the slope start to increase over time with a variable rate that could be related to the rate of the sediment loss. It is clear that the slope progresses over time, which is corresponding to growth of the cavity due to loss of underground sediment until the time of a visible surface collapse.

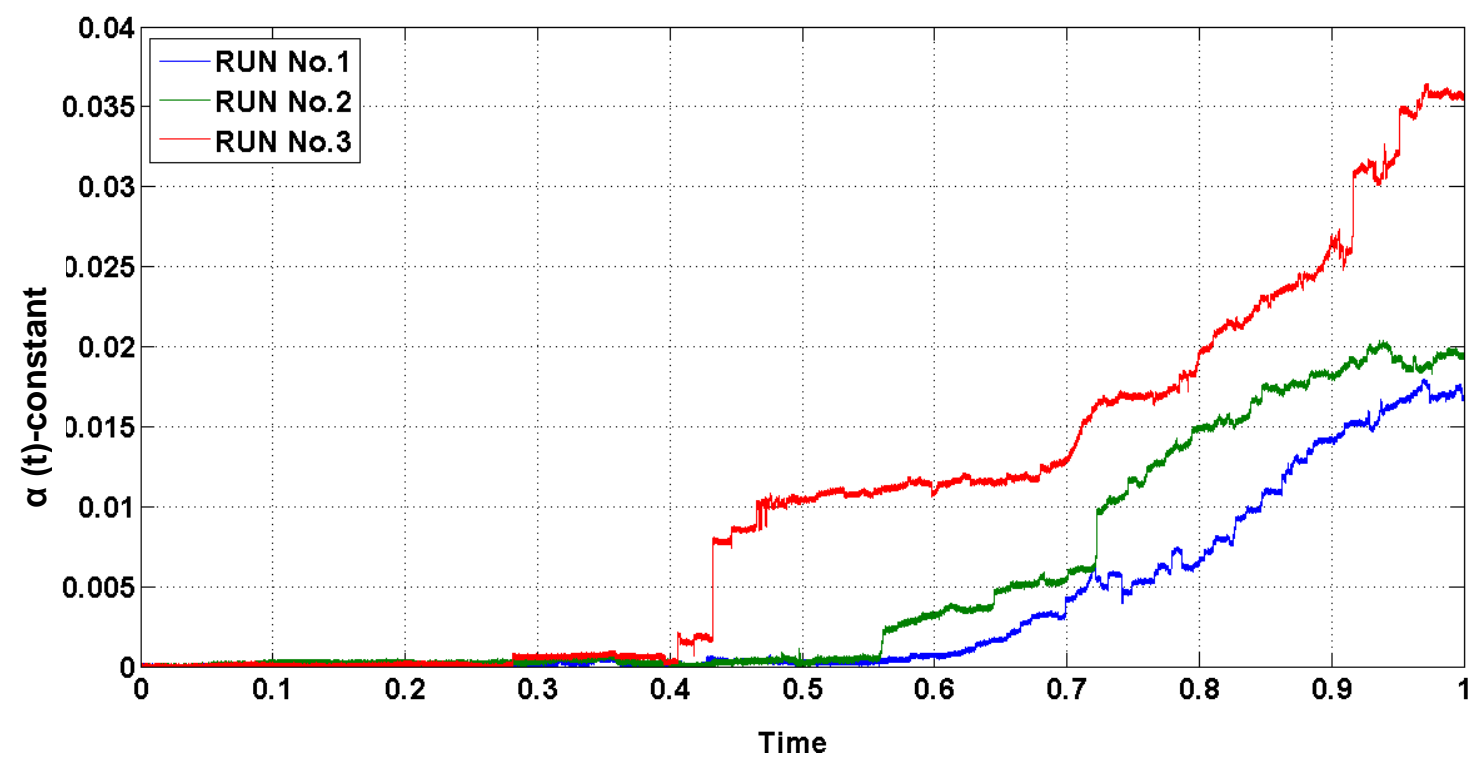

Figure 37: $\alpha(\mathrm{t})$ constant over normalized time for three test runs 
In order to fit the data of the groundwater slope versus time, different functions were examined to represent the data. The exponential function showed a very good agreement with the actual slope data and is adopted. In addition, the least-squares fitting technique was used initially to fit the nonlinear slope data. However, the main disadvantage of the least-squares method is the sensitivity to the outliers. Since the slope of groundwater data has some sudden changes in its values due to the actual behavior of the internal local collapses during sinkhole formation, the least-squares method did not provide the best data fit. In order to minimize the influence of the outliers, a robust least-squares regression technique is used in this analysis. One of the several robust regression methods is the Bisquare Weights method. This method minimizes a weighted sum of squares. For instance, the data closer to the fitted line is weighted higher, while the data further away is assigned a lower weight. Thus, the Bisquare Weights method tends to find a fitting curve to the bulk of the data while minimizing the effect of outliers. Figure 48 shows the slope of the groundwater level curve using the Bisquare Weights method. It must be noted that the exponential equation, given in equation 3 , is the equation of the fitting curve. 


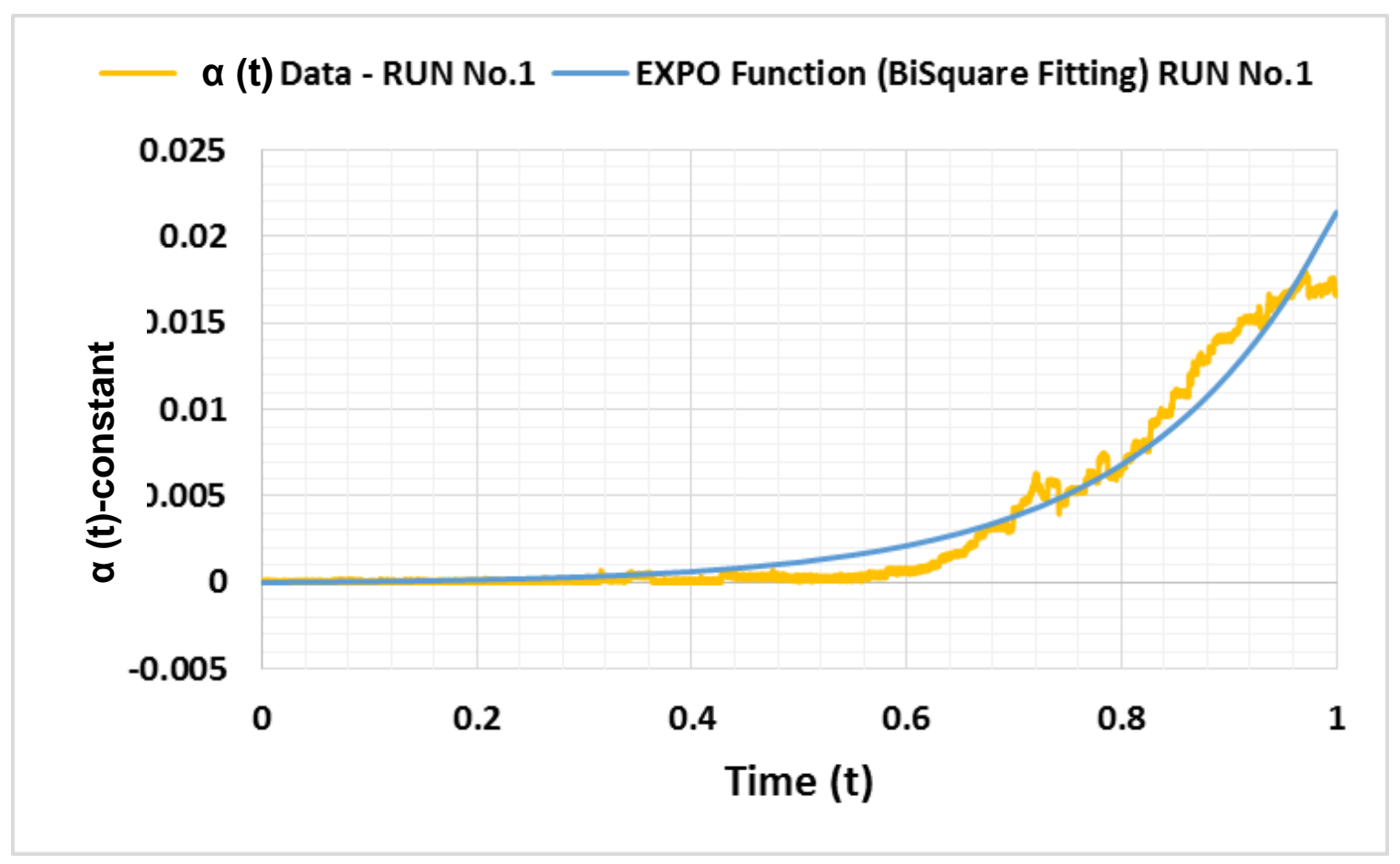

Figure 38: The slope of the groundwater level data with its best fitting curve

The exponential curve fitting equation can be written as:

$$
\alpha(t)=a\left(e^{(t * \beta)}-1\right)
$$

Where, $\alpha=$ the slope of the G.W.T curve; $\mathrm{a}=\mathrm{a}$ value that controls the intercept location; $\mathrm{t}=$ normalized time; $\beta=$ time constant. The next section presents the results of all 24 tests using this methodology. 
By substituting Equation (3) in Eq. (2), the groundwater table cone of depression equation can be written as:

$$
y(r, t)=\left[a\left(1-e^{(t * \beta)}\right)(\ln (r))\right]+b
$$

Where, $y(r, t)=$ the groundwater table as a function of different radial locations ( $\mathrm{r}$ ) of the monitoring wells over time $(\mathrm{t})$.

\section{Effect of Initial Groundwater Level}

The above-mentioned analysis is conducted for all of the twenty-four test runs. The test results for the first group (150 mm overburden soil thickness) and the second group (200 mm overburden soil thickness) are summarized in Table 3 and 4, respectively.

Table 3: Summary of the Slope Fitting Equation Variables for the $150 \mathrm{~mm}$ Soil

\begin{tabular}{|c|c|c|c|c|}
\hline \multicolumn{5}{|c|}{ Overburden soil thickness $(\mathrm{h}=150 \mathrm{~mm})$} \\
\hline Set No. & Run No. & $\mathrm{a}$ & $\beta$ & Average $(\beta)$ \\
\hline \multirow{3}{*}{ SET-1 (10\% h) } & RUN No.1 & 0.0000356 & 9.478 & \multirow{3}{*}{6.87} \\
\hline & RUN No. 2 & 0.00002839 & 7.584 & \\
\hline & RUN No.3 & 0.001109 & 3.559 & \\
\hline \multirow{3}{*}{ SET-2 (15\% h) } & RUN No.1 & 0.0002894 & 3.581 & \multirow{3}{*}{5.35} \\
\hline & RUN No.2 & $9.513 \mathrm{E}-07$ & 8.952 & \\
\hline & RUN No.3 & 0.0004619 & 3.508 & \\
\hline \multirow{3}{*}{ SET-3 $(20 \%$ h) } & RUN No.1 & 0.000184 & 2.88 & \multirow{3}{*}{4.58} \\
\hline & RUN No.2 & 0.0001474 & 2.604 & \\
\hline & RUN No.3 & $1.24 \mathrm{E}-08$ & 8.251 & \\
\hline \multirow{3}{*}{ SET-4 (30\% h) } & RUN No.1 & 0.0003092 & 3.124 & \multirow{3}{*}{2.65} \\
\hline & RUN No. 2 & 0.00005462 & 5.182 & \\
\hline & RUN No.3 & 0.0003425 & 2.185 & \\
\hline
\end{tabular}


Table 4: Summary of the Slope Fitting Equation Variables for the $200 \mathrm{~mm}$ Soil

\begin{tabular}{|c|c|c|c|c|}
\hline \multicolumn{5}{|c|}{ Overburden soil thickness (h=200 mm) } \\
\hline Set No. & Run No. & $\mathrm{a}$ & $\beta$ & Average $(\beta)$ \\
\hline \multirow{3}{*}{ SET-1 (10\% h) } & RUN No.1 & 0.0008775 & 3.135 & \multirow{3}{*}{2.82} \\
\hline & RUN No.2 & 0.0006443 & 3.478 & \\
\hline & RUN No.3 & 0.001526 & 1.848 & \\
\hline \multirow{3}{*}{ SET-2 (15\% h) } & RUN No.1 & 0.0002679 & 4.086 & \multirow{3}{*}{2.55} \\
\hline & RUN No.2 & 0.0028621 & 1.666 & \\
\hline & RUN No.3 & 0.003014 & 1.89 & \\
\hline \multirow{3}{*}{ SET-3 $(20 \%$ h) } & RUN No.1 & 0.001928 & 2.125 & \multirow{3}{*}{2.37} \\
\hline & RUN No.2 & 0.002649 & 2.239 & \\
\hline & RUN No.3 & $1.12 \mathrm{E}-03$ & 2.754 & \\
\hline \multirow{3}{*}{ SET-4(30\% h) } & RUN No.1 & 0.003082 & 1.283 & \multirow{3}{*}{1.53} \\
\hline & RUN No.2 & 0.004771 & 1.15 & \\
\hline & RUN No.3 & 0.001284 & 2.155 & \\
\hline
\end{tabular}

The exponential function given in equation 3 is an exponential growth function. The exponential growth function occurs when the rate of the growth of the value of a function is proportional to the function's current value, which results in its growth with time. The time constant $(\beta)$ is a parameter that characterizes the response to a step input of a first order, linear time-invariant system. In general, the time constant can be used to indicate how rapidly an 
exponential function grows. Thus, the time constant for average values of each data set are plotted to study the effects of the controlling parameters, soil thickness and initial groundwater level, on the growth rate of the slope of the groundwater drawdown and consequently on the rate of sinkhole development. Figures 39 and 40 illustrates the behavior of the time constant of the exponential curve against different initial groundwater levels. It is observed based on both figures that the time constant grows to higher values with shallower groundwater (measured from the ground surface). This behavior means that the soil samples with smaller height of hydrostatic head of water, such as SET-4, has less distance and time to escape from the limestone crack than the one with higher hydrostatic head of water, such as SET-1. Consequently, the growth rate of the slope of groundwater cone of depression gets higher in samples with a higher height of hydrostatic head of water. 


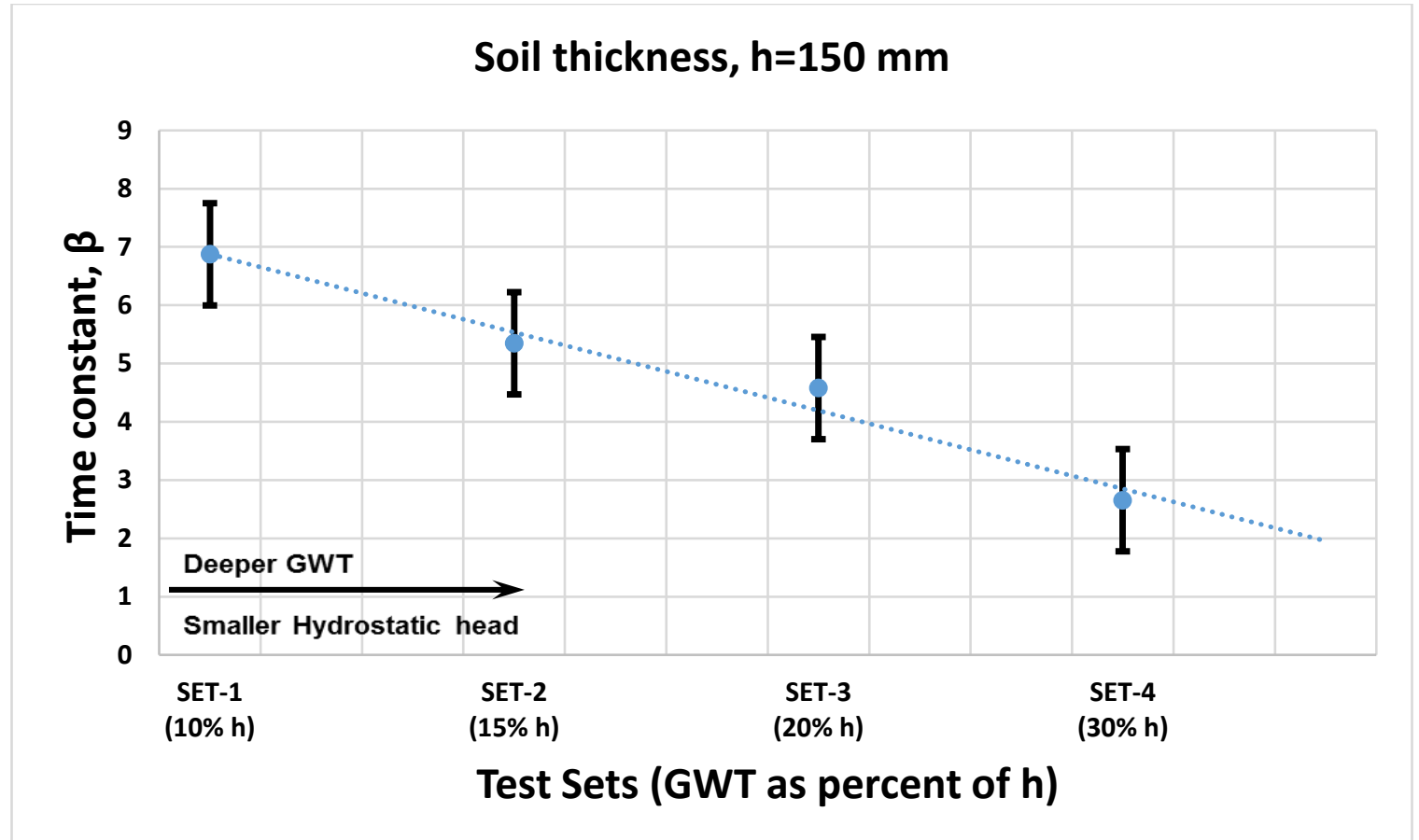

Figure 39: Time constant changes with different initial groundwater levels for the $150 \mathrm{~mm}$ samples 


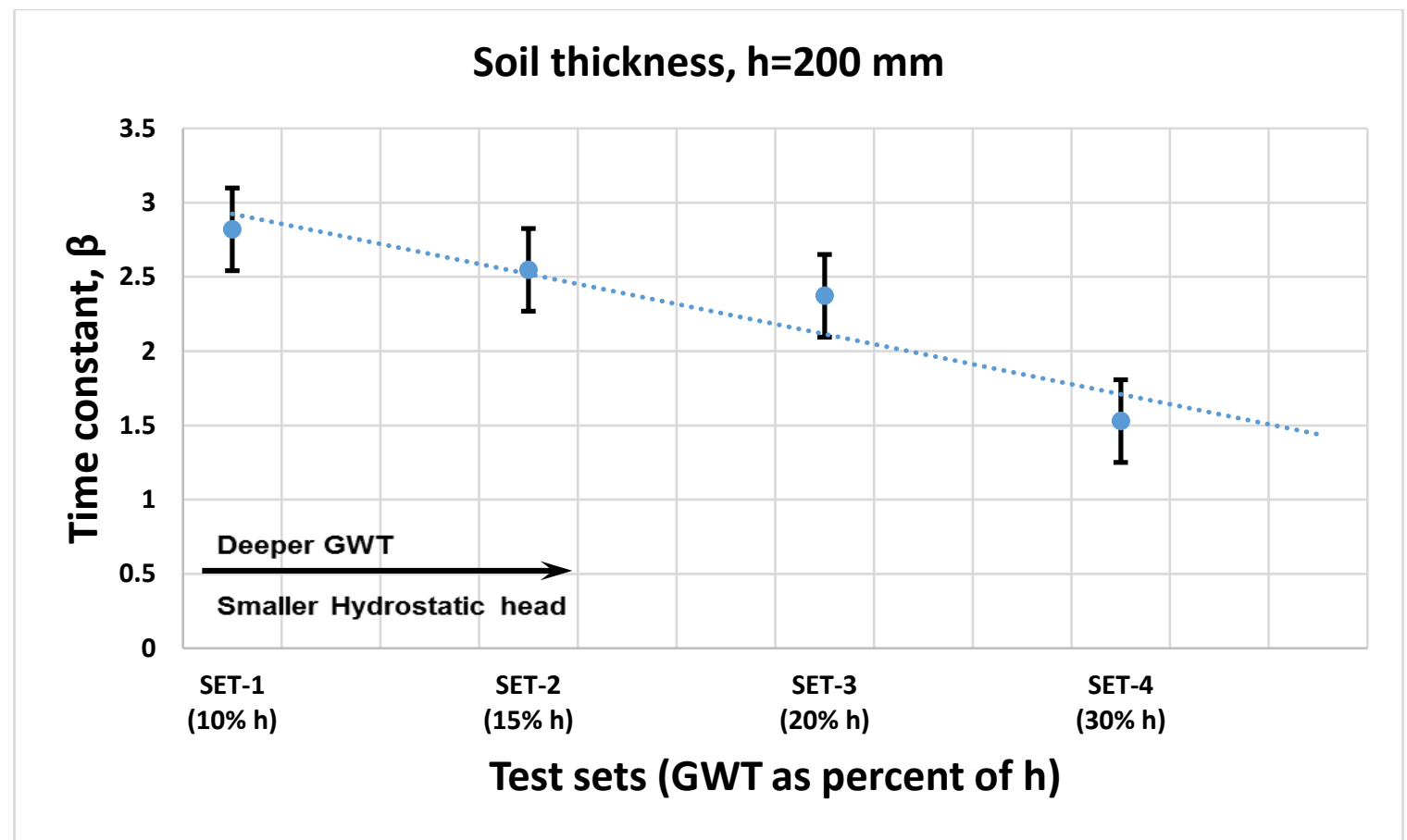

Figure 40: Time constant changes with different initial groundwater levels for the $200 \mathrm{~mm}$ samples

\section{Effect of Overburden Soil Thickness}

In the following section, the effect of the overburden soil thickness is studied using four sets of different initial groundwater levels which are 10\%, 15\%, 20\%, and 30\% of the soil thickness. Figures 41 (a, b, c, and d) shows the changes of the time constant in corresponding to the $150 \mathrm{~mm}$ and $200 \mathrm{~mm}$ soil thicknesses respectively. These four sets of samples of different initial groundwater levels are combined and plotted in Figure 41.

Figures 41 and 42 illustrate the relationship between the time constant and soil thickness. It can be observed, that the time constant decreases with the increase of the overburden soil thickness. 
Thus, the growth rate of the slope of groundwater cone of depression gets higher in samples with a thinner overburden soil thickness on top of the limestone crack.

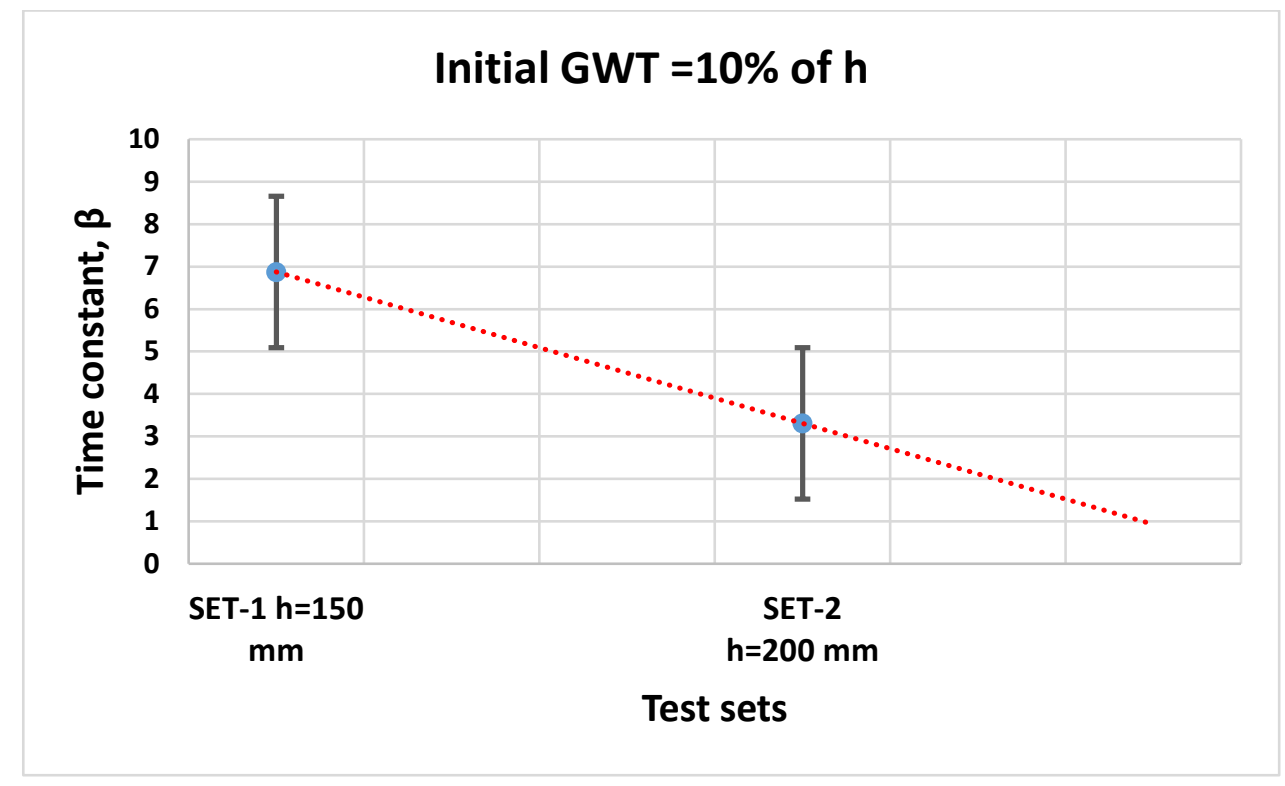

(a)

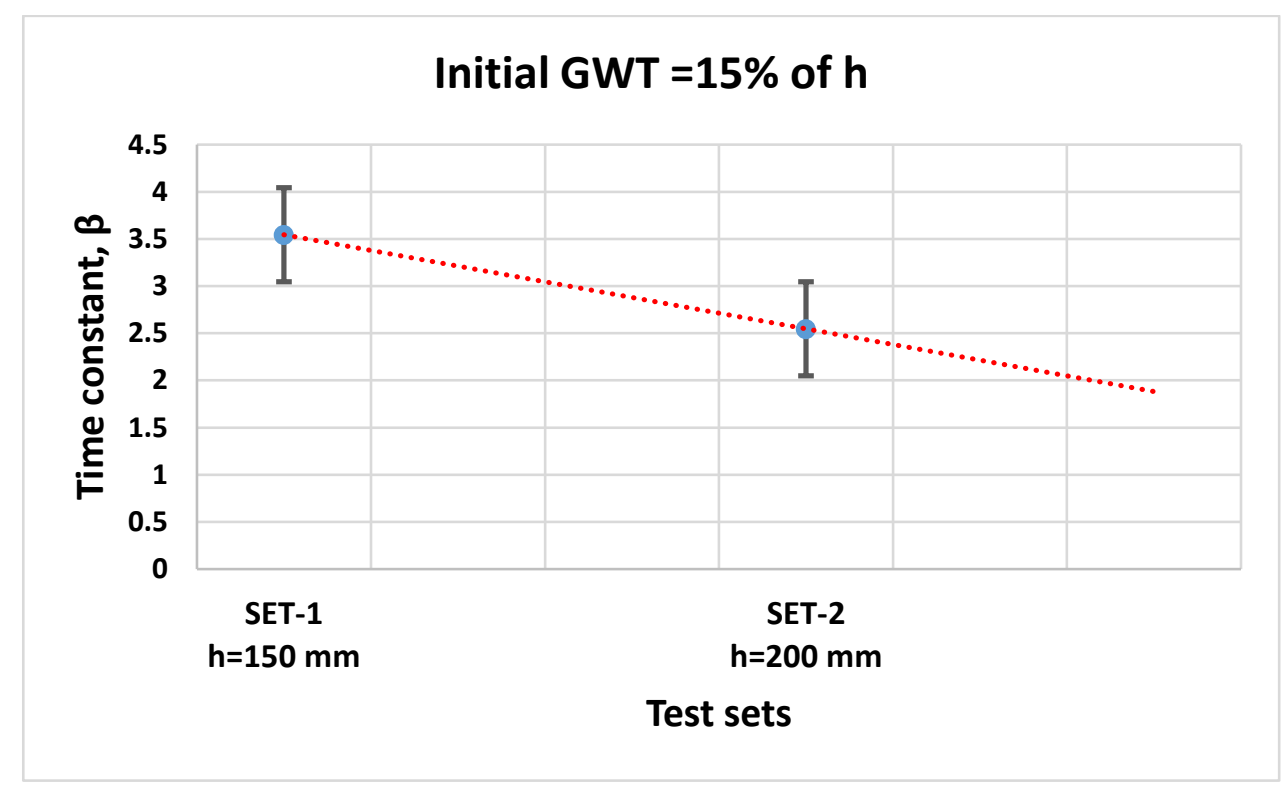

(b) 


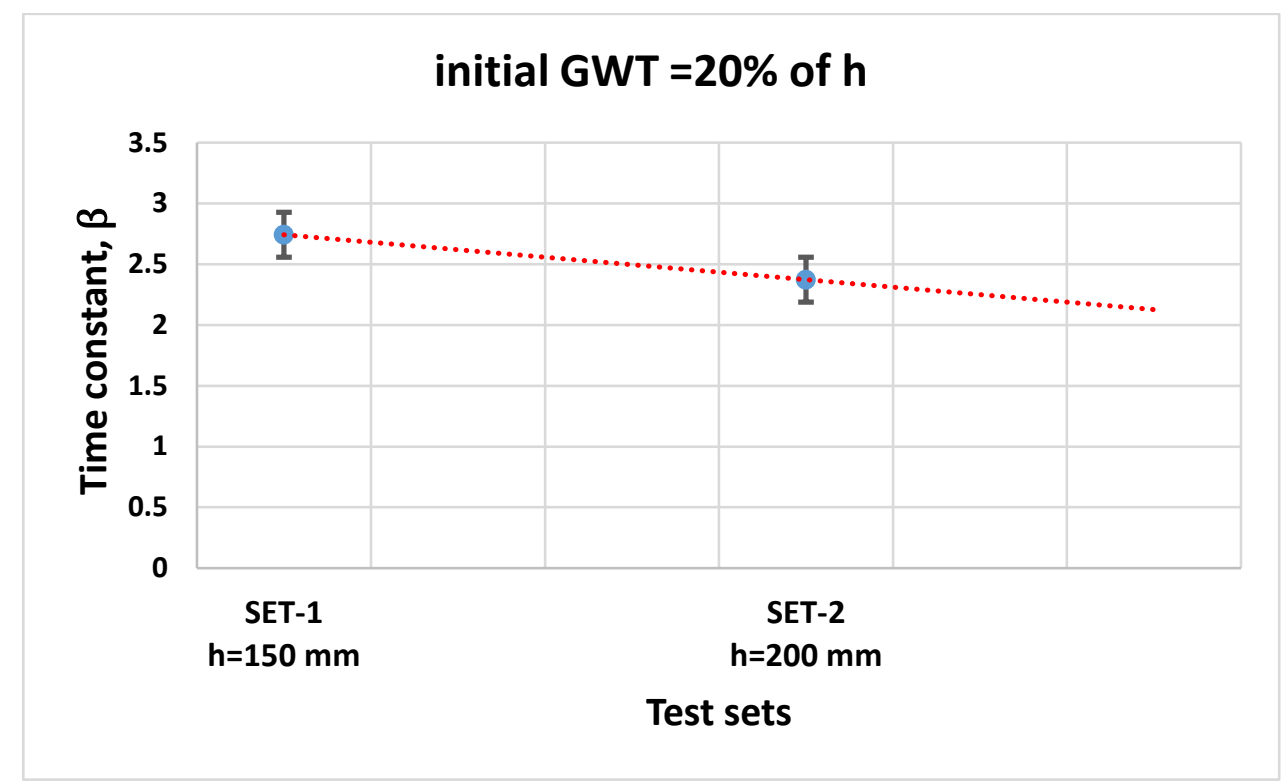

(c)

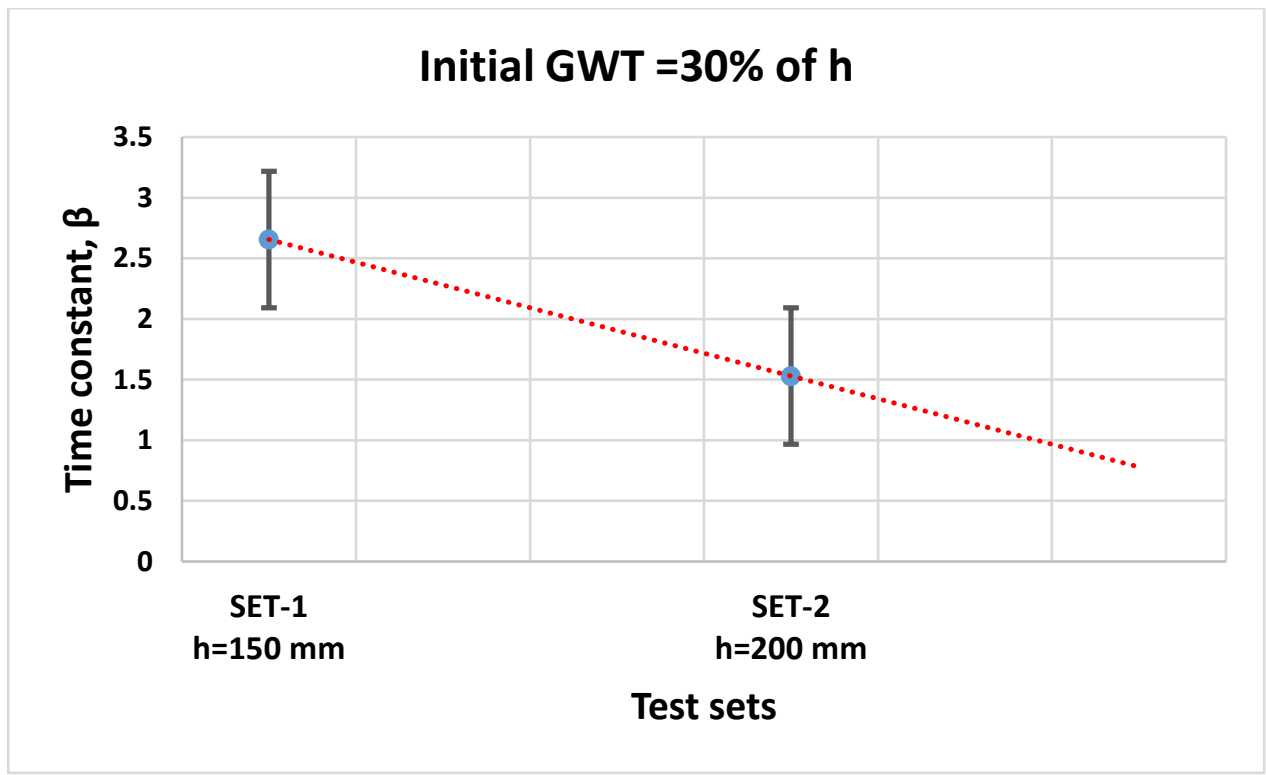

(d)

Figure 41: Time constant changes with different overburden soil thicknesses 


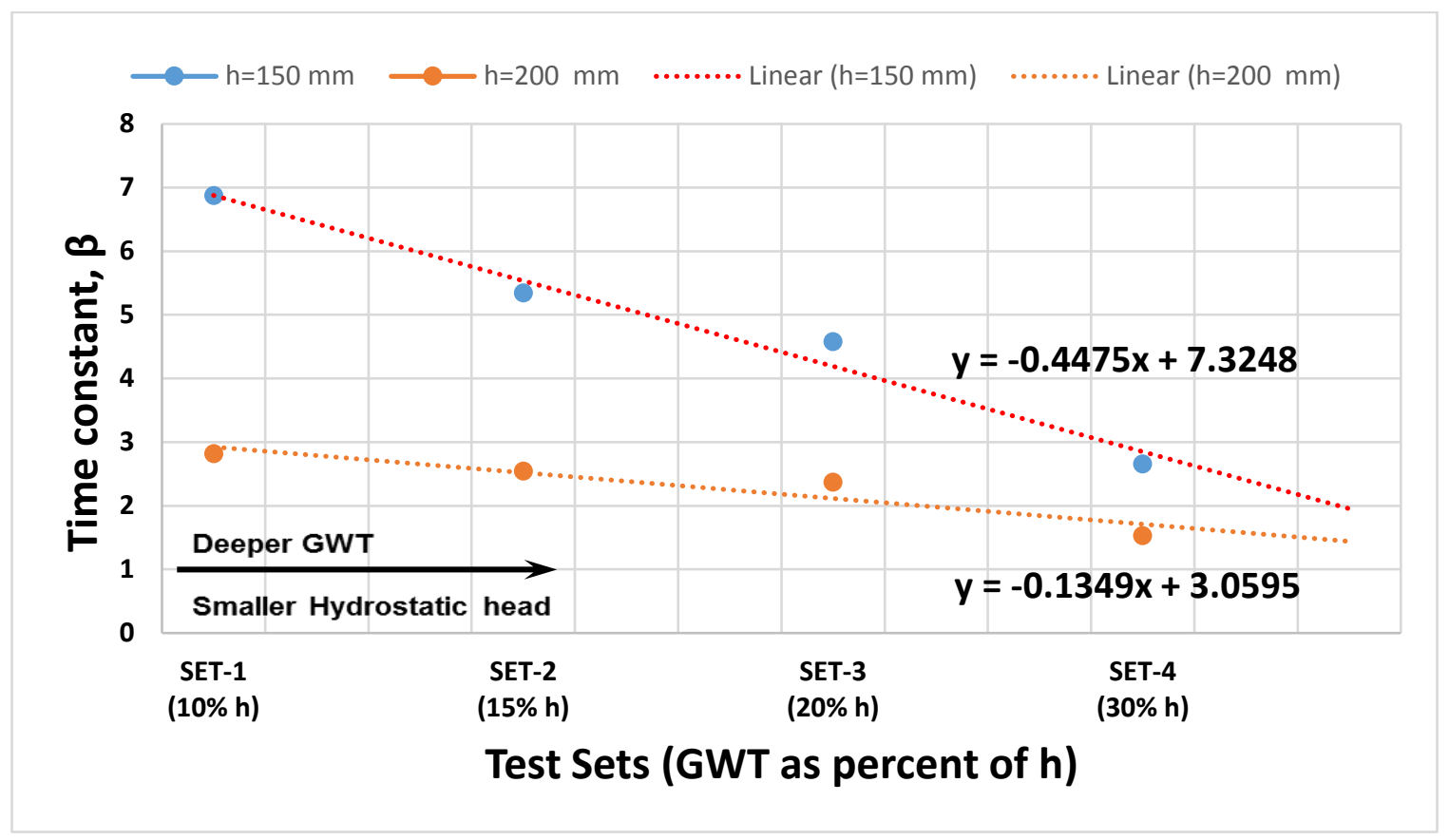

Figure 42: Combined plot of time constant changes versus different overburden soil thicknesses with various initial groundwater levels

Figure 42 shows a general agreement in all test runs in terms of the impact of the overburden thicknesses on the growth rate of the slope of the groundwater cone of depression. In addition, the figure also shows the impact of the initial groundwater levels on the time constant and the growth rate of the groundwater slope. It is observed that the rate of change of the slope of groundwater cone of depression is higher for a higher height of hydrostatic head of water (shallower groundwater level). 


\section{$\underline{\text { Conclusions }}$}

A sinkhole physical model was constructed to simulate and study the natural sinkhole collapse by Alrowaimi et al (2015) and Alrowaimi et al (2016). The results of this physical model were used in this research to study the effects of controlling parameters, namely soil thickness and initial groundwater level, on the rate of change of the slope of the groundwater drawdown and consequently on the rate of sinkhole development. The sinkhole phenomenon was monitored in this study using a network of groundwater monitoring wells, which were distributed spatially in radial locations around a predetermined sinkhole location. Alrowaimi et al (2015) and Alrowaimi et al (2015) concluded, that prior to the eventual surface collapse of the sinkhole, even when there are no visible surface indications, a cone of groundwater table depression develops due to recharge of the aquifer by migration of soil and water through the crack. Thus, the slope of the groundwater drawdown is studied in this research since this cone of water underground may be used as a tool to predict the potential location of sinkholes.

A series of twenty-four (24) experimental model runs were conducted in order to correlate the groundwater drops to the sinkhole development. These test runs have been divided into two main groups based on the overburden soil thicknesses in the model, which are 150 and $200 \mathrm{~mm}$. Each group is divided to four different soil samples in term of the initial conditions of the groundwater table. The initial groundwater table was considered as a percentage of the whole soil thickness with $10 \%, 15 \%, 20 \%$, and $30 \%$. The cone of groundwater depression was represented by a logarithmic trend line function. The constants $\alpha(\mathrm{t})$, which is a constant that controls the steepness of the groundwater table cone of depression, were plotted over time. An exponential growth equation with a constant parameter called the time constant was used to 
represent the changes of these slopes over time. The time constant of that equation is an indicator of how rapidly an exponential function grows. Using the average values of each data set, the time constants are plotted to study the effects of the controlling parameters on the growth rate of the slope of the groundwater drawdown and consequently on the rate of sinkhole progression.

The study of the impact of the controlling parameters on the sinkhole formations showed that the growth rate of the slope of groundwater cone of depression gets higher for a higher height of hydrostatic head of water (shallower groundwater level). It can be also concluded that the time constant decreases with the increase of the overburden soil thickness. Also, the growth rate of the slope of groundwater cone of depression gets higher with a thinner overburden soil thickness on the top of the limestone crack.

Based on the findings, it is likely that in areas with shallow groundwater level (measured from the ground surface) the slope of the cone of the water depression is steeper than areas with a deeper groundwater levels during underground cavity development. This behavior occurs due to the longer travel path of the groundwater and associated soil sediments to reaches the limestone cracks in the areas with the shallow groundwater since the higher hydrostatic head of water means a higher driving force for the suffosion process. This could lead to quicker sinkhole collapse.

It is also expected in areas with thinner overburden soils on top of the limestone bedrock that the slope of the cone of the water depression is steeper than those with a thicker overburden layer. This behavior also leads to a faster escape of the water and soil sediments through the bedrock crack. Consequently, it may not provide sufficient time for the cavity to propagate to the ground surface. This explains that a sinkhole takes longer time to develop in areas with a very 
thick overburden compared to areas with a thinner overburden soil in similar geological and hydrological conditions. 


\title{
CHAPTER SEVEN: SUMMARY AND CONCLUSION
}

\author{
Summary
}

A sinkhole physical model is constructed to simulate and study natural sinkhole collapse. The sinkhole simulator consisted of two main components: The soil mold and the monitoring system. The monitoring system was used to conduct an analysis of data collected from a network of groundwater monitoring wells (sensors). These wells were distributed in a radially around a predetermined location of a sinkhole. A different soil levels (overburden soil) and initial groundwater levels were tested in this model. This model has a single circular opening to simulate a crack in the limestone that allows the transfer of a volume of soil through the dissolving bedrock layer.

A series of twenty-four (24) experimental runs were conducted in order to correlate the groundwater drops to the sinkhole developments. These test runs have been divided into two main groups based on the overburden soil thicknesses in the model, which are 150 and $200 \mathrm{~mm}$. Each group is divided to four different soil samples in term of the initial conditions of the groundwater table. The initial groundwater table was considered as a percentage of the whole soil thickness with $10 \%, 15 \%, 20 \%$, and $30 \%$. Figure 43 shows the detailed flow chart of the tests and their constant and controlling parameters.

Based on the results from initial testing using this scaled physical model, there were clear indications of a groundwater cone of depression. This was the motivation to validate this behavior of the groundwater drops by conducting a large number of experiments to study the correlation between the changes in the groundwater table and the mechanism of sinkhole formation. The data from the network of monitoring wells was ultimately aimed at pinpointing 
the potential location of a sinkhole by observing major drops in the local groundwater levels in the proximity of a sinkhole.

Finally, a parametric study was conducted by dividing the tests into two main groups based on the overburden soil thicknesses and also four different soil samples in term of the initial conditions of the groundwater table. The results of this physical model runs were used to study the effects of these two controlling parameters on the growth rate of the slope of the groundwater drawdown and consequently on the rate of sinkhole development. 


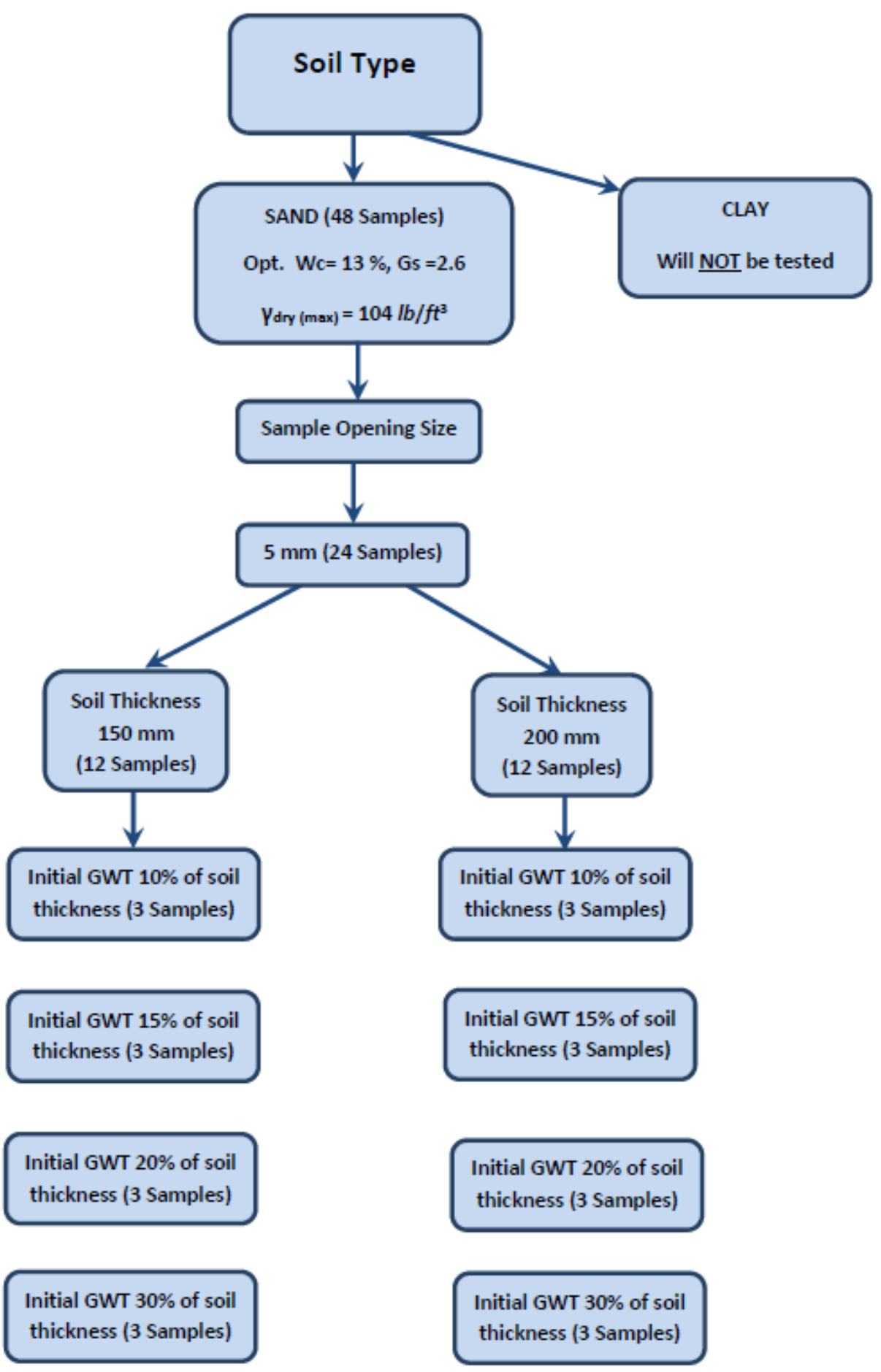

Figure 43: A flow chart of the total number of experiments \& their controlling parameters 


\section{$\underline{\text { Overall Conclusions }}$}

Based on the results from the testing, the drops in the groundwater levels showed a very distinctive trend. The level in the wells nearer to the sinkhole always showed water levels lower than the distant wells. This naturally occurring behavior can be referred to as a cone of depression. It can be concluded that the current physical model was successful in showing the formation of this groundwater cone of depression that occurs before there are any surface signs of sinkholes. This localized depressed water level, in turn, can be used in predicting the potential location of sinkholes that are forming underground and show no surface indications.

By studying sensor data, some progressive drops were evident, which are consistently seen at the same location over multiple runs. The progressive drops are a result of actual material (soil sediment) loss rate in terms of the drop amplitude value. Also, these progressive drops migrate in time from the closer sensor to the sinkhole to the further sensor. This time lag behavior and the corresponding progressive drops are indicators of the potential location of sinkholes. Thus, both the progressive drops and their time lags can help in investigating the sinkhole locations and the sinkhole progressing rate. This is achieved by correlating an actual progressing sinkhole to the groundwater table drawdown and progressive drop measurements.

A time-frequency analysis of the progressive drops was also used in this study. It applies a pattern detection algorithm called Auto Modulating Detection Pattern Algorithm (AMD) on the raw groundwater table data to represent the progressive drops in terms of peaks. These peaks are then counted and plotted with distance and time. The results of the time-frequency analysis proved that progressive drops peaks of the groundwater are a good indicator of the potential 
location of the sinkhole formation prior to any visible signs on the ground surface of the collapse.

The results of the twenty-four runs of the physical model were used in this research to study the effects of controlling parameters, which are the overburden soil thickness and initial groundwater level, on the growth rate of the slope of the cone of the groundwater drawdown and consequently on the rate of sinkhole development. These test runs have been divided into two main groups based on the overburden soil thicknesses in the model, which are 150 and $200 \mathrm{~mm}$. Each group is divided to four different soil samples in term of the initial conditions of the groundwater table. The initial groundwater table was considered as a percentage of the whole soil thickness with $10 \%, 15 \%, 20 \%$, and $30 \%$. The cone of groundwater depression was represented by a logarithmic trend line function. The slopes of the groundwater cones of depressions were plotted over time. An exponential growth equation with a constant parameter called the time constant was used to represent the changes of these slopes over time. The time constant of that equation is an indicator of how rapidly an exponential function grows. Using the average values of each data set, the time constants are plotted to study the effects of the controlling parameters on the growth rate of the slope of the groundwater drawdown and consequently on the rate of sinkhole progression.

The study of the impact of the controlling parameters on the sinkhole formations showed that the growth rate of the slope of groundwater cone of depression gets higher for a higher height of hydrostatic head of water (shallower groundwater level). It can be also concluded that the time constant decreases with the increase of the overburden soil thickness. Also, the growth 
rate of the slope of groundwater cone of depression gets higher with a thinner overburden soil thickness on the top of the limestone crack.

Based on the findings, it is likely that in areas with shallow groundwater level (measured from the ground surface) the slope of the cone of the water depression is steeper than areas with a deeper groundwater levels during underground cavity development. This behavior occurs due to the longer travel path of the groundwater and associated soil sediments to reaches the limestone cracks in the areas with the shallow groundwater since the higher hydrostatic head of water means a higher driving force for the suffosion process. This could lead to quicker sinkhole collapse.

It is also expected in areas with thinner overburden soils on top of the limestone bedrock that the slope of the cone of the water depression is steeper than those with a thicker overburden layer. This behavior also leads to a faster escape of the water and soil sediments through the bedrock crack. Consequently, it may not provide sufficient time for the cavity to propagate to the ground surface. This explains that a sinkhole takes longer time to develop in areas with a very thick overburden compared to areas with a thinner overburden soil in similar geological and hydrological conditions.

Finally, the concept of groundwater drops as an indicator of sinkhole progression and collapse may be used as an indicator to determine the ultimate location of a growing underground cavity that may become a sinkhole. By monitoring the changes in natural groundwater levels in the field from either an existing network of groundwater monitoring wells or additional installations, the methodology discussed in this dissertation may be used for possible foreseeing of the surface collapse of sinkholes. 


\section{APPENDIX: EXPERIMENTAL RESULTS}




\begin{tabular}{|c|c|c|c|c|c|c|c|}
\hline & & & Sieve & nalysis & & & \\
\hline Descripti & of soil & Poorly g & aded fine 5 & AND (A3) & Sample No. & 1 & \\
\hline & & & & Mass of ov & en dry sample, $W$ & 508.56 & $\mathrm{~g}$ \\
\hline Location & Soil Dum & p behind Base & ball field, L & CF, Orlando & & & \\
\hline $\begin{array}{l}\text { Tested } \\
\text { by }\end{array}$ & & & & & Date & $\begin{array}{l}\text { December } \\
20,2011 \\
\end{array}$ & \\
\hline $\begin{array}{l}\text { Sieve } \\
\text { No. }\end{array}$ & $\begin{array}{c}\text { Sieve } \\
\text { opening } \\
(\mathrm{mm})\end{array}$ & $\begin{array}{c}\text { Mass of soil } \\
\text { retained on } \\
\text { each sieve, } \\
\quad W_{n}(g)\end{array}$ & $\begin{array}{c}\text { Percent } \\
\text { of mass } \\
\text { retained } \\
\text { on each } \\
\text { sieve, } R_{n} \\
\end{array}$ & $\begin{array}{c}\text { Cumulative } \\
\text { percent } \\
\text { retained, } \\
\sum \boldsymbol{R}_{n}\end{array}$ & $\begin{array}{l}\text { Percent finer, } \\
100-\sum R_{n}\end{array}$ & & \\
\hline 4 & 4.750 & 6.1 & 1.2 & 1.2 & 98.8 & & \\
\hline 10 & 2.000 & 6.9 & 1.4 & 2.6 & 97.4 & & \\
\hline 20 & 0.850 & 4.5 & 0.9 & 3.4 & 96.6 & & \\
\hline 40 & 0.425 & 23.7 & 4.7 & 8.1 & 91.9 & & \\
\hline 60 & 0.250 & 150.9 & 29.7 & 37.8 & 62.2 & & \\
\hline 140 & 0.106 & 303.7 & 59.7 & 97.5 & 2.5 & & \\
\hline 200 & 0.075 & 8.3 & 1.6 & 99.1 & 0.9 & & \\
\hline Pan & -- & 3.1 & 0.6 & & & & \\
\hline & & $W_{1}=\sum$ & 507.2 & $\mathrm{~g}$ & & & \\
\hline Mass lo & $\begin{array}{r}\text { during sic } \\
W] \\
\end{array}$ & $\begin{array}{l}\text { ve analysis }=[ \\
\times 100=\end{array}$ & $\left.V-W_{1}\right) \div$ & 0.27 & $\begin{array}{c}\% \text { (OK if less } \\
\text { than } 2 \%)\end{array}$ & & \\
\hline
\end{tabular}




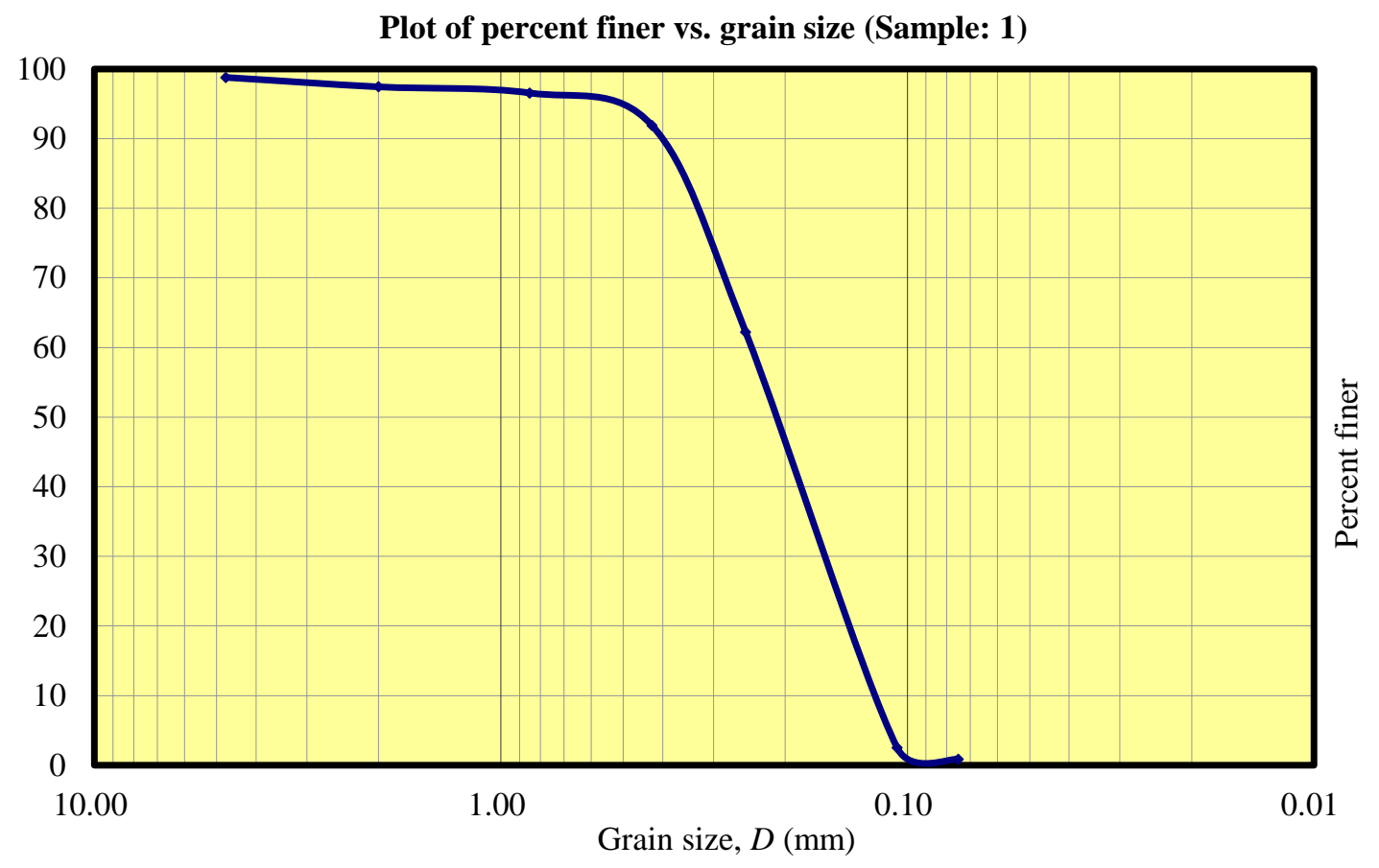

\begin{tabular}{|c|c|c|c|c|c|}
\hline D60 = & 0.24 & \multirow{3}{*}{\multicolumn{2}{|c|}{$\begin{array}{c}\text { (Determined from graph, } \\
\text { corresponding to percents } \\
\text { finer of } 60 \%, 30 \% \text {, and } \\
10 \%)\end{array}$}} & & \\
\hline $\mathrm{D} 30=$ & 0.16 & & & & \\
\hline $\mathrm{D} 10=$ & 0.13 & & & & \\
\hline \multicolumn{4}{|c|}{ Uniformity coefficient, $C_{u}=\left(D_{60} / D_{10}\right)=$} & 1.85 & \\
\hline \multicolumn{4}{|c|}{ Coefficient of gradation, $C_{c}=\left[D^{2}{ }_{30} \div\left(D_{60} \times D_{10}\right)\right]=$} & 0.82 & \\
\hline \multicolumn{3}{|c|}{$\begin{array}{l}\text { Effective size of soil sample, } \\
D_{10}=\end{array}$} & 0.13 & $\mathrm{~mm}$ & \\
\hline \multicolumn{3}{|c|}{$\begin{array}{l}\text { AASHTO Classification } \\
\text { System:- }\end{array}$} & \multicolumn{2}{|l|}{ A3 (Fine sand) } & \\
\hline \multicolumn{3}{|c|}{ Unified Classification System:- } & \multicolumn{2}{|c|}{ SP (Poorly graded sand) } & \\
\hline
\end{tabular}




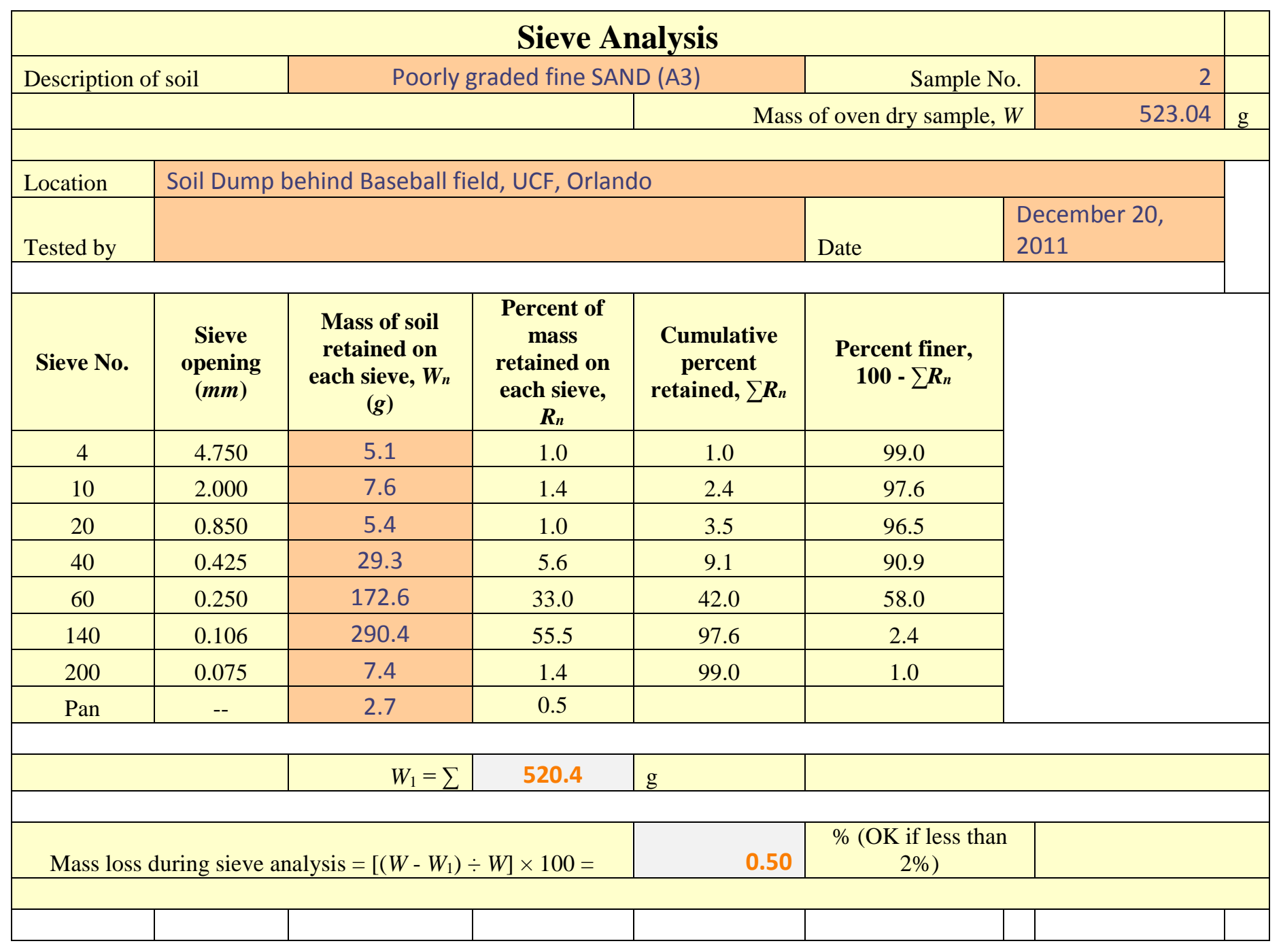


Plot of percent finer vs. grain size (Sample: 2)

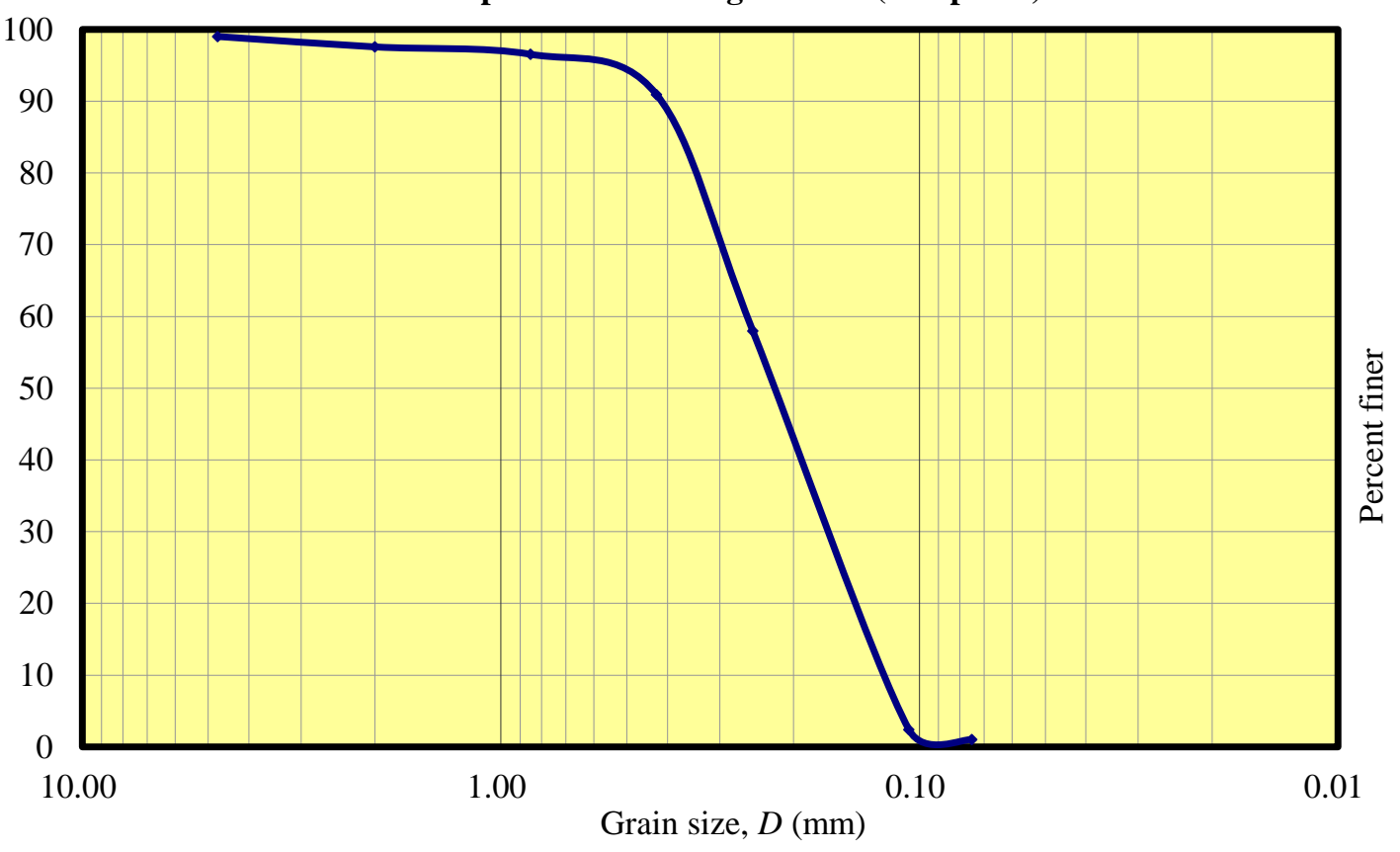

\begin{tabular}{|c|c|c|c|c|c|}
\hline$D_{60}=$ & 0.26 & \multirow{3}{*}{\multicolumn{2}{|c|}{$\begin{array}{l}\text { (Determined from graph, } \\
\text { corresponding to percents } \\
\text { finer of } 60 \%, 30 \% \text {, and } 10 \%)\end{array}$}} & & \\
\hline$D_{30}=$ & 0.17 & & & & \\
\hline$D_{10}=$ & 0.14 & & & & \\
\hline \multicolumn{4}{|c|}{ Uniformity coefficient, $C_{u}=\left(D_{60} / D_{10}\right)=$} & 1.86 & \\
\hline \multicolumn{4}{|c|}{ Coefficient of gradation, $C_{c}=\left[D^{2}{ }_{30} \div\left(D_{60} \times D_{10}\right)\right]=$} & 0.79 & \\
\hline \multicolumn{3}{|c|}{$\begin{array}{l}\text { Effective size of soil sample, } \\
D_{10}=\end{array}$} & 0.14 & $m m$ & \\
\hline \multicolumn{3}{|c|}{$\begin{array}{l}\text { AASHTO Classification } \\
\text { System:- }\end{array}$} & \multicolumn{2}{|l|}{ A3 (Fine sand) } & \\
\hline \multicolumn{3}{|c|}{ Unified Classification System:- } & \multicolumn{2}{|c|}{ SP (Poorly graded sand) } & \\
\hline
\end{tabular}




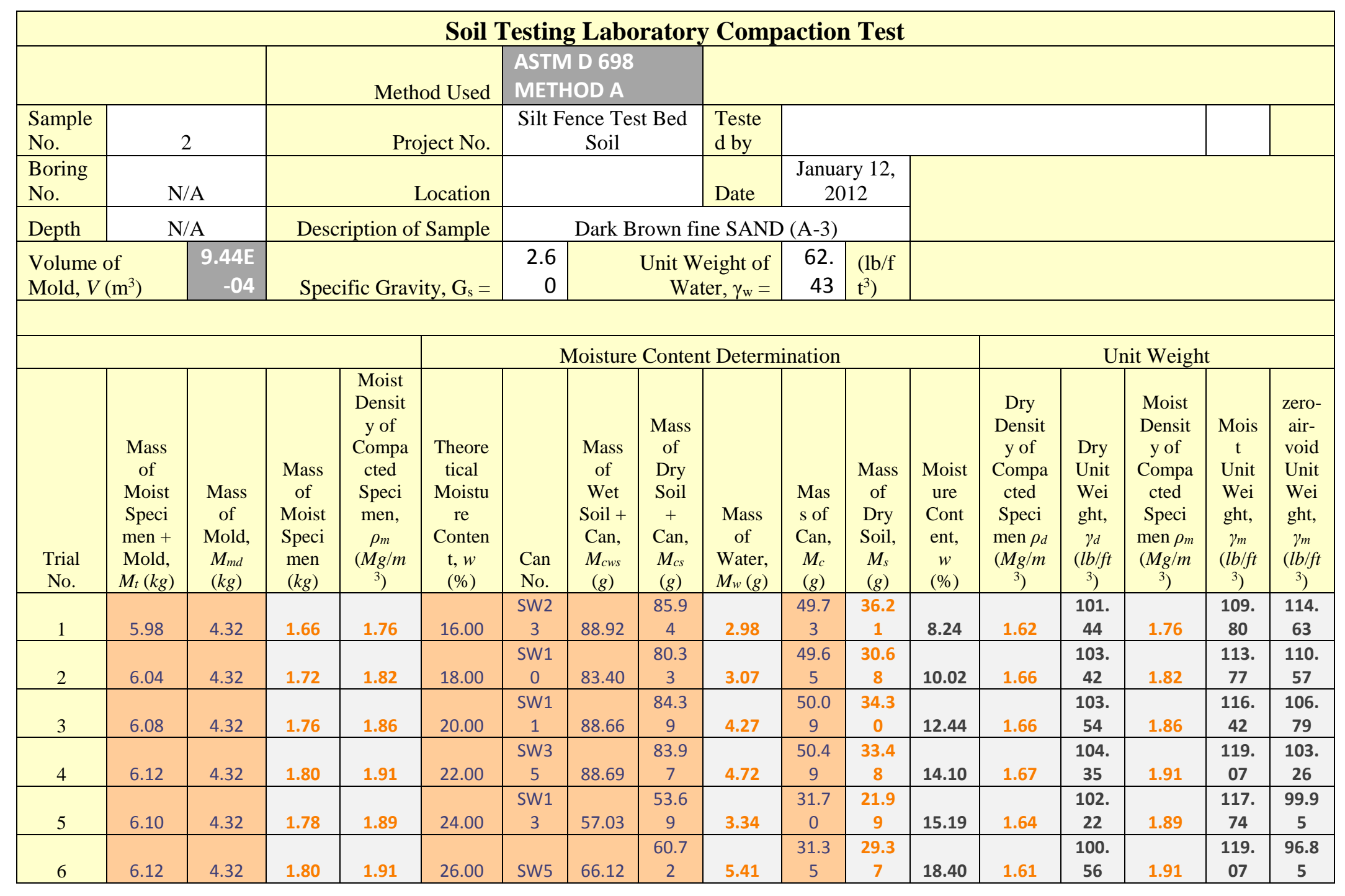




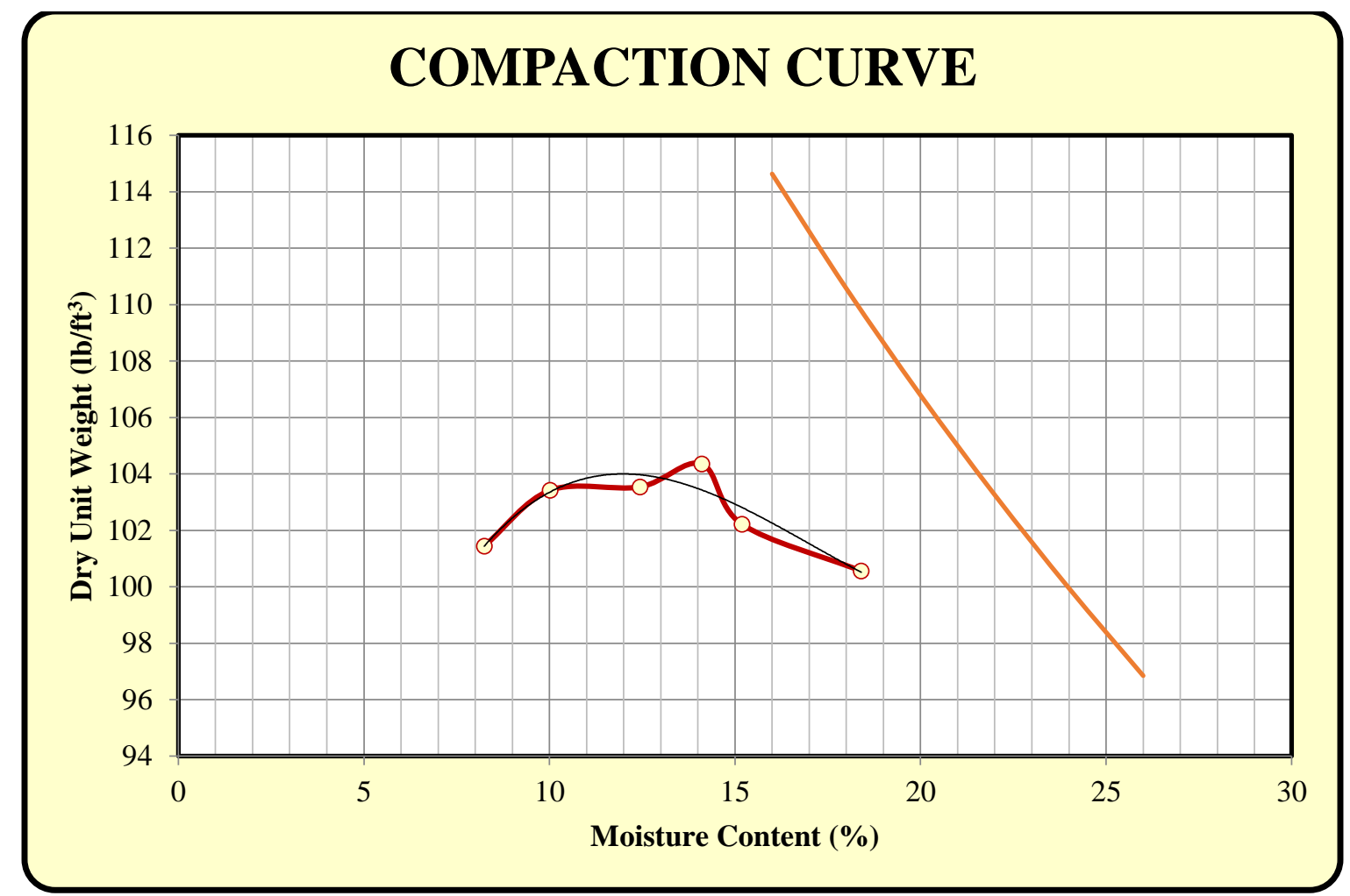




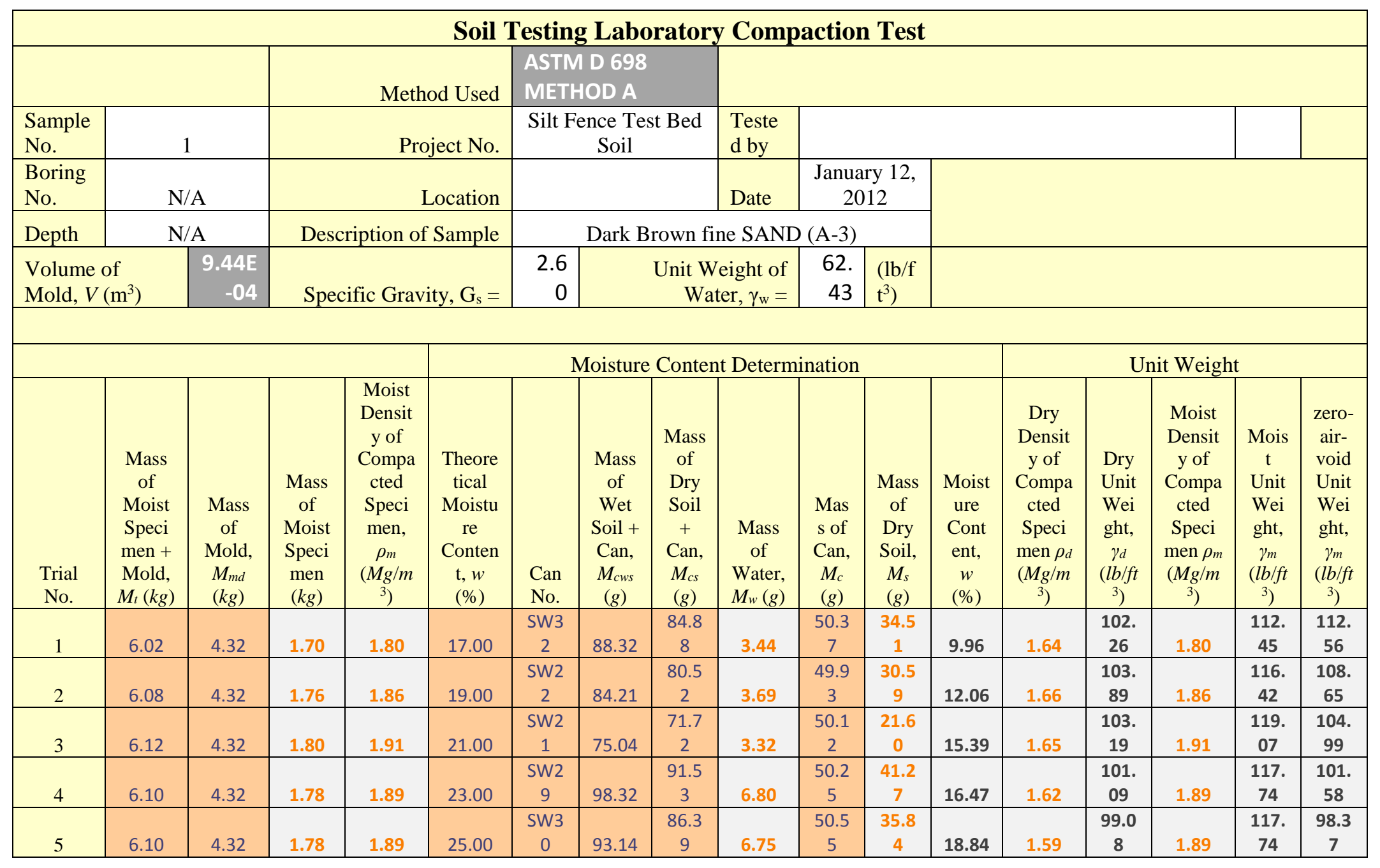




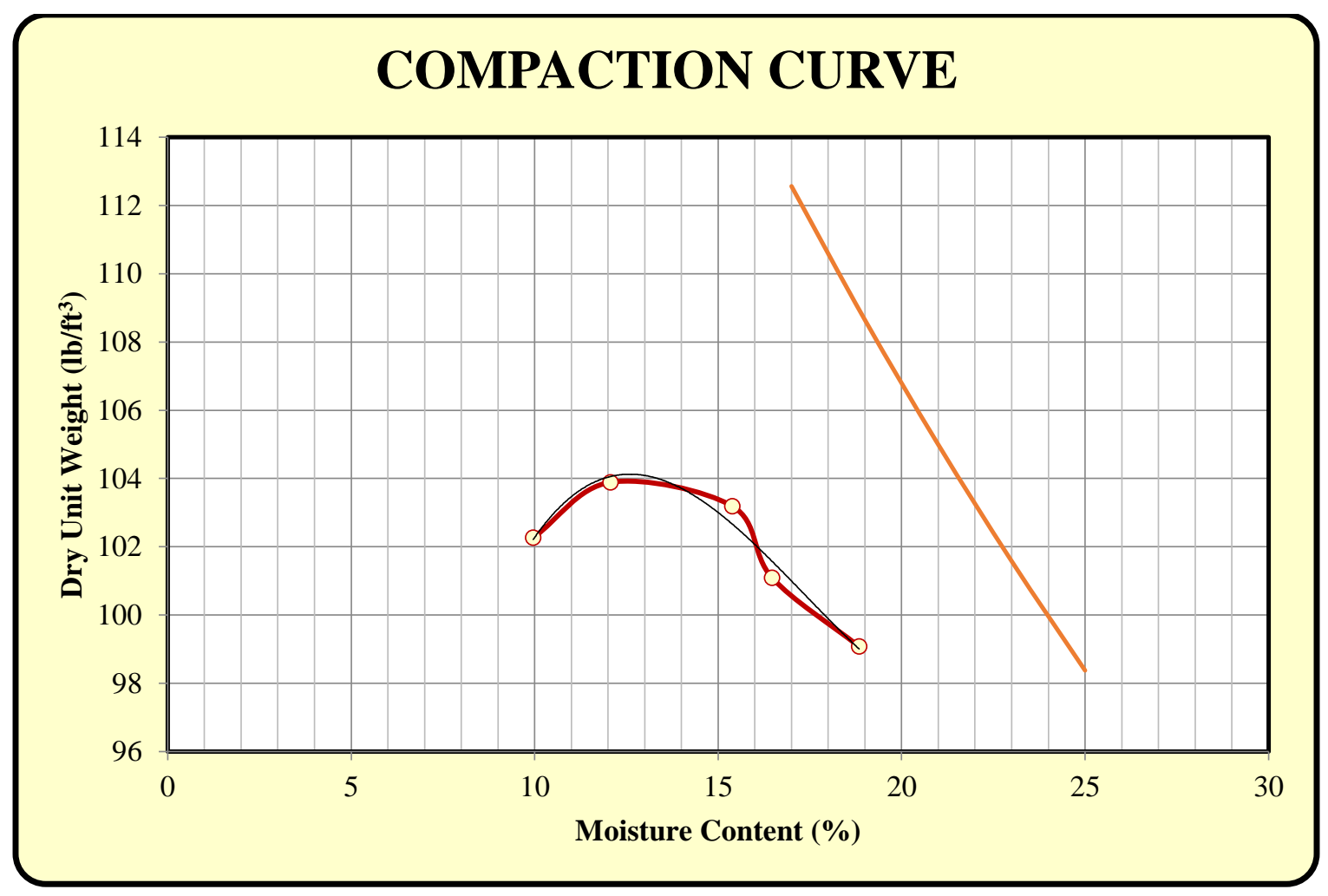




\begin{tabular}{|c|c|c|c|c|}
\hline \multicolumn{5}{|c|}{ Specific Gravity of Soil Solids } \\
\hline Description of soil: & \multicolumn{2}{|c|}{ Brown fine sand } & \multicolumn{2}{|l|}{ Sample No. } \\
\hline Volume of flask at $20^{\circ} \mathrm{C}$ : & 23 & ${ }^{\circ} \mathrm{C}$ & $A$ & 0.9993 \\
\hline Location: & \multicolumn{4}{|c|}{ Test bed for Silt Fence } \\
\hline Tested by: & & & Date: & $12 / 20 / 2011$ \\
\hline \multirow{2}{*}{\multicolumn{2}{|c|}{ Item }} & \multicolumn{3}{|c|}{ Test No. } \\
\hline & & 1 & 2 & 3 \\
\hline \multicolumn{5}{|l|}{ Volumetric flask No. } \\
\hline \multicolumn{2}{|l|}{$\begin{array}{l}\text { Mass of flask + water filled to mark, } \mathrm{W}_{1} \\
(\mathrm{~g})\end{array}$} & 664.27 & 680.32 & 664.40 \\
\hline \multicolumn{2}{|l|}{$\begin{array}{l}\text { Mass of flask + soil + water filled to } \\
\text { mark, } \mathrm{W}_{2}(\mathrm{~g})\end{array}$} & 726.10 & 741.93 & 725.86 \\
\hline \multicolumn{2}{|l|}{ Mass of dry soil, $\mathrm{W}_{\mathrm{s}}(\mathrm{g})$} & 100.01 & 100.00 & 100.01 \\
\hline \multicolumn{2}{|l|}{$\begin{array}{l}\text { Mass of equal volume of water as the } \\
\text { soil solids, } W_{W}(g)=\left(W_{1}+W_{S}\right)-W_{2}\end{array}$} & 38.18 & 38.39 & 38.55 \\
\hline \multicolumn{2}{|l|}{$\mathrm{G}_{\mathrm{S}\left(\mathrm{T} 1^{\circ} \mathrm{C}\right)}=\mathrm{W}_{\mathrm{S}} / \mathrm{W}_{\mathrm{W}}$} & 2.62 & 2.60 & 2.59 \\
\hline \multicolumn{2}{|l|}{$\mathrm{G}_{\mathrm{S}\left(20^{\circ} \mathrm{C}\right)}=\mathrm{G}_{\mathrm{S}\left(\mathrm{T} 1^{\circ} \mathrm{C}\right)} \times \mathrm{A}$} & 2.62 & 2.60 & 2.59 \\
\hline \multicolumn{2}{|l|}{ Average Gs } & \multicolumn{3}{|c|}{2.60} \\
\hline
\end{tabular}


Soil Thickness, $\mathrm{h}=150 \mathrm{~mm} \quad$ Initial Groundwater Table $=10 \%$ of $\mathrm{h}$

\section{RUN No.1}

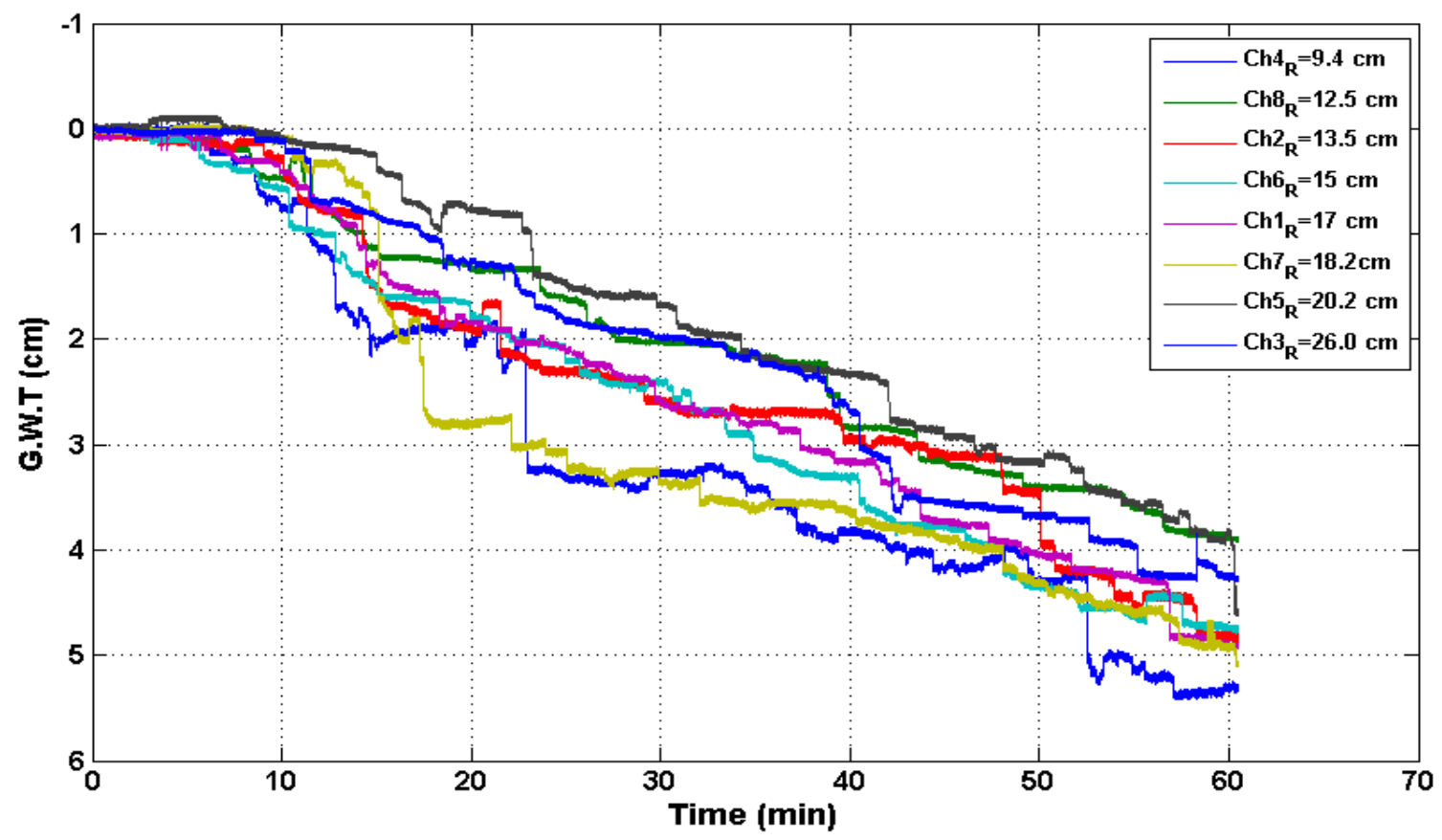


Soil Thickness, $\mathrm{h}=150 \mathrm{~mm} \quad$ Initial Groundwater Table $=10 \%$ of $\mathrm{h}$

RUN No.2

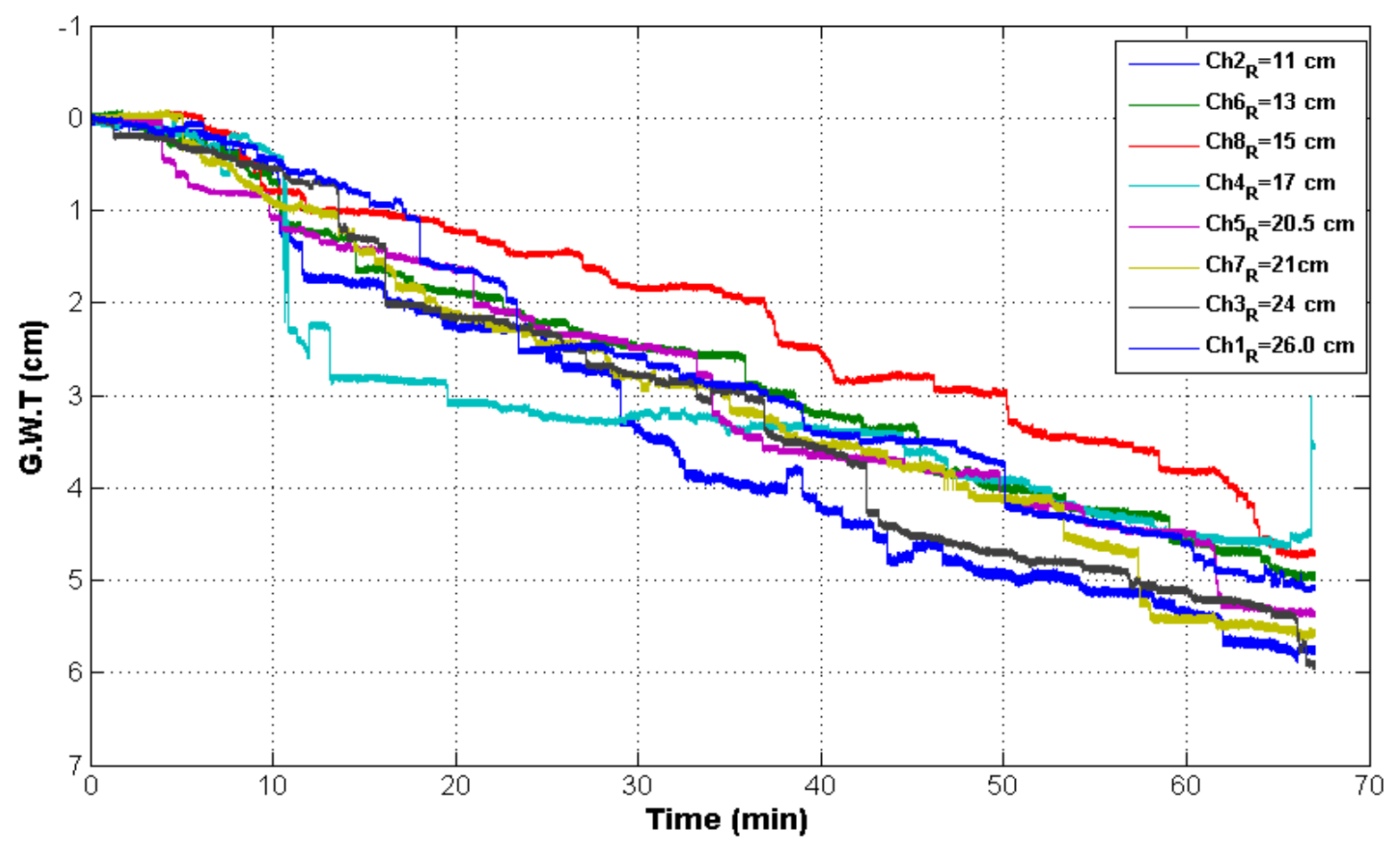


Soil Thickness, $\mathrm{h}=150 \mathrm{~mm} \quad$ Initial Groundwater Table $=10 \%$ of $\mathrm{h}$ RUN No.3

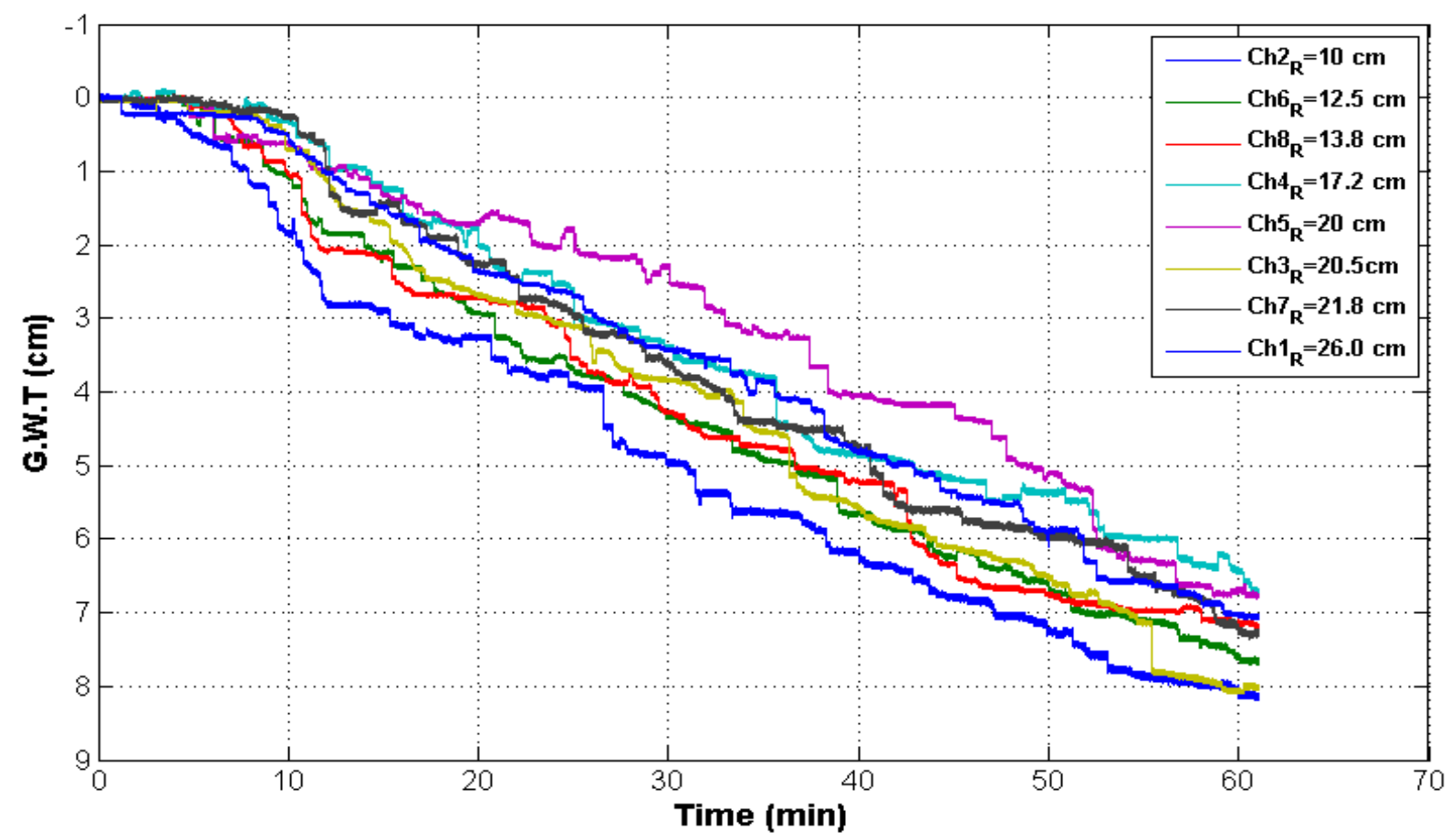


Soil Thickness, $\mathrm{h}=150 \mathrm{~mm} \quad$ Initial Groundwater Table $=15 \%$ of $\mathrm{h}$ RUN No.1

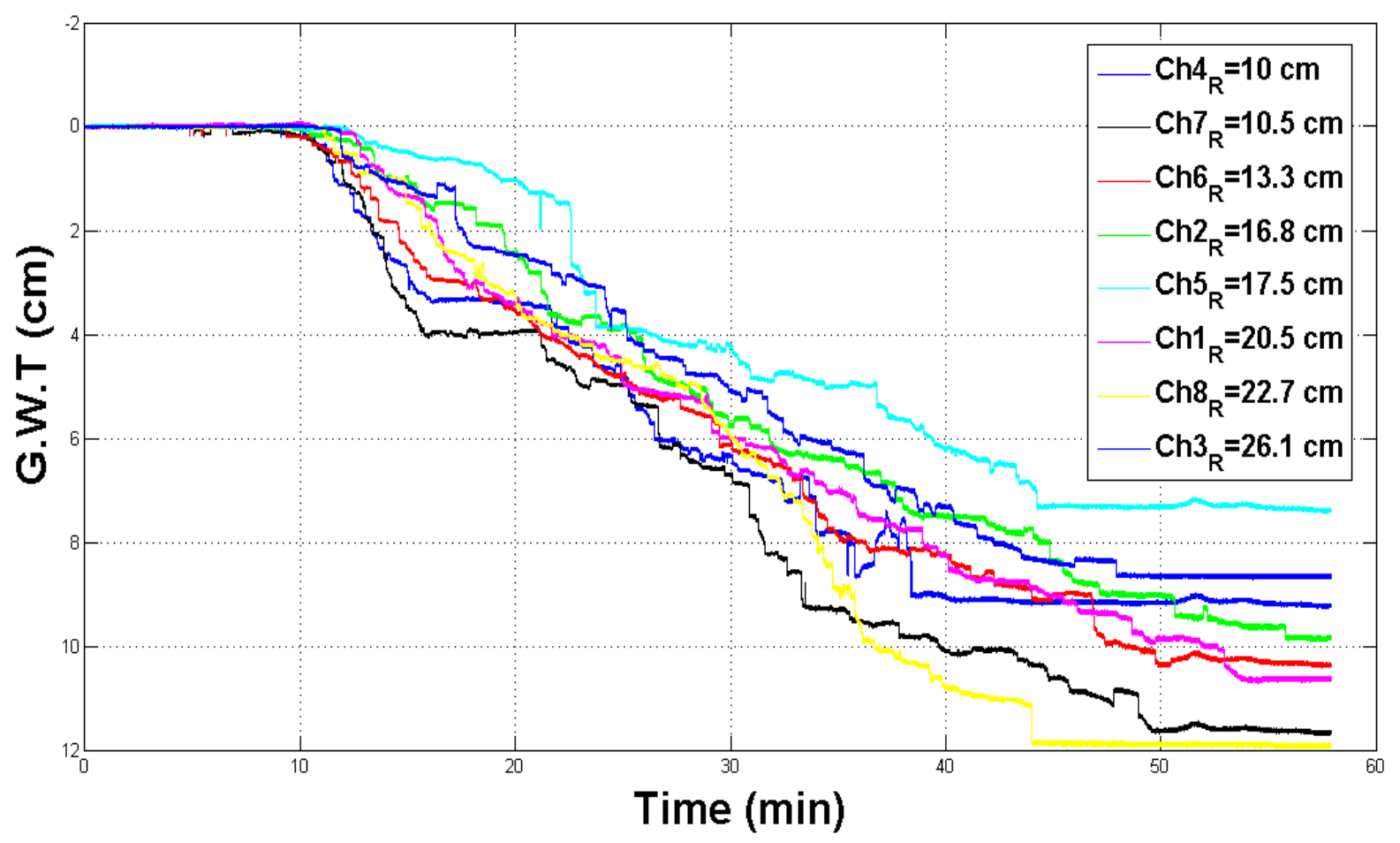


Soil Thickness, $\mathrm{h}=150 \mathrm{~mm} \quad$ Initial Groundwater Table $=15 \%$ of $\mathrm{h}$ RUN No.2

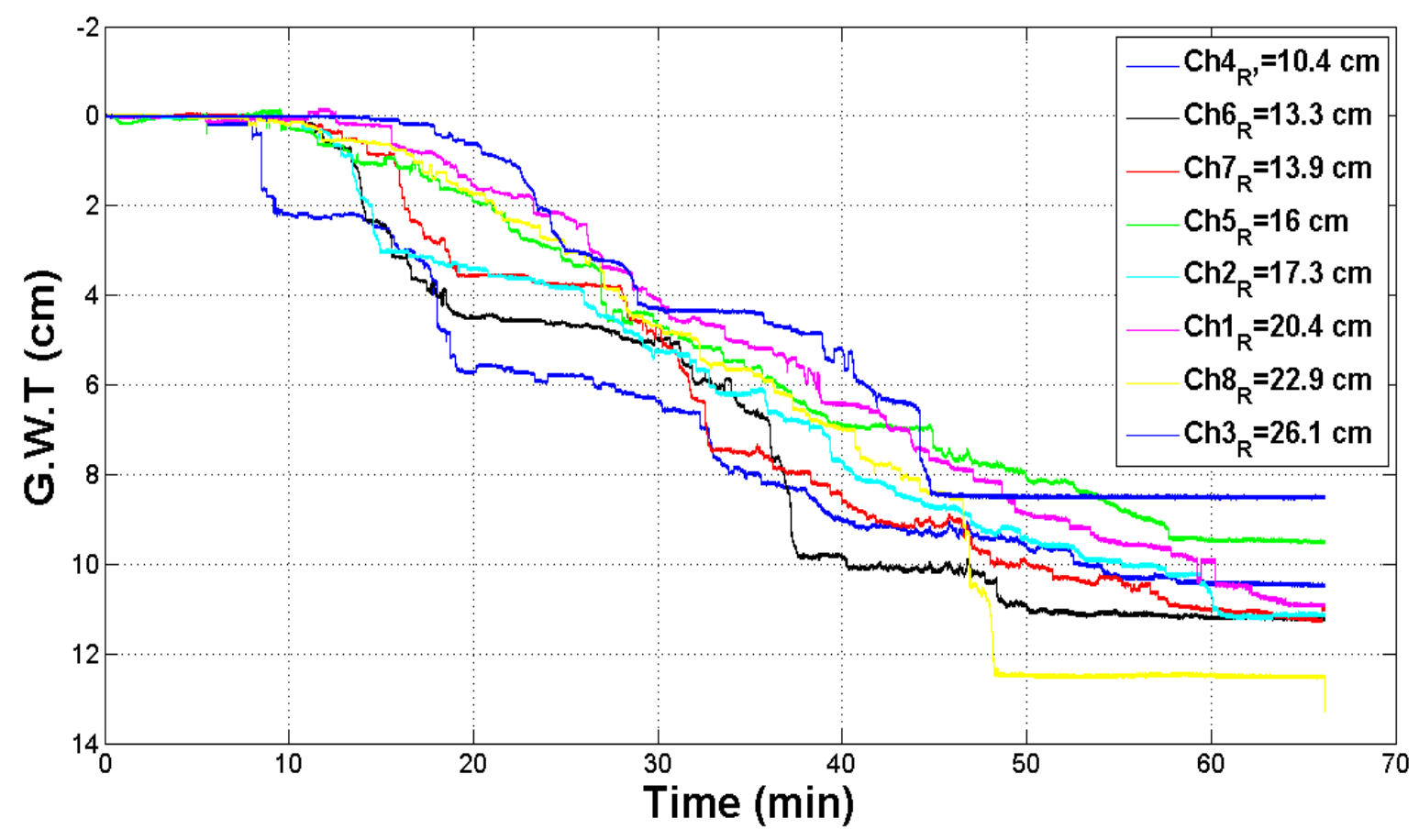


Soil Thickness, $\mathrm{h}=150 \mathrm{~mm} \quad$ Initial Groundwater Table $=15 \%$ of $\mathrm{h}$ RUN No.3

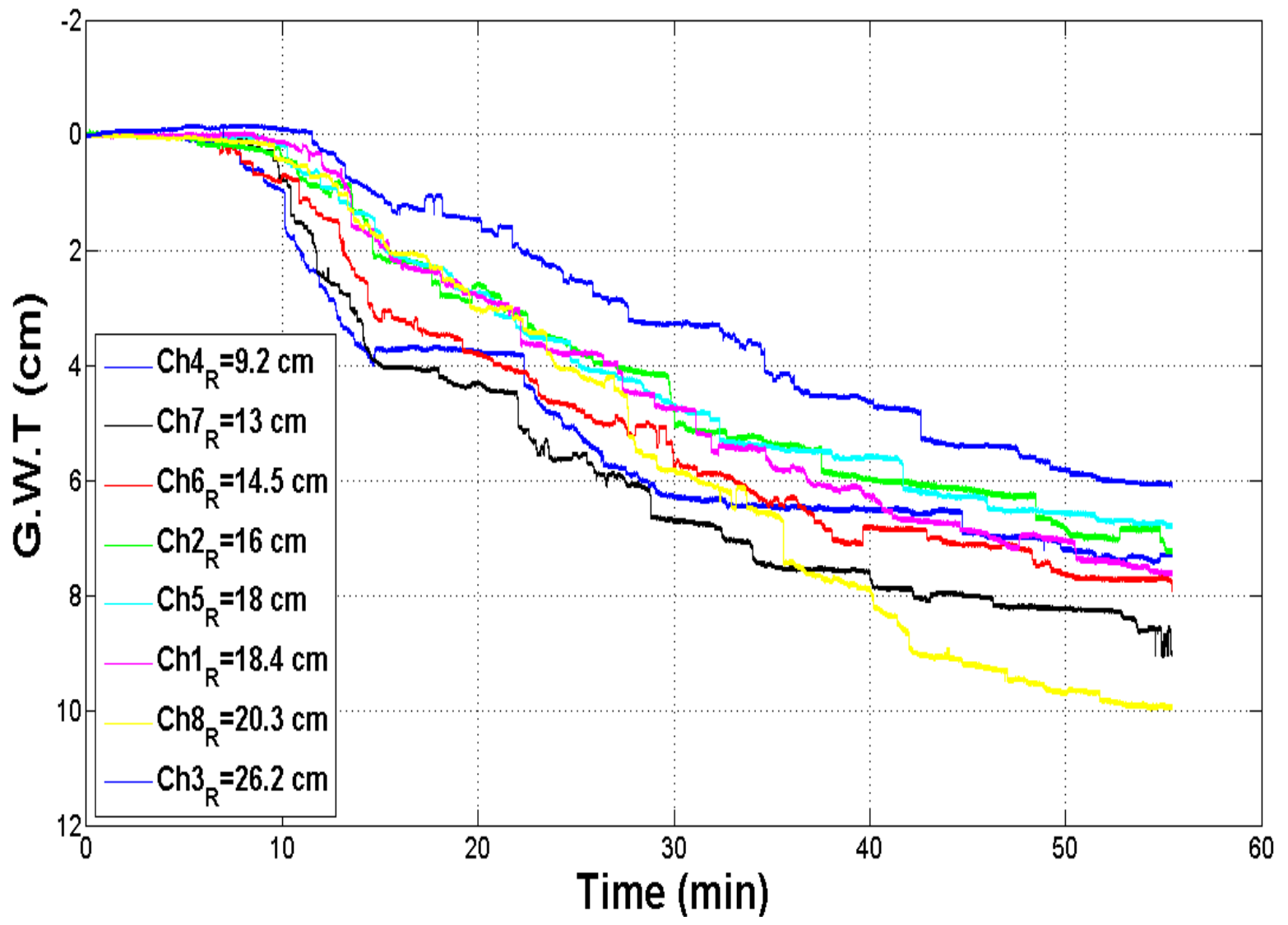


Soil Thickness, $\mathrm{h}=150 \mathrm{~mm} \quad$ Initial Groundwater Table $=30 \%$ of $\mathrm{h}$ RUN No.1

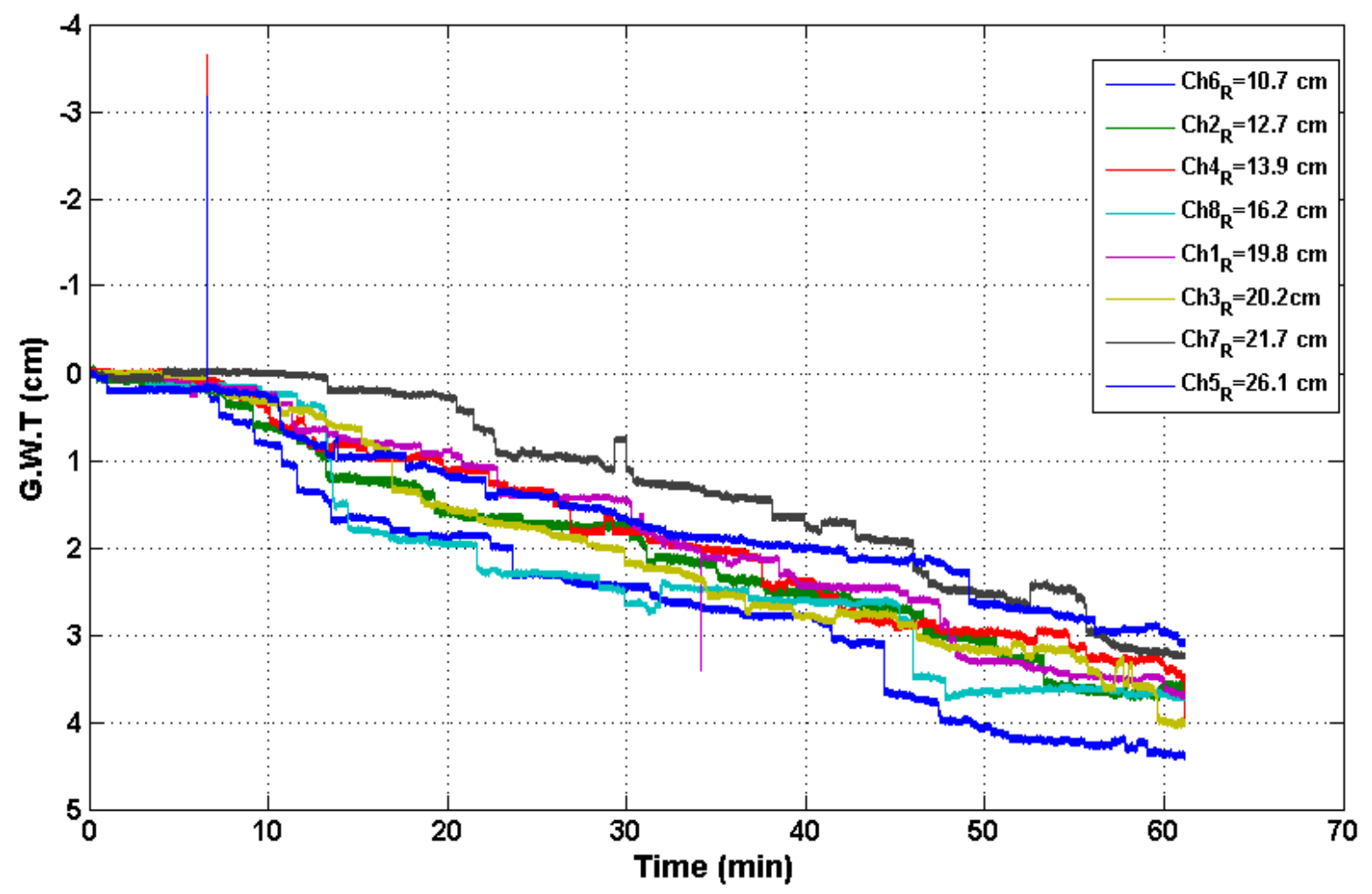


Soil Thickness, $\mathrm{h}=150 \mathrm{~mm} \quad$ Initial Groundwater Table $=30 \%$ of $\mathrm{h}$

RUN No.2

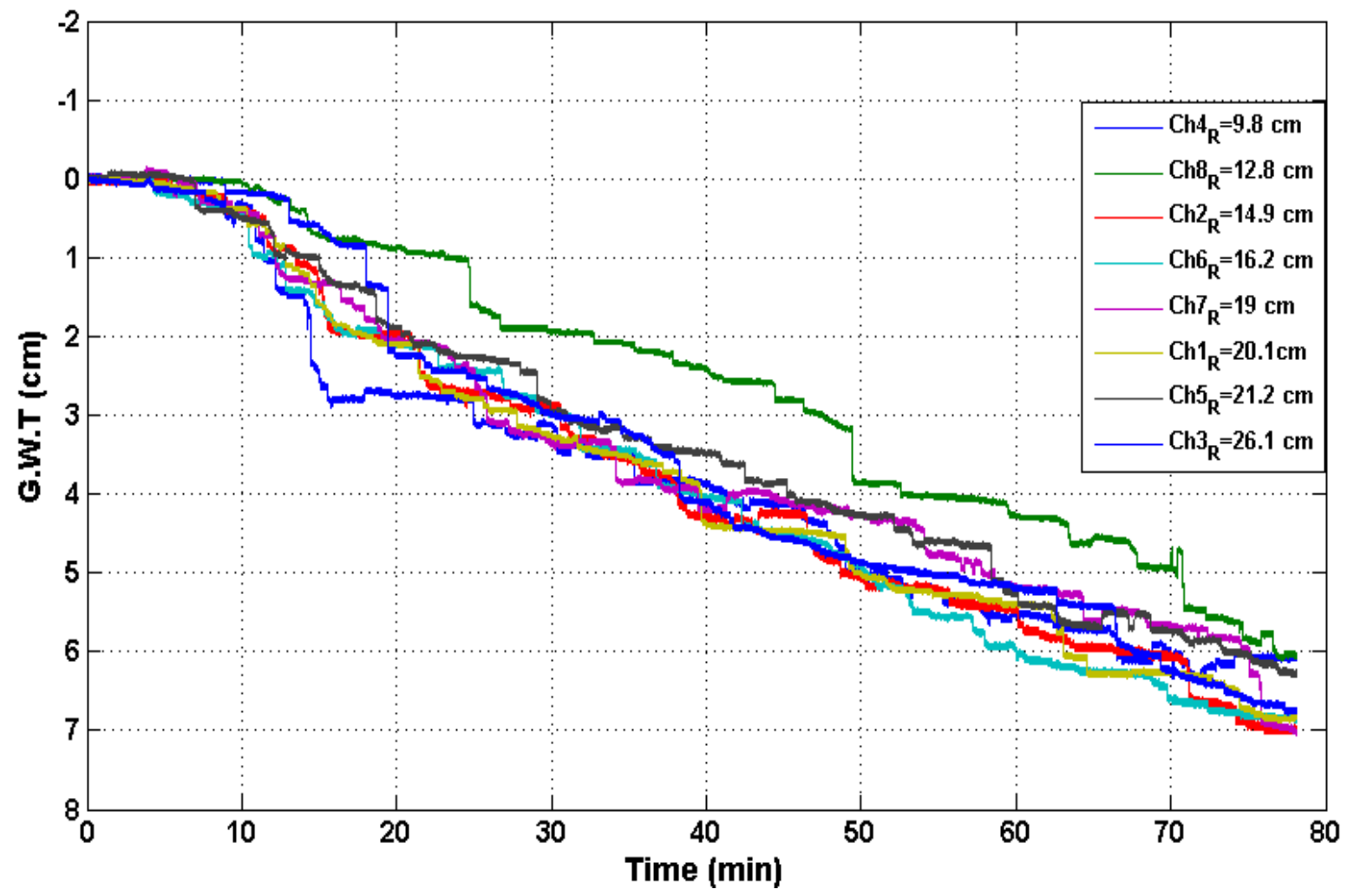


Soil Thickness, $\mathrm{h}=150 \mathrm{~mm} \quad$ Initial Groundwater Table $=30 \% \mathrm{of} \mathrm{h}$

\section{RUN No.2}

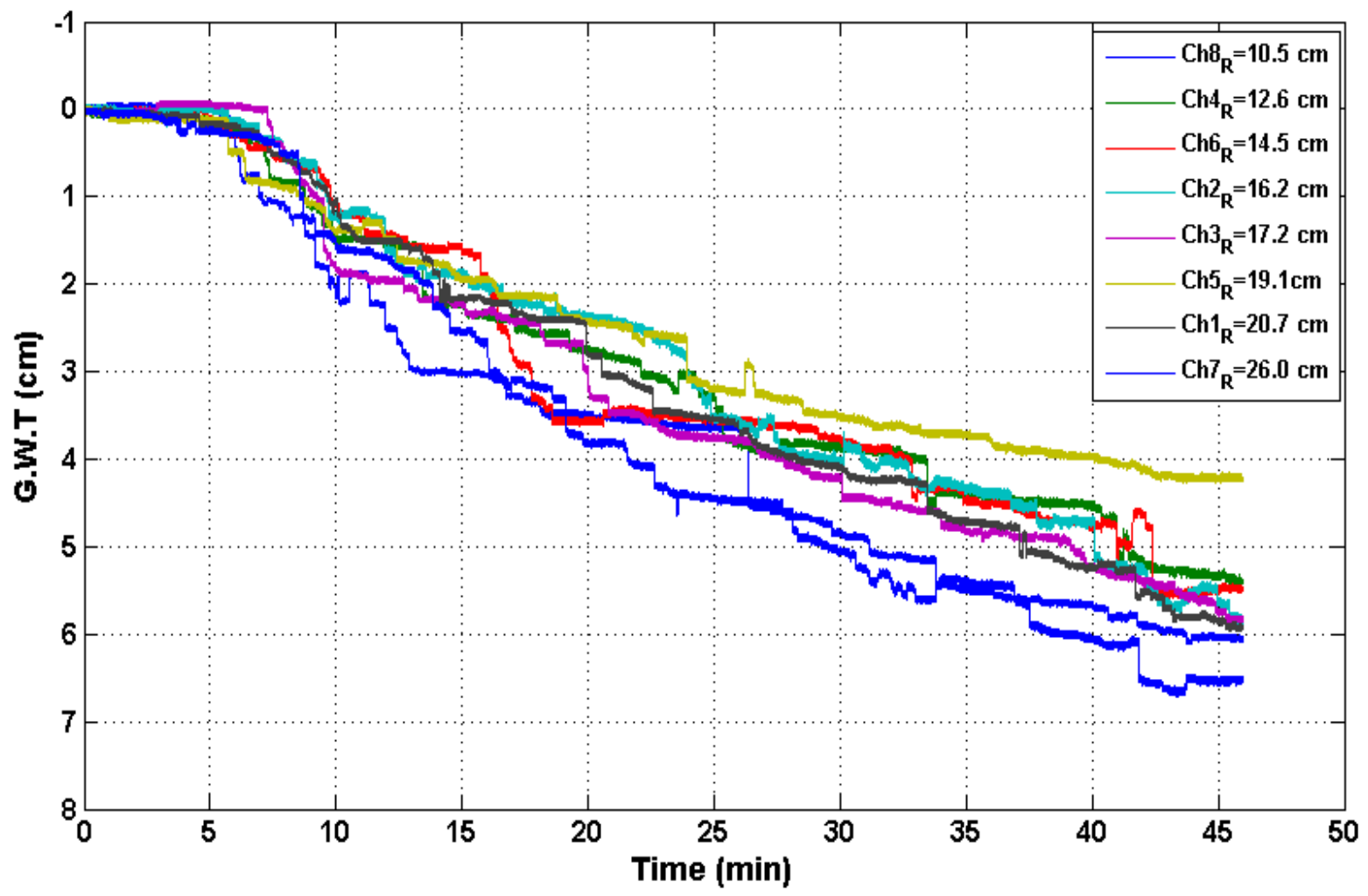


Peak counts for $\mathrm{h}=150 \mathrm{~mm}$ Samples
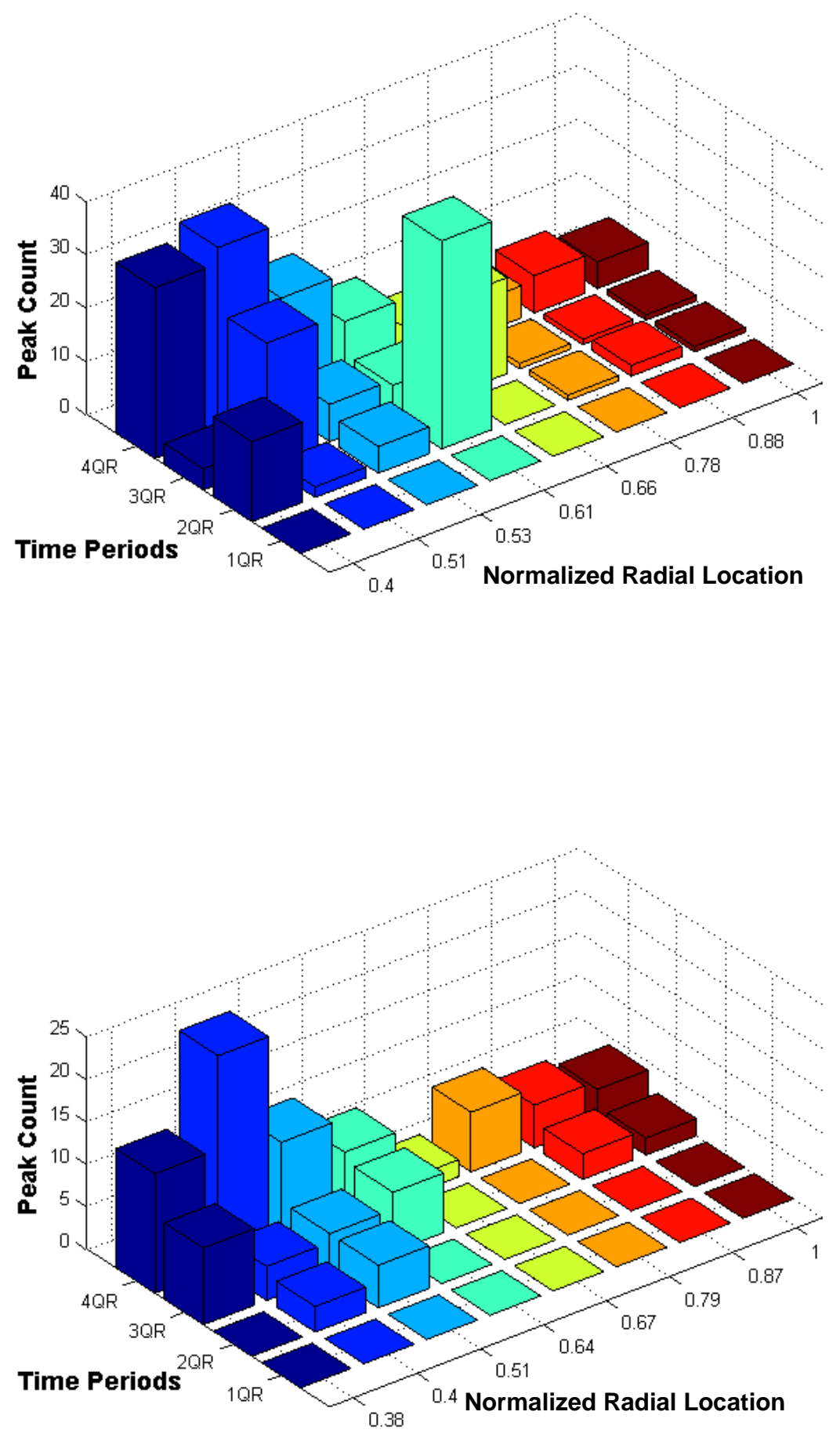
Peak counts for $\mathrm{h}=150 \mathrm{~mm}$ Samples
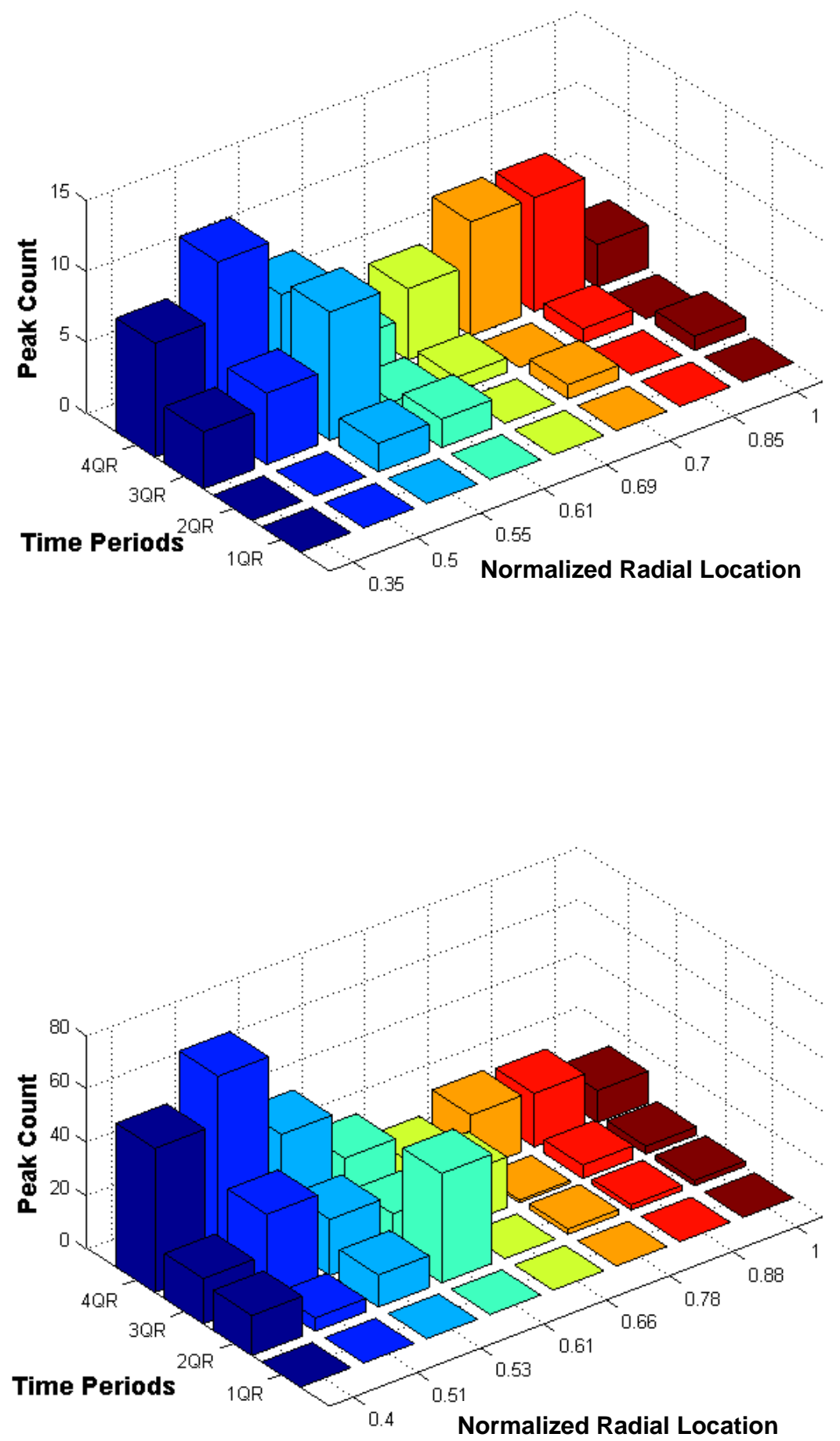
Peak counts for $\mathrm{h}=150 \mathrm{~mm}$ Samples
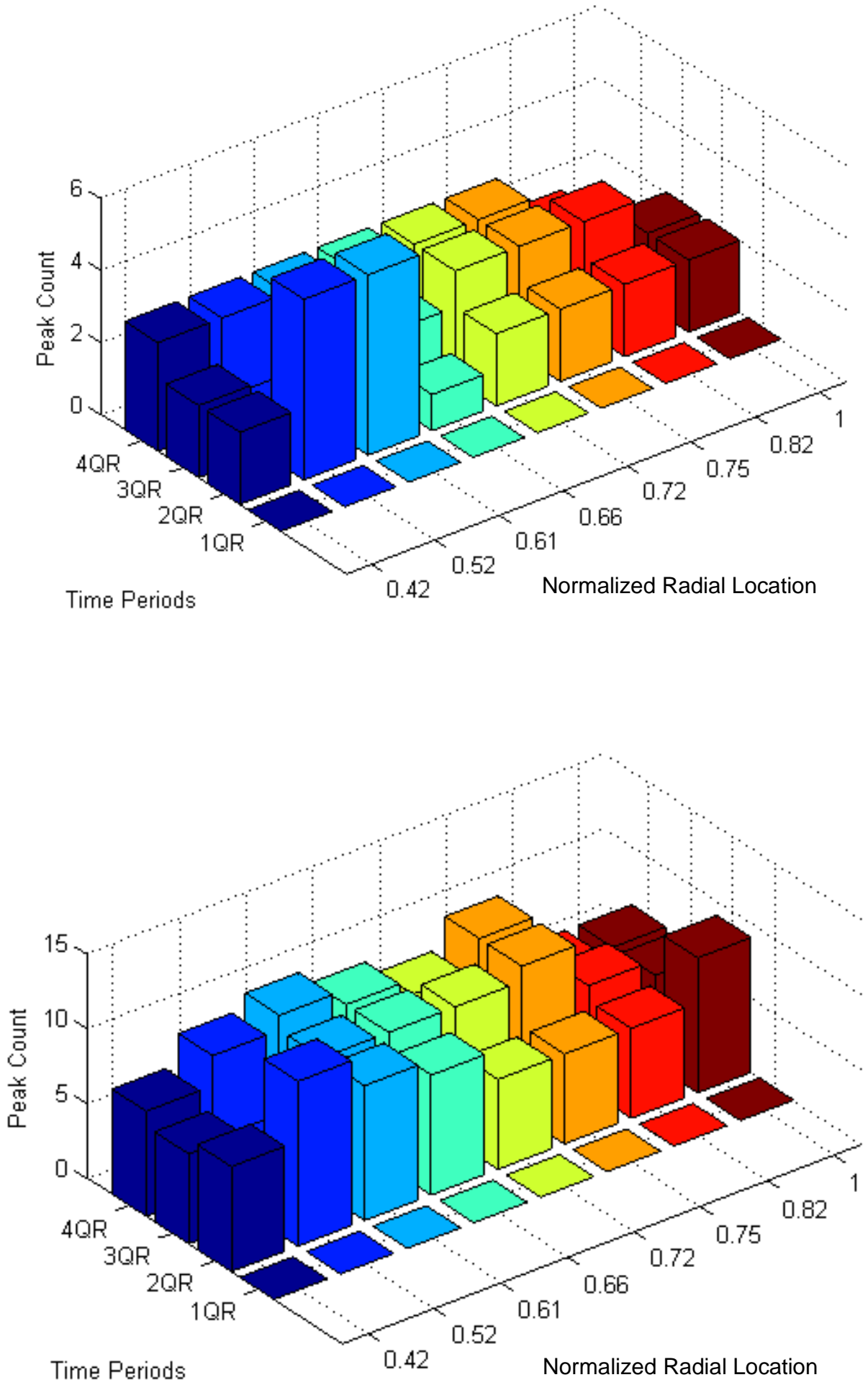
Peak counts for $\mathrm{h}=150 \mathrm{~mm}$ Samples
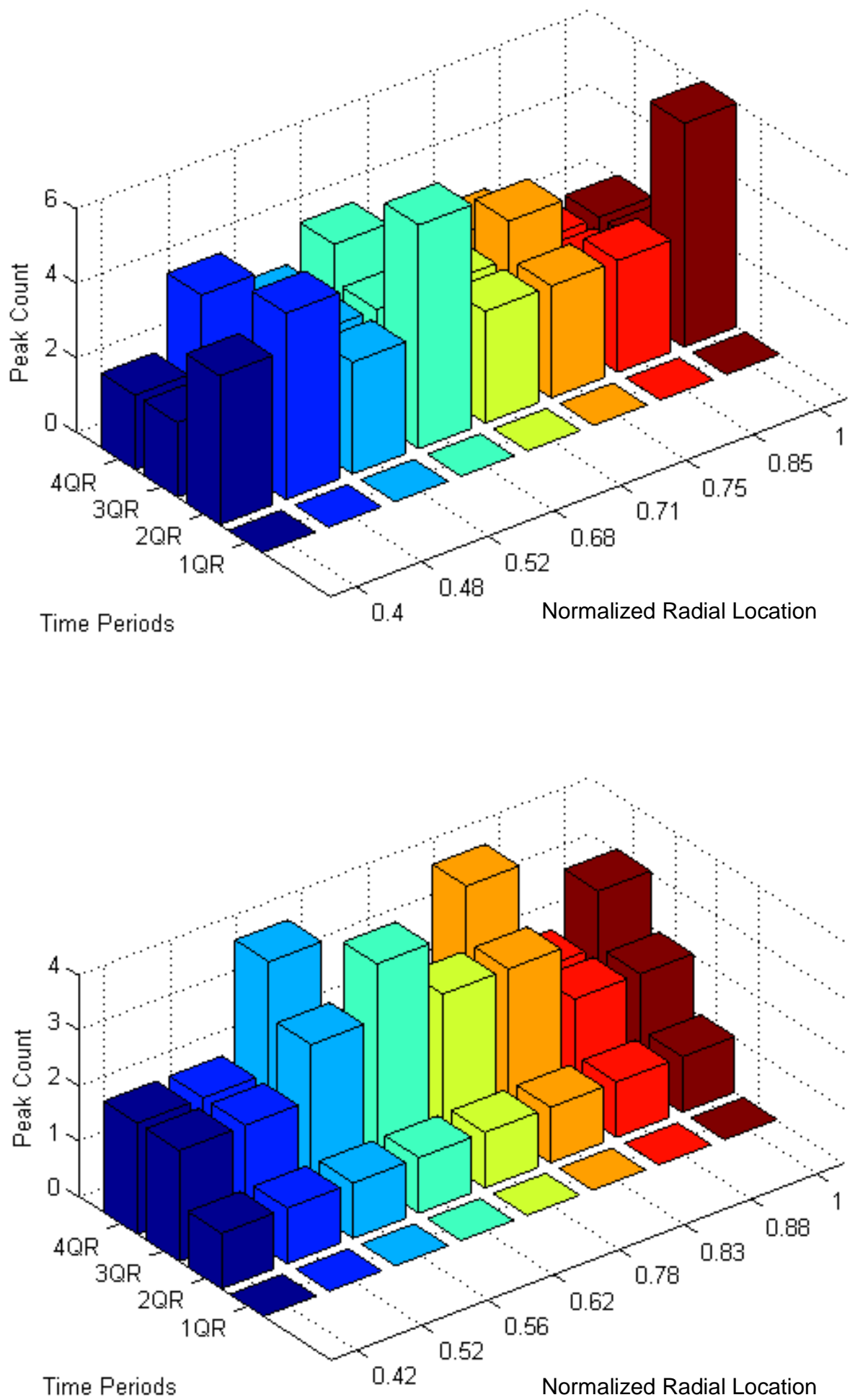
Peak counts for $\mathrm{h}=150 \mathrm{~mm}$ Samples
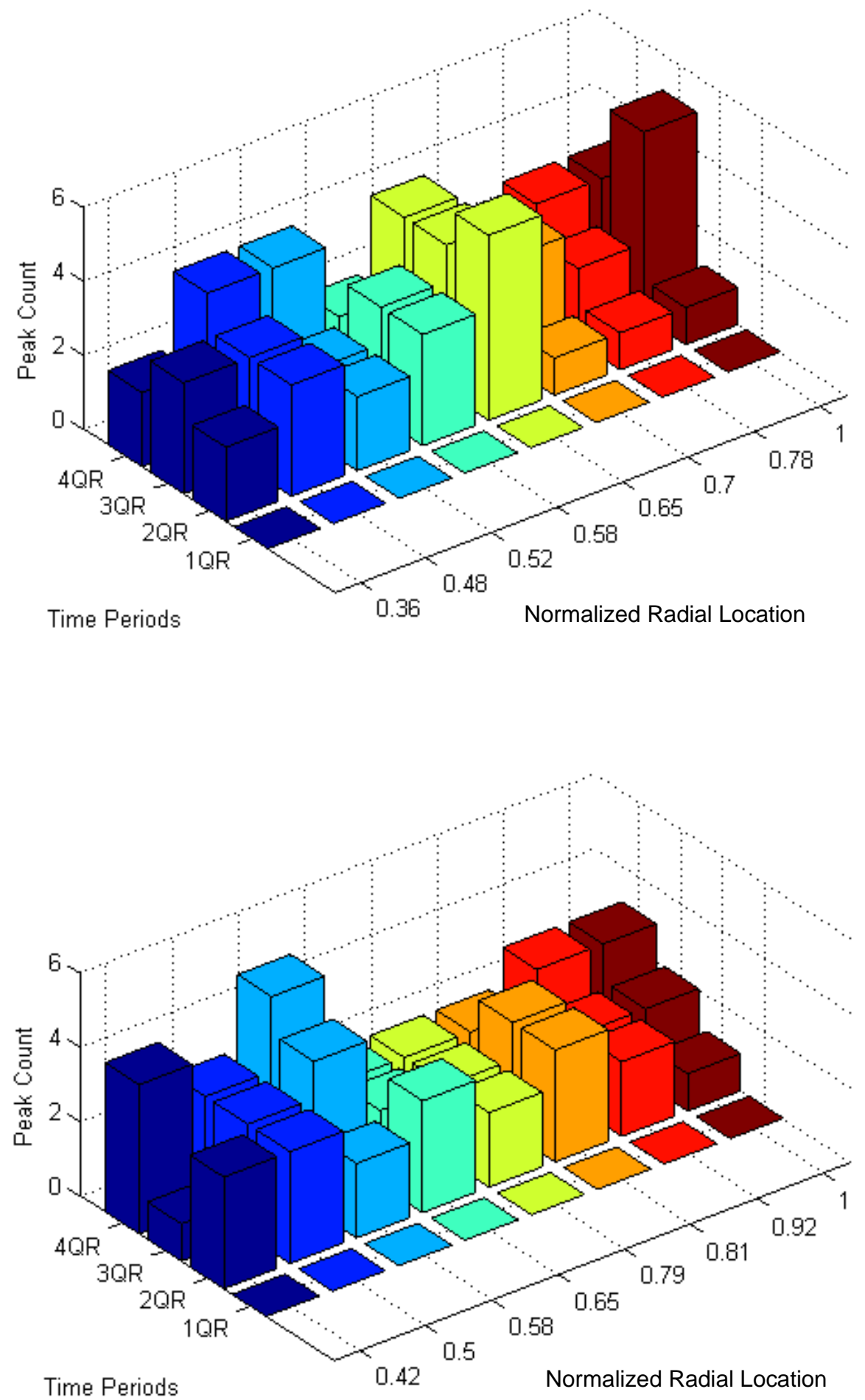
Peak counts for $\mathrm{h}=150 \mathrm{~mm}$ Samples

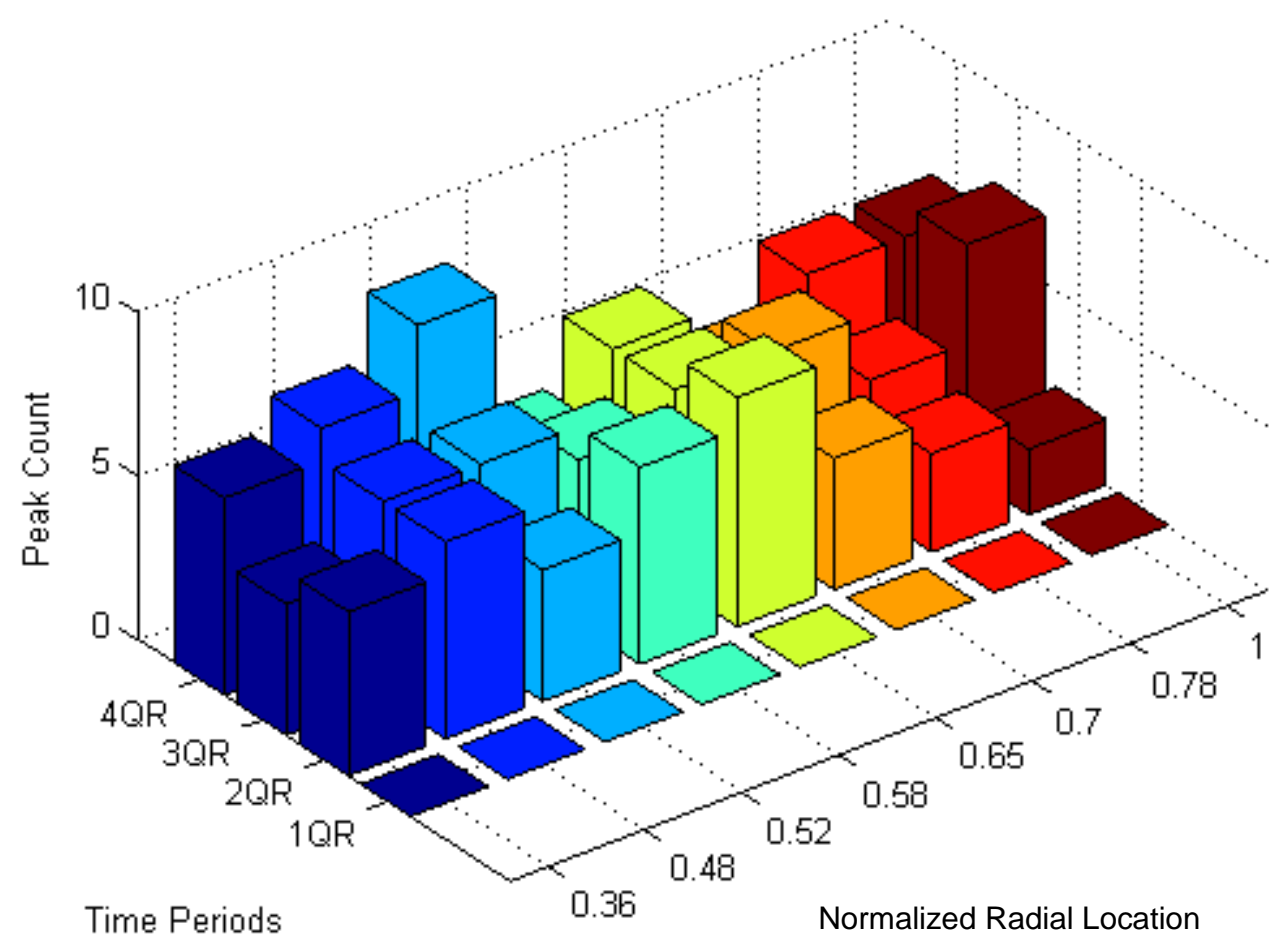




\section{$\mathrm{h}=150 \mathrm{~mm}$ and $\mathrm{GWT}=22.5 \mathrm{~mm}$}
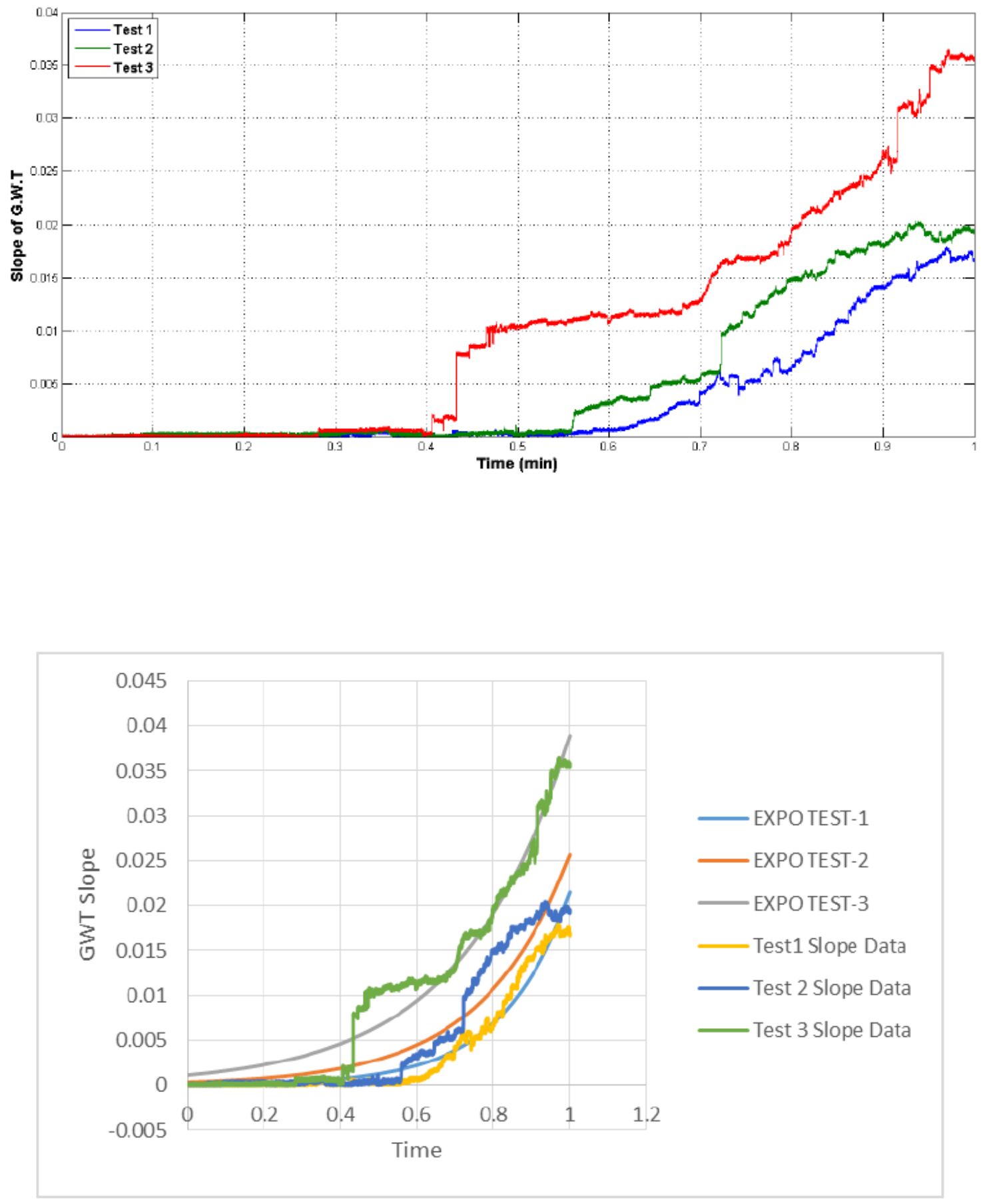
$\mathrm{h}=150 \mathrm{~mm}$ and $\mathrm{GWT}=22.5 \mathrm{~mm}$
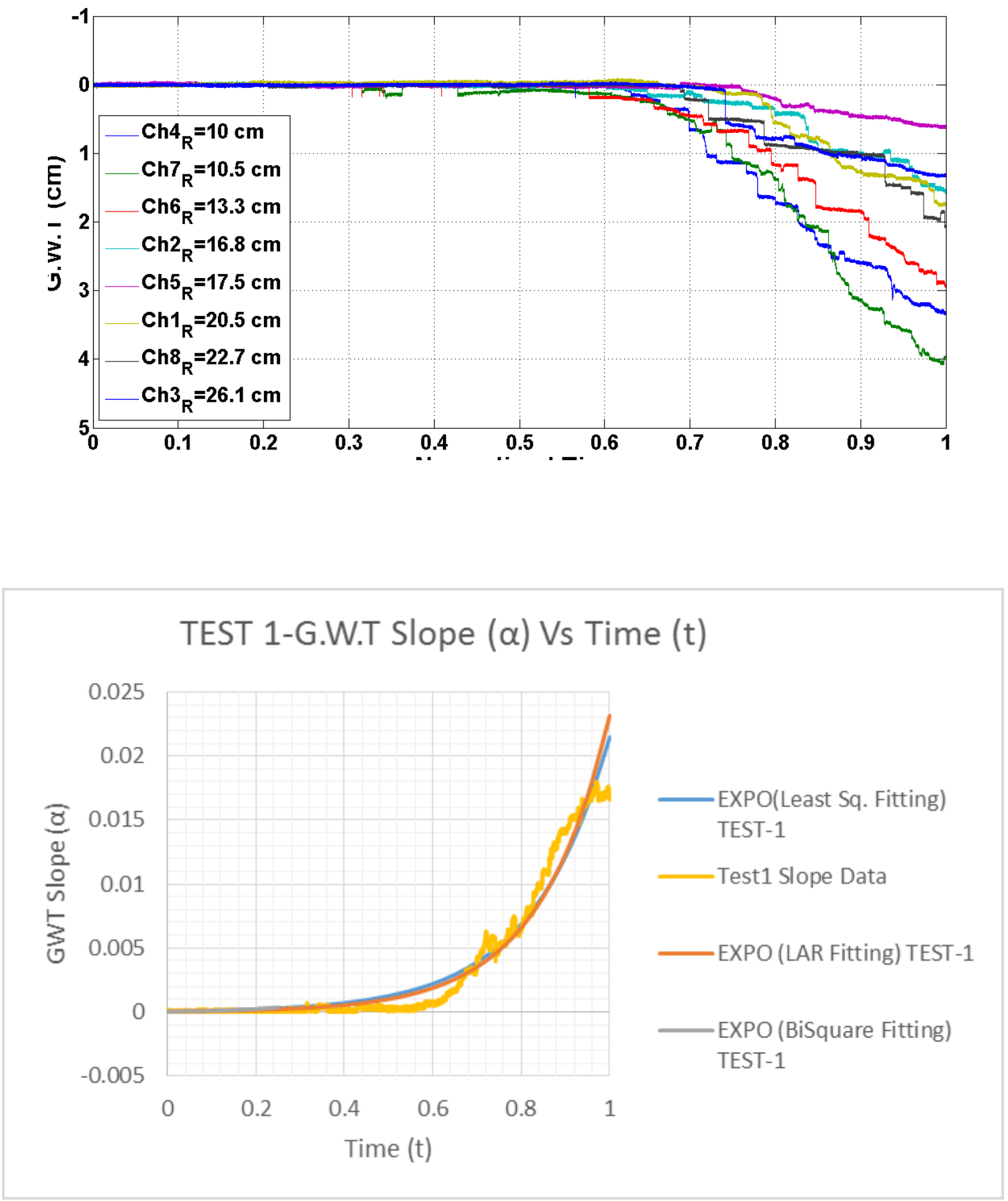


\section{$\mathrm{h}=150 \mathrm{~mm}$ and $\mathrm{GWT}=22.5 \mathrm{~mm}$}
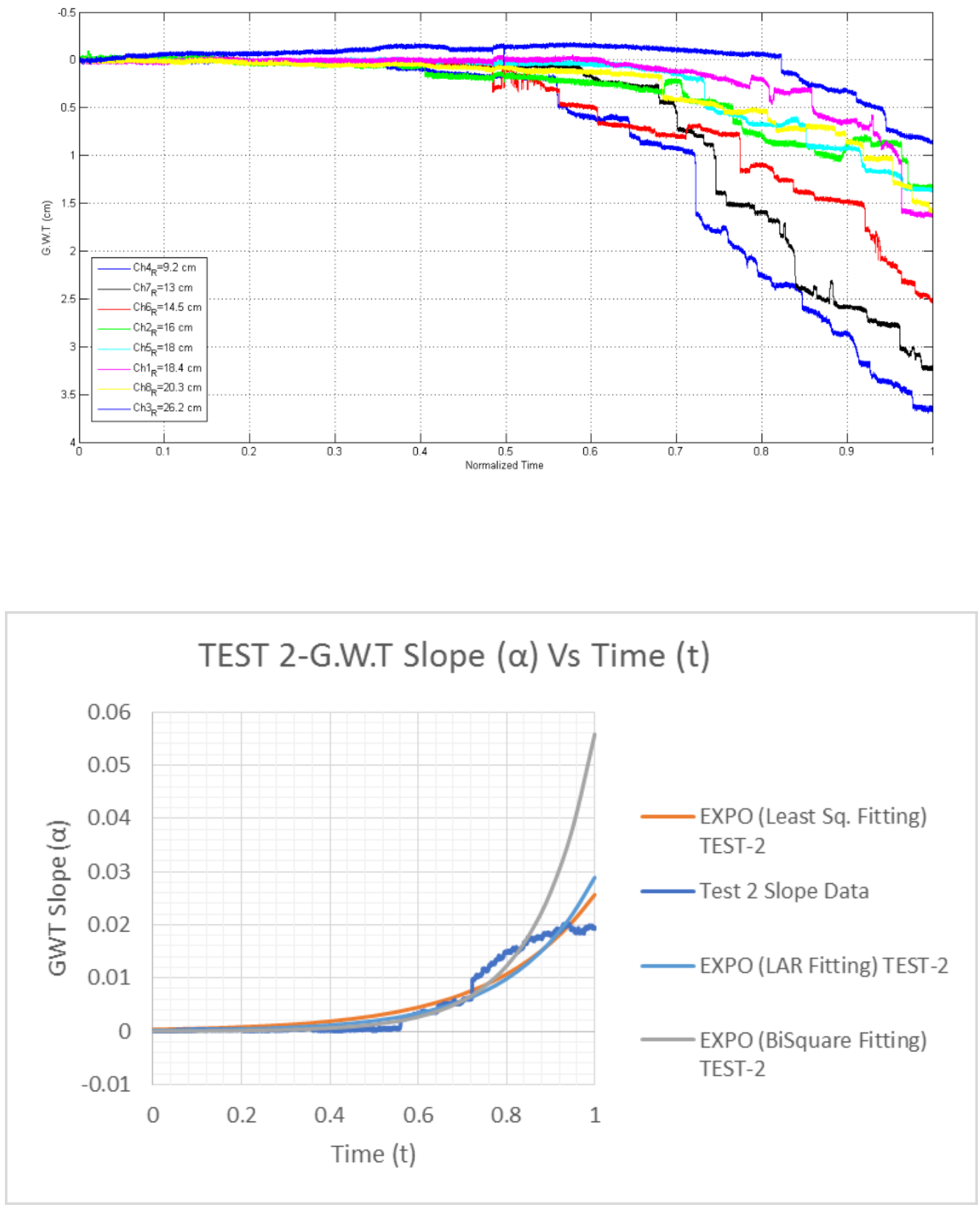
$\mathrm{h}=150 \mathrm{~mm}$ and $\mathrm{GWT}=22.5 \mathrm{~mm}$
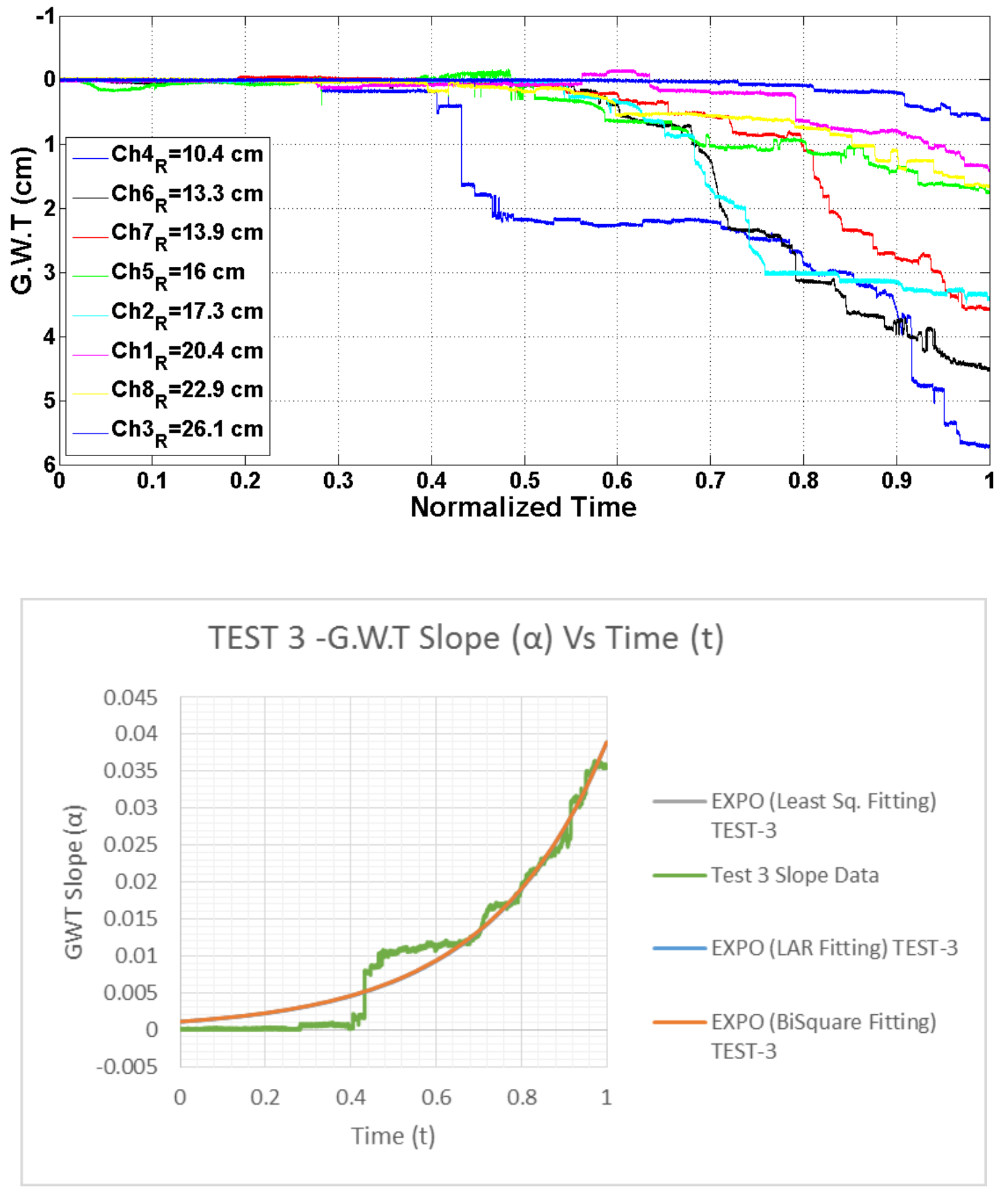
$\mathrm{h}=200 \mathrm{~mm}$ and $\mathrm{GWT}=30 \mathrm{~mm}$
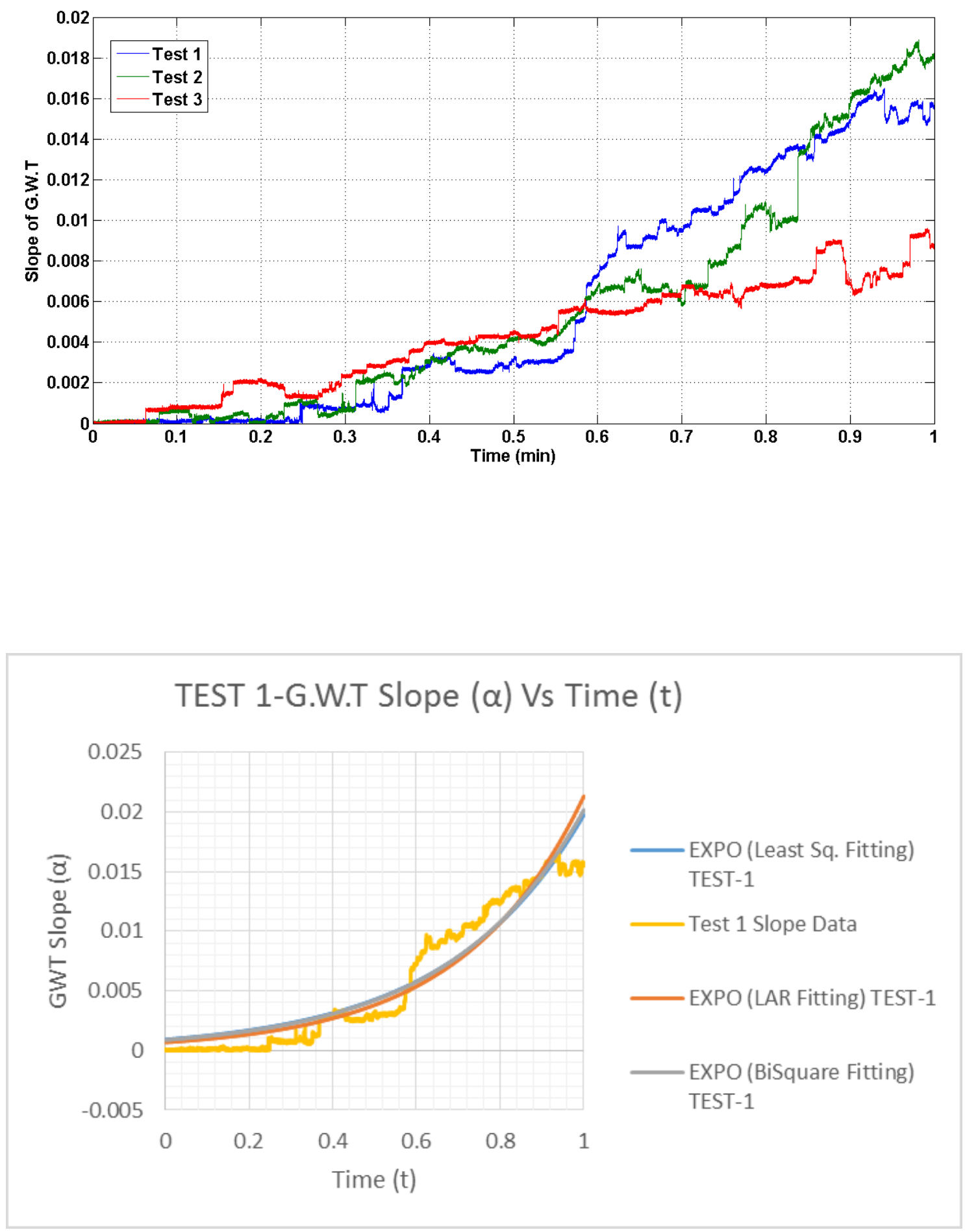
$\mathrm{h}=200 \mathrm{~mm}$ and $\mathrm{GWT}=30 \mathrm{~mm}$
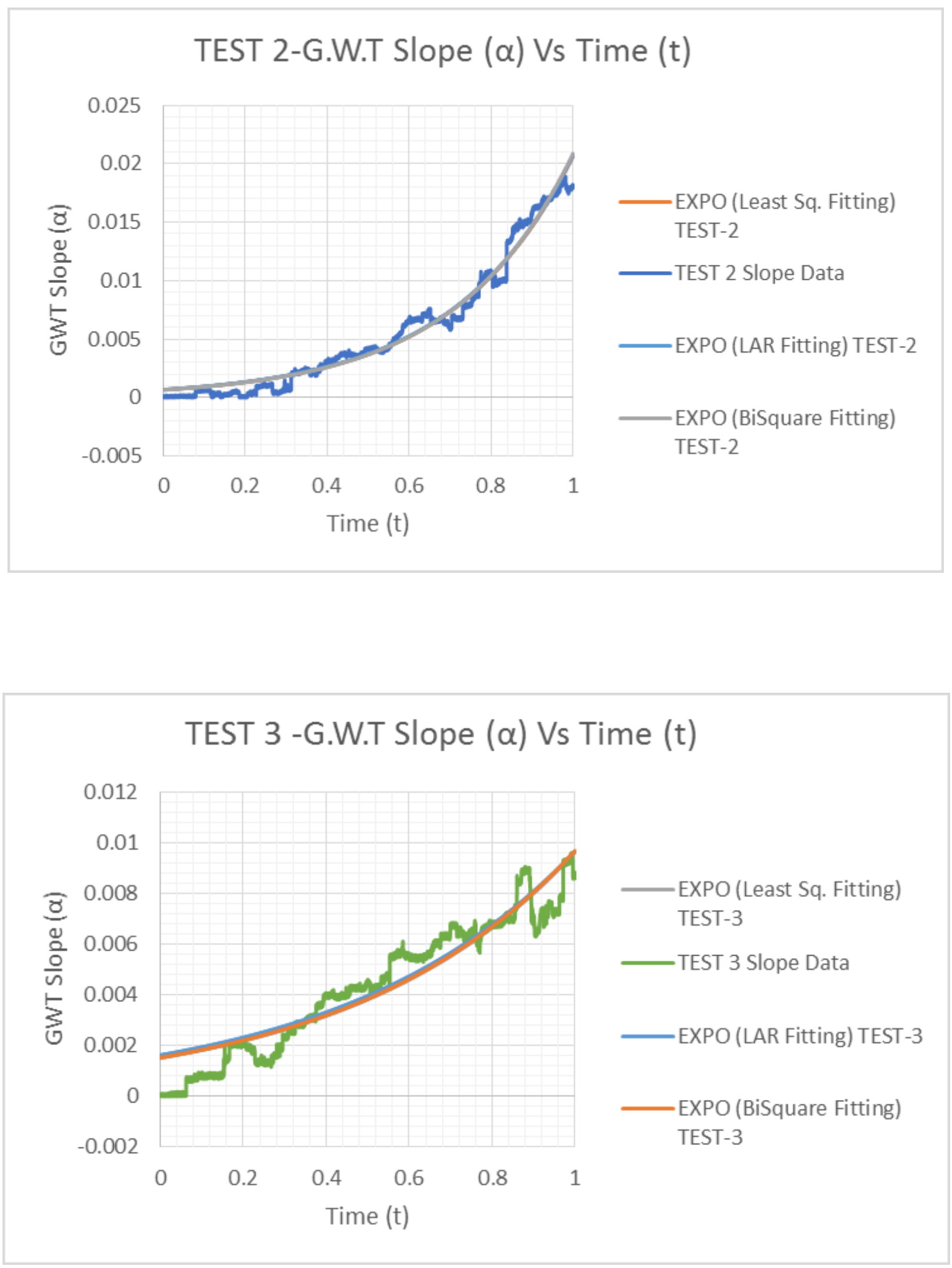
$\mathrm{h}=150 \mathrm{~mm}$ and $\mathrm{GWT}=15 \mathrm{~mm}$
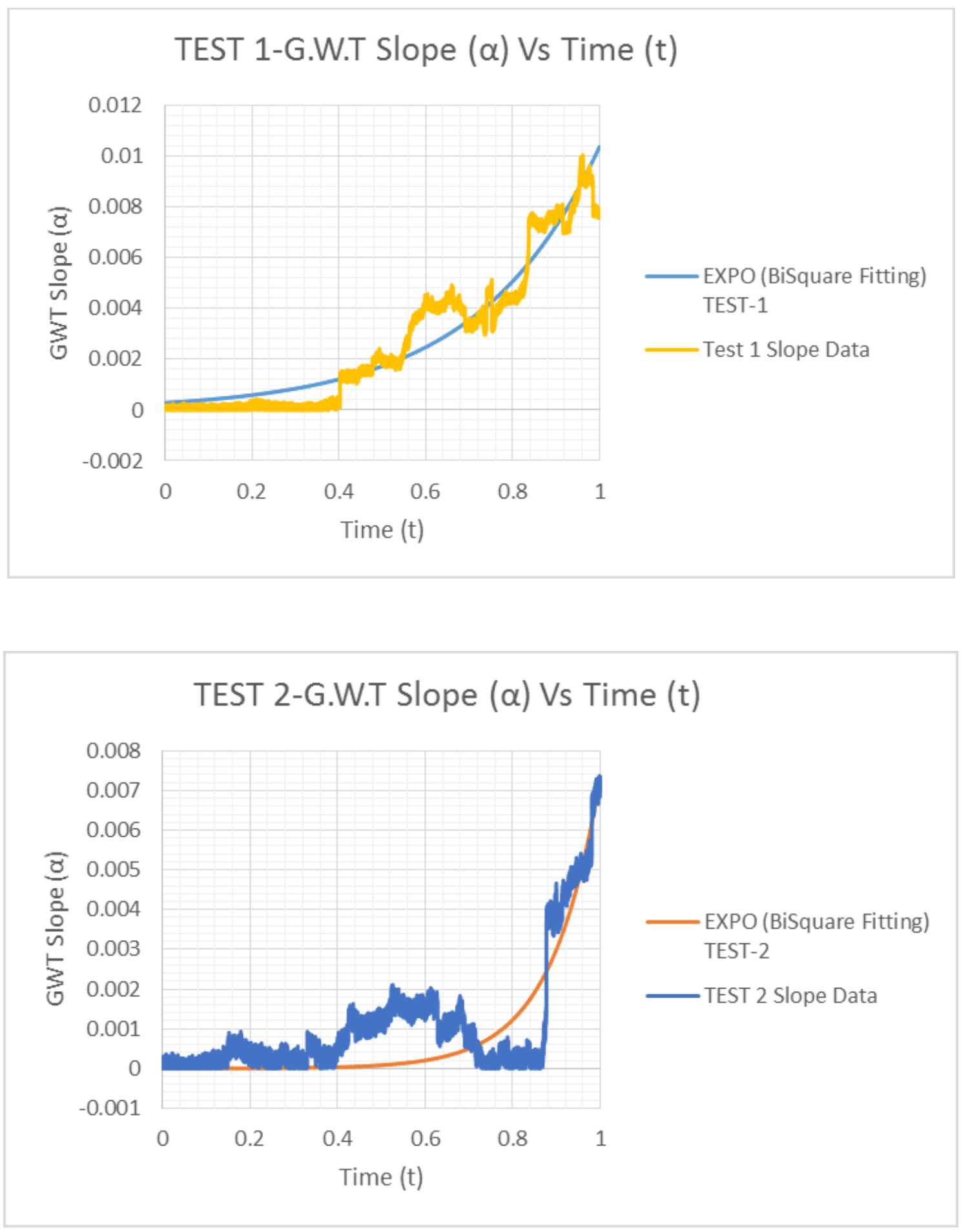
$\mathrm{h}=150 \mathrm{~mm}$ and $\mathrm{GWT}=15 \mathrm{~mm}$

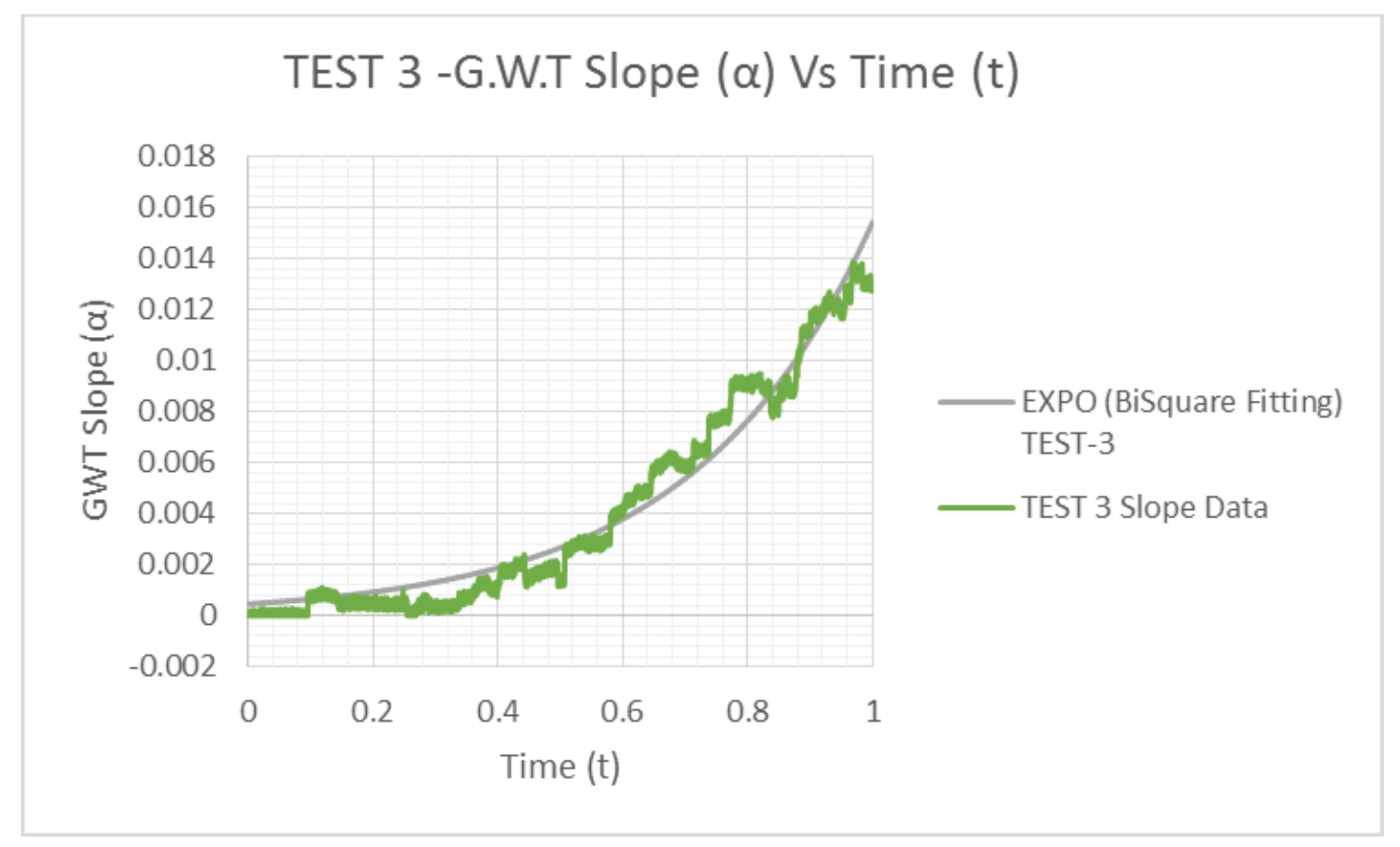



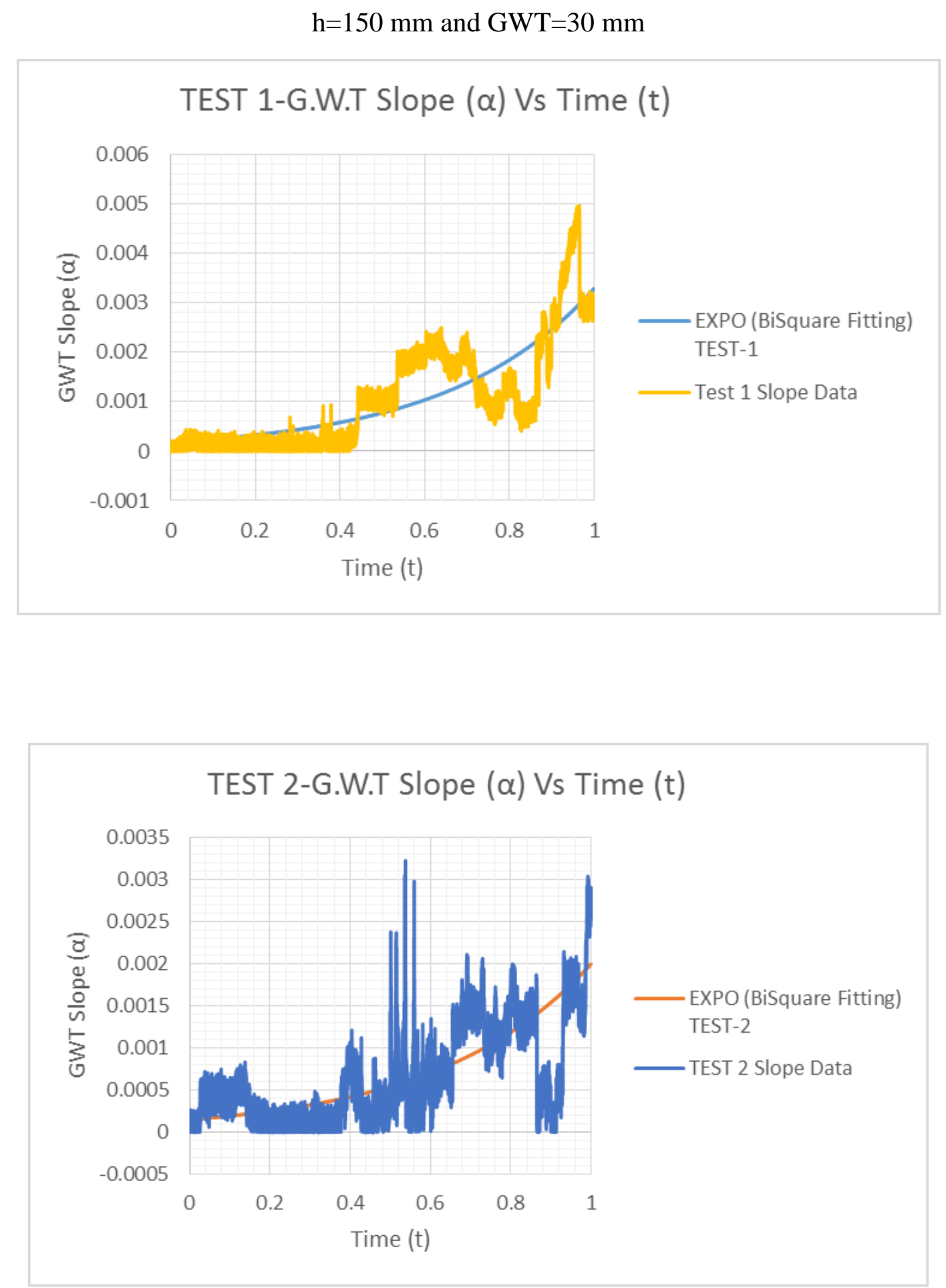
$\mathrm{h}=150 \mathrm{~mm}$ and $\mathrm{GWT}=30 \mathrm{~mm}$

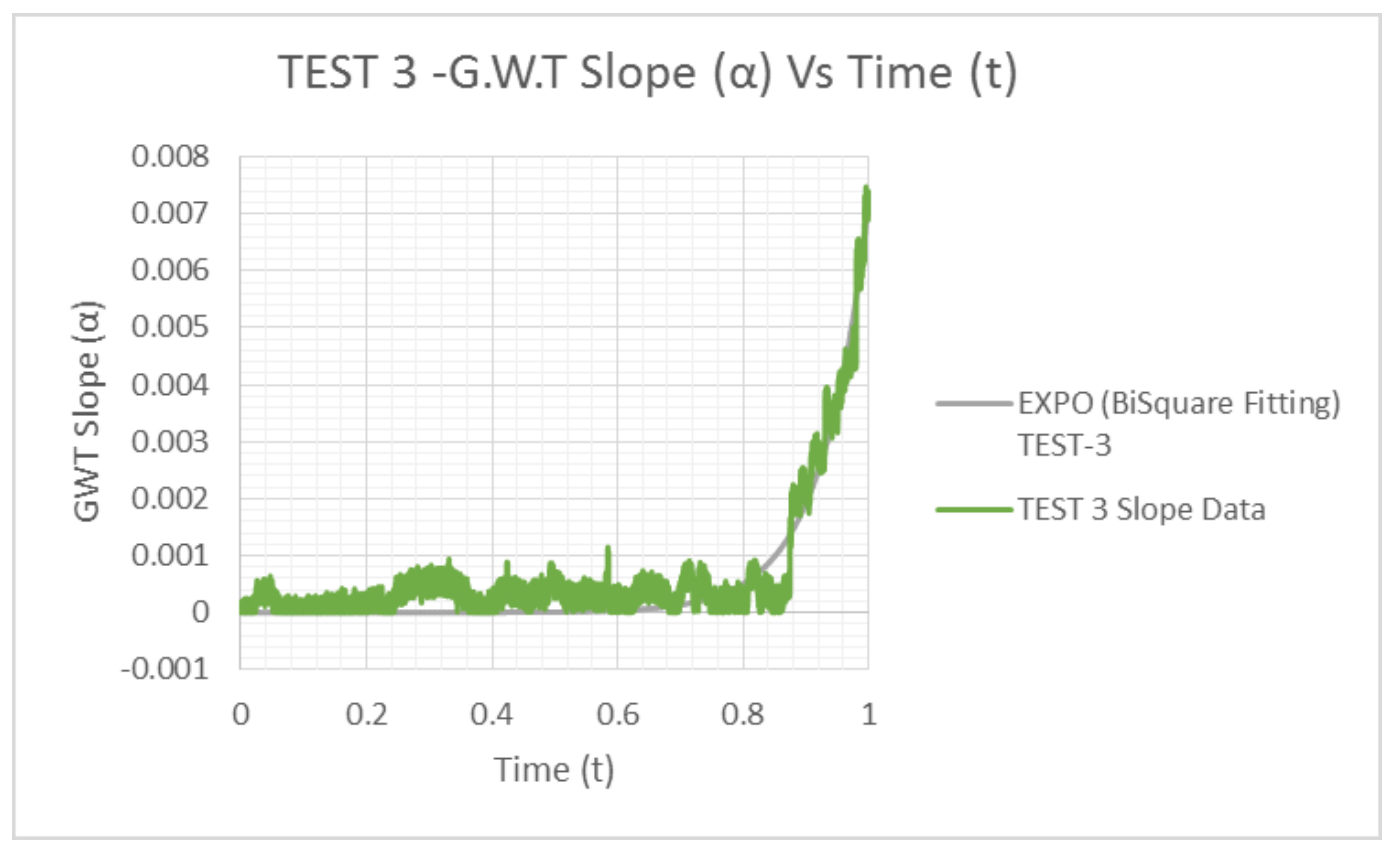


$\mathrm{h}=150 \mathrm{~mm}$ and $\mathrm{GWT}=45 \mathrm{~mm}$
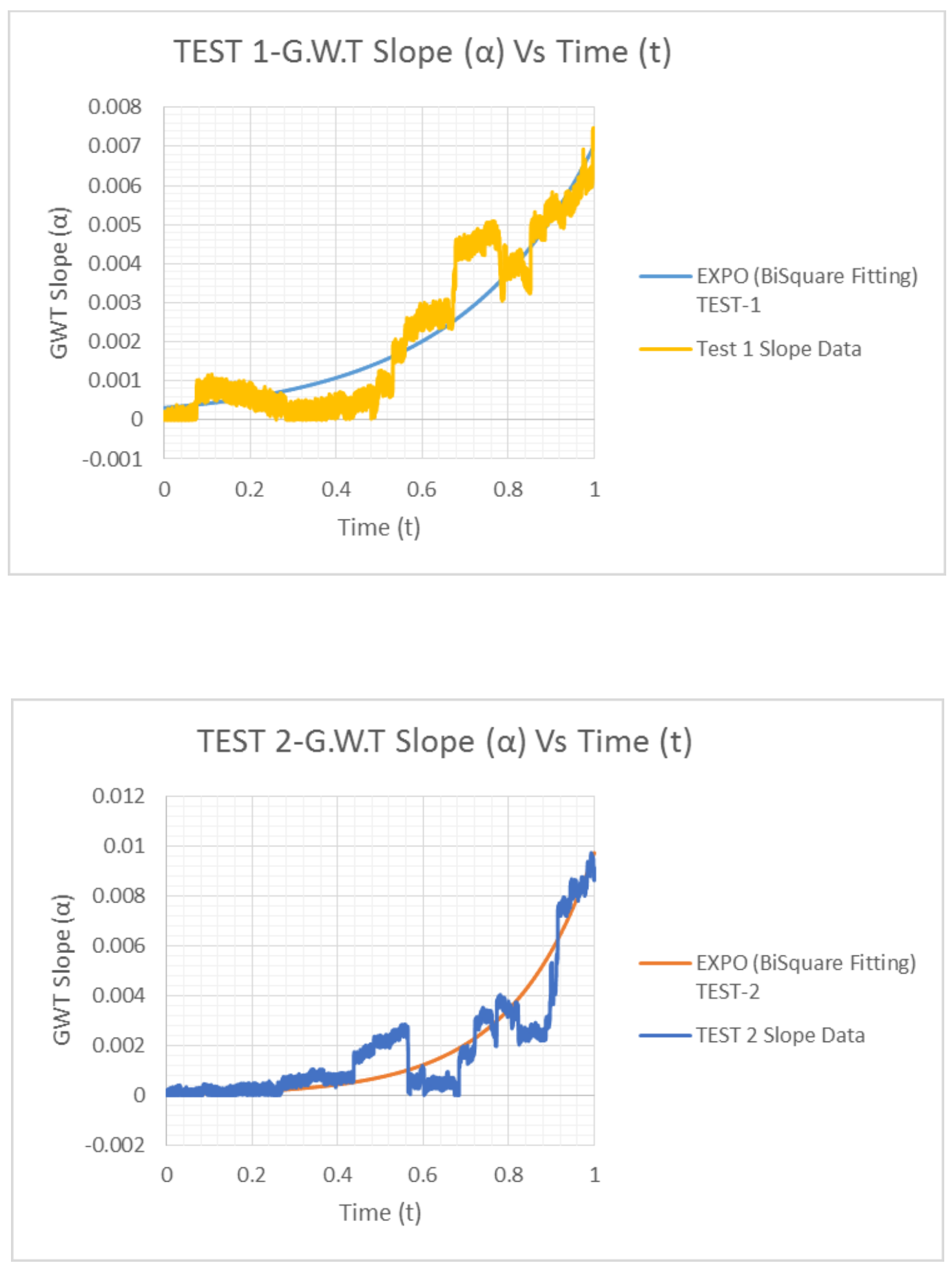


\section{$\mathrm{h}=150 \mathrm{~mm}$ and $\mathrm{GWT}=45 \mathrm{~mm}$}

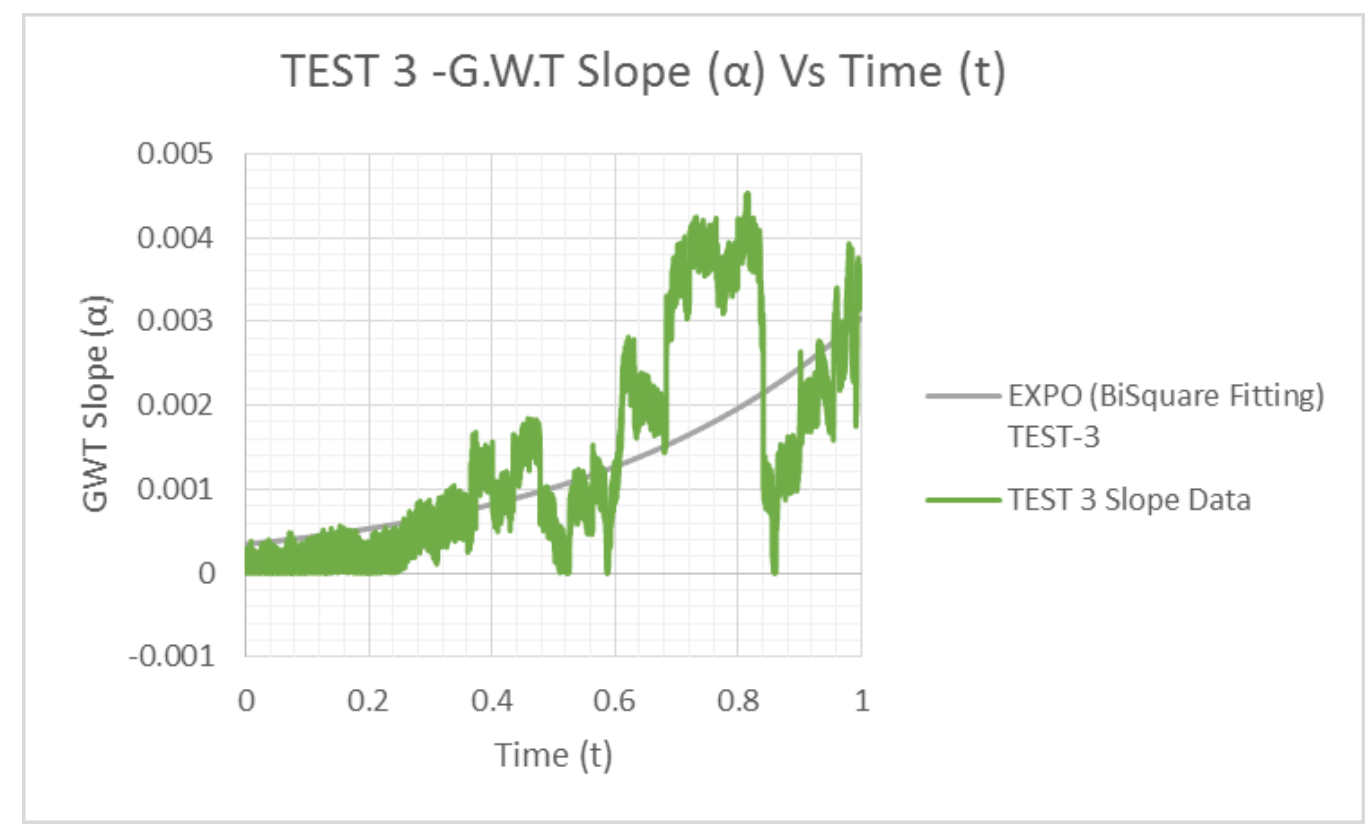




\section{REFERENCES}

Abdulla, W. A., \& Goodings, D. J., (1996). Modeling Of Sinkholes in Weakly Cemented Sand ASCE Journal of Geotechnical Engineering 122 (12), 998-1005.

Atkinson, T. (1977) Diffuse flow and conduit flow in limestone terrain in the Mendip Hills, Somerset (Great Britain): Journal of Hydrology, v. 35, p. 93-110.

Alrowaimi, M., Yun, H. B., \& Chopra, M. (2015). "Sinkhole Physical Models to Simulate and Investigate Sinkhole Collapses." Proceedings of the fourteen multidisciplinary conference on sinkholes and the engineering and environmental impacts of karst, Rochester, Minnesota , Florida, 559-568.

Alrowaimi, M., Yun, H. B., \& Chopra, M. (2016). "Experimental Study of Sinkhole Failure Related To Groundwater Level Drops". Journal of Testing and Evaluation. Submitted

Alrowaimi, M., Yun, H. B., \& Chopra, M. (2016). "Effects of Controlling Parameters on a Predictive Model for Sinkholes Based on Groundwater Drawdown". Journal of Testing and Evaluation. To be Submitted

Augarde, C. E., Lyamin, A. V, \& Sloan, S. W. (2003). Prediction of Undrained Sinkhole Collapse, J. Geotech. Geoenviron. Eng., 2003, vol. 129, 197-205.

Beck, B.F. and Sinclair, W.C. (1986) Sinkhotes in Ftorida: An introduction. Florida Sinkhole Research Institute Report 85-86-4, 16pp. 
Bednar, D. and Aley, T. (2001) Groundwater dye tracing: An effective tool to use during the highway development process to avoid or minimize impacts to karst groundwater resources. In: Beck, B.F. and Herring, J.G. (eds), Geotechnical and Environmental Applications of Karst Geology and Hydrology, pp. 201-207.

Boogli, A. (1980) Karst Hydrotogy and Physicat Speteotogy, 284pp. Springer-Verlag: Berlin.

Bottrell, S. H., Ford, D., \& Williams, P. (1991). Karst Geomorphology and Hydrology. The Geographical Journal, 157(1), 87.

Brooks, H.K. (1981) Guide to the physiographic divisions of Florida: Gainesville, Florida Cooperative Extension Service, Institute of Food and Agricultural Sciences, University of Florida, $11 \mathrm{p}$.

Brucker, R.W., Hess, J.W., and White, W.B. (1972) Role of vertical shafts in the movement of ground water in carbonate aquifers: Ground Water, v. 10, p. 5-13.

Bullock, P. J., \& Dillman, A. (2003). Sinkhole detection in florida using GPR and CPT, The 3rd International Conference on Aplied Geophysics, Orlando, Fla.

Caudron, M., Emeriault, F., Kastner, R., \& Al Heib, M. (2006). Sinkhole and soil-structure interactions : Development of an experimental model. International Conference of Physical Modeling in Geotechnics, Hong Kong, 1261-1267

Caudron, M., Emeriault, F., Kastner, R., \& Al Heib, M. (2006). Collapses of undergroud cavities and soil-structure interactions :Experimental and numerical models. Proceedings of the 1st 
Euro mediterranean symposium on advances on geomaterials and structures, Hammamet, Tunisia, pp. 311-316.

Caudron M., Emeriault F., \& Al Heib M. (2006). Numerical modelling of the soil-structure interaction during sinkholes. Schweiger H.F. (Ed.). Numerical methods in geotechnical engineering: proceedings of the 6th European conference, Graz, Austria. London : Taylor and Francis, pp. 267-273.

Caudron M., Al Heib M., \& Emeriault F. (2008). Collapses of underground cavities and soilstructure interactions: influences of the position of the structure relative to the cavity. Proceedings of the 12th international conference of Int. Association for Computer Methods and Advances in Geomechanics, Goa, India.

Chen, J., \& Beck B. (1989). "Quantitative modeling of the cover-collapse process." Proceedings of the third multidisciplinary conference on sinkholes and the engineering and environmental impacts of karst, St Petersburg Beach, Florida, Balkema, Rotterdam, 89-95.

Crawford, N.C., and Ulmer, C.S. (1993) Groundwater investigations to determine contaminant movement in the karst aquifers of the Lewisburg, Tennessee area. In: Beck, B.F. (ed.), Applied Karst Geology, pp. 79-87.

Culshaw, M.G., and Waltham, A.C. (1987). Natural and artificial cavities as ground engineering hazards: Quarterly Journal of Engineering Geology, v. 20, p. 139-150. 
Florida Geological Survey (1997). Geologic and geotechnical assessment for the evaluation of sinkhole claims ,Florida Geological Survey, 1-46.

Ford, D.C. and Williams, P.F. (1989) Karst Geomorphotogy and Hydrotogy, 601pp. Unwin Hyman: London.

Foshee J and Bixler B. (1994). "Cover-subsidence sinkhole evaluation of state road 434, longwood, florida". ASCE, Journal of geotechnical engineering 120 (11): 2026-2040.

Goodings, D. J., \& Abdulla, W. A. (2002). Stability charts for predicting sinkholes in weakly cemented sand over karst limestone. Engineering Geology, 65, 179-184.

Gutiérrez, F., Cooper, a. H., \& Johnson, K. S. (2007). Identification, prediction, and mitigation of sinkhole hazards in evaporite karst areas. Environmental Geology, 53(5), 1007-1022.

Handfelt, L.D. and Attwooll, W.J. (1988) Exploration of karst conditions in central Florida. American Society of Civil Engineers Geotechnical Special Publication 14, 40-52.

Harrison, H.D. and Hiltunen, D.R. (2003) Characterization of karst terrane via SASW seismic wave method. American Society of Civil Engineers Geotechnical Special Publication 122, $519-528$.

Heidari, M., Khanlari, G. R., Taleb Beydokhti, a. R., \& Momeni, a. a. (2011). The formation of cover collapse sinkholes in North of Hamedan, Iran. Geomorphology, 132(3-4), 76-86. 
Jackson, P.D. and McCann, D.M. (1997) Cross-hole seismic tomography for engineering site investigation. Geotogicat Society Engineering Geotogy Speciat Pubtication 12, 247-264.

Jammal, J. (1981). The Winter Park Sinkhole Then and Now, 19-21.

Jennings, J.N. (1985) Karst Geomorphotogy, 293pp. Blackwell: Oxford.

Lane, E. (1987). Karst in Florida ,Florida Geological Survey Special publication 29 , 1-175.

Lattman, L.H., and Parizek, R.R. (1964). Relationship between fracture traces and the occurrence of ground water in carbonaterocks: Journal of Hydrology, v. 2, p. 73-91.

Lei M, Jiang X, Yu L (1994) The model experiment on karstcollapse. In: Proc 7th Int IAEG Congr, Lisboa, pp 1883-1889.

Lei M., Jiang X. \& Yu L. (2002). New advances of karst collapse research in China. In: Beck, B.F. and Herring, J.G. (eds), Geotechnicat and Environmentat Apptications of Karst Geotogy and Hydrotogy, pp. 145-151.

Lei, M., Gao, Y., Jiang, X., \& Hu, Y. (2005). Experimental Study of Physical Models for Sinkhole Collapses in Wuhan, China. Sinkholes and the Engineering and Environmental Impacts of Karst, pp. 91-102

Lewelling, B.R., Tihansky, A.B., and Kindinger, J.L. (1998) Assessment of the hydraulic connection between ground water and the Peace River, west-central Florida: U.S. Geological Survey Water-Resources Investigations Report 97-4211, 96 p. 
Littlefield, J.R., Culbreth, M.A., Upchurch, S.B., and Stewart, M.T. (1984). Relationship of modern sinkhole development to largescale photolinear features: Multidisciplinary Conference on Sinkholes, 1st, Orlando, Fla., October 15-17, [Proceedings, Beck, B.F., ed., Sinkholes--Their geology, engineering and environmental impact: Boston, Mass., Balkema, A.A.], p. 189-195.

Lowe, D. and Waltham, T. (2002). Dictionary of karst and caves. British Cave Research Association Cave Studies, 10, 40pp.

McDowell, P.W., Barker, R.D., Butcher, A.P., Culshaw, M.G., Jackson, P.D., McCann, D.M., Skipp, B.O., Matthews, S.L. and Arthur, J.C.R. (2002) Geophysics in Engineering Investigations. Construction Industry Research and Information Association Report C592 (and Geological Society Engineering Geology Special Publication 19) CIRIA, London. $252 \mathrm{pp}$.

Mochales, T., Casas, a. M., Pueyo, E. L., Pueyo, O., Román, M. T., Pocoví, a., ... Ansón, D. (2007). Detection of underground cavities by combining gravity, magnetic and ground penetrating radar surveys: a case study from the Zaragoza area, NE Spain. Environmental Geology, 53(5), 1067-1077.

Nisio, S., Caramanna, G., \& Ciotoli, G. (2007). Sinkholes in Italy : first results on the inventory and analysis, (Nisio 2003), 23-45. 
Quinlan, J.F., Davies, G.J., and Worthington, S.R. (1993). Review of groundwater quality monitoring network design: Journal of Hydraulic Engineering, v. 119, p. 1436-1441. [Discussion, with reply, p. 1141-1142.]

Quinlan, J.F. and Ewers, R.O. (1989) Subsurface drainage in the Mammoth Cave area. In: White W.B. and White, E.L. (eds), Karst Hydrotogy, Concepts from the Mammoth Cave Area, pp. 65-103.

Ryder, P.D. (1985). Hydrology of the Floridan aquifer system in west-central Florida: U.S. Geological Survey Professional Paper1403-F.

Schneebeli, G. (1956). Une analogie mécanique pour les terres sans cohésion”, C.R. Acad. Sc. Paris, pp. 125-126.

Sinclair, W. C. (1986). Sinkhole development from ground-water withdrawal in the the Tampa area, Florida, U.S. Geological Survey, Water resources investigations 81-50.

Sinclair, W.C., and Stewart, J.W. (1985). Sinkhole type, development, and distribution in Florida: U.S. Geological Survey Map Series 110.

Southeastern Geological Society (1986) Hydrogeological units of Florida: Florida Geological Survey Special Publication 28, 9 p.

Steinacker, R., Dorninger, M., Pospichal, B., Eisenbach, S., Holzer, a. M., Whiteman, C. D., \& Baumann, K. (2007). A Sinkhole Field Experiment in the Eastern Alps. Bulletin of the American Meteorological Society, 88(5), 701-716. 
Stewart, M., and Parker, J. (1992) Localization and seasonal variation of recharge in a covered karst aquifer system, Florida, USA: International Contributions to Hydrogeology, v. 13, Springer-Verlag, p. 443-460.

Tan, B.K. (1987) Some geotechnical aspects of urban development over limestone terrain in Malaysia. Buttetin International Association Engineering Geology, 3., 57-63.

Tharp, T. M. (1999). Mechanics of upward propagation of cover-collapse sinkholes, Engineering Geology, 52, 23-33.

Tihansky, A.B. (1999). Sinkholes, west-central Florida: A link between surface water and ground water, i: Galloway, Devin, Jones, D.R., and Ingebritsen, S.E., 1999, Land Subsidence in the United States: U.S. Geological Survey, Circular 1182, p. 121-141.

Waltham, T., Bell, F., \& Culshaw, M. (2005). Sinkholes and Subsidence: Karst and Cavernous Rocks in Engineering and Construction, Berlin, Germany, Springer, 382pp.

White, W.A. (1970) Teh geomorphology of the Florida Peninsula: Florida Bureau of Geology Geological Bulletin 51, 164 p.

Wilson, W.L. and Beck, B.F. (1988) Evaluating sinkhole hazards in mantled karst terrane. American Society of Civil Engineers Geotechnical Special Publication 14, 1-24.

Williams, P.W. (2004) Dolines. In: Gunn, J. (ed.), Encyctopedia of Caves and Karst Science, pp. 304-310. Fitzroy Dearborn: New York. 
Xeidakis, G. S., Torok, A., Skias, S., \& Kleb, B. (2004). Engineering geological problems associated with karst terrains : their investigation, monitoring, and mitigation and design of engineering structures on karst terrains, Proceedings of the 10th International Congress, Thessaloniki,Bulletin of the Geological Society of Greece vol. XXXVI, 1932-1941.

Yun, H. B., Sundaresan, G., Jung, Y., Kim, J. W., \& Parkl, K. T. (2013). "Novel Pattern Detection Algorithm for Monitoring Phase Change of Moisture on Concrete Pavement Using Surface Temperature Data." Journal of Computing in Civil Engineering, 10.1061/(ASCE)CP.1943-5487, 0000330. 